$$
\begin{aligned}
& \text { UNIVERSIDADE DE SÃO PAULO } \\
& \text { INSTITUTO DE GEOCIÊNCIAS }
\end{aligned}
$$

\title{
CARACTERIZAÇÃO GEOMECÂNICA E ESTRUTURAL DO TRECHO 3, LINHA 4 (AMARELA) DO METRÔ DE SÃO PAULO
}

\author{
Davi Carvalho Beck
}

Orientador: Prof. Dr. Edilson Pizzato

\begin{abstract}
DISSERTAÇÃO DE MESTRADO
Programa de Pós-Graduação em Geociências - Área de Recursos Minerais e Hidrogeologia
\end{abstract}

SÃO PAULO

2020 
DAVI CARVALHO BECK

\section{CARACTERIZAÇÃO GEOMECÂNICA E ESTRUTURAL DO TRECHO 3, LINHA 4 (AMARELA) DO METRÔ DE SÃO PAULO}

Dissertação apresentada ao Instituto de Geociências da Universidade de São Paulo para obtenção do título de Mestre em Geologia.

SÃO PAULO

2020 
UNIVERSIDADE DE SÃO PAULO

INSTITUTO DE GEOCIÊNCIAS

\title{
CARACTERIZAÇÃO GEOMECÂNICA E ESTRUTURAL DO TRECHO 3, LINHA 4 (AMARELA) DO METRÔ DE SÃO PAULO
}

\section{DAVI CARVALHO BECK}

Orientador: Prof. Dr. Edilson Pizzato

\author{
Dissertação de Mestrado \\ № 856 \\ COMISSÃO JULGADORA \\ Dr. Edilson Pizzato \\ Dr. Tarcisio Barreto Celestino \\ Dr. Omar Yazbek Bitar
}

SÃO PAULO

2020 
Uma longa jornada começa com um único passo. 


\section{AGRADECIMENTOS}

Agradeço a minha família.

À minha mãe que me ensinou que o sucesso e reconhecimento só são obtidos com o trabalho dos justos.

Ao meu pai que me mostrou que devemos sempre aprender e nunca é tarde para se iniciar um novo projeto.

À minha esposa Fabiana, que ao longo desses meses me deu força e apoio para que continuasse a pesquisa, ela e minha filhota Bianca suportando as crises de estresse e minha ausência em diversos momentos.

Agradeço ao meu orientador, Professor Doutor Edilson Pizzato, cujo conhecimento e colaboração foram fundamentais para a elaboração deste trabalho.

Agradeço à Companhia do Metropolitano de São Paulo, em especial ao Marcelo Denser, pelo compartilhamento de informação e dados técnicos.

Agradeço ao colega Giuliano de Mio que me ajudou a lidar com os dados em BIM, agilizando o processamento de informações.

Agradeço aos colegas Carlos Alessandro, Cristiane Caravielo e Rogério Perini que intercederam junto a empresa Egis Engenharia para utilização de software para análise de dados de fraturas.

Agradeço aos meus sócios e amigos Gustavo Cioto e Marco Ribeiro da Geo Coring Serviços Geotécnicos cuja experiência técnica se provou inúmeras vezes útil no andamento deste trabalho e cujo apoio constante dentro da empresa me deram um pouco de tempo para me dedicar a pesquisa. 


\section{RESUMO}

Com o intuito de expandir a rede ferroviária da Companhia do Metropolitano de São Paulo, diversas sondagens foram realizadas, além de levantamentos geofísicos, ensaios laboratoriais e in situ de forma a conhecer o substrato rochoso e suas características geomecânicas que são de extrema importância para prever o tipo de tratamento utilizado durante a escavação de túneis.

Foram utilizados a caracterização dos perfis de sondagem e os ensaios laboratoriais para a classificação geomecânica das sondagens. Com ajuda do BIM foram realizados perfis geotécnicos com as classes de maciço rochoso. As imagens de perfilagem ótica foram reclassificadas utilizando o software WellCad, identificando-se todas as descontinuidades para criar um modelo estrutural do maciço rochoso.

Palavras Chave: classificação de maciço rochoso, perfilagem ótica, geologia estrutural 


\begin{abstract}
In order to expand the railway network of Companhia do Metropolitano de São Paulo, several surveys were carried out, in addition to geophysical surveys, laboratory and in situ tests in order to know the rocky substrate and its geomechanical characteristics, which are extremely important to predict the type of treatment used when excavating tunnels.

The characterization of the drilling logs and laboratory tests were used for the geomechanical classification of the drills. With the help of BIM, geotechnical profiles were made with the classes of rock mass. The optical profiling images were reclassified using the WellCad software, identifying all discontinuities to create a structural model of the rock massif.
\end{abstract}

Keywords: rock mass classification, optical optical televiewer, structural geology 


\section{SUMÁRIO}

\section{Sumário}

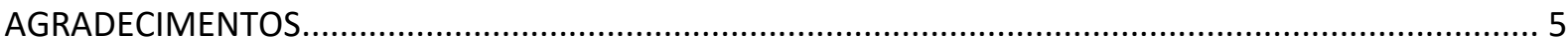

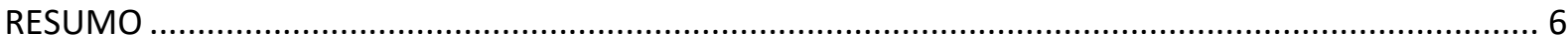

ABSTRACT

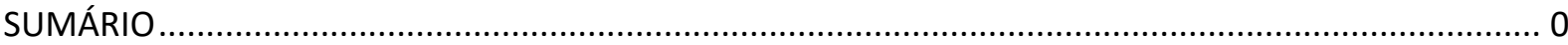

ÍNDICE DE QUADROS

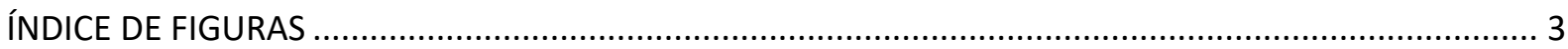

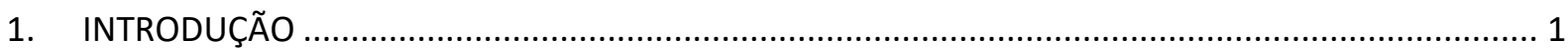

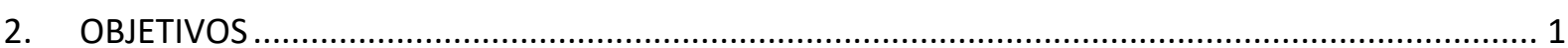

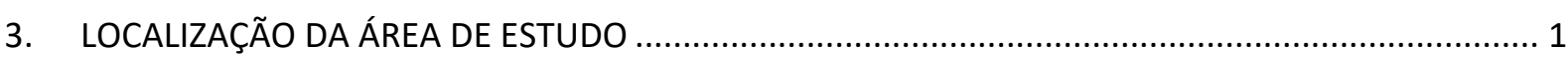

4. GEOLOGIA DA REGIÃO METROPOLITANA DE SÃO PAULO ........................................................... 2

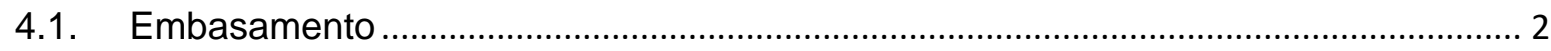

4.2. Sedimentos da Bacia de São Paulo .......................................................................... 7

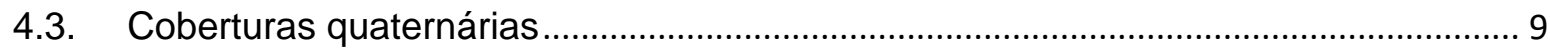

5. CARACTERIZAÇÃO E CLASSIFICAÇÃO DE MACIÇOS ROCHOSOS ............................................... 10

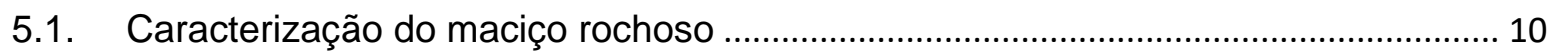

5.2. DETERMINAÇÃO DA ORIENTAÇÃO DE DESCONTINUIDADES........................... 20

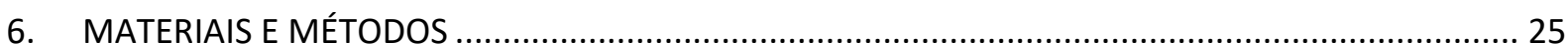

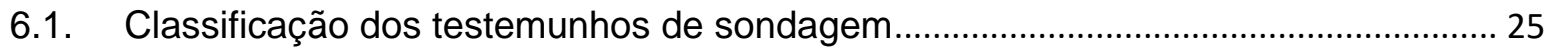

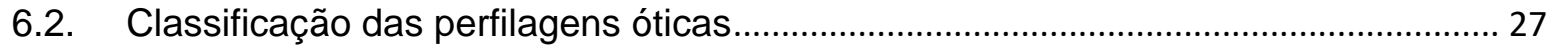

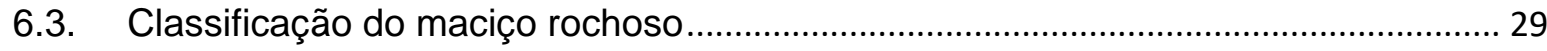

6.4. Modelagem do maciço e túnel...................................................................................... 30

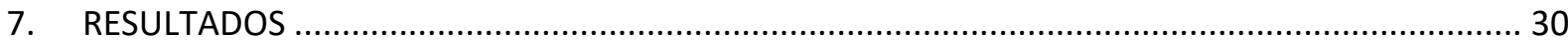

7.1. Descontinuidades e classificação geomecânica das perfilagens ............................... 30

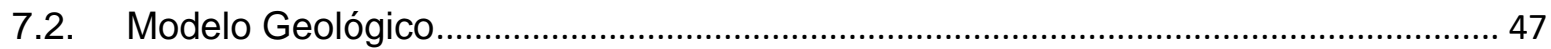

7.3. Modelo Geotécnico do maciço rochoso ....................................................................... 48

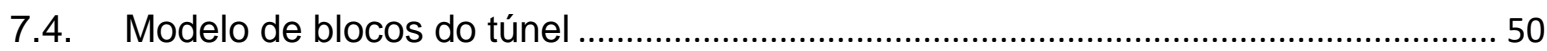

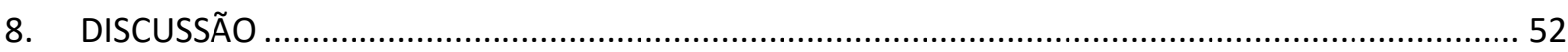

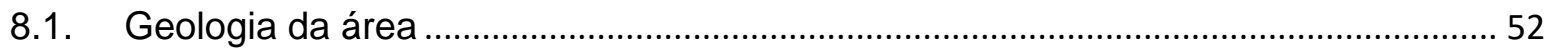

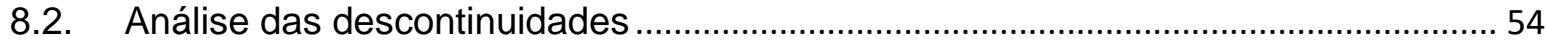

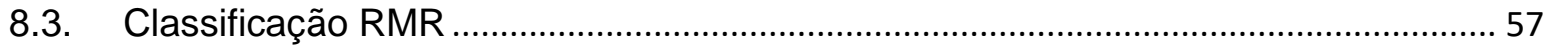

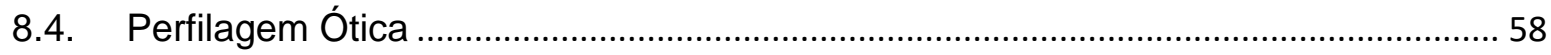




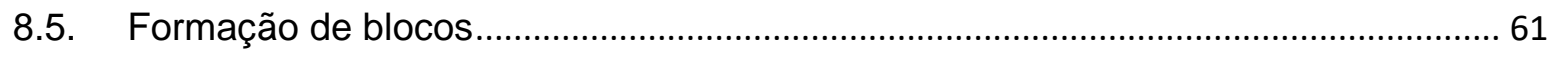

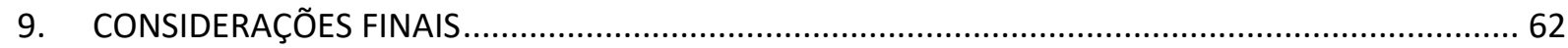

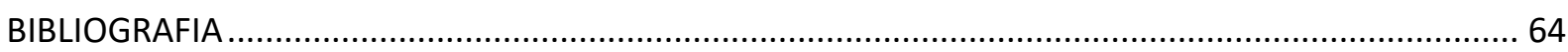

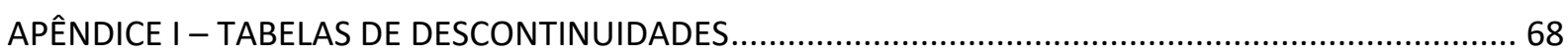

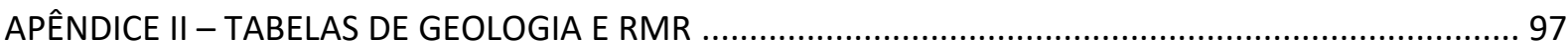

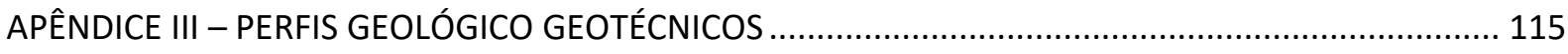

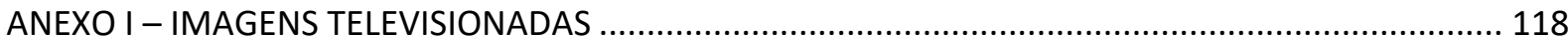




\section{ÍNDICE DE QUADROS}

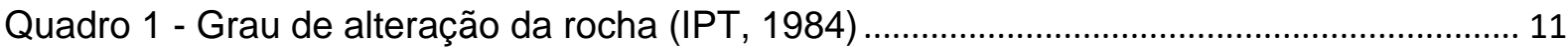

Quadro 2 - Graus de Coerência (GUIDICINI et al., 1972) ...................................................... 12

Quadro 3 - Espaçamento de descontinuidades (ABGE, 1983). ............................................... 13

Quadro 4 - Tipos de superfície e preenchimento de descontinuidade (IPT, 1984) ................. 14

Quadro 5 - Graus de Fraturamento (IPT, 1984) .................................................................... 15

Quadro 6 - Qualidade da rocha pelo RQD (DEERE, 1988)................................................... 16

Quadro 7 - Parâmetros de Classificação RMR (BIENIAWSKI, 1993)....................................... 18

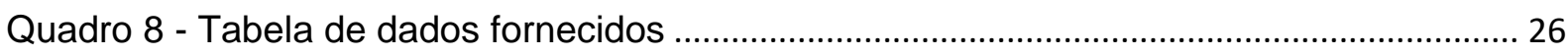

Quadro 9 - RMR modificado, Companhia do Metropolitano de São Paulo................................ 30

Quadro 10 - Classificação da SM-4503 com base em Bieniawski (1989) modificada ............ 31

Quadro 11 - Classificação da SM-4505 com base em Bieniawski (1989) modificada ............ 32

Quadro 12 - Classificação da SM-4515 com base em Bieniawski (1989) modificada ............ 33

Quadro 13 - Classificação da SM-4528 com base em Bieniawski (1989) modificada ............ 34

Quadro 14 - Classificação da SM-4532 com base em Bieniawski (1989) modificada ............ 35

Quadro 15 - Classificação da SM-4536 com base em Bieniawski (1989) modificada ............. 36

Quadro 16 - Classificação da SM-4540 com base em Bieniawski (1989) modificada ............ 37

Quadro 17 - Classificação da SM-4544 com base em Bieniawski (1989) modificada ............ 38

Quadro 18 - Classificação da SM-4545 com base em Bieniawski (1989) modificada ............ 39

Quadro 19 - Classificação da SM-4548 com base em Bieniawski (1989) modificada ............ 40

Quadro 20 - Classificação da SM-4559 com base em Bieniawski (1989) modificada ............ 41

Quadro 21 - Classificação da SM-4564 com base em Bieniawski (1989) modificada ............ 42

Quadro 22 - Classificação da SM-4572 com base em Bieniawski (1989) modificada ............ 43

Quadro 23 - Classificação da SM-4581 com base em Bieniawski (1989) modificada ............ 44

Quadro 24 - Classificação da SM-4596 com base em Bieniawski (1989) modificada ............ 45

Quadro 25 - exemplo de classificação para exportar em arquivo BIM ..................................... 47

Quadro 26 - exemplo de classificação para exportar em arquivo BIM ..................................... 49 


\section{ÍNDICE DE FIGURAS}

Figura 1 - Na parte superior o traçado das sondagens localizado na Região Metropolitana de São Paulo (superior), com os rios tietê e Pinheiros destacados em azul e na parte inferior a localização dos pontos de sondagem (branco) e sondagens com perfilagem ótica (vermelho).

Figura 2 - Mapa Geológico da Região Metropolitana de São Paulo com aproximação na área de estudo que está representada pela linha amarela (CPRM, 2006)

Figura 3 - Evolução esquemática da Faixa Ribeira Central (MEIRA, 2014) ............................... 5

Figura 4 - Esquema evolutivo dos grupos Serra do Itaberaba e São Roque (JULIANI, 1993)6 Figura 5 - Quadro litoestratigráfico e evolução tectono-sedimentar do segmento central do RCSB, com as letras: $\mathrm{t}$ - depósitos de tálus, ca - depósitos colúvio-aluviais, $\mathrm{c}$ - depósitos coluviais e a - depósitos aluviais (RICCOMINI, 1989) ........................................................... 8

Figura 6 - Perfis de rugosidade (BARTON, 1987)................................................................... 14

Figura 7- Gráficos para parâmetros de compressão uniaxial (superior esquerdo), RQD (superior direito), espaçamento das descontinuidades (inferior esquerdo), correlação entre

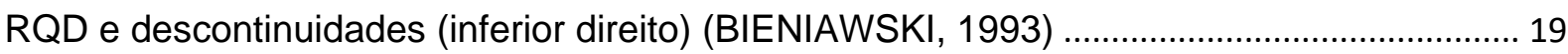

Figura 8 - Tempo de auto sustentação (BIENIAWSKI, 1993) .................................................... 20

Figura 9 - Sonda OPTV, mostrando os componentes externos (a) e o funcionamento interno

(b) (HUBBARD et al., 2012).

Figura 10 - descontinuidade esquemática em um furo de sondagem (c) e sua representação

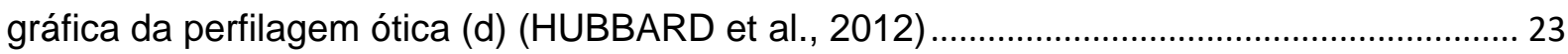

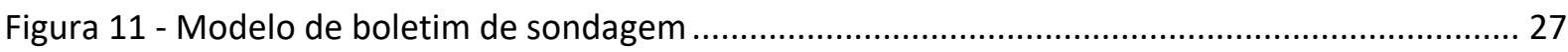

Figura 12 - Trecho da perfilagem ótica da SM-4505, mostrando rocha altamente fraturada. A

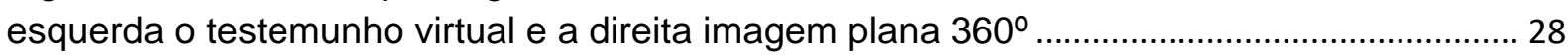

Figura 13 - Trecho da perfilagem ótica da SM-4503, mostrando rocha altamente fraturada. A

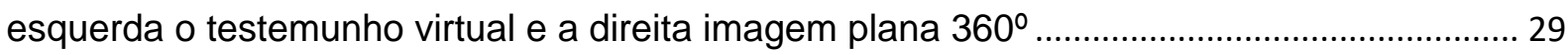

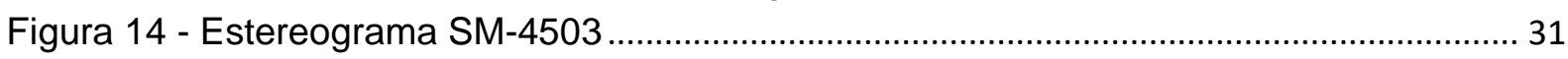

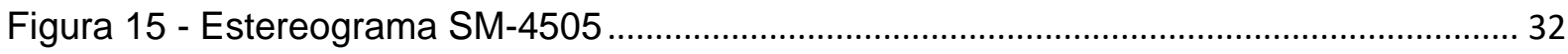

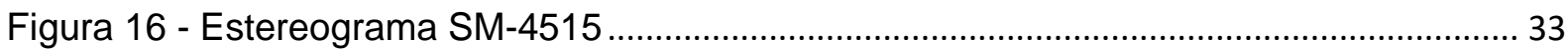

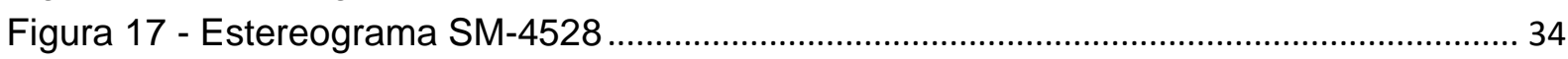

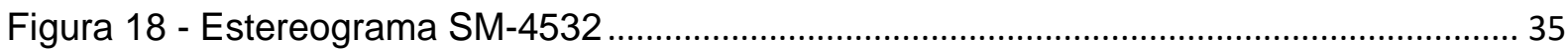

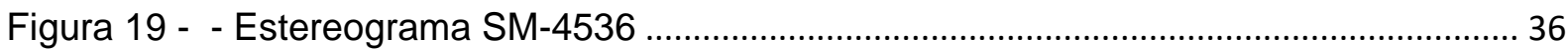

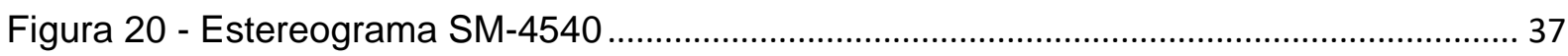

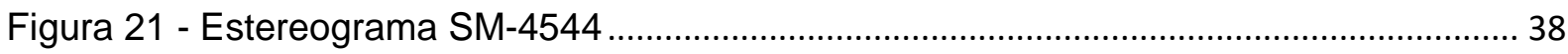

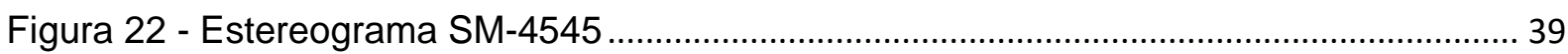

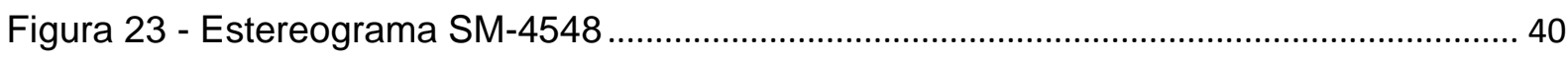

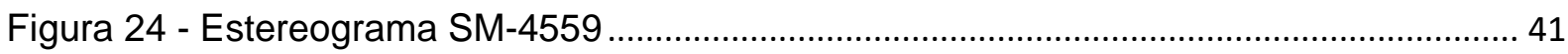

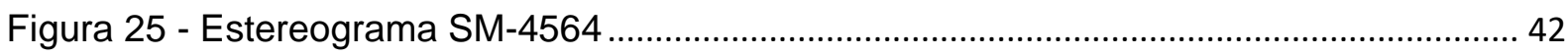

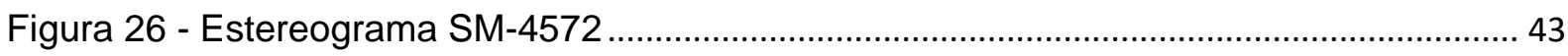

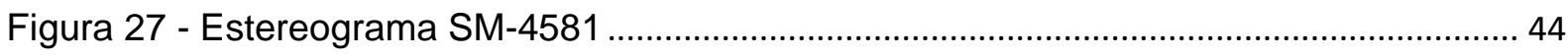

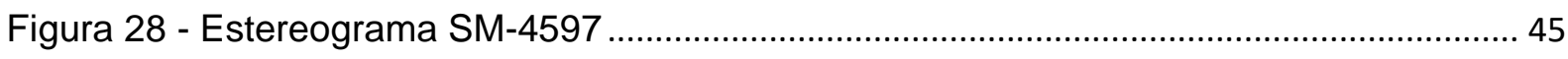

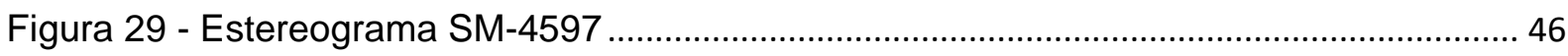

Figura 30 - Traçado das sondagens com a divisão dos perfis realizados ............................... 47

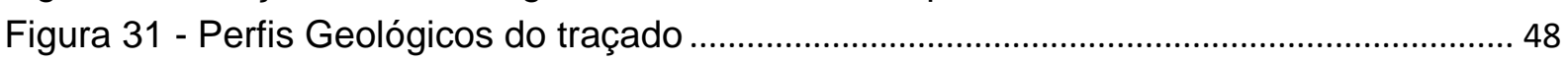




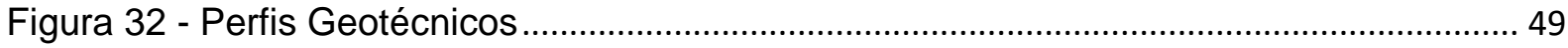

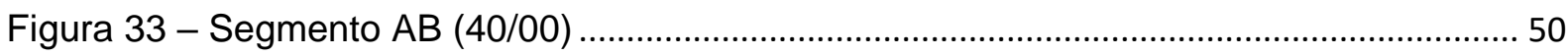

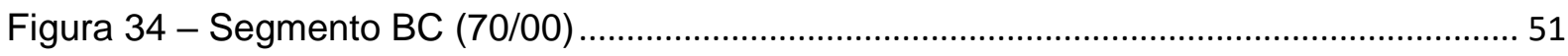

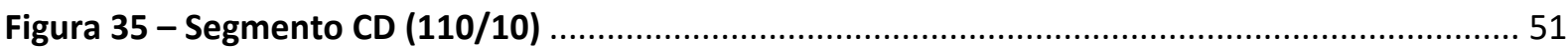

Figura 36 - Gnaisse de granulação fina a média, com fratura parcialmente soldada entre 27 e 28 metros de profundidade na SM-4528..

Figura 37 - Gnaisse migmatizado, presente entre 34 e 35 metros de profundidade na SM4515

Figura 38 - Gnaisse, com enclave, presente entre 7 e 8 metros de profundidade na SM-4544

Figura 39 - Estereograma com a distribuição de descontinuidades .......................................... 55

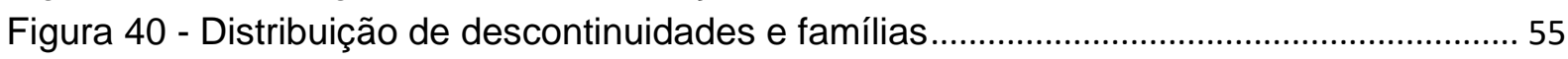

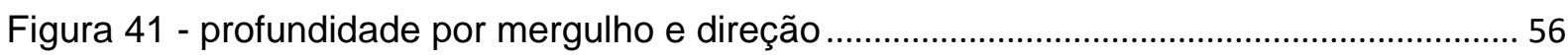

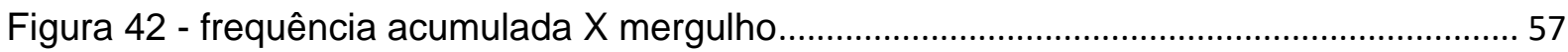

Figura 43 - Perfilagem com problemas de definição devido a turbidez na água, trecho entre

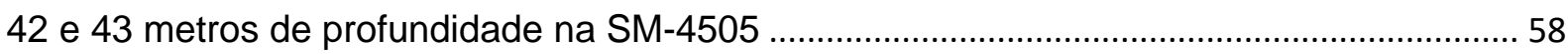

Figura 44 - Marca da sedimentação e arraste da sonda entre 27 e 28 metros da SM-4539 59

Figura 45 - Problema de iluminação prejudicando a visualização das estruturas, entre 13 e

14 metros da SM-4532

Figura 46 - Trecho de baixa recuperação, muito fraturado e alterado, entre 17 e 18 metros

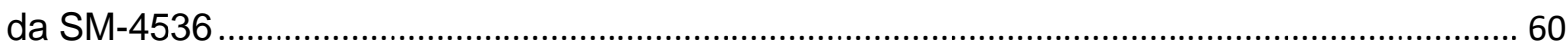

Figura 47 - Estereograma com a representação das principais famílias e direção do segmento $A B\left(40^{\circ}\right)$ do túnel (setas). 


\section{INTRODUÇÃO}

Em obras subterrâneas é essencial o conhecimento do material a ser escavado, desta forma a Companhia do Metropolitano de São Paulo, realizou uma campanha de investigações geotécnicas para conhecer o substrato rochoso e as características geomecânicas dos terrenos no qual será escavado o trecho 3 da Linha 4 amarela do Metrô.

A caracterização dos testemunhos de sondagem em conjunto com os ensaios realizados permite a classificação geomecânica do maciço, além de fornecerem dados importantes para a definição de possíveis áreas de instabilidade, sendo de extrema importância para prever o tipo de tratamento utilizado durante a escavação dos túneis.

O presente trabalho utiliza os dados levantados durante a investigação geotécnica para realizar a classificação geomecânica, identificando zonas de instabilidade.

\section{OBJETIVOS}

O objetivo deste trabalho é utilizar os perfis de sondagem e análise de perfilagem ótica obtidos durante a fase de investigação geotécnica para a criação de um modelo de maciço rochoso que consiga indicar sua qualidade e possíveis problemas associados ao tunelamento.

\section{LOCALIZAÇÃO DA ÁREA DE ESTUDO}

A área de estudo compreende o trecho 3 do traçado da Linha 4 - Amarela da companhia do Metropolitano de São Paulo, que se estende do município de Taboão da Serra a partir do km 270 da Rodovia Régis Bitencourt até o município de São Paulo, no cruzamento da Avenida Professor Francisco Morato com a Rua Caminho do Engenho. Na Figura 1 o traçado das sondagens, destacado em vermelho pode ser visualizado na Região Metropolitana de São Paulo, com os Rios Tietê e Pinheiros 
destacados em azul, bem como as sondagens realizadas, as sondagens em vermelho apresentaram ensaios de perfilagem ótica.

Figura 1 - Na parte superior o traçado das sondagens localizado na Região Metropolitana de São Paulo (superior), com os rios tietê e Pinheiros destacados em azul e na parte inferior a localização dos pontos de sondagem (branco) e sondagens com perfilagem ótica (vermelho).

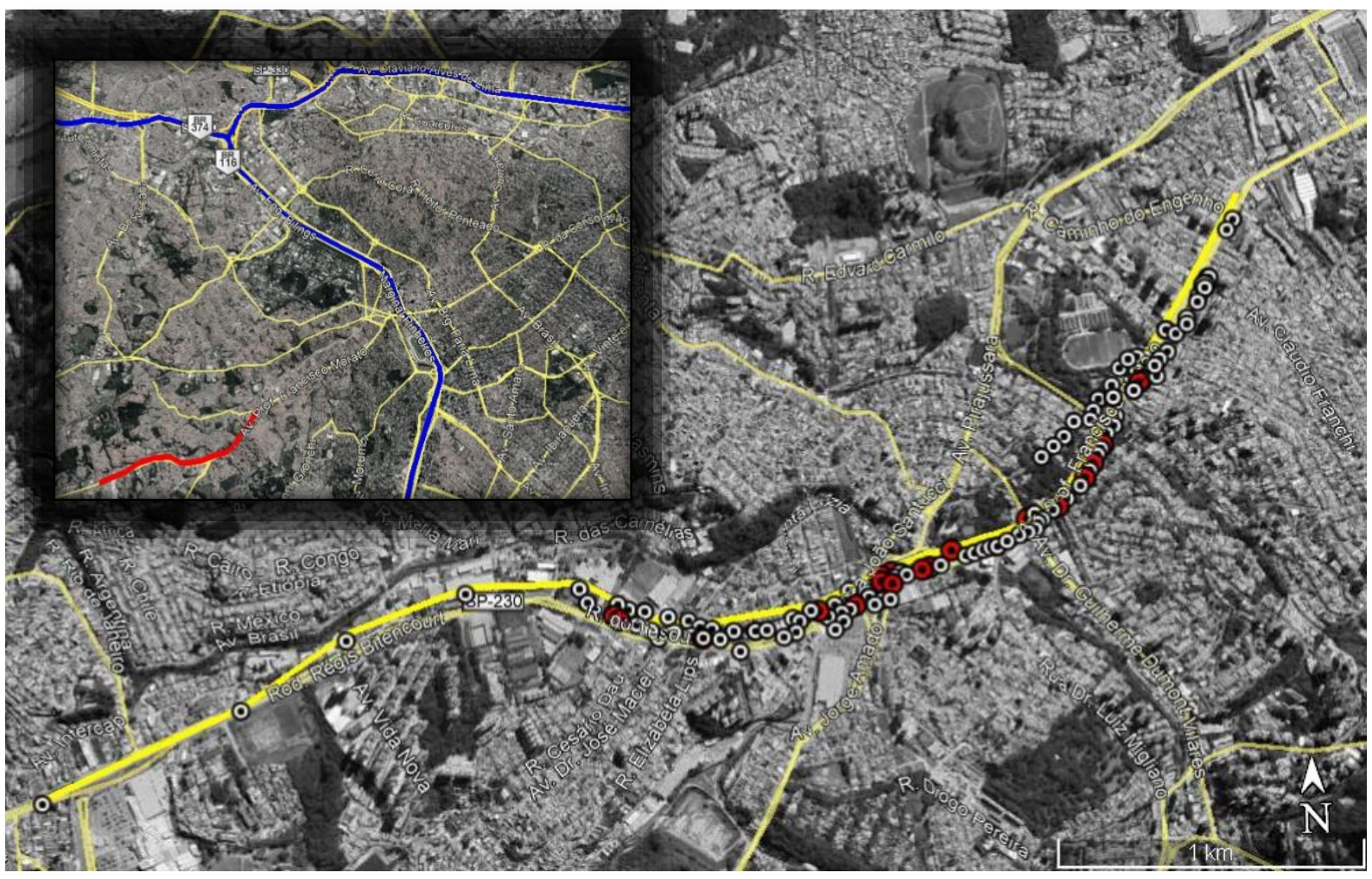

\section{GEOLOGIA DA REGIÃO METROPOLITANA DE SÃO PAULO}

A Geologia da Região Metropolitana de São Paulo (RMSP) pode ser compartimentada em três grupos são eles: os sedimentos quaternários, os sedimentos paleógenos a neógenos da Bacia de São Paulo e o embasamento PréCambriano, no qual estão localizados os túneis e projetos da linha 4 do Metrô de São Paulo.

\subsection{Embasamento}

O embasamento da RMSP está inserido em um complexo sistema influenciado por várias entidades geotectônicas que remontam à formação e fragmentação dos 
Supercontinentes Colúmbia (Arqueano e Paleoproterozóico), Rodínia (Paleoproterozóico a Mesoproterozóico), Gondwana (Neoproterozóico a Cambriano) e Pangea (Cambriano a Triássico) que culminam na formação da Bacia de São Paulo, com os processos distensivos da ruptura do Pangea e a Reativação Sul-Atlantiana. (HASUI, 2010)

Hasui, Carneiro e Coimbra (1975) propõem uma zona de transcorrência de São Paulo, com movimentação dextral, que possui estruturação regional NNE-SSW e pode ser delimitada pelas falhas de Taxaquara, Caucaia, Jundiuvira, Cubatão e outras. (Figura 2)

A falha de Taxaquara divide o norte da Bacia de São Paulo das rochas do Terreno Apiaí (Grupos São Roque e Serra do Itaberaba), enquanto a falha Caucaia divide estas de terrenos geológicos da Faixa Ribeira, representada pelo Complexo Embu, ao sul.

Figura 2 - Mapa Geológico da Região Metropolitana de São Paulo com aproximação na área de estudo que está representada pela linha amarela (CPRM, 2006)

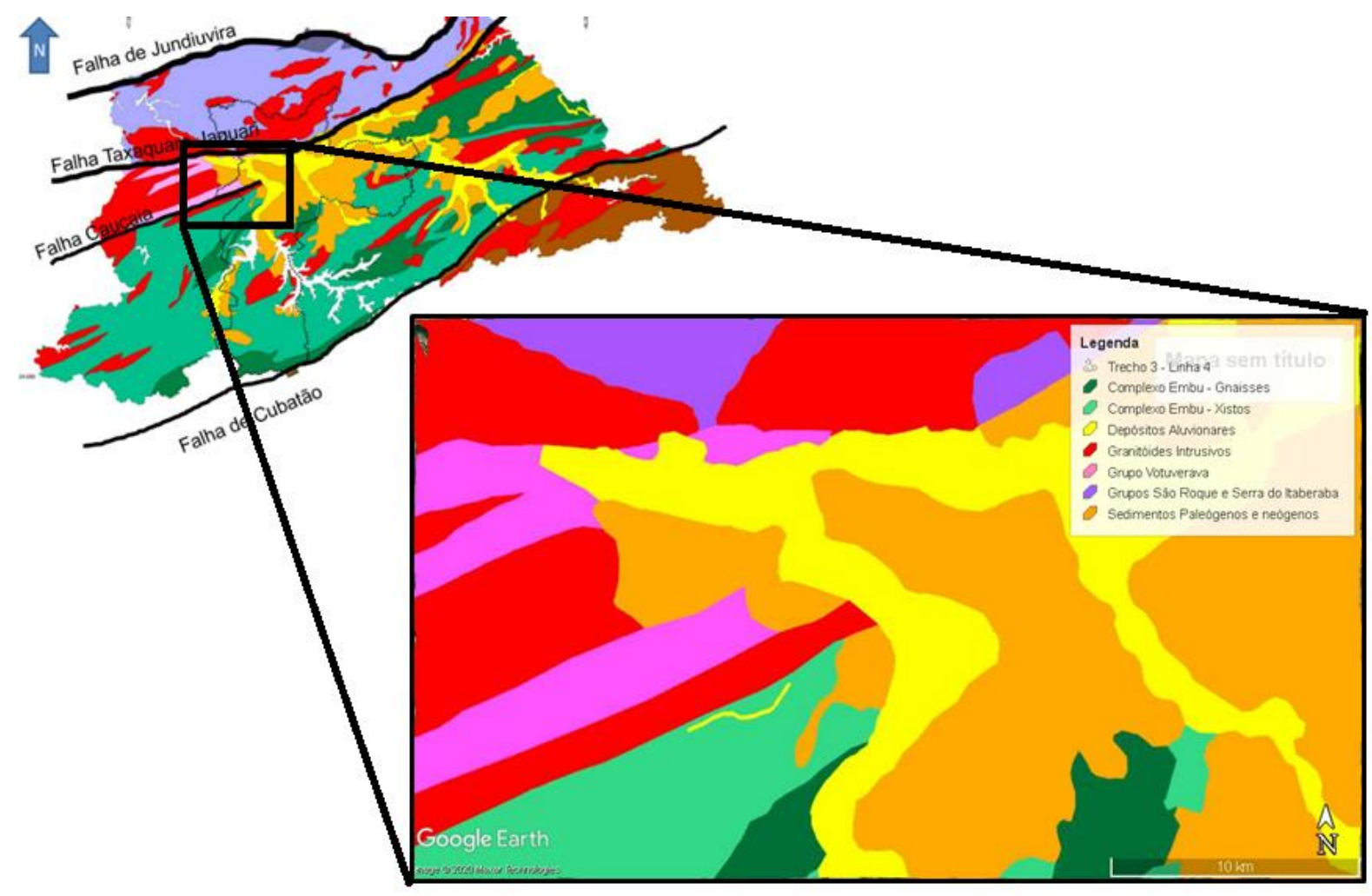


Segundo Monteiro, Gurgueira \& Rocha (2012) as rochas que compõem o embasamento são ígneas e metamórficas, associadas ao Complexo Embu e aos grupos São Roque e Serra do Itaberaba, além de rochas granitóides intrusivas.

\section{Complexo Embu}

O Complexo Embu ocorre na porção central da RMSP, e segundo Meira (2014) faz parte do evento de construção da Gondwana Ocidental, tendo as sequencias metassedimentares se deformado inicialmente quando da subducção da Faixa Brasília (700-650 Ma.) e continuado durante o estágio colisional e de orogenia intracontinental (650-600 Ma.) que foi seguido por um processo distensional (600-560 Ma.). A sequência de eventos pode ser observada na Figura 3.

O Complexo Embu, de acordo com Juliani (1992), é constituído de três litotipos:

- Ortognaisses polimigtizados e polideformados que constituem o Complexo Granito-Gnáissico-Migmatítico, de idades arqueanas a paleoproterozóicas, constituem o embasamento das suprecrustais. Hasui (1994) indica a unidade como um conjunto de gnaisses diversos (porfiróides e homogêneos predominantes, bandados, subordinados e por vezes laminados), moderadamente migmatizados (estruturas bandadas ou estromatíticas) com enclaves esparsos e restritos de rochas metassedimentares e anfibolitos).

- Metassedimentos em grau metamórfico elevado, incluindo gnaisses com extensas faixas de xisto de fácies anfibolito médio a superior. Hasui (1994) evidencia a ocorrência de metassedimentos de fácies anfibolito, representados por micaxistos, quartzitos e rochas cálcio-siliciclásticas, com anfibolitos associados, moderadamente migmatizadas (estruturas bandadas ou estromatíticas)

- Sericita xistos e filitos de baixo grau metamórfico, que podem corresponder às rochas metassedimentares supracitadas em condições de temperatura mais baixas. 
Figura 3 - Evolução esquemática da Faixa Ribeira Central (MEIRA, 2014)
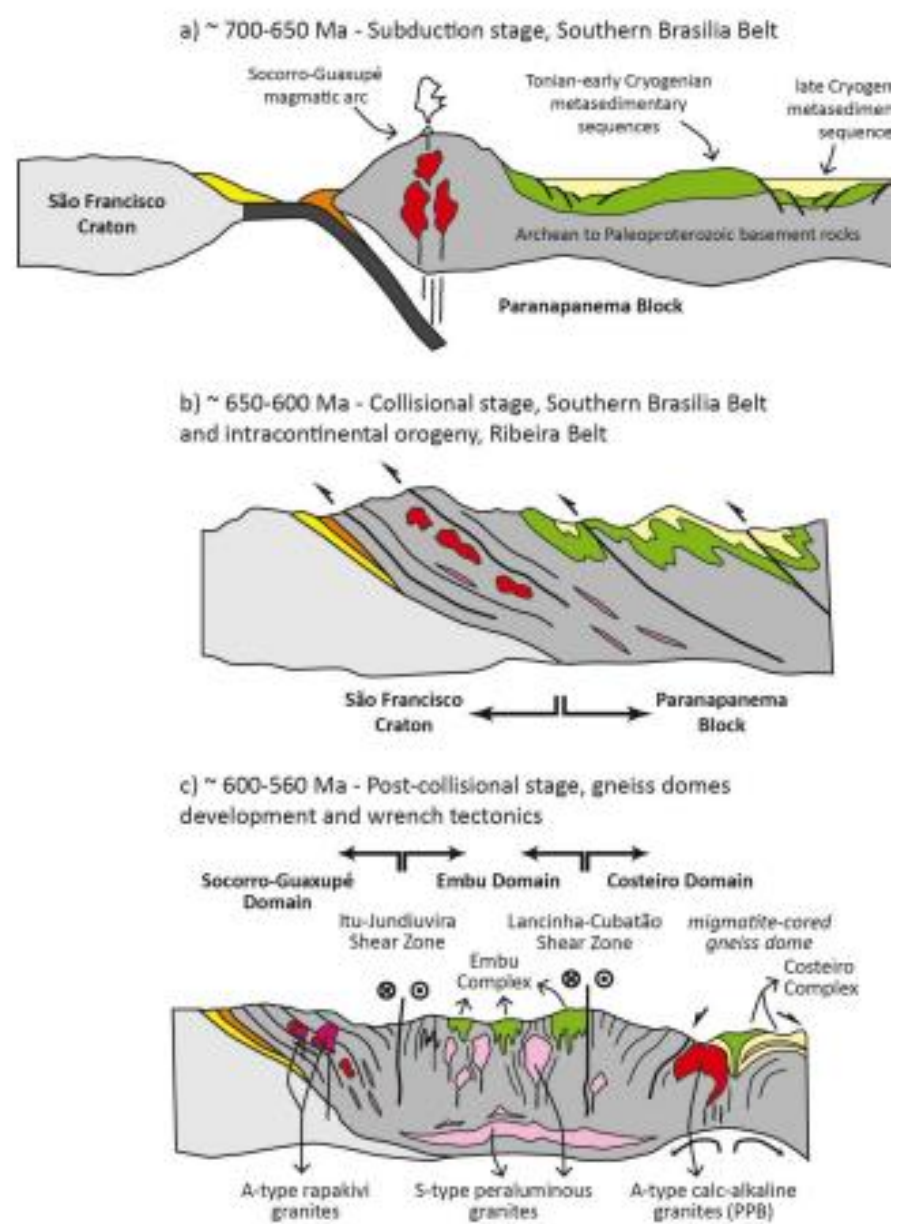

\section{Grupo São Roque e Serra do Itaberaba}

Os Grupos São Roque e Serra do Itaberaba estão presentes na porção norte da RMSP, em contato com o Complexo Embu a sul pelos sistemas de falhas de Taxaquara e Jaguari e constituídos por filitos, metarenitos e quartzitos e ocorrência secundária de anfibolitos, metacalcários, dolomitos, xistos porfiroblásticos e calciossilicáticas (JULIANI; BELJAVSKIS, 1995)

As rochas do Grupo Itaberaba, de origem pré-cambriana, são uma sequência metavulcanossedimentar, na qual estão representados da base para o topo metabasitos de dorsais oceânicas, metavulcanoclásticas e metassedimentos tufíticos da Formação Morro da Pedra Preta, metapelitos, xistos e metassedimentos tufíticos 
da Formação Jardim Fortaleza e xistos ferro manganisíferos e calciossilicáticos da Formação Nhangaçu. (AGUILAR et al., 2012)

Figura 4 - Esquema evolutivo dos grupos Serra do Itaberaba e São Roque (JULIANI, 1993)
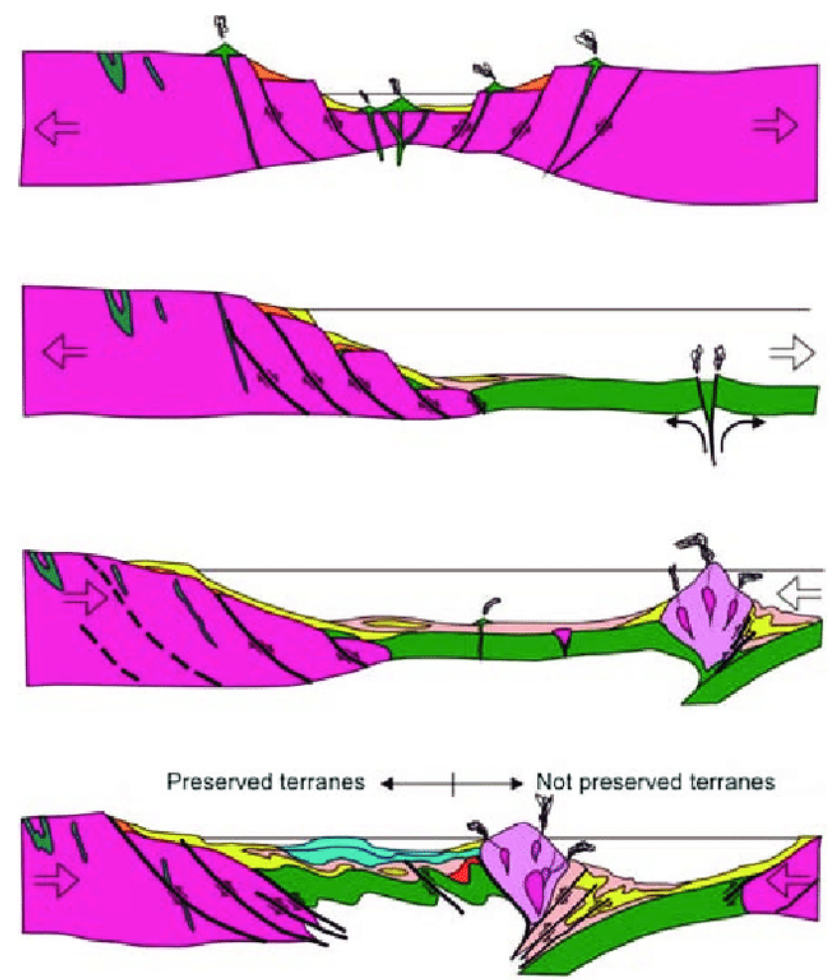

$1395 \mathrm{Ma}$

(andesitos GSI)

$\sim 1200 \mathrm{Ma}$

(metamorfismo GSI)

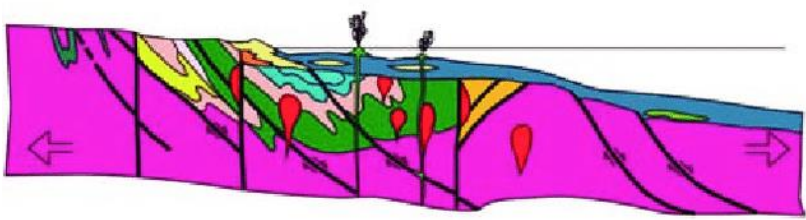

$628 \mathrm{Ma}$

(Vulcanismo

básico GSR
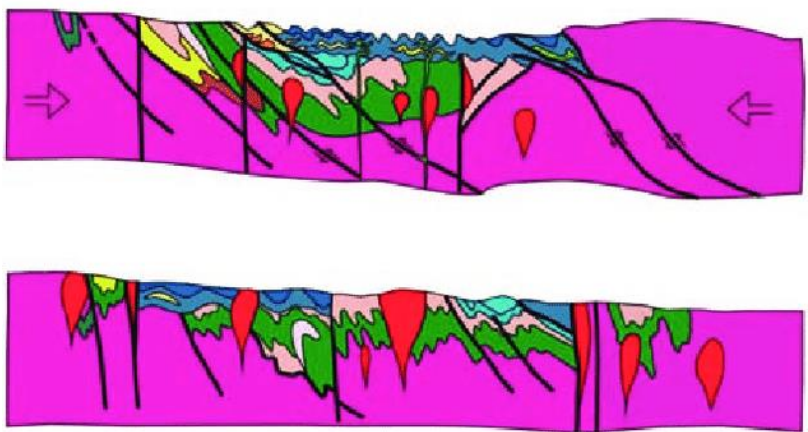

Recent 
Como esboçado na Figura 4, esta sequência é originária da abertura de um oceano durante o Mesoproterozóico e consequente deposição dos metabasitos, posteriormente ocorre um regime de esforços compressivos gerando a subducção da crosta oceânica com uma bacia de retroarco com a qual se desenvolvem corpos ígneos, brechas vulcânicas e tufos que por sua vez estão associados ao hidrotermalismo que influenciou os xistos manganisíferos e calciossilicáticos.(AGUILAR et al., 2012)

O ambiente vulcanossedimentar do Grupo São Roque é um fundo marinho de águas rasas, com geração de magmatismo básico em bacia do tipo rift, formado por filitos carbonáticos intercalados com filitos sericíticos, carbonáticos e metabasitos da Formação Pirapora do Bom Jesus, metaconglomerados, metarcóseos e filitos da Formação Morro Doce, metarritmitos da Formação Estrada dos Romeiros e filitos e metabasitos da Formação Jordanésia. (BERGMANN, 1988; JULIANI; BELJAVSKIS, 1995)

\section{Granitóides intrusivos}

Estes com composição principal granodiorítica a monzogranítica, finos a muito grossos de cores cinza claro a cinza escuro e avermelhados, sendo principalmente sin a tarditectônicas. (DANTAS, 1991)

\subsection{Sedimentos da Bacia de São Paulo}

A Bacia de São Paulo, cuja representação litoestratigráfica encontra-se na Figura 5 é uma bacia do tipo rift, cujo preenchimento sedimentar corresponde a deposição paleógena do Grupo Taubaté (Formações Resende, Tremembé e São Paulo) e neógena da Formação Itaquaquecetuba, que foi retrabalhada por falhas pós sedimentares que causaram soerguimentos e abatimentos locais de seus substratos. (GURGUEIRA, 2013)

A unidade basal e lateral do Grupo Taubaté é a Formação Resende que de acordo com Riccomini (1989) corresponde ao início da fase rift e é constituída por um 
sistema de leques aluviais associados à planície fluvial de rios entrelaçados. Monteiro (2012) aponta que a Formação Resende apresenta duas litofácies principais, a primeira formada por conglomerados polimíticos, interdigitados com arenitos e lamitos arenosos que corresponde aos leques aluviais proximais, situados próximos ao embasamento, a segunda composta por arenitos intercalados com lamitos que correspondem aos leques aluviais associados a rios entrelaçados.

Figura 5 - Quadro litoestratigráfico e evolução tectono-sedimentar do segmento central do RCSB, com as letras: $\mathbf{t}$ - depósitos de tálus, ca - depósitos colúvio-aluviais, $\mathrm{c}$ - depósitos coluviais e a - depósitos aluviais (RICCOMINI, 1989)

\section{CRONO}

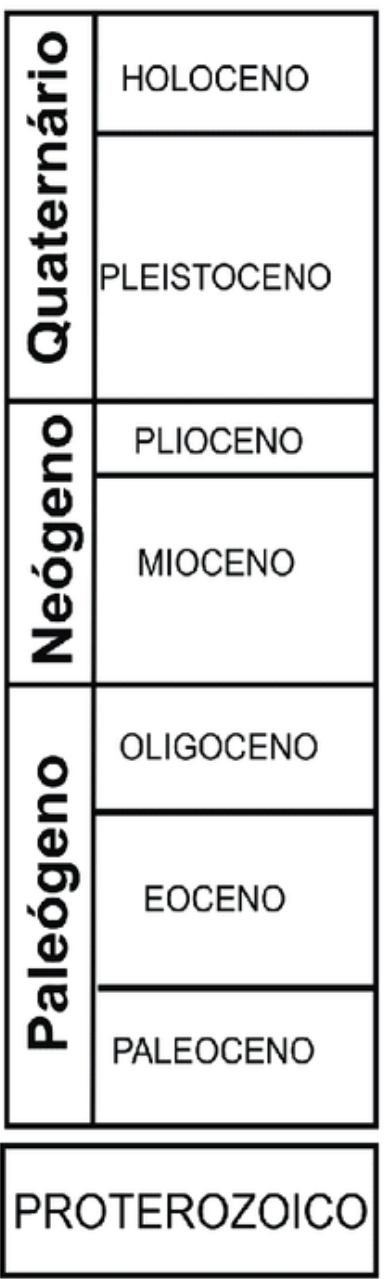

\section{LITOESTRATIGRAFIA}

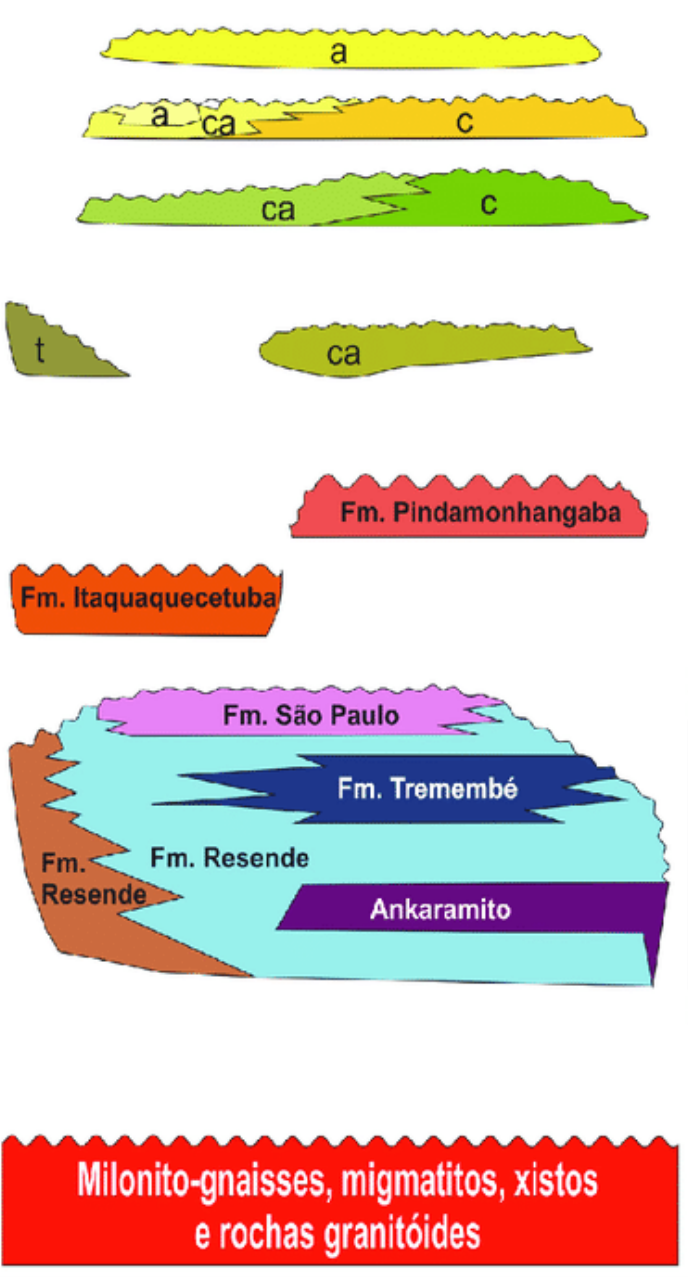

\section{TECTÔNICA}

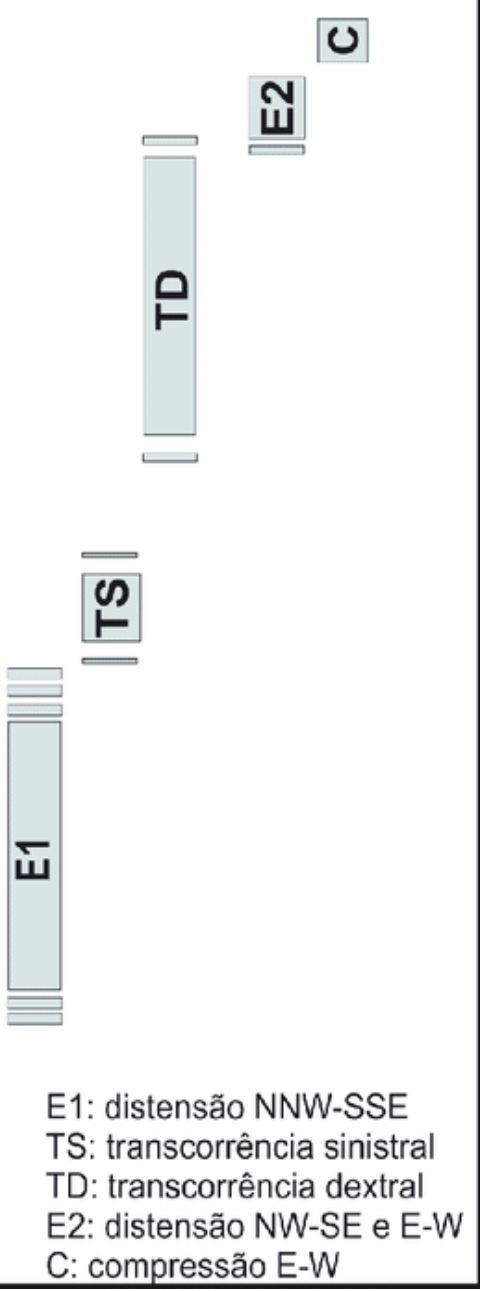


De ocorrência interdigitada lateral e vertical com a Formação Resende, a Formação Tremembé representa o ambiente lacustre tipo playa-lake, formada por argilitos verdes maciços intercalados com argilitos cinza escuro a preto, ricos em matéria orgânica.(GURGUEIRA, 2013; RICCOMINI, 1989)

A Formação São Paulo se encontra no topo do Grupo Taubaté e compreende um sistema fluvial meandrante, com condições climáticas mais úmidas, suas principais fácies sedimentares são arenitos grossos, conglomeráticos, com estratificações cruzadas frequentes, base erosiva e presença de clastos argilosos, representantes de canais meandrantes; siltitos e argilitos laminados, podendo conter como resultados de depósitos de meandros abandonados o registro fossilífero (linhitos); e arenitos médios a grossos provenientes do rompimento de diques marginais com gradação para sedimentos mais finos, rítmicos e laminados, típicos de planícies de inundação. (MONTEIRO; GURGUEIRA; ROCHA, 2012; RICCOMINI, 1989)

A Formação Itaquaquecetuba é restrita a área geográfica da Bacia de São Paulo, de ambiente fluvial entrelaçado com deposição controlada por falhas de direção ENE e NNW, e composta por arenitos arcoseanos com estratificação cruzada acanalada e tabular de grande porte, com conglomerados basais. (Gurgueira, 2013)

\subsection{Coberturas quaternárias}

Os depósitos quaternários compreendem coluviões argiloarenosos com lentes argilosas e conglomeráticas e aluviões conglomeráticos basais sobrepostos por areias grossas a conglomeráticas com estratificações cruzadas de idade pleistocênica e coluviões e aluviões de idade holocênica que são compostos por camadas arenosas e argilosas ricas em matéria orgânica e eventuais cascalheiras na base. (Monteiro et al. 2012) 


\section{CARACTERIZAÇÃO E CLASSIFICAÇÃO DE MACIÇOS ROCHOSOS}

Do ponto de vista da engenharia, um maciço rochoso é um conjunto de blocos de rocha, justapostos e articulados, essencialmente heterogêneo, anisotrópico e descontínuo. A natureza do maciço difere em função da história geológica da região estudada, sendo necessário evidenciar os atributos do meio rochoso que condicionam seu comportamento (caracterização) e posteriormente hierarquizar tais características e organizá-las em conjuntos ou classes (classificação), levando em consideração as solicitações impostas pela obra. (OLIVEIRA; BRITO, 1998)

\subsection{Caracterização do maciço rochoso}

\subsubsection{Litologia}

O tipo de rocha é determinado de acordo com seu processo formador, estruturas principais, granulação e composição mineralógica que por sua vez exibem relação direta com as propriedades do maciço, como a resistência a compressão, a resistência a alterabilidade e a porosidade.

Ao ser aplicada à engenharia, a nomenclatura da litologia deve ser simplificada e objetiva de forma que proporcione resultados práticos, com esta finalidade Matula (1981) apresentou o que chamou de termos genéricos, que consistem de um número limitado, porém distintivo, de rochas tipo.

\subsubsection{Intemperismo}

O intemperismo é o processo pelo qual as rochas são destruídas na superfície terrestre, podendo ocorrer pela alteração ou dissolução dos minerais que compõem a rocha (químico) ou com a fragmentação devido a processos mecânicos, que não mudam a composição química da rocha (físico) (FOOKES; GOURLEY; OHIKERE, 1988).

O conjunto de processos que alteram a rocha pode ser quantificado ao serem comparadas as características das rochas estudadas com os padrões obtidos de rochas sãs, utilizando para isso as relações estabelecidas nos graus de alteração, coerência e fraturamento. 
Oliveira \& Brito (1998) definem alteração como o conjunto de modificações físicas e químicas a que as rochas se encontram submetidas e que conduz a degradação de suas características mecânicas, podendo ser avaliada com base em variações do brilho e cor dos minerais e da rocha, além da friabilidade.

O Quadro 1 apresenta os critérios adotados para a definição dos graus de alteração, cujas siglas se referem a alteração $(A)$, do inglês weathering $(W)$ e a qualidade da rocha, que grada da rocha sã (RS), para rocha alterada dura (RAD), rocha alterada mole (RAM) e rocha extremamente alterada (REA).

Quadro 1 - Grau de alteração da rocha (IPT, 1984)

\begin{tabular}{|ll|l|l|}
\hline \multicolumn{2}{|c|}{ Siglas } & Denominação & \multicolumn{1}{|c|}{ Características da rocha } \\
\hline A1 W1 RS & $\begin{array}{c}\text { Rocha Sã ou } \\
\text { praticamente } \\
\text { sã }\end{array}$ & $\begin{array}{l}\text { Minerais primários sem vestígio de alterações ou com } \\
\text { alterações físicas e químicas insipientes. Neste caso a } \\
\text { rocha é ligeiramente descolorida. }\end{array}$ \\
\hline A2 W2 RAD & $\begin{array}{c}\text { Medianamente } \\
\text { alterada }\end{array}$ & $\begin{array}{l}\text { Minerais medianamente alterados e a rocha é bastante } \\
\text { descolorida. }\end{array}$ \\
\hline A3 W3 RAM & $\begin{array}{c}\text { Muito alterada } \\
\text { Minerais muito alterados, por vezes pulvurulentos e } \\
\text { friáveis. }\end{array}$ \\
\hline A4 W4 REA & $\begin{array}{c}\text { Extremamente } \\
\text { alterada }\end{array}$ & $\begin{array}{l}\text { Minerais totalmente alterados e a rocha é intensamente } \\
\text { descolorida, gradando para cores de solo. }\end{array}$ \\
\hline
\end{tabular}

Enquanto a alteração é marcada pela aparência da rocha, a coerência é caracterizada por meio da resistência da rocha, seja ao impacto do martelo, risco da lâmina de aço ou pressão dos dedos, com base na tenacidade, dureza e friabilidade das rochas, seus parâmetros são definidos no Quadro 2. (GUIDICINI et al., 1972) 
Quadro 2 - Graus de Coerência (GUIDICINI et al., 1972)

\begin{tabular}{|l|l|l|}
\hline Sigla & Denominação & Característica da rocha \\
\hline C1 & $\begin{array}{l}\text { Rocha } \\
\text { coerente }\end{array}$ & $\begin{array}{l}\text { Quebra com dificuldade ao golpe do martelo, produzindo } \\
\text { fragmentos de bordas cortantes. Superfície dificilmente riscável por } \\
\text { lâmina de aço. Somente escavável a fogo. }\end{array}$ \\
\hline C2 & $\begin{array}{l}\text { Medianamente } \\
\text { coerente }\end{array}$ & $\begin{array}{l}\text { Quebra com dificuldade ao golpe do martelo. Superfície riscável } \\
\text { com lâmina de aço. Escavável a fogo. }\end{array}$ \\
\hline C3 & $\begin{array}{l}\text { Pouco } \\
\text { coerente }\end{array}$ & $\begin{array}{l}\text { Quebra com facilidade ao golpe do martelo, produzindo fragmentos } \\
\text { que podem ser partidos manualmente. Superfície facilmente } \\
\text { riscável com lâmina de aço. Escarificável. }\end{array}$ \\
\hline C4 & Incoerente & $\begin{array}{l}\text { Quebra com a pressão dos dedos, desagregando-se. Pode ser } \\
\text { cortada com lâmina de aço; friável e escavável com lâmina. }\end{array}$ \\
\hline
\end{tabular}

\subsubsection{Descontinuidades}

Segundo Matula (1981) uma descontinuidade é uma superfície no maciço rochoso que está aberta ou possui o potencial para abrir devido às tensões aplicadas, podendo possuir diversas origens (ex: acamamentos, juntas, clivagens, foliações ou falhas).

Bieniawski (1993) ressalta a importância das descontinuidades, cujas propriedades, por vezes, tendem a ofuscar as propriedades da rocha intacta, tais como: orientação, persistência, rugosidade, abertura, preenchimento, infiltração, número de famílias e formação de blocos.

A orientação, que pode ser medida com uma bússola, fornece a informação do grau de inclinação da superfície (mergulho) e para onde está inclinada (direção do mergulho), fornecendo uma informação espacial da descontinuidade.

Um conjunto de descontinuidades que tenham a mesma origem e orientação semelhante compõe uma família, cuja distância entre seus componentes fornecem o espaçamento (Quadro 3). 
Quadro 3 - Espaçamento de descontinuidades (ABGE, 1983).

\begin{tabular}{|l|l|l|}
\hline SIGLAS & ESPAÇAMENTO $(\mathrm{cm})$ & DENOMINAÇÃO \\
\hline E1 & $>200$ & Muito afastadas \\
\hline E2 & 60 a 200 & Afastadas \\
\hline E3 & 20 a 60 & Medianamente afastadas \\
\hline E4 & 6 a 20 & Próximas \\
\hline E5 & $<6$ & Muito Próximas \\
\hline
\end{tabular}

Além dos parâmetros espaciais, que avaliam o conjunto das descontinuidades como um todo e definem a formação de blocos no maciço, é interessante verificar as características inerentes a cada descontinuidade.

A abertura é a distância entre as paredes de uma descontinuidade, embora o conceito seja simples, por vezes é difícil de ser mensurada em testemunhos de sondagem devido à cominuição dos mesmos e lacunas no trecho recuperado.

A rugosidade faz referência à aspereza da descontinuidade, bem como ondulações que possam existir na mesma influencia diretamente sobre a resistência ao cisalhamento do material. Pode ser medida pela sua forma geométrica de forma comparativa (figura 6)

O preenchimento é o material presente no interior da abertura e apresenta um papel fundamental na estabilidade do maciço, percebe-se a influência do tipo de material ao comparar a resistência ao cisalhamento de uma fratura preenchida por material argiloso e pétreo. Os tipos de preenchimento são descritos no Quadro 4. 
Figura 6 - Perfis de rugosidade (BARTON, 1987)

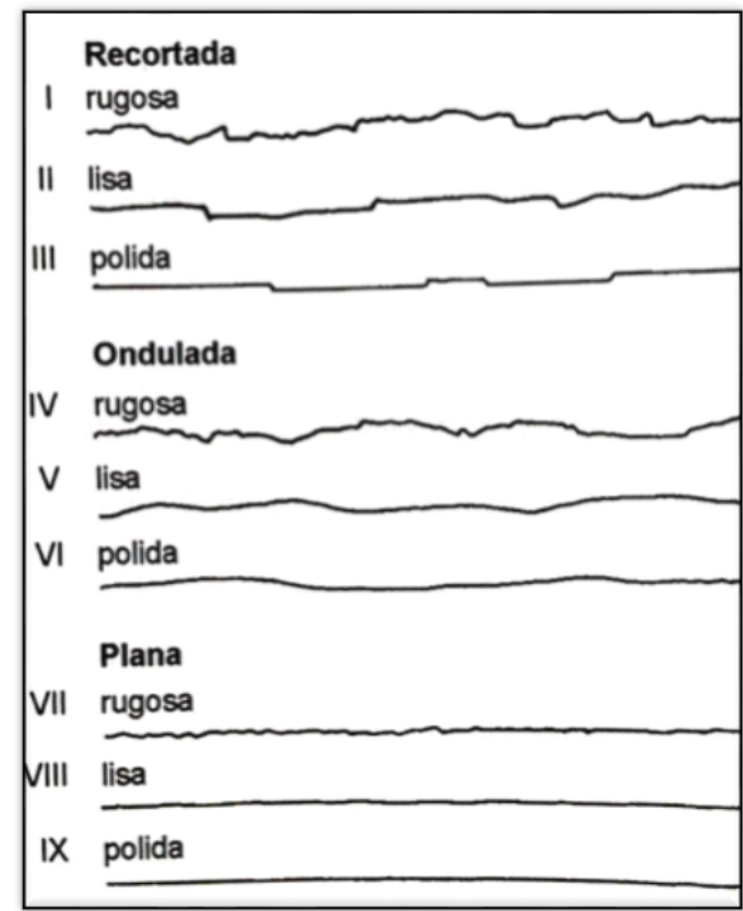

Quadro 4 - Tipos de superfície e preenchimento de descontinuidade (IPT, 1984)

\begin{tabular}{|l|l|}
\hline Sigla & SUPERFÍCIE DAS DESCONTINUIDADES \\
\hline D1 & Contato rocha-rocha, paredes sãs \\
\hline D2 & $\begin{array}{l}\text { Contato rocha-rocha, presença de material pétreo rijo } \\
\text { Ca - calcita } \\
\text { Si - sílica }\end{array}$ \\
\hline D3 & $\begin{array}{l}\text { Paredes com alteração insipiente, sinais de percolação de água, preenchimento } \\
\text { ausente }\end{array}$ \\
\hline D4 & $\begin{array}{l}\text { Paredes alteradas, preenchimento ausente } \\
\text { Aaredes alteradas com preenchimento } \\
\text { Gr10 - preenchimento argiloso com espessura de 1mm }\end{array}$ \\
\hline
\end{tabular}




\subsubsection{Fraturamento}

O Fraturamento é a quantidade de descontinuidades que intercepta o testemunho, é definido em trechos com espaçamento homogêneo e expresso em número de fraturas por metro. IPT (1984) sugere a utilização de um grau de intensidade de fraturamento, adotando intervalos de frequências de fraturas (Quadro $5)$.

Quadro 5 - Graus de Fraturamento (IPT, 1984).

\begin{tabular}{|l|l|l|}
\hline SIGLAS & FRATURAS/M & DENOMINAÇÃO \\
\hline F1 & $<1$ & Ocasionalmente fraturado \\
\hline F2 & 1 a 5 & Pouco fraturado \\
\hline F3 & 6 a 10 & Medianamente fraturado \\
\hline F4 & 11 a 20 & Muito fraturado \\
\hline F5 & $>20$ & Extremamente fraturado \\
\hline
\end{tabular}

\subsubsection{RQD}

O RQD (Rock Quality Designation - Designação da qualidade de rocha) foi criado por Don U. Deere em 1964, originalmente como forma de descrever qualitativamente se uma rocha tem condições favoráveis para ser escavada e hoje como medida padrão na classificação de testemunhos e classificação de maciços rochosos. Neste método a somatória dos pedaços maiores de $10 \mathrm{~cm}$ de comprimento é dividida pelo tamanho total da manobra perfurada. Desta forma o RQD pode ser entendido como uma medida de qualidade de testemunho, ou de frequência de fratura, como apontado no Quadro 6 (DEERE, 1988).

Segundo Vavro et al. (2015) uma das dificuldades de classificação do RQD é a difícil diferenciação entre as estruturas planares naturais em rochas sedimentares e 
metamórficas, daquelas quebradas durante o processo de perfuração, quando analisados testemunhos de sondagens.

Quadro 6 - Qualidade da rocha pelo RQD (DEERE, 1988)

\begin{tabular}{|l|l|}
\hline RQD (\%) & Descrição da qualidade da rocha \\
\hline $0-25$ & Muito pobre \\
\hline $25-50$ & Pobre \\
\hline $50-75$ & Mediana \\
\hline $75-90$ & Boa \\
\hline $90-100$ & Excelente \\
\hline
\end{tabular}

\subsubsection{Classificação de maciços rochosos}

Segundo Bieniawski (1990), uma classificação de maciços rochosos deve ter como propósito a divisão do maciço em grupos com comportamento geomecânico similar, de forma a facilitar o planejamento e construção da escavação e providenciar uma base para facilitar a compreensão das características destes grupos e a comunicação de todos os membros envolvidos. O autor também acredita que o método deve ser simples, fácil de ser lembrado e compreensível, que seja amplamente aceito no meio técnico, cujos parâmetros utilizados possam ser mensurados e determinados por testes rápidos, relevantes e baratos e que seja funcional ao providenciar dados quantitativos.

A classificação geomecânica de maciços rochosos teve origem com a classificação de Terzaghi em 1946, que foi seguida por diversos autores nos anos que se seguiram, mas hoje aquelas que são mais corriqueiramente utilizadas são 0 Sistema RMR (BIENIAWSKI, 1974) e o Sistema Q. (BARTON; LIEN; LUNDE, 1974)

Choi \& Park (2002) apontam que ambos os sistemas apresentam o mesmo conceito básico, no qual são alocadas notas em propriedades que influenciam o comportamento do maciço rochoso que resultam num parâmetro quantitativo, RMRtotal e valor-Q, que é utilizado para correlacionar com o desempenho final do maciço 
em escavações. Os autores destacam que apesar de algumas diferenças três propriedades da rocha são levadas em consideração por ambos os sistemas, são eles: grau de fraturamento, condições das descontinuidades e água subterrânea.

O presente trabalho se utilizou da classificação RMR devido ao acesso limitado apenas aos perfis de sondagem, que estavam adaptados para este sistema.

\subsubsection{Classificação $Q$}

Proposta por Barton, Lien e Lunde (1974), a classificação Q ou Rock Mass Quality é proveniente do estudo de mais de 200 casos de túneis e utiliza a Equação (1) para realizar o cálculo de qualidade da rocha.

$$
\mathrm{Q}=\left(\frac{\mathrm{RQD}}{\mathrm{J}_{\mathrm{n}}}\right) *\left(\frac{\mathrm{J}_{\mathrm{r}}}{\mathrm{J}_{\mathrm{a}}}\right) *\left(\frac{\mathrm{J}_{\mathrm{w}}}{\mathrm{SRF}}\right)
$$

Onde:

$$
\begin{aligned}
& \mathrm{RQD}=\text { Rock Quality Designation } \\
& \mathrm{Jn}=\text { número de famílias } \\
& \mathrm{Jr}=\text { índice de rugosidade } \\
& \mathrm{Ja}=\text { índice de alteração } \\
& \mathrm{JW}=\text { Fator de redução devido à presença de água } \\
& \mathrm{SRF}=\text { Fator de Redução de Tensão }
\end{aligned}
$$

\subsubsection{Classificação RMR}

O sistema RMR (Rock Mass Rating - Classificação de Maciço Rochoso) foi desenvolvido por Bieniawski em 1972-73 e embora tenha mantido a essência dos procedimentos, as informações obtidas em novos casos foi fundamental para seu aperfeiçoamento.

Para a classificação geomecânica de Bieniawski são levados em consideração a resistência à compressão uniaxial da rocha, o RQD, as condições da água subterrânea e a orientação, condição e o espaçamento das descontinuidades. (BIENIAWSKI, 1990)

Para a avaliação pode-se utilizar tanto a tabela (Quadro 7) como os gráficos propostos por (BIENIAWSKI, 1993). 
Quadro 7 - Parâmetros de Classificação RMR (BIENIAWSKI, 1993)

\begin{tabular}{|c|c|c|c|c|c|c|c|c|c|}
\hline \multicolumn{10}{|c|}{ Parâmetros de Classificação } \\
\hline & \multirow{2}{*}{$\begin{array}{l}\text { Resistência } \\
\text { do } \\
\text { Material } \\
\text { Intacto }\end{array}$} & $\begin{array}{c}\text { Índice de } \\
\text { resistência } \\
\text { a carga pontual } \\
(\mathrm{Mpa})\end{array}$ & $>10$ & 10 a 4 & 4 a 2 & 2 a 1 & \multicolumn{3}{|c|}{$\begin{array}{c}\text { Somente para } \\
\text { compressão } \\
\text { simples }\end{array}$} \\
\hline 1 & & $\begin{array}{c}\text { Resistência a } \\
\text { compressão } \\
\text { uniaxial }\end{array}$ & $>250$ & 250 a 100 & 100 a 50 & 50 a 25 & $\begin{array}{c}25 \mathrm{a} \\
5\end{array}$ & $\begin{array}{c}5 \mathrm{a} \\
1\end{array}$ & $<1$ \\
\hline & \multicolumn{2}{|c|}{ Peso } & 15 & 12 & 7 & 4 & 2 & 1 & 0 \\
\hline 2 & \multicolumn{2}{|c|}{$\begin{array}{l}\text { Qualidade do testemunho - } \\
\text { RQD (\%) }\end{array}$} & 100 a 90 & 90 a 75 & 75 a 50 & 50 a 25 & \multicolumn{3}{|c|}{$<25$} \\
\hline & \multicolumn{2}{|r|}{ Peso } & 20 & 17 & 13 & 8 & \multicolumn{3}{|c|}{3} \\
\hline \multirow[t]{2}{*}{3} & \multicolumn{2}{|c|}{$\begin{array}{c}\text { Espaçamento das } \\
\text { descontinuidades }(\mathrm{mm})\end{array}$} & $>2.000$ & 2000 a 600 & 600 a 200 & 200 a 60 & \multicolumn{3}{|c|}{$<60$} \\
\hline & \multicolumn{2}{|c|}{ Peso } & 20 & 15 & 10 & 8 & \multicolumn{3}{|c|}{5} \\
\hline \multirow[t]{2}{*}{4} & \multicolumn{2}{|c|}{$\begin{array}{c}\text { Condição das } \\
\text { descontinuidades }\end{array}$} & $\begin{array}{c}\text { Superfícies } \\
\text { muito } \\
\text { rugosas, } \\
\text { descontínuas, } \\
\text { fechadas, } \\
\text { paredes } \\
\text { duras }\end{array}$ & $\begin{array}{l}\text { Superfícies } \\
\text { pouco } \\
\text { rugosas, } \\
\text { abertura } \\
<1 \mathrm{~mm}, \\
\text { paredes } \\
\text { duras }\end{array}$ & \begin{tabular}{|} 
Superfícies \\
pouco \\
rugosas, \\
abertura \\
$<1 \mathrm{~mm}$, \\
paredes \\
moles
\end{tabular} & $\begin{array}{c}\text { Superfícies } \\
\text { estriadas ou } \\
\text { preenchimento } \\
<5 \mathrm{~mm} \text { ou } \\
\text { abertura de } 1 \\
\text { a } 5 \mathrm{~mm}, \\
\text { contínuas }\end{array}$ & \multicolumn{3}{|c|}{$\begin{array}{c}\text { Preenchimento } \\
\text { mole }>5 \mathrm{~mm} \text { ou } \\
\text { abertura } \\
>5 \mathrm{~mm}, \\
\text { contínuas }\end{array}$} \\
\hline & \multicolumn{2}{|c|}{ Peso } & 30 & 25 & 20 & 10 & \multicolumn{3}{|c|}{0} \\
\hline \multirow{4}{*}{5} & \multirow{3}{*}{$\begin{array}{c}\text { Água } \\
\text { subterrânea }\end{array}$} & $\begin{array}{l}\text { Infiltr. em 10m } \\
\text { de túnel (L/min) }\end{array}$ & 0 & $<10$ & 10 a 25 & 25 a 125 & \multicolumn{3}{|c|}{$>125$} \\
\hline & & $\begin{array}{c}\text { Pressão da } \\
\text { água na } \\
\text { fratura/tensão } \\
\text { Principal }\end{array}$ & 0 & $<0,1$ & 0,1 a 0,2 & 0,2 a 0,5 & & $>0,5$ & \\
\hline & & $\begin{array}{c}\text { Condições } \\
\text { Gerais }\end{array}$ & Seco & Umedecido & Úmido & Gotejamento & $\mathrm{abi}$ & $\begin{array}{l}\text { Fluxo } \\
\text { undan }\end{array}$ & \\
\hline & \multicolumn{2}{|r|}{ Peso } & 15 & 10 & 7 & 4 & \multicolumn{3}{|c|}{0} \\
\hline \multicolumn{10}{|c|}{ Ajuste para orientação de descontinuidades } \\
\hline \multicolumn{3}{|c|}{$\begin{array}{c}\text { Direção e mergulho das } \\
\text { descontinuidades }\end{array}$} & $\begin{array}{c}\text { Muito } \\
\text { favorável }\end{array}$ & Favorável & Aceitável & Desfavorável & \multicolumn{3}{|c|}{$\begin{array}{c}\text { Muito } \\
\text { desfavorável }\end{array}$} \\
\hline \multirow{3}{*}{\multicolumn{2}{|c|}{ Peso }} & Túneis & 0 & -2 & -5 & -10 & \multicolumn{3}{|c|}{-12} \\
\hline & & Fundações & 0 & -2 & -7 & -15 & \multicolumn{3}{|c|}{-25} \\
\hline & & Taludes & 0 & -5 & -25 & -50 & \multicolumn{3}{|c|}{-60} \\
\hline & & Classe de & naciços rochosos & determinada $\mathrm{p}$ & pela somatória & dos pesos & & & \\
\hline & Somatór & ia dos pesos & 100 a 81 & 80 a 61 & 60 a 41 & 40 a 21 & & $<20$ & \\
\hline & & lasse & 1 & II & III & IV & & V & \\
\hline & & scrição & Muito Bom & Bom & Regular & Pobre & Muit & to pobr & \\
\hline & & & Significado & as classes de & naciços & & & & \\
\hline & & lasse & 1 & II & III & IV & & V & \\
\hline & Stand & -up médio & $\begin{array}{c}20 \text { anos para } \\
15 \mathrm{~m}\end{array}$ & $\begin{array}{l}1 \text { ano para } \\
10 \mathrm{~m}\end{array}$ & $\begin{array}{l}1 \text { semana } \\
\text { para } 5 \mathrm{~m}\end{array}$ & $\begin{array}{l}10 \text { horas para } \\
2,5 \mathrm{~m}\end{array}$ & $30 \mathrm{mir}$ & $\begin{array}{l}\text { nutos } p \\
1 \mathrm{~m}\end{array}$ & \\
\hline & Coesão da ma & ssa rochosa (kPa) & $>400$ & 400 a 300 & 300 a 200 & 200 a 100 & & $<100$ & \\
\hline & Ângulo de & atrito (graus) & $>45$ & 45 a 35 & 35 a 25 & 25 a 15 & & $<15$ & \\
\hline
\end{tabular}


Enquanto a tabela fornece pesos determinísticos, os gráficos (figura 7) fornecem o peso dos parâmetros com maior precisão, além destes dados o autor propõe o tempo de auto sustentação (Figura 8) baseado nas classes determinadas pelo método e no diâmetro do túnel, onde é possível perceber qual o tempo de sustentação para determinado vão de seção.

Figura 7- Gráficos para parâmetros de compressão uniaxial (superior esquerdo), RQD (superior direito), espaçamento das descontinuidades (inferior esquerdo), correlação entre RQD e descontinuidades (inferior direito) (BIENIAWSKI, 1993)
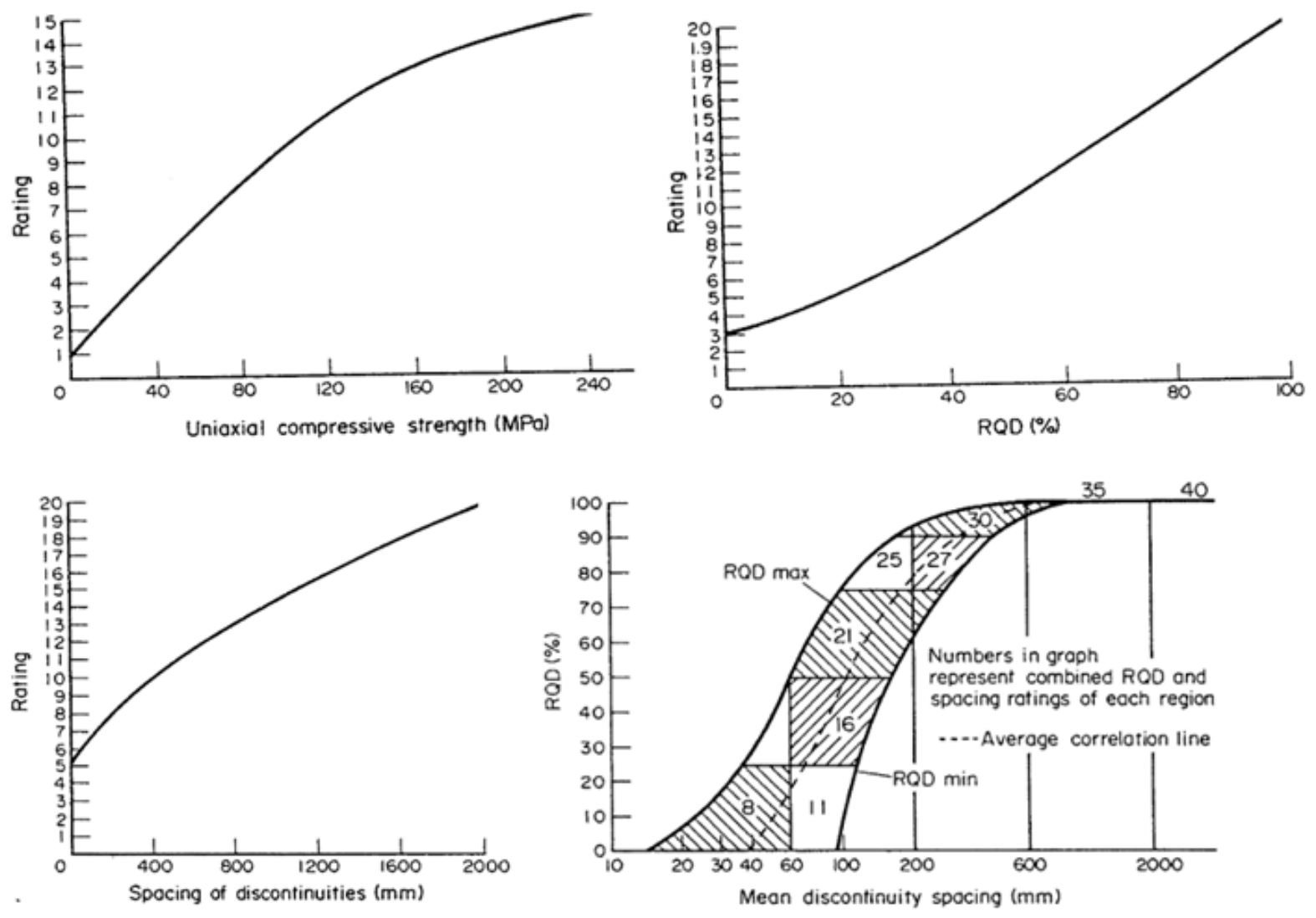
Figura 8 - Tempo de auto sustentação (BIENIAWSKI, 1993)

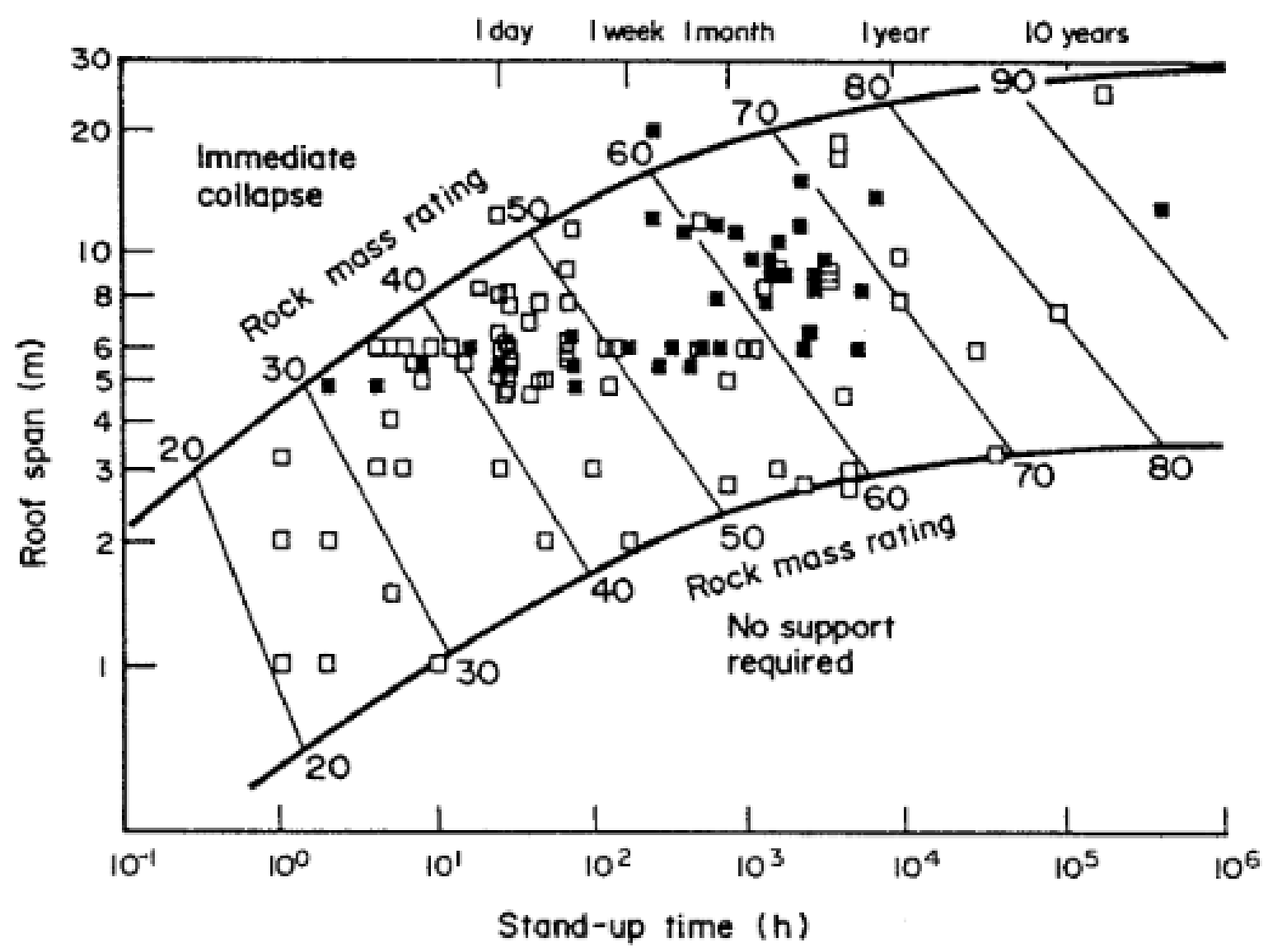

\subsection{DETERMINAÇÃO DA ORIENTAÇÃO DE DESCONTINUIDADES}

Como visto anteriormente as descontinuidades presentes na rocha são um dos fatores de maior importância para se determinar a classificação do maciço rochoso, assim o estudo de suas atitudes permite prever a formação de blocos, antecipando problemas durante a escavação. (HOLMØY, 2008)

A orientação de testemunhos de sondagem é um dos métodos mais baratos, consiste na marcação da parte superior do testemunho de sondagem, antes de iniciada a perfuração da manobra, seja por meio físico ou digital. O método possui diversas limitações, não podendo ser feito em furos verticais, rasos ou muito fraturados. (THOMAS et al., 2015)

O televisamento dos furos de sondagem tem ganhado espaço na geologia de engenharia, com as sondas acústicas e óticas. O estudo é realizado depois de executada a sondagem, com o furo terminado é descido um equipamento com 
sensores que permitam a orientação magnética e acelerativa que possibilitam a visualização de características da rocha in situ.

A perfilagem acústica transmite e capta a amplitude e o tempo de percurso de pulsos ultrassônicos refletidos nas paredes do furo, enquanto a perfilagem ótica capta uma imagem colorida real e contínua do furo.

A perfilagem ótica é um método geofísico de aquisição de dados no qual uma câmera é descida em um furo de sondagem, obtendo-se uma imagem orientada e contínua do furo. Embora a sondagem rotativa seja a principal fonte de informação durante a fase de investigação, as perfilagens óticas têm sido utilizadas de forma a complementar a fonte de dados com orientação de estruturas e preenchimento de lacunas, tais como trechos de baixa recuperação (DE FREDRICK et al., 2014; GAILLOT et al., 2007; WEIR, 2015).

A versatilidade da perfilagem ótica é evidenciada pelos estudos nas mais distintas áreas: identificação de zonas ricas em bolhas de ar em geleiras e glaciares onde não existe a recuperação de testemunhos (MALONE et al., 2013; ROBERSON; HUBBARD, 2010); verificação de equipamentos e caracterização de fluidos de poços na indústria petrolífera (MADDOX, 1997); caracterização de depósitos minerais (SAUMUR et al., 2015), caracterização hidrogeológica de maciços fraturados, (MONTEIRO, 2016), estudo de viabilidade de pontes (LAFRONZ et al., 2004), estudo de injeção de argamassa (ELLEDGE; DUBEAU; HEENAN, 2012) e estudos de maciços rochosos para a execução de túneis (STUMM et al., 2013).

\subsubsection{Componentes da perfilagem ótica}

O equipamento de perfilagem ótica (Optical Televiewer-OPTV) consiste de uma sonda de aço com uma câmera interna que possui um sistema de espelhos e lâmpadas LEDs para gerar a imagem do furo de sondagem e um conjunto de magnetômetros, inclinômetros e acelerômetros tri-ortogonais para obter orientação. Esta sonda é ligada a um cabo, que promove sustentação e envia todas as informações a um computador, e é movimentada com o auxílio de centralizadores que inibem a movimentação pendular e um guincho que fornece a informação de cota (Figura 9). 
Figura 9 - Sonda OPTV, mostrando os componentes externos (a) e o funcionamento interno (b) (HUBBARD et al., 2012)

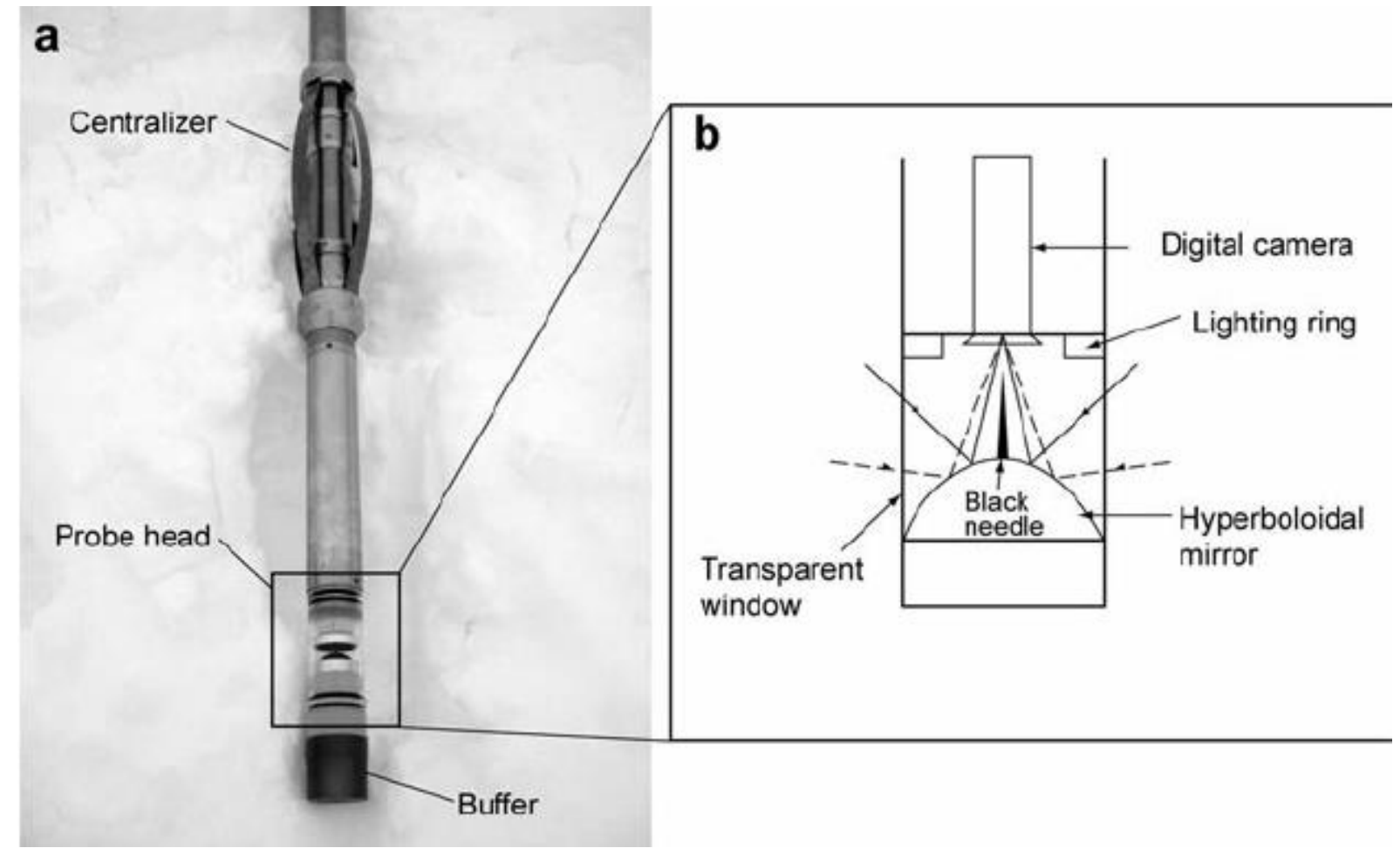

A descida da sonda no furo de sondagem permite o registro de uma sequência de pixels horizontais da circunferência do furo que, quando posicionados, verticalmente geram uma imagem panorâmica $360^{\circ}$ orientada plana do furo.

A gravação pode ser feita no ar ou na água, porém a presença de material particulado na água, assim como precipitação química e crescimento bacteriano, pode comprometer a qualidade das imagens. As configurações estabelecidas no momento do registro também auxiliam na definição da imagem, tais como: qualidade, taxa de quadros, resolução, luminosidade, exposição à luz e velocidade de decida da sonda irão interferir no produto final.

O arquivo gerado é uma imagem de alta resolução, plana e orientada do furo, na qual as descontinuidades aparecem como senóides e podem ter suas medidas de direção e mergulho calculadas. (Figura 10) 
Figura 10 - descontinuidade esquemática em um furo de sondagem (c) e sua representação gráfica da perfilagem ótica (d) (HUBBARD et al., 2012)

C

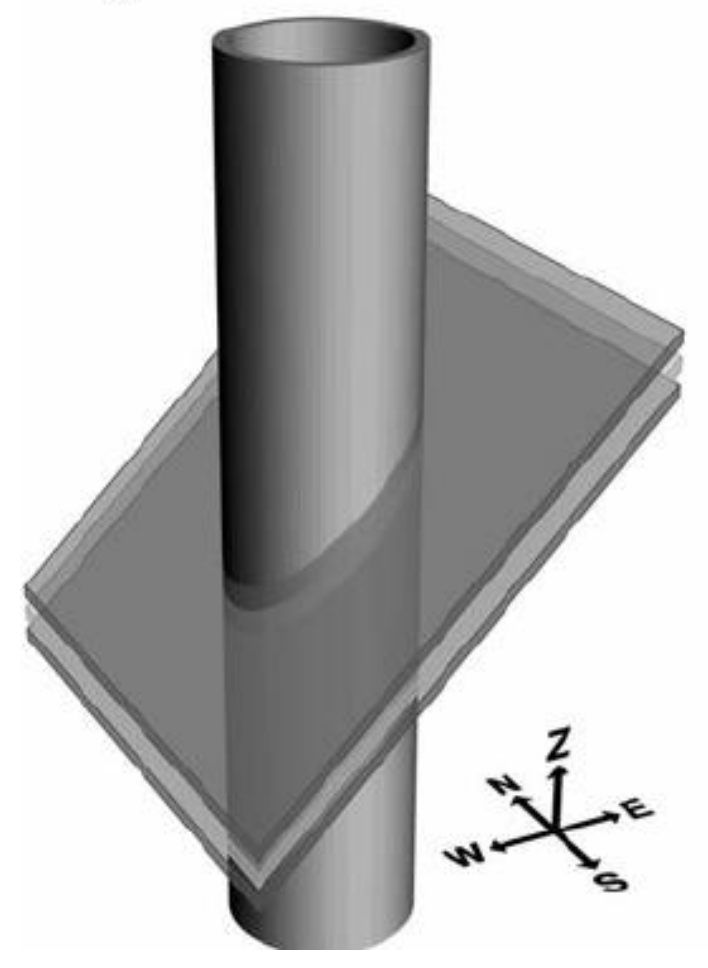

d

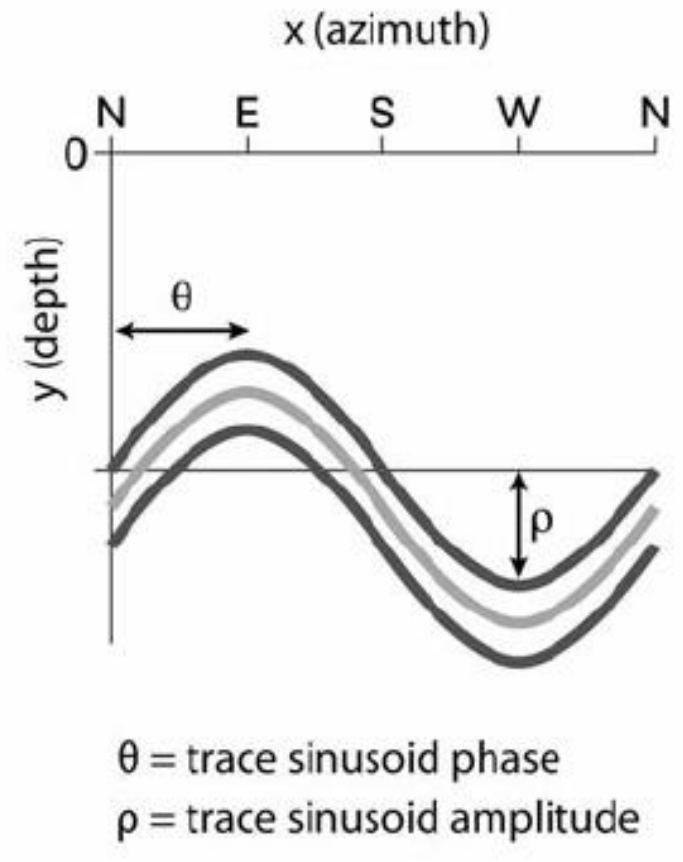

\subsubsection{Caracterização utilizando a perfilagem ótica.}

Quando analisada a utilização da perfilagem ótica na construção civil é necessário perceber que ela é complementar a aquisição de dados tradicional (ex: perfuração e classificação de testemunho de sondagens, testes e ensaios laboratoriais), levando a fornecer informações que dificilmente seriam obtidas sem sua aplicação (ex: orientação das descontinuidades, trechos com baixa recuperação).

Observam-se, em campo, diversos problemas técnicos que podem influenciar na obtenção de testemunhos que representem verdadeiramente o maciço estudado. As velocidades de perfuração e rotação inadequadas, utilizada pelo operador da sonda rotativa, pode cominuir testemunhos de rochas com baixa coesão, subestimando trechos de rocha competente. O manuseio e armazenagem inadequados dos testemunhos podem ocasionar quebras ou falta de organização no armazenamento, que prejudicam a correta classificação de um determinado trecho ou mesmo da sondagem inteira, além disso, o próprio material estudado pode estar sujeito a um 
rápido intemperismo e provocar um pastilhamento que dificultaria a interpretação geotécnica do maciço.

As rochas sedimentares e com maior grau de alteração são as que estão mais sujeitas a este tipo de problema, ao estudarem fundações de barragens em arenitos, Pastore, Cruz \& FREITAS JR (2015) relataram lacunas de informação nos testemunhos de sondagem em camadas friáveis, suscetíveis a piping, e apontaram que estes hiatos podem ser suplantados com a utilização da perfilagem ótica, diminuindo assim os riscos geotécnicos.

Da mesma forma De Fredrick et al. (2014) e Hubbard et al. (2008) mostram que a natureza dos dados da perfilagem ótica permite uma avaliação mais precisa de zonas com baixa recuperação de testemunho de sondagem, que pode ocorrer pelo grande número de fraturas ou pelo desgaste produzido pela ferramenta, além de recriar um testemunho de sondagem virtual que pode ser armazenado em um banco de dados sem sofrer qualquer tipo de alteração.

Outro problema encontrado na classificação de sondagens se dá em furos inclinados, nos quais a ferramenta de corte tende a se deslocar para ficar perpendicular a foliação ou fratura principal, fator que pode ser corrigido ao utilizar a perfilagem ótica. (GANERØD et al., 2006)

Segundo Gwynn, Brown \& MOHR (2013) as perfilagens tem se tornado rotina, pois proporcionam dados de forma rápida e precisa, essenciais para identificar dados estruturais geotécnicos.

A classificação da orientação de descontinuidades também mostra um efeito positivo com a digitalização do testemunho Holcombe (2000) comparou a classificação de testemunhos de sondagem de diferentes indivíduos para verificar a variação de tomadas de atitudes e percebe uma variação média de $16^{\circ}, 12^{\circ}$ e $9^{\circ}$ para as análises de testemunhos com diâmetro $\mathrm{NQ}, \mathrm{HQ}$ e $\mathrm{PQ}$, respectivamente. Quando comparadas as classificações de diferentes pessoas que analisaram perfilagens óticas a variação era de no máximo 5ํㅡㄹ normalmente exibindo uma média de $1^{\circ}$.

A distinção entre as rugosidades no entanto não possui o mesmo efeito positivo, enquanto podem ser facilmente distinguidas quando analisado o testemunho, não é tão simples de ser obtida devido a limitações da resolução de imagem. (DE FREDRICK et al., 2014) 


\section{MATERIAIS E MÉTODOS}

Com a finalidade de estender o alcance do metrô até o município de Taboão da Serra foram realizadas 113 sondagens durante setembro de 2013 e julho de 2014 , as sondagens totalizam 4.983,24 m, sendo 2.914,85 m em solo e 2.068,39 m de rocha. Além das sondagens foram realizadas perfilagens óticas e geofísicas, além de ensaios de compressão simples (RCU) e de perda d'água sobre pressão (EPA).

O quadro 8 apresenta um resumo de todas as sondagens realizadas, bem como as informações obtidas da perfilagem ótica, RCU e EPA.

\subsection{Classificação dos testemunhos de sondagem}

Devido à restrição de acesso aos testemunhos e amostras coletados durante a campanha de sondagens, o presente trabalho utilizou perfis de sondagem fornecidos pelo Metrô nos quais a rocha do embasamento é descrita como:

- Migmatito de granulação média a grossa, com foliação sub-horizontal a subvertical, podendo apresentar porções miloníticas localizadas.

- Biotita-gnaisse, de granulação média a grossa, foliação subvertical e textura migmatítica. 
Quadro 8 - Tabela de dados fornecidos

\begin{tabular}{|c|c|c|c|c|c|c|c|c|c|c|c|}
\hline SM & EPA & TV & $\mathrm{RCU}$ & SM & EPA & TV & $\mathrm{RCU}$ & $S M$ & EPA & TV & $\mathrm{RCU}$ \\
\hline 4500 & & & & 4541 & & & & 4586 & & & \\
\hline 4501 & & & & 4542 & & & & 4587 & & & \\
\hline 4503 & & $\mathrm{x}$ & & 4543 & & & & 4588 & & & \\
\hline 4504 & & & & 4544 & & $x$ & & 4589 & & & \\
\hline 4505 & $x$ & $x$ & & 4545 & $x$ & $x$ & & 4590 & & & \\
\hline 4506 & & & & \begin{tabular}{|l|l}
4546 \\
\end{tabular} & & & & 4592 & & & \\
\hline 4507 & & & & 4548 & & $x$ & & 4593 & & & \\
\hline 4508 & & & & 4549 & & & & 4594 & & & \\
\hline 4509 & & & & 4550 & & & & 4595 & & & \\
\hline 4510 & & & & 4551 & & & & 4596 & & $x$ & \\
\hline 4511 & & & & 4552 & & & & 4597 & & $x$ & \\
\hline 4512 & $x$ & & & 4553 & & & & 4598 & & & \\
\hline 4513 & & & & 4554 & & & & 4599 & & & \\
\hline 4514 & & & & 4555 & & & & 4600 & & & \\
\hline 4515 & & $\mathrm{x}$ & & 4556 & & & & 4601 & & & \\
\hline 4516 & & & & 4559 & & $x$ & & 4602 & & & \\
\hline 4517 & & & & 4560 & & & & 4603 & & $x$ & \\
\hline 4518 & & & & 4561 & & & & 4604 & & & \\
\hline 4519 & & & & 4562 & & & & 4605 & & & $x$ \\
\hline 4520 & & & & 4563 & & & & 4606 & & & \\
\hline 4522 & & & & 4564 & $x$ & $x$ & & 4607 & & & \\
\hline 4523 & & & & 4566 & & & & 4608 & & & \\
\hline 4524 & & & & 4567 & & & & 4609 & & & \\
\hline 4525 & & & & 4568 & & & & 4610 & & & \\
\hline 4526 & & & & 4569 & & & & 4611 & & & \\
\hline 4527 & & & & \begin{tabular}{|l|l}
4570 \\
\end{tabular} & & & & 4612 & & & \\
\hline 4528 & $x$ & $x$ & & 4571 & & & & 4613 & & & \\
\hline 4529 & & & & 4572 & & $x$ & & 4614 & & & \\
\hline 4530 & & & & 4573 & & & & 4617 & & & \\
\hline 4531 & & & & 4574 & & & & 4619 & & & \\
\hline 4532 & & $x$ & & 4575 & & & & 4620 & & & \\
\hline 4533 & & & & 4576 & & & & 4621 & & & \\
\hline 4534 & & & $x$ & 4578 & & & & 4622 & & & \\
\hline 4535 & & & & 4580 & & & & 4623 & & & \\
\hline 4536 & & $x$ & & 4581 & & $x$ & & 4624 & & & \\
\hline 4537 & & & & 4582 & & & & 4635 & $x$ & & \\
\hline 4538 & & & & 4583 & $x$ & & & 4638 & & & \\
\hline 4539 & & $x$ & & 4584 & & & & 4639 & & & \\
\hline 4540 & & $x$ & & 4585 & & & & & & & \\
\hline
\end{tabular}


A classificação geomecânica segue o padrão do metrô, no qual são analisados - Grau de alteração, grau de coerência, grau de fraturamento, superfície, preenchimento e inclinação das descontinuidades, conforme o modelo de boletim (Figura 11).

Figura 11 - Modelo de boletim de sondagem

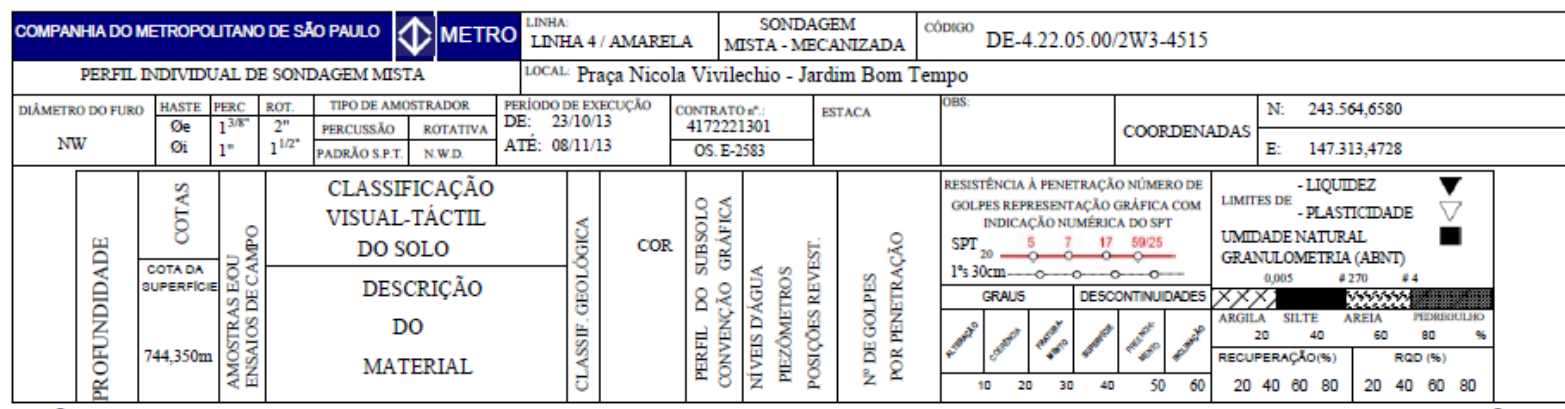

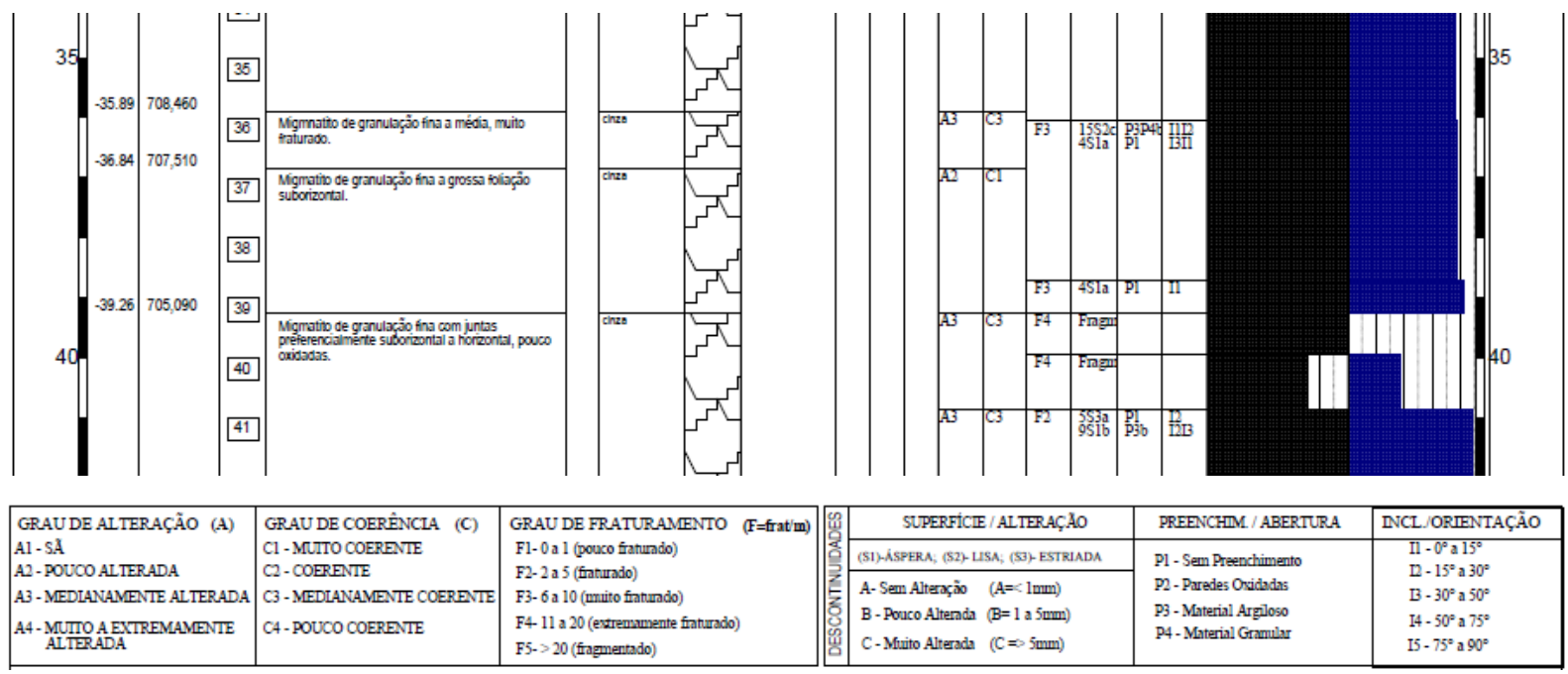

\subsection{Classificação das perfilagens óticas}

Foram providenciados pelo metrô tanto as imagens de televisamento dos 18 furos de sondagem como os relatórios gerados, o presente trabalho se propôs a reinterpretar a perfilagem ótica, de forma identificando as descontinuidades que fornecerão os dados necessários para o modelo geológico-geotécnico de perfuração do túnel.

Para a interpretação dos dados foi utilizado o software WellCad, que permite a sobreposição de imagens e criação de camadas orientadas pelo operador que ao 
identificar uma descontinuidade combina a senóide da descontinuidade com a gerada pelo programa, identificando sua direção e mergulho.

Primeiramente é necessário determinar a orientação do furo de sondagem, determinando a direção na qual foi perfurado bem como a inclinação da torre da perfuratriz.

Depois de identificada uma descontinuidade na imagem plana o software calcula sua atitude utilizando a distância da parte mais baixa do senóide para a lateral (norte magnético), obtendo a direção, e valendo-se da amplitude do senóide, para o cálculo do mergulho.

As figuras 12 e 13 mostram imagens do programa, com o testemunho virtual a esquerda e imagem aberta a direita, o Apêndice I apresenta os televisionamentos utilizados. Quando analisado no programa é possível perceber tanto uma zona extremamente fraturada (Figura 12), como um trecho de rocha sã com presença de foliação (Figura 13).

Figura 12 - Trecho da perfilagem ótica da SM-4505, mostrando rocha altamente fraturada. A esquerda o testemunho virtual e a direita imagem plana $360^{\circ}$

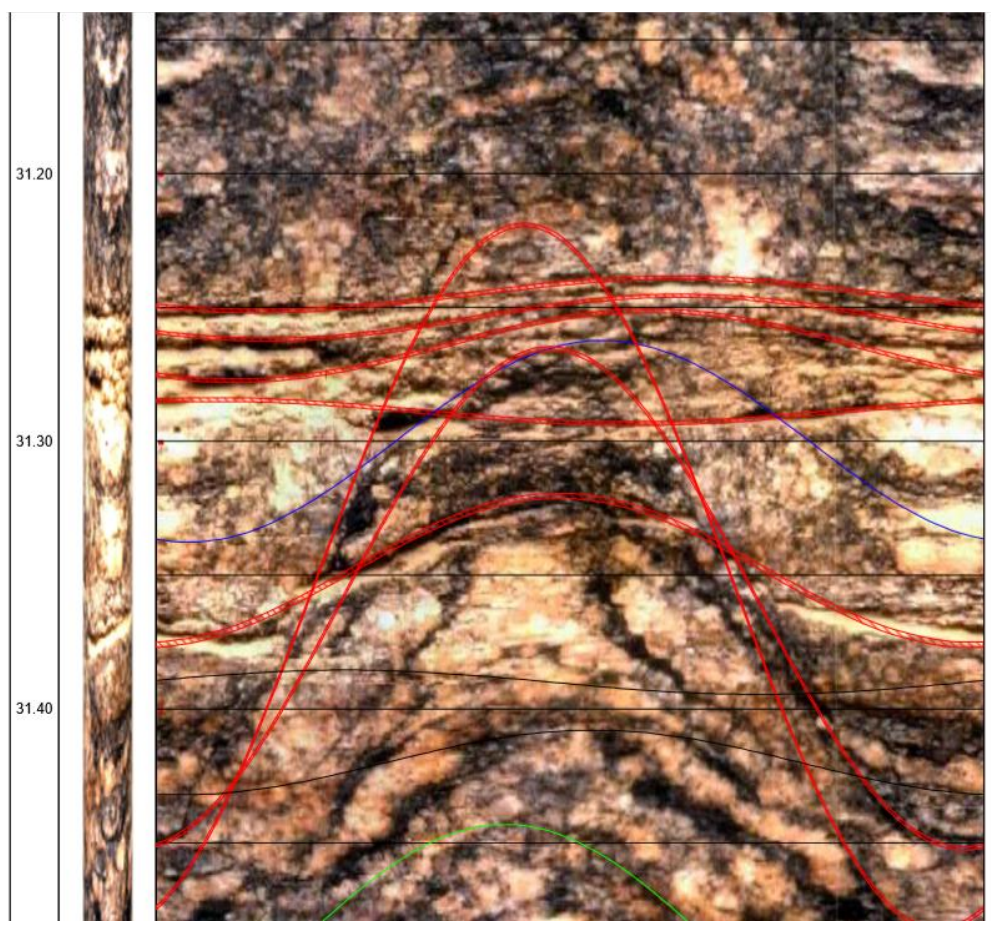


Figura 13 - Trecho da perfilagem ótica da SM-4503, mostrando rocha altamente fraturada. A esquerda o testemunho virtual e a direita imagem plana $360^{\circ}$
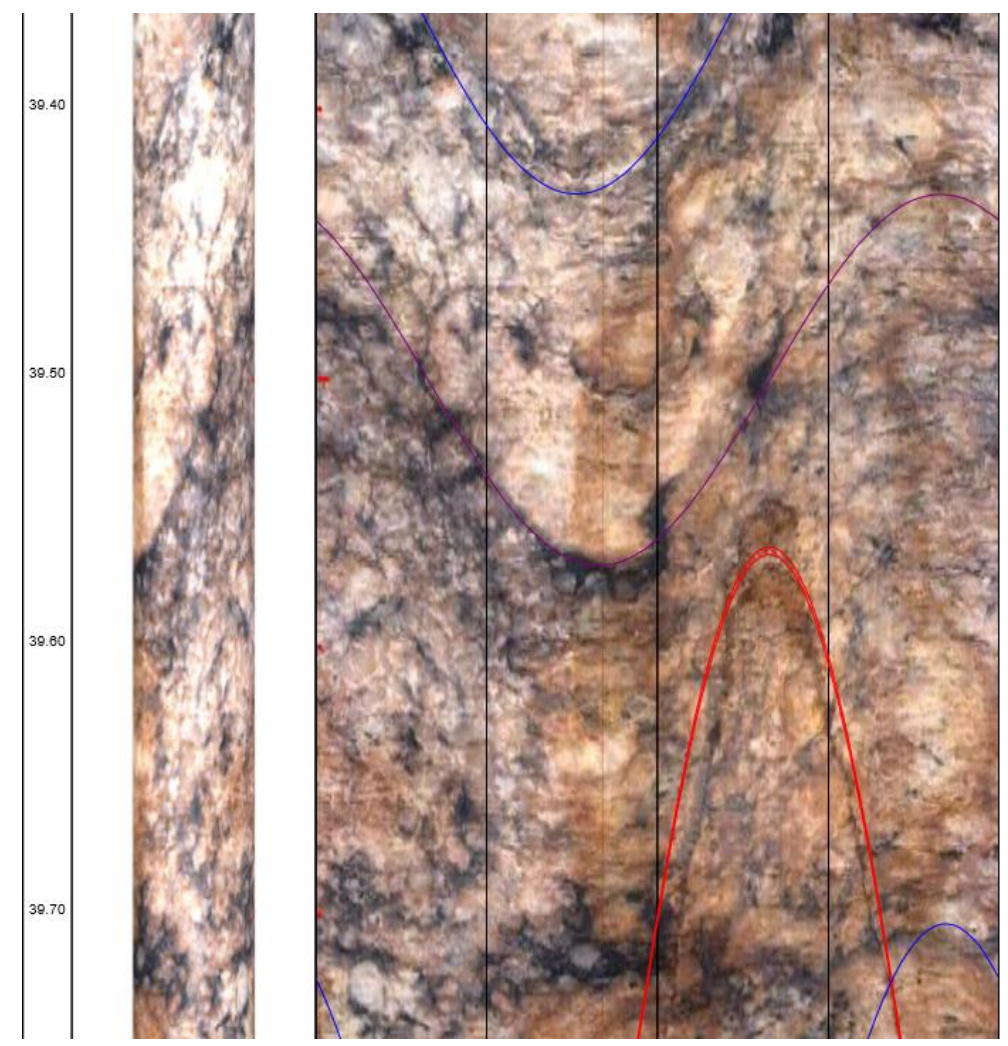

$\mathrm{Na}$ etapa seguinte utiliza-se as descontinuidades obtidas para gerar estereogramas para cada perfilagem. Para isso foi utilizado o software Dips que, além de formar os estereogramas, possibilita o cálculo de médias de descontinuidades, fornecendo informações de famílias de descontinuidades através do agrupamento de polos.

\subsection{Classificação do maciço rochoso}

Com a descrição geológica obtida nos perfis de sondagem foi possível delimitar as diferentes camadas de solo, bem como o topo rochoso.

Para a caracterização do maciço rochoso foi utilizada a classificação RMR modificada (quadro 9), com as notas atribuídas através das informações geotécnicas dos perfis individuais de sondagem (dados de fraturamento, recuperação, RQD, alteração e coerência) somados com os ensaios RCU e EPA. 
Quadro 9 - RMR modificado, Companhia do Metropolitano de São Paulo

\begin{tabular}{|c|c|c|c|c|c|c|c|c|c|}
\hline \multicolumn{10}{|c|}{ Parâmetros de Classificação } \\
\hline \multirow{3}{*}{1} & \multirow{2}{*}{$\begin{array}{l}\text { Resistên } \\
\text { cia do } \\
\text { Material } \\
\text { Intacto }\end{array}$} & \multirow{2}{*}{\begin{tabular}{|c} 
Índice de resistência \\
a carga pontual (Mpa)
\end{tabular}} & \multirow{2}{*}{$\begin{array}{l}>10 \\
>250\end{array}$} & \multirow{2}{*}{$\frac{10 \text { a } 4}{250 \text { a } 100}$} & \multirow{2}{*}{$\begin{array}{c}4 \text { a } 2 \\
100 \text { a } 50\end{array}$} & \multirow{2}{*}{$\begin{array}{c}2 \text { a } 1 \\
50 \text { a } 25\end{array}$} & \multicolumn{3}{|c|}{$\begin{array}{c}\text { Somente para } \\
\text { compressão } \\
\text { simples }\end{array}$} \\
\hline & & & & & & & 25 a 5 & 5 a 1 & $<1$ \\
\hline & & Peso & 15 & 12 & 7 & 4 & 2 & 1 & 0 \\
\hline \multirow[t]{2}{*}{2} & \multicolumn{2}{|c|}{$\begin{array}{c}\text { Qualidade do testemunho - RQD } \\
(\%)\end{array}$} & 100 a 90 & 90 a 75 & 75 a 50 & 50 a 25 & \multicolumn{3}{|c|}{$<25$} \\
\hline & & Peso & 20 & 17 & 13 & 8 & \multicolumn{3}{|c|}{3} \\
\hline \multirow[t]{2}{*}{3} & \multicolumn{2}{|c|}{$\begin{array}{c}\text { Espaçamento das } \\
\text { descontinuidades }(\mathrm{mm})\end{array}$} & $\mathrm{F} 1$ & F1-F2 & F2-F3 & F3 & \multicolumn{3}{|c|}{ F4-F5 } \\
\hline & & Peso & 20 & 15 & 10 & 8 & \multicolumn{3}{|c|}{5} \\
\hline \multirow{2}{*}{4} & \multicolumn{2}{|c|}{ Padrão das descontinuidades } & S1 & $\mathrm{S} 2$ & $\mathrm{~S} 2 \mathrm{C}$ & S3 A/B & \multicolumn{3}{|c|}{ P3C } \\
\hline & & Peso & 30 & 25 & 20 & 10 & \multicolumn{3}{|c|}{0} \\
\hline \multirow{2}{*}{5} & & gua subterrânea & $\mathrm{F} 1$ & $\mathrm{~F} 1$ & $\mathrm{~F} 2$ & F3 & \multicolumn{3}{|c|}{$\mathrm{F} 4-5$} \\
\hline & & Peso & 15 & 10 & 7 & 4 & \multicolumn{3}{|c|}{0} \\
\hline
\end{tabular}

\subsection{Modelagem do maciço e túnel}

Através do planilhamento compatível com o software Hole Base foi possível a geração de um arquivo BIM que foi facilmente importado pelo módulo geotécnico do software Autodesk Civil 3D, que foi utilizado para gerar os perfis geológicos e geotécnicos do traçado.

Utilizando as famílias de fraturas foi possível criar no software UnWedge o modelo tridimensional do túnel no qual estão inseridas as fraturas, combinando a direção do túnel com as atitudes das descontinuidades.

\section{RESULTADOS}

7.1. Descontinuidades e classificação geomecânica das perfilagens

Os estereogramas e a classificação geomecânica apresentadas em separado são aquelas onde foram realizadas as perfilagens óticas, estando a interpretação das demais nos perfis geotécnicos. As propriedades estão apresentadas separadamente de acordo com cada sondagem, com ênfase no trecho alvo onde se imagina que irá ocorrer a passagem do túnel, que se estima ter 9 metros de diâmetro. A tabela com as descontinuidades encontradas encontra-se no Apêndice II. 
$\underline{\mathrm{SM}-4503}$

A perfilagem ótica iniciou-se com 21,40 metros e terminou com 44,3 metros, perfazendo 22,90 metros de aquisição de imagem, a rocha foi classificada como um gnaisse de granulação média a grossa, com foliação inclinada a subvertical.

O Quadro 10 apresenta a classificação geomecânica do material, que segundo Bieniawsk (1993) possui tempo de auto sustentação de 3 dias. O estereograma apresenta as descontinuidades presentes na classificação do televisamento (Figura $14)$, bem como as famílias de fraturas presentes $1 \mathrm{~m}(312 / 34), 2 \mathrm{~m}(135 / 39)$ e $3 \mathrm{~m}$ $(144 / 81)$

Quadro 10 - Classificação da SM-4503 com base em Bieniawski (1989) modificada

\begin{tabular}{|l|c|c|}
\hline Sondagem & \multicolumn{2}{|c|}{ SM-4503 } \\
\hline Parâmetro & Classificação & Peso \\
\hline Resistência (Mpa) & 33 & 5 \\
\hline RQD (\%) & $69-78$ & 13 \\
\hline Espaçamento das descontinuidades & F5 a F2 & 8 \\
\hline Condição das descontinuidades & P3 a S1 & 20 \\
\hline Ação da água subterrânea & F5 a F2 & 3 \\
\hline Classificação & \multicolumn{2}{|c|}{ III - Regular (49) } \\
\hline
\end{tabular}

Figura 14 - Estereograma SM-4503
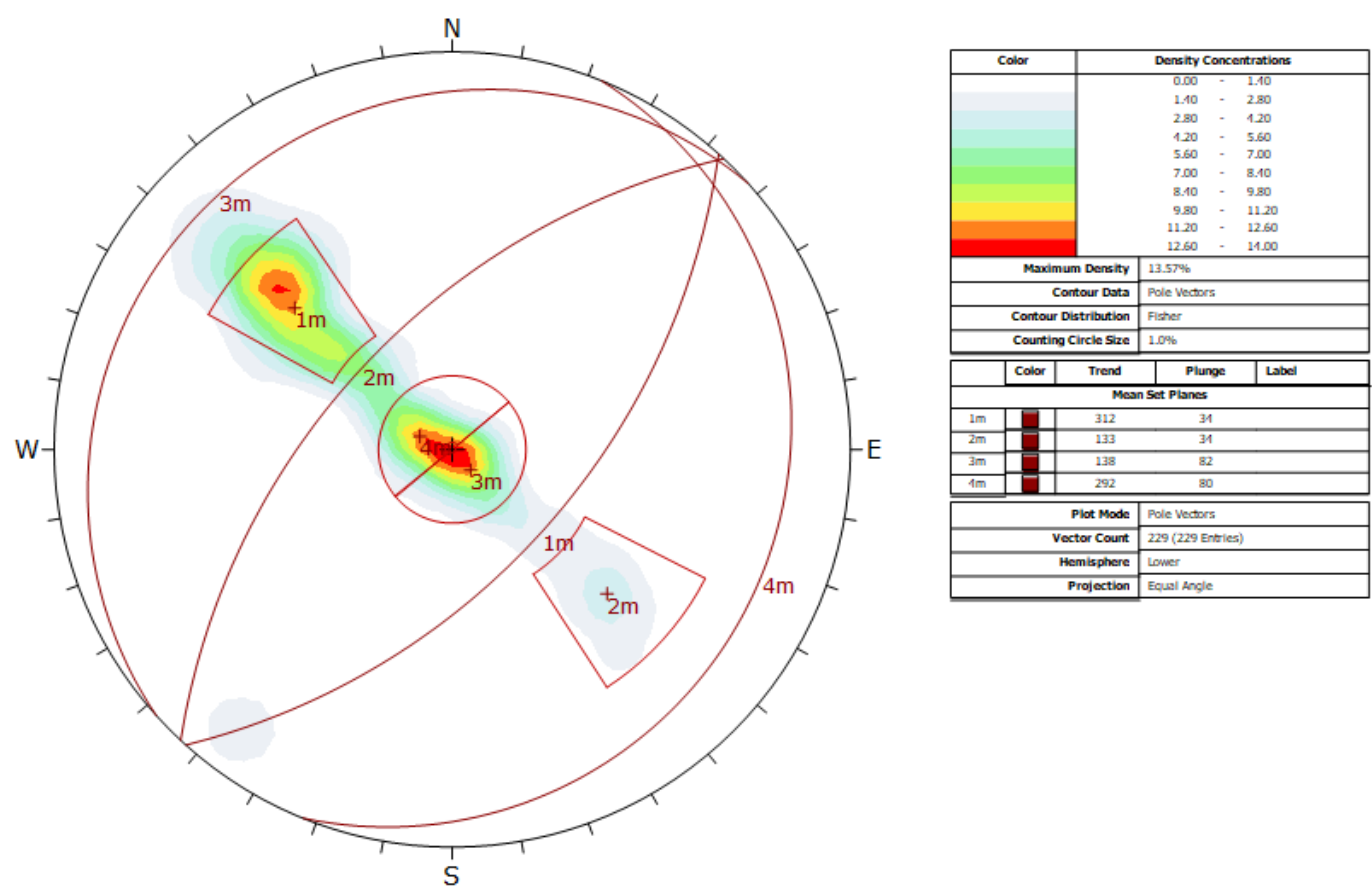


\section{$\underline{\mathrm{SM}-4505}$}

A perfilagem ótica iniciou-se com 26,60 metros e terminou com 44,20 metros, perfazendo 17,80 metros de aquisição de imagem, a rocha foi descrita como um migmatito de granulação grossa, foliação milonítica com grãos de quartzo-feldspato envoltos pela foliação, micácea, com foliação inclinada a subvertical.

O quadro 11 apresenta a classificação geomecânica do material, que segundo Bieniawsk (1993) possui tempo de auto sustentação de mais de dois anos. O estereograma apresenta as descontinuidades presentes na classificação do televisamento (Figura 15), bem como as famílias de fraturas presentes $1 \mathrm{~m}(324 / 13)$, $2 m$ (144/14), $3 m(140 / 50)$ e $4 m(322 / 65)$.

Quadro 11 - Classificação da SM-4505 com base em Bieniawski (1989) modificada
\begin{tabular}{|l|c|c|}
\hline Sondagem & \multicolumn{2}{|c|}{ SM-4505 } \\
\hline Parâmetro & Classificação & Peso \\
\hline Resistência (Mpa) & 37 & 6 \\
\hline RQD (\%) & 82 a 100 & 18 \\
\hline Espaçamento das descontinuidades & F2 a F1 & 19 \\
\hline Condição das descontinuidades & S2 a S1 & 28 \\
\hline Ação da água subterrânea & F2 a F1 & 13 \\
\hline Classificação & I - Muito Bom (84) \\
\hline
\end{tabular}

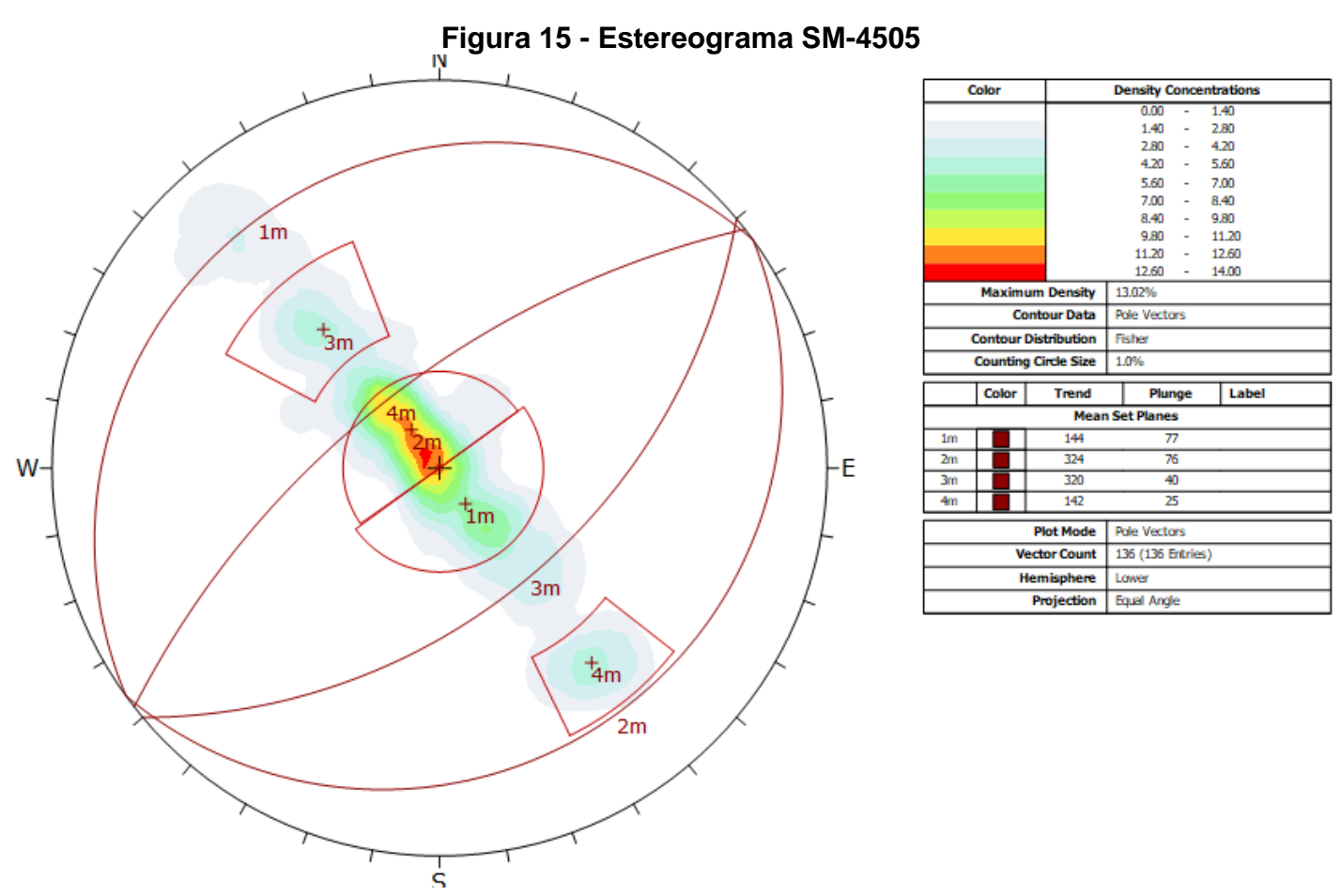




\section{$\underline{\text { SM-4515 }}$}

A perfilagem ótica iniciou-se com 26,90 metros e terminou com 64,70 metros, perfazendo 37,80 metros de aquisição de imagem, a rocha foi descrita como um migmatito de granulação fina a grossa, foliação inclinada a sub-horizontal e veios de quartzo e feldspato.

O quadro 12 apresenta a classificação geomecânica do material, que segundo Bieniawsk (1993) possui tempo de auto sustentação de 35 dias. O estereograma apresenta as descontinuidades presentes na classificação do televisamento (Figura 16), bem como as famílias de fraturas presentes $1 \mathrm{~m}$ (130/51), 2m (308/24), 3m $(318 / 15)$ e $4 \mathrm{~m}(126 / 14)$.

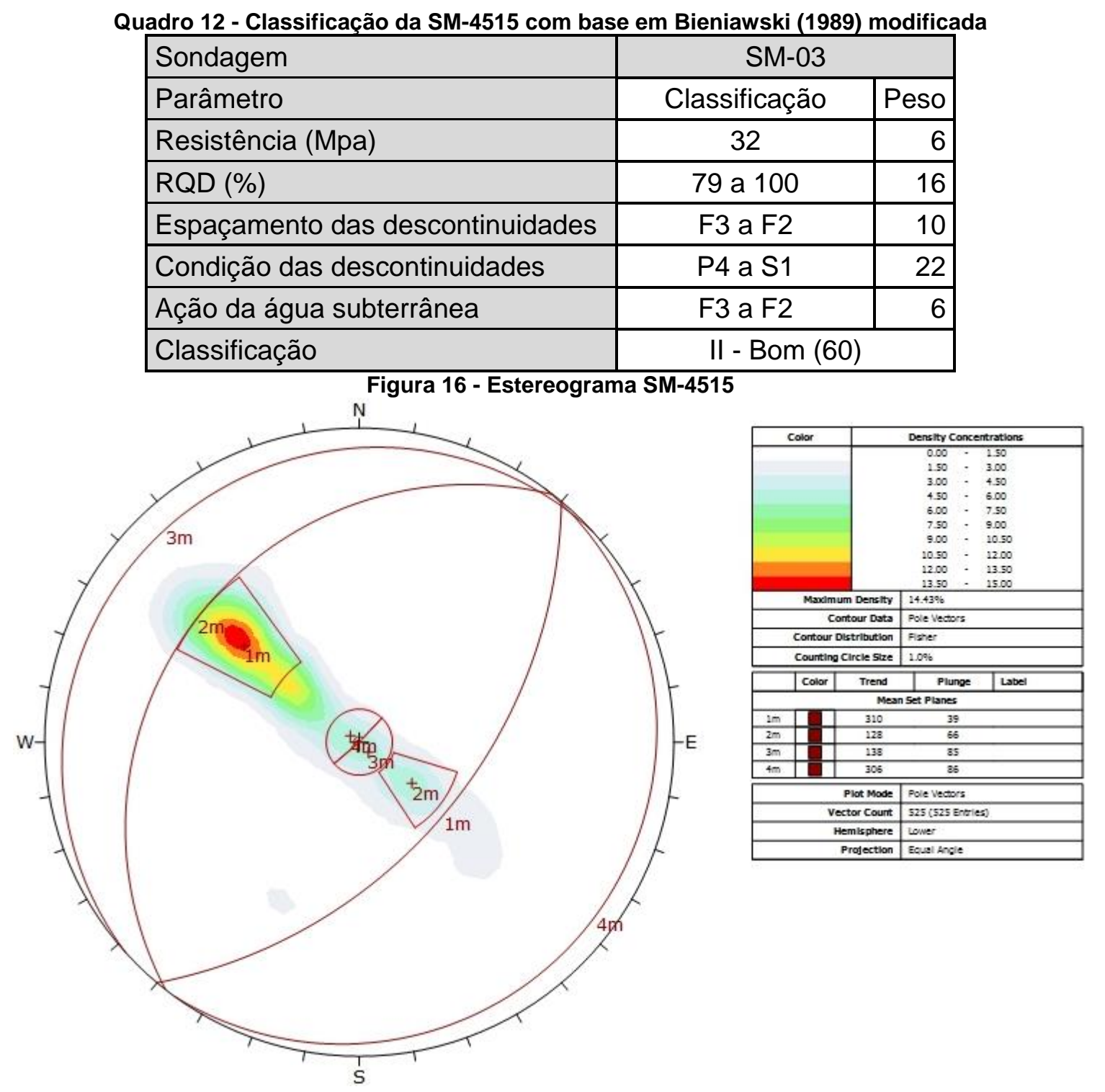




\section{$\underline{\mathrm{SM}-4528}$}

A perfilagem ótica iniciou-se com 12,20 metros e terminou com 35,90 metros, perfazendo 23,70 metros de aquisição de imagem, a rocha foi classificada como um gnaisse de granulação média a grossa.

O quadro 13 apresenta a classificação geomecânica do material, que segundo Bieniawsk (1993) possui tempo de auto sustentação de 35 dias. O estereograma apresenta as descontinuidades presentes na classificação do televisamento (Figura 17), bem como as famílias de fraturas presentes $1 \mathrm{~m}$ (131/75), $2 \mathrm{~m}$ (127/44), 3m (309/75), $4 \mathrm{~m}(308 / 52)$ e $5 \mathrm{~m}(21 / 03)$.

Quadro 13 - Classificação da SM-4528 com base em Bieniawski (1989) modificada
\begin{tabular}{|l|c|c|}
\hline Sondagem & \multicolumn{2}{|c|}{ SM-4528 } \\
\hline Parâmetro & Classificação & Peso \\
\hline Resistência (Mpa) & 45 & 7 \\
\hline RQD (\%) & 94 a 98 & 19 \\
\hline Espaçamento das descontinuidades & F3 a F2 & 12 \\
\hline Condição das descontinuidades & S3 a S1 & 15 \\
\hline Ação da água subterrânea & F3 a F2 & 7 \\
\hline Classificação & II - Bom (60) \\
\hline
\end{tabular}
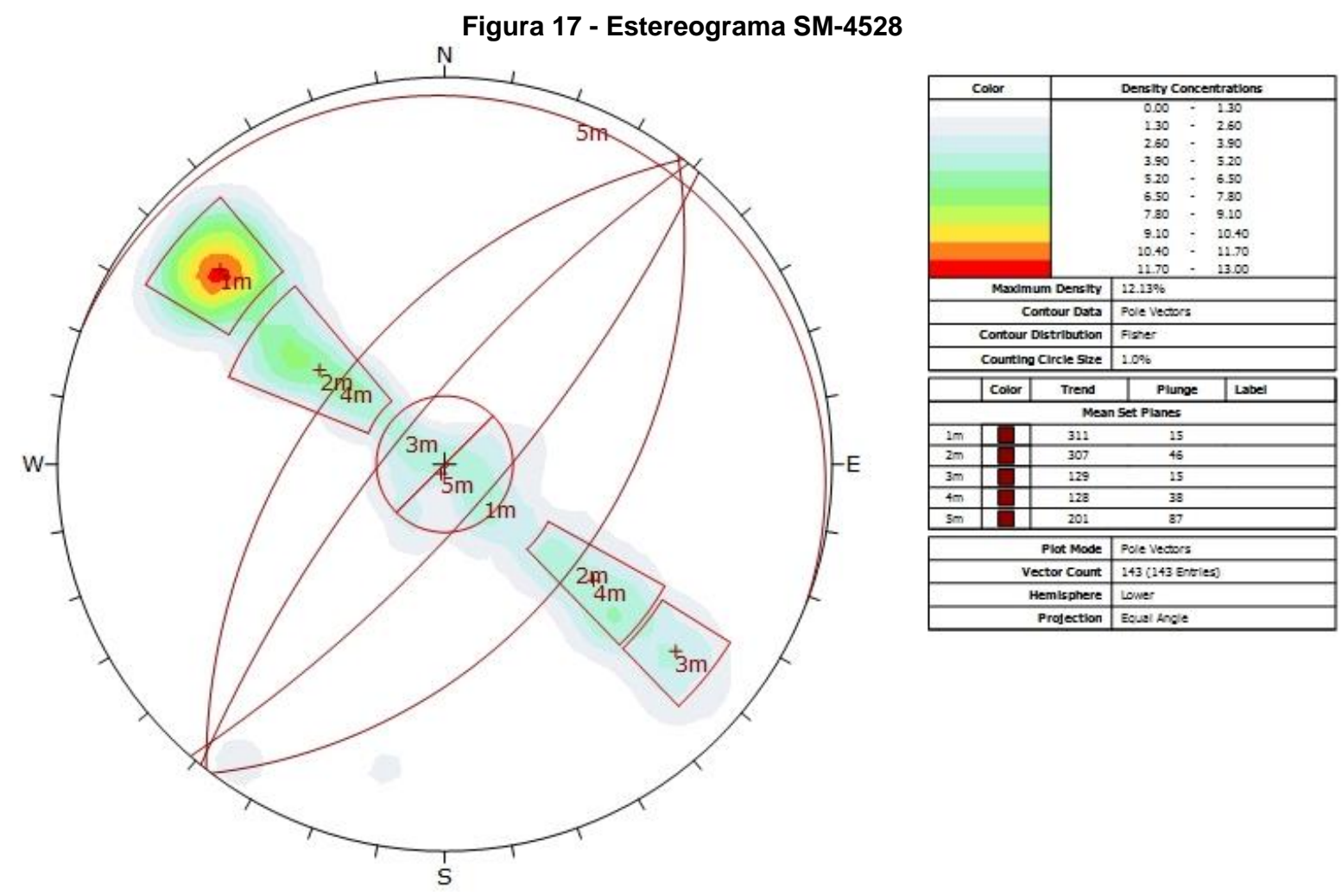


\section{$\underline{\mathrm{SM}-4532}$}

A perfilagem ótica iniciou-se com 7,61 metros e terminou com 39,14 metros, perfazendo 31,53 metros de aquisição de imagem, a rocha é um gnaisse de granulação grossa.

O quadro 14 apresenta a classificação geomecânica do material, que segundo Bieniawsk (1993) possui tempo de auto sustentação de 40 dias. O estereograma apresenta as descontinuidades presentes na classificação do televisamento (Figura 18), bem como as famílias de fraturas presentes $1 \mathrm{~m}$ (137/56) e $2 \mathrm{~m}(313 / 57)$.

Quadro 14 - Classificação da SM-4532 com base em Bieniawski (1989) modificada
\begin{tabular}{|l|c|c|}
\hline Sondagem & \multicolumn{2}{|c|}{ SM-4532 } \\
\hline Parâmetro & Classificação & Peso \\
\hline Resistência (Mpa) & 42 & 6 \\
\hline RQD (\%) & 58 a 100 & 16 \\
\hline Espaçamento das descontinuidades & F3 a F2 & 13 \\
\hline Condição das descontinuidades & S3 a S1 & 20 \\
\hline Ação da água subterrânea & F3 a F2 & 6 \\
\hline Classificação & II - Bom (61) \\
\hline
\end{tabular}

Figura 18 - Estereograma SM-4532
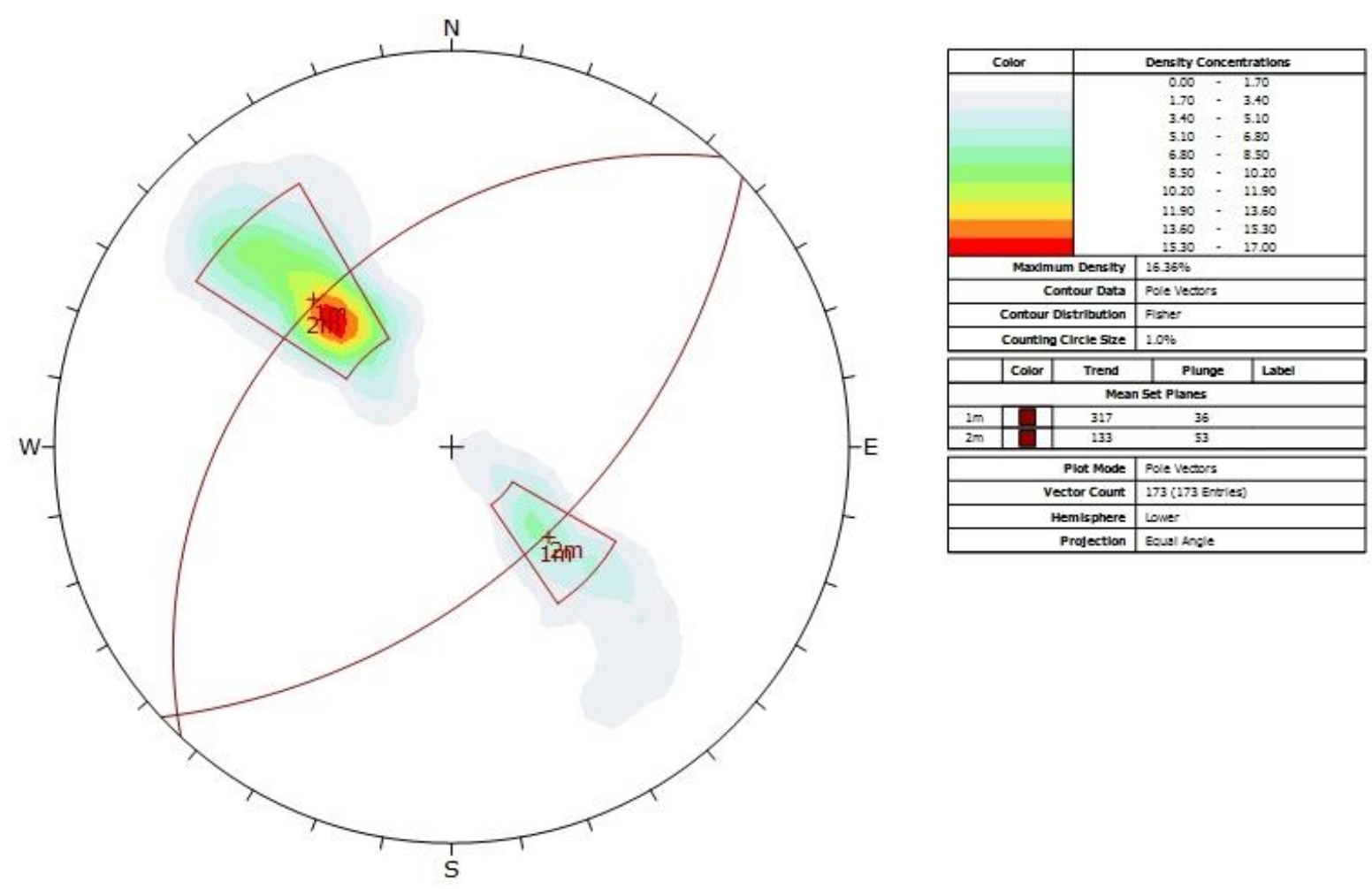


\section{$\underline{\mathrm{SM}-4536}$}

A perfilagem ótica iniciou-se com 14,90 metros e terminou com 40,25 metros, perfazendo 25,35 metros de aquisição de imagem, a rocha foi classificada como um gnaisse de granulação média.

O quadro 15 apresenta a classificação geomecânica do material, que segundo Bieniawsk (1993) possui tempo de auto sustentação de mais de dez anos. O estereograma apresenta as descontinuidades presentes na classificação do televisamento (Figura 19), bem como as famílias de fraturas presentes 1m (134/62) e $2 m(313 / 68)$.

\begin{tabular}{|c|c|c|}
\hline Sondagem & \multicolumn{2}{|l|}{ SM-4536 } \\
\hline Parâmetro & Classificação & Peso \\
\hline Resistência (Mpa) & 70 & 9 \\
\hline RQD (\%) & 83 a 90 & 16 \\
\hline Espaçamento das descontinuidades & $\mathrm{F} 1$ & 20 \\
\hline Condição das descontinuidades & S1 & 30 \\
\hline Ação da água subterrânea & $\mathrm{F} 1$ & 15 \\
\hline Classificação & \multicolumn{2}{|c|}{ I - Muito Bom (90) } \\
\hline
\end{tabular}

Figura 19 - - Estereograma SM-4536

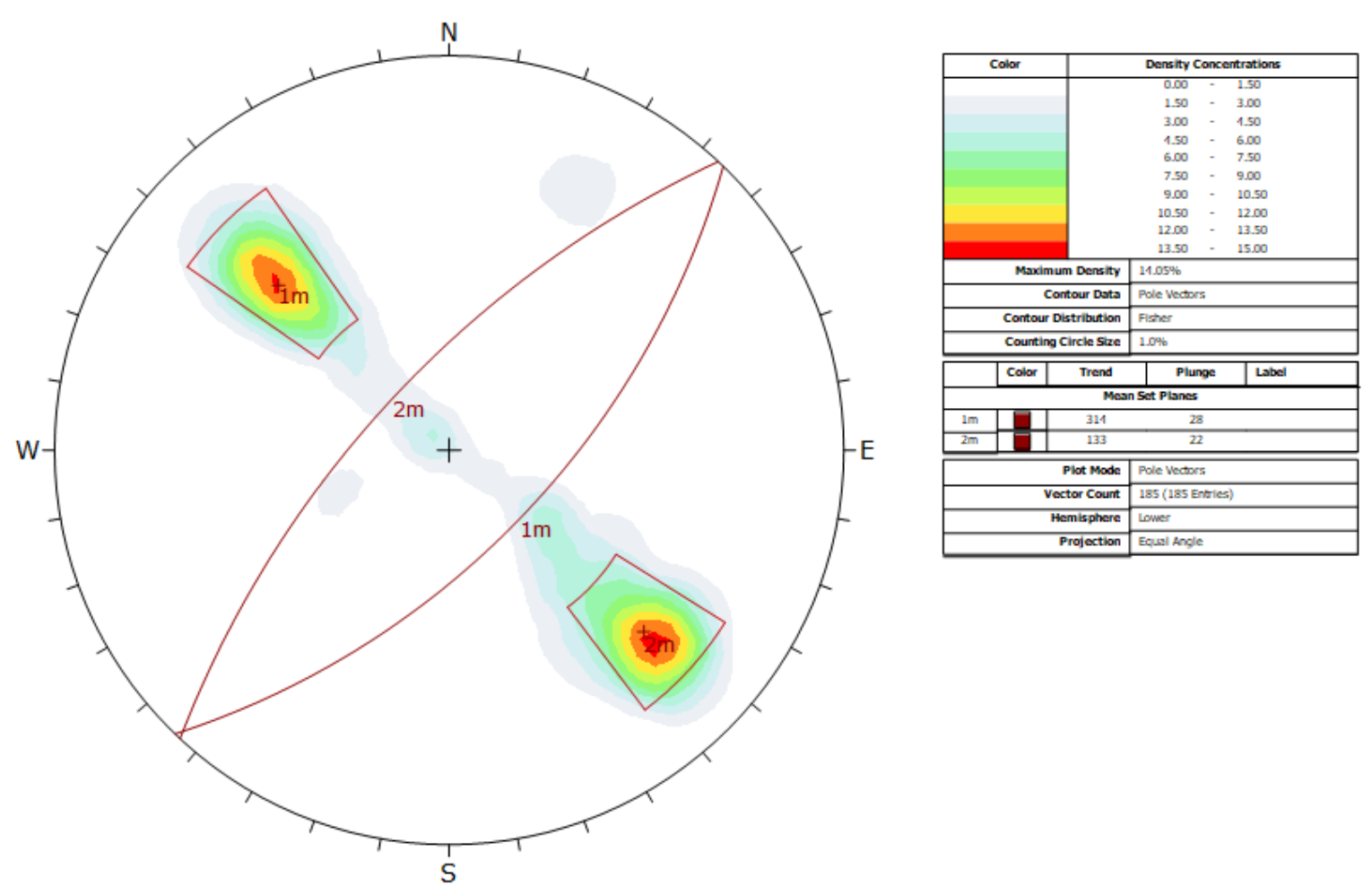




\section{SM-4540}

A perfilagem ótica iniciou-se com 12,80 metros e terminou com 40,25 metros, perfazendo 27,45 metros de aquisição de imagem, a rocha foi classificada como um gnaisse de granulação grossa.

O quadro 16 apresenta a classificação geomecânica do material, que segundo Bieniawsk (1993) possui tempo de auto sustentação de mais de dez anos. O estereograma apresenta as descontinuidades presentes na classificação do televisamento (Figura 20), bem como as famílias de fraturas presentes $1 \mathrm{~m}(127 / 65)$, $2 m(128 / 26)$, 3m (137/05), 4m (301/32) e 5m (304/72).

\section{Quadro 16 - Classificação da SM-4540 com base em Bieniawski (1989) modificada}

\begin{tabular}{|c|c|c|}
\hline Sondagem & \multicolumn{2}{|c|}{ SM-4540 } \\
\hline Parâmetro & Classificação & Peso \\
\hline Resistência (Mpa) & 40 & 6 \\
\hline RQD (\%) & 96 & 18 \\
\hline Espaçamento das descontinuidades & $\mathrm{F} 1$ & 20 \\
\hline Condição das descontinuidades & S1 & 30 \\
\hline Ação da água subterrânea & $\mathrm{F} 1$ & 15 \\
\hline Classificação & \multicolumn{2}{|c|}{ I - Muito Bom (89) } \\
\hline
\end{tabular}

Figura 20 - Estereograma SM-4540
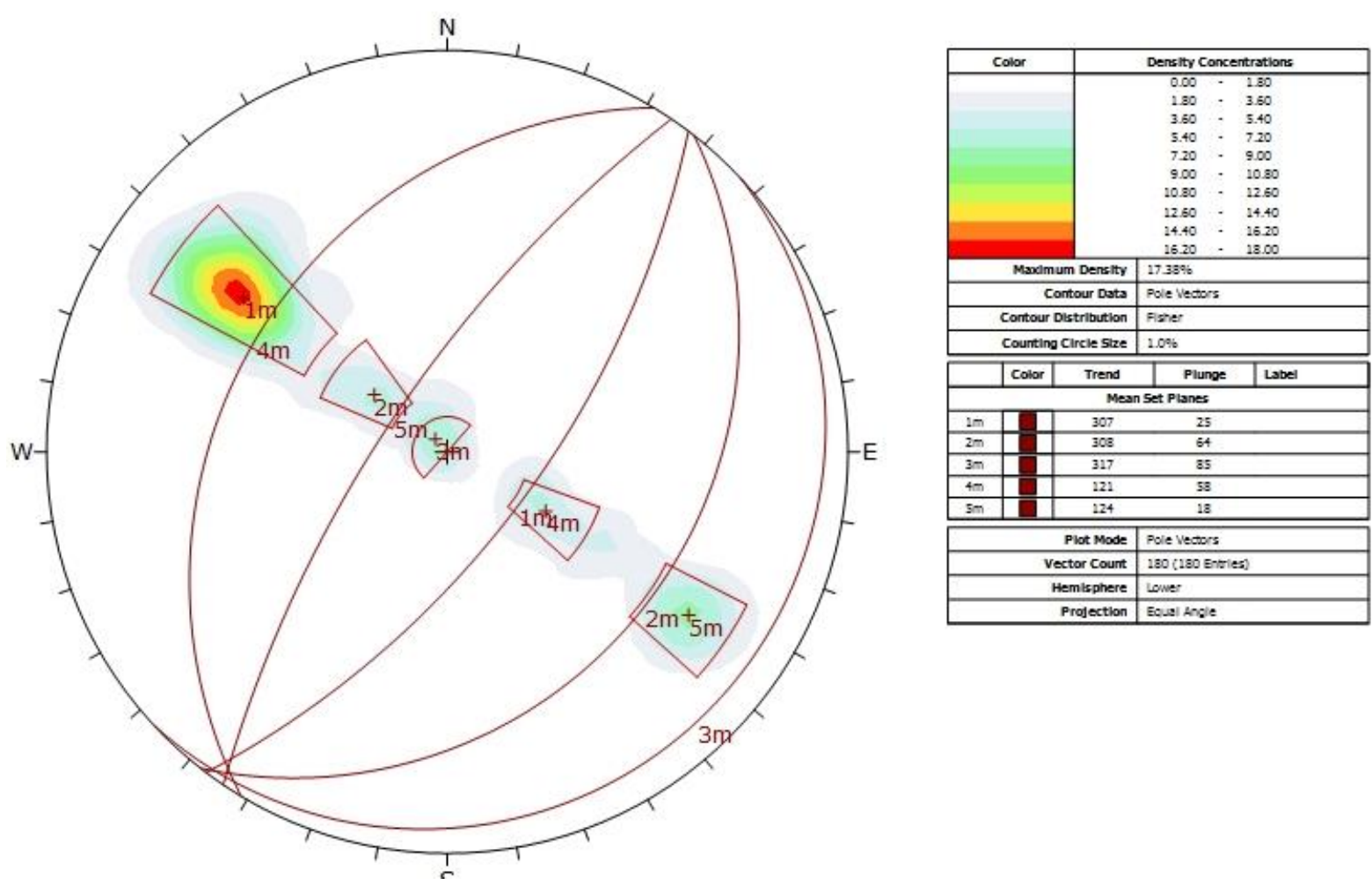


\section{$\underline{\mathrm{SM}-4544}$}

A perfilagem ótica iniciou-se com 4,60 metros e terminou com 38,60 metros, perfazendo 34,00 metros de aquisição de imagem, a rocha foi classificada como um Migmatito, de granulação grossa.

O quadro 17 apresenta a classificação geomecânica do material, que segundo Bieniawsk (1993) possui tempo de auto sustentação de mais de 1 ano. O estereograma apresenta as descontinuidades presentes na classificação do televisamento (Figura 21), bem como as famílias de fraturas presentes $1 \mathrm{~m}$ (127/72), $2 m(126 / 25), 3 m(300 / 14), 4 m(299 / 53)$ e $5 m(24 / 75)$.

\section{Quadro 17 - Classificação da SM-4544 com base em Bieniawski (1989) modificada}

\begin{tabular}{|l|c|c|}
\hline Sondagem & \multicolumn{2}{|c|}{ SM-4544 } \\
\hline Parâmetro & Classificação & Peso \\
\hline Resistência (Mpa) & 40 & 6 \\
\hline RQD (\%) & 96 & 15 \\
\hline Espaçamento das descontinuidades & F1 a F2 & 17 \\
\hline Condição das descontinuidades & S1 a P3 & 22 \\
\hline Ação da água subterrânea & F1 a F2 & 11 \\
\hline Classificação & \multicolumn{2}{|c|}{ II - Bom (71) } \\
\hline
\end{tabular}

Figura 21 - Estereograma SM-4544
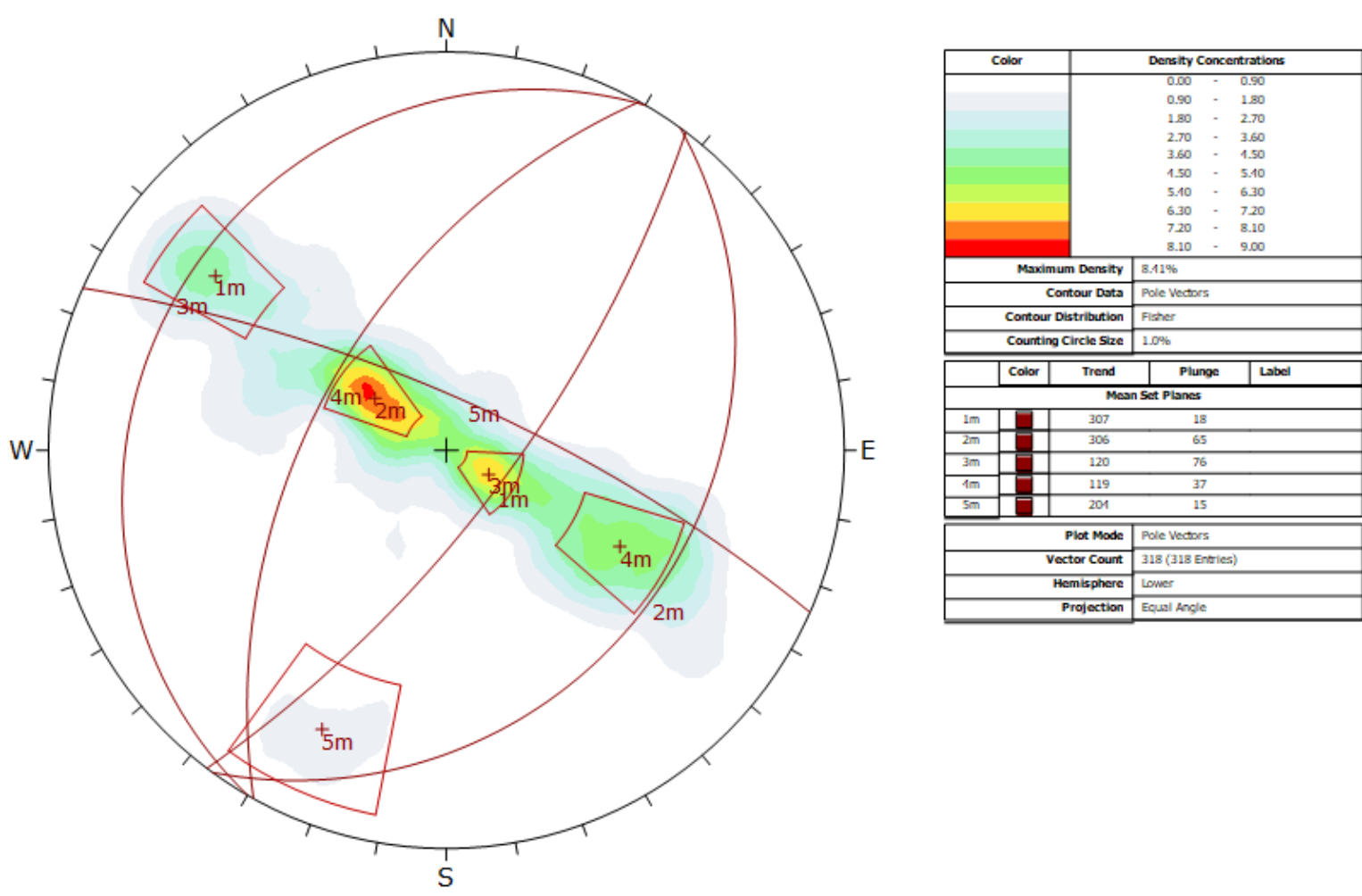


\section{$\underline{\mathrm{SM}-4545}$}

A perfilagem ótica iniciou-se com 3,50 metros e terminou com 39,10 metros, perfazendo 35,60 metros de aquisição de imagem, a rocha foi classificada como um Migmatito, de granulação grossa.

O quadro 18 apresenta a classificação geomecânica do material, que segundo Bieniawsk (1993) não possui tempo de auto sustentação, encontrando-se a esquerda dográfico de tempo de auto sustentação. O estereograma apresenta as descontinuidades presentes na classificação do televisamento (Figura 22), bem como as famílias de fraturas presentes $1 \mathrm{~m}$ (129/74), 2m (128/47), 3m (100/11), 4m (289/34) e $5 \mathrm{~m}(307 / 77)$

Quadro 18 - Classificação da SM-4545 com base em Bieniawski (1989) modificada

\begin{tabular}{|c|c|c|}
\hline Sondagem & \multicolumn{2}{|c|}{ SM-4545 } \\
\hline Parâmetro & Classificação & Peso \\
\hline Resistência (Mpa) & 8 & 3 \\
\hline RQD (\%) & 42 & 6 \\
\hline Espaçamento das descontinuidades & F3 & 8 \\
\hline Condição das descontinuidades & S1 a P3 & 15 \\
\hline Ação da água subterrânea & F3 & 4 \\
\hline Classificação & \multicolumn{2}{|c|}{ IV - Pobre (36) } \\
\hline
\end{tabular}

Figura 22 - Estereograma SM-4545
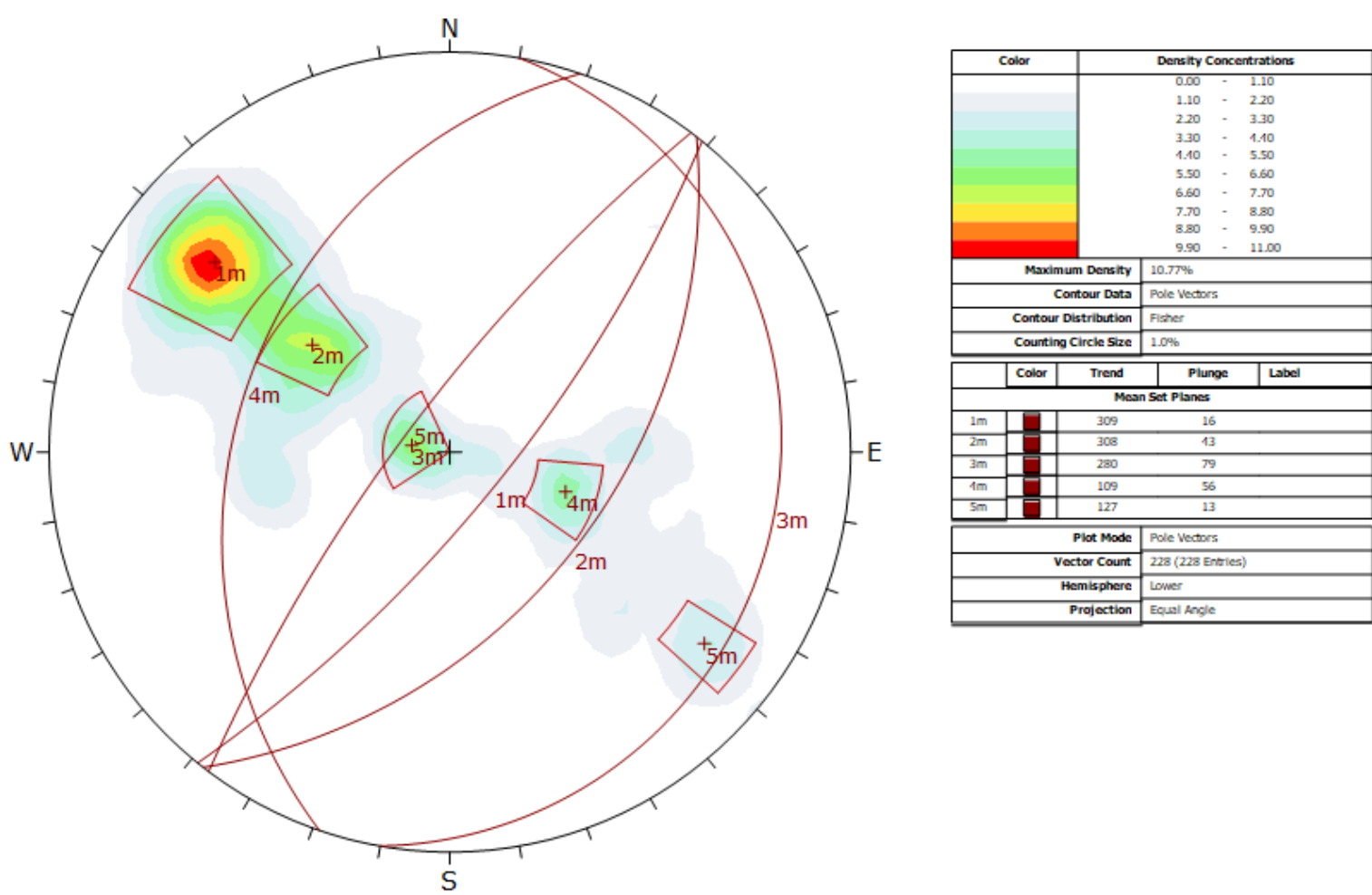


\section{$\underline{\mathrm{SM}-4548}$}

A perfilagem ótica iniciou-se com 10,10 metros e terminou com 45,68 metros, perfazendo 35,58 metros de aquisição de imagem, a rocha foi classificada como um gnaisse de granulação média a grossa.

O quadro 19 apresenta a classificação geomecânica do material, que segundo Bieniawsk (1993) possui tempo de auto sustentação de 8 meses. O estereograma apresenta as descontinuidades presentes na classificação do televisamento (Figura 23), bem como as famílias de fraturas presentes $1 \mathrm{~m}$ (117/61) e $2 \mathrm{~m}$ (294/51).

\section{Quadro 19 - Classificação da SM-4548 com base em Bieniawski (1989) modificada}

\begin{tabular}{|l|c|c|}
\hline Sondagem & \multicolumn{2}{|c|}{ SM-4548 } \\
\hline Parâmetro & Classificação & Peso \\
\hline Resistência (Mpa) & 30 & 5 \\
\hline RQD (\%) & 90 & 17 \\
\hline Espaçamento das descontinuidades & F2 a F3 & 11 \\
\hline Condição das descontinuidades & S2 a S1 & 29 \\
\hline Ação da água subterrânea & F2 a F3 & 5 \\
\hline Classificação & \multicolumn{2}{|c|}{ II - Bom (67) } \\
\hline
\end{tabular}

Figura 23 - Estereograma SM-4548
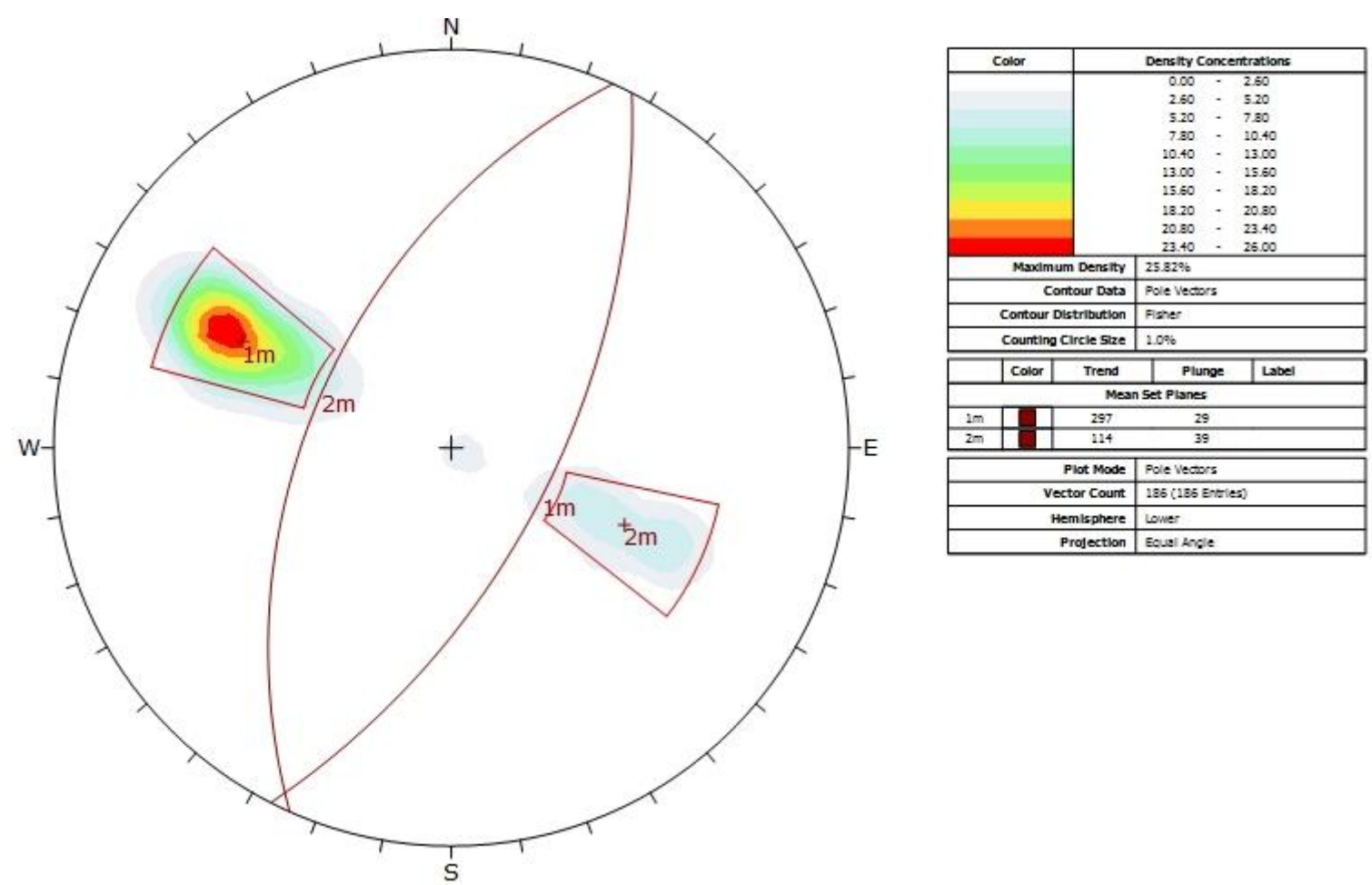


\section{$\underline{\mathrm{SM}-4559}$}

A perfilagem ótica iniciou-se com 10,80 metros e terminou com 49,60 metros, perfazendo 38,80 metros de aquisição de imagem, a rocha foi classificada como um gnaisse de granulação fina a média.

O quadro 20 apresenta a classificação geomecânica do material, que segundo Bieniawsk (1993) possui tempo de auto sustentação de mais de 10 anos. O estereograma apresenta as descontinuidades presentes na classificação do televisamento (Figura 24), bem como as famílias de fraturas presentes $1 \mathrm{~m}$ (127/72) e $2 \mathrm{~m}(324 / 07)$.

Quadro 20 - Classificação da SM-4559 com base em Bieniawski (1989) modificada

\begin{tabular}{|c|c|c|}
\hline Sondagem & \multicolumn{2}{|c|}{ SM-4559 } \\
\hline Parâmetro & Classificação & Peso \\
\hline Resistência (Mpa) & 40 & 6 \\
\hline RQD (\%) & 96 & 17 \\
\hline Espaçamento das descontinuidades & $\mathrm{F} 1$ & 20 \\
\hline Condição das descontinuidades & S1 & 30 \\
\hline Ação da água subterrânea & $\mathrm{F} 1$ & 15 \\
\hline Classificação & \multicolumn{2}{|c|}{ I - Muito Bom (88) } \\
\hline
\end{tabular}

Figura 24 - Estereograma SM-4559
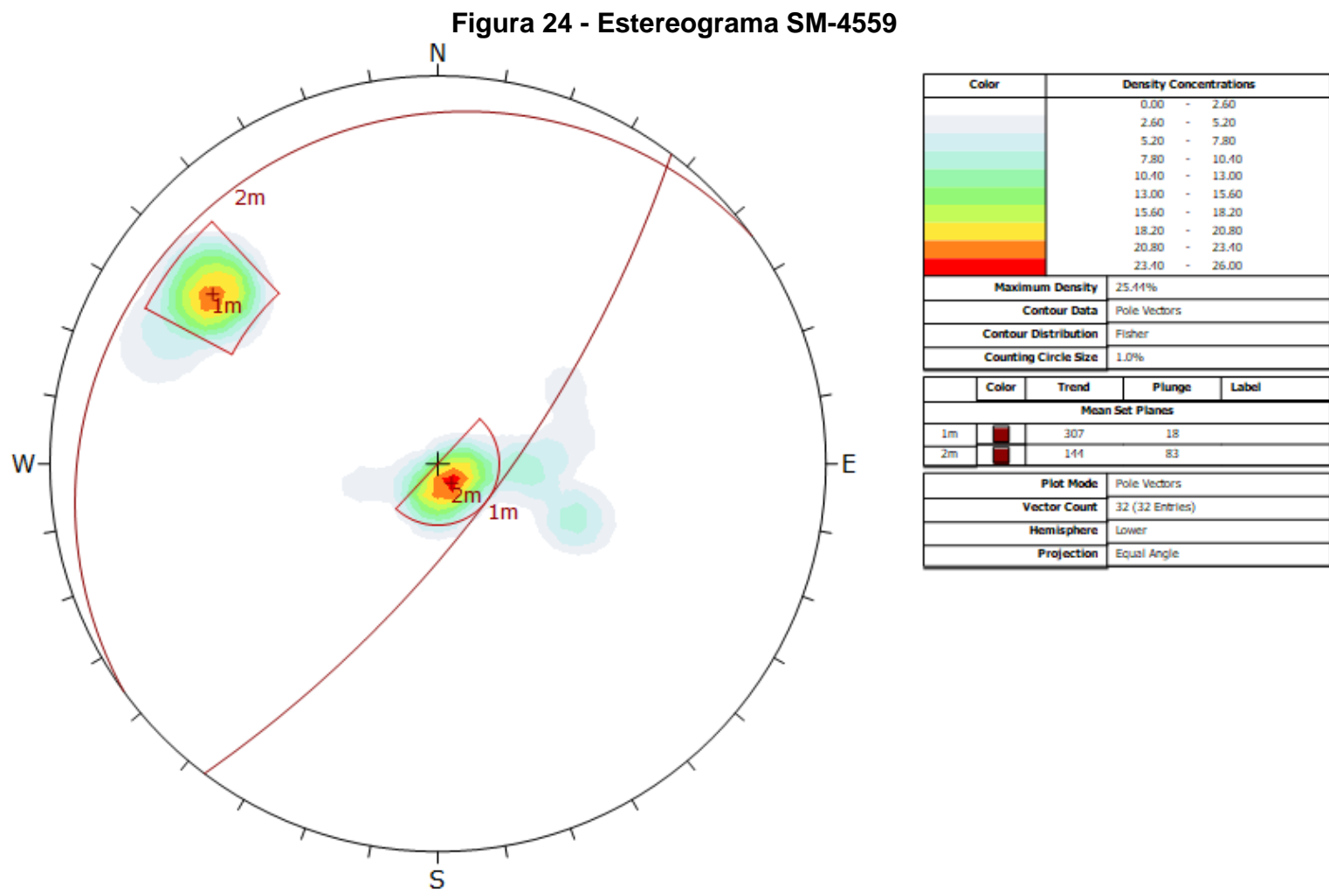


\section{$\underline{\text { SM-4564 }}$}

A perfilagem ótica iniciou-se com 16,60 metros e terminou com 51,10 metros, perfazendo 34,50 metros de aquisição de imagem, a rocha foi classificada como um Migmatito de granulação grossa.

O quadro 21 apresenta a classificação geomecânica do material, que segundo Bieniawsk (1993) possui tempo de auto sustentação de mais de oito anos. O estereograma apresenta as descontinuidades presentes na classificação do televisamento (Figura 25), bem como as famílias de fraturas presentes $1 \mathrm{~m}(125 / 69)$ e $2 m(115 / 24)$.

Quadro 21 - Classificação da SM-4564 com base em Bieniawski (1989) modificada

\begin{tabular}{|l|c|c|}
\hline Sondagem & \multicolumn{2}{|c|}{ SM-4564 } \\
\hline Parâmetro & Classificação & Peso \\
\hline Resistência (Mpa) & 30 & 4 \\
\hline RQD (\%) & 83 & 15 \\
\hline Espaçamento das descontinuidades & F1 a F2 & 18 \\
\hline Condição das descontinuidades & S1 & 30 \\
\hline Ação da água subterrânea & F1 a F2 & 12 \\
\hline Classificação & \multicolumn{2}{|c|}{ II - Bom (79) } \\
\hline
\end{tabular}

Figura 25 - Estereograma SM-4564
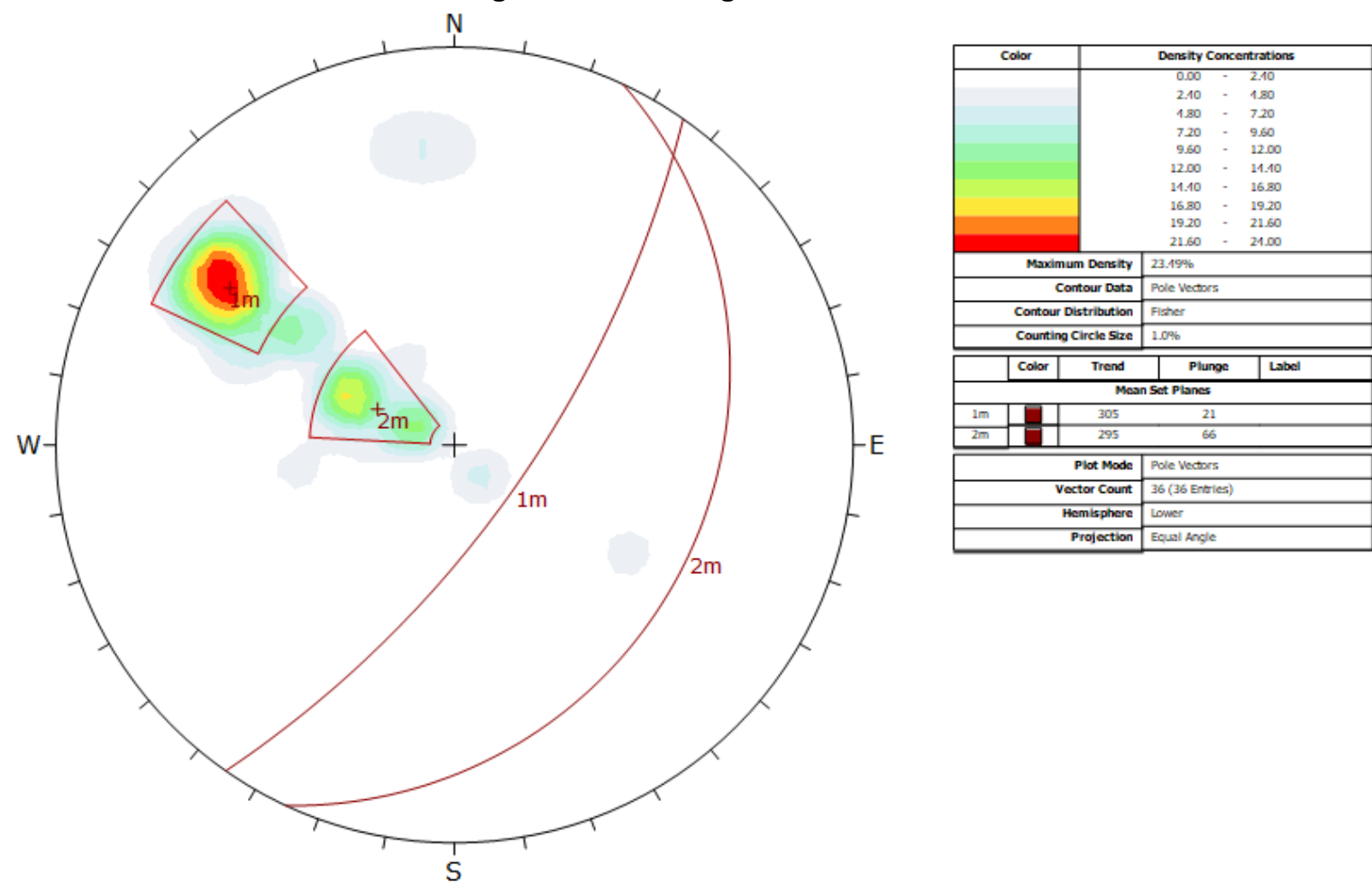


\section{$\underline{\text { SM-4572 }}$}

A perfilagem ótica iniciou-se com 18,50 metros e terminou com 44,12 metros, perfazendo 25,62 metros de aquisição de imagem, a rocha foi classificada como um gnaisse de granulação média.

O quadro 22 apresenta a classificação geomecânica do material, que segundo Bieniawsk (1993) possui tempo de auto sustentação de 1 ano. O estereograma apresenta as descontinuidades presentes na classificação do televisamento (Figura 26), bem como a família de fraturas presentes $1 \mathrm{~m}$ (133/77).

\section{Quadro 22 - Classificação da SM-4572 com base em Bieniawski (1989) modificada}

\begin{tabular}{|l|c|c|}
\hline Sondagem & \multicolumn{2}{|c|}{ SM-4572 } \\
\hline Parâmetro & Classificação & Peso \\
\hline Resistência (Mpa) & 30 & 4 \\
\hline RQD (\%) & 87 & 16 \\
\hline Espaçamento das descontinuidades & F2 & 15 \\
\hline Condição das descontinuidades & S1 & 30 \\
\hline Ação da água subterrânea & F2 & 7 \\
\hline Classificação & \multicolumn{2}{|c|}{ II - Bom (72) } \\
\hline
\end{tabular}

Figura 26 - Estereograma SM-4572
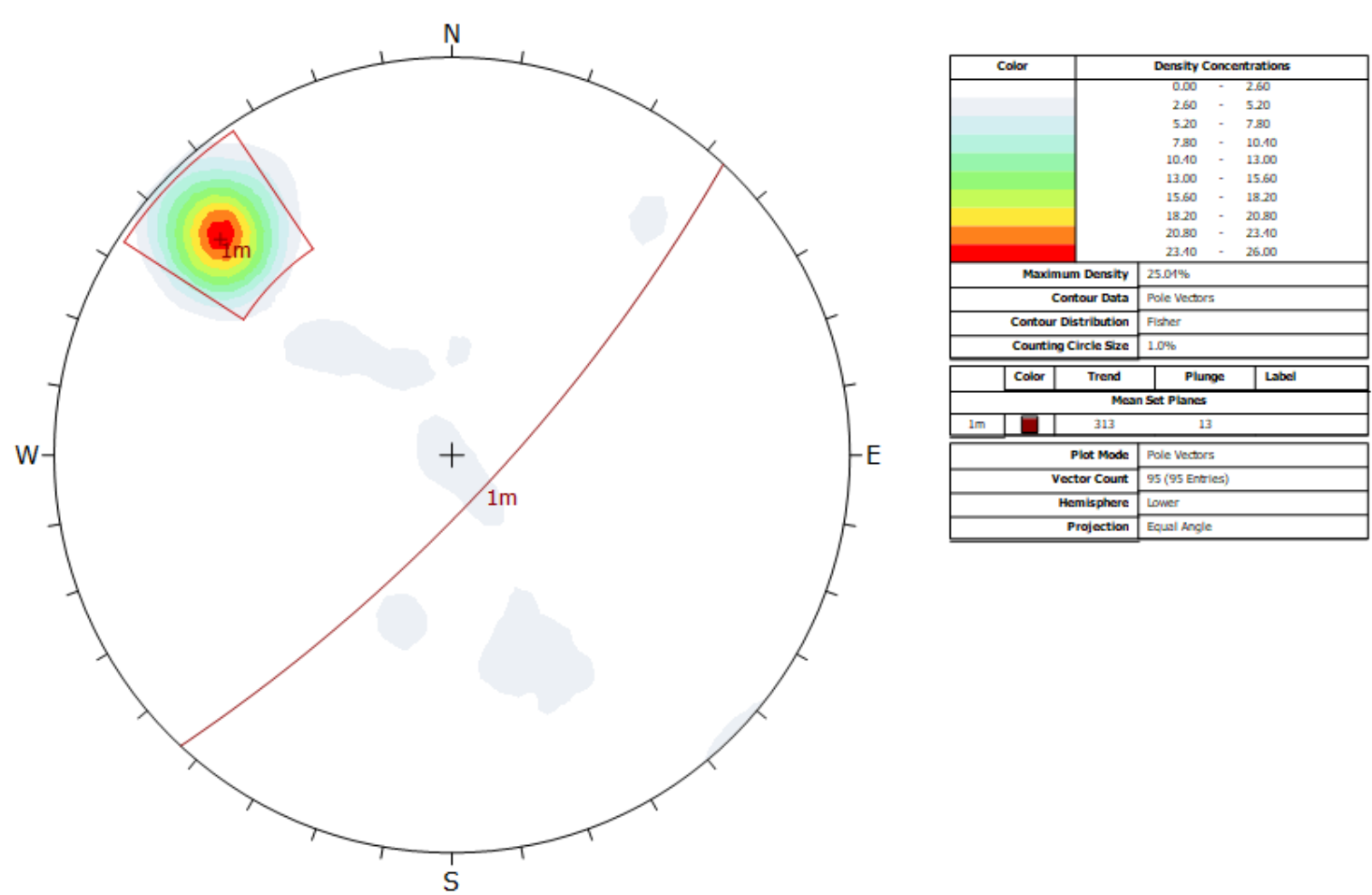


\section{$\underline{\mathrm{SM}-4581}$}

A perfilagem ótica iniciou-se com 26,60 metros e terminou com 45,05 metros, perfazendo 18,45 metros de aquisição de imagem, a rocha foi classificada como um gnaisse de média.

O quadro 23 apresenta a classificação geomecânica do material, que segundo Bieniawsk (1993) possui tempo de auto sustentação de 20 dias. O estereograma apresenta as descontinuidades presentes na classificação do televisamento (Figura $27)$, bem como as famílias de fraturas presentes $1 \mathrm{~m}(133 / 50)$ e $2 \mathrm{~m}(319 / 25)$.

\section{Quadro 23 - Classificação da SM-4581 com base em Bieniawski (1989) modificada}

\begin{tabular}{|l|c|c|}
\hline Sondagem & \multicolumn{2}{|c|}{ SM-4581 } \\
\hline Parâmetro & Classificação & Peso \\
\hline Resistência (Mpa) & 30 & 4 \\
\hline RQD (\%) & 20 & 9 \\
\hline Espaçamento das descontinuidades & F2 a F4 & 9 \\
\hline Condição das descontinuidades & S1 & 30 \\
\hline Ação da água subterrânea & F2 a F4 & 4 \\
\hline Classificação & \multicolumn{2}{|c|}{ III - Regular (56) } \\
\hline
\end{tabular}

Figura 27 - Estereograma SM-4581
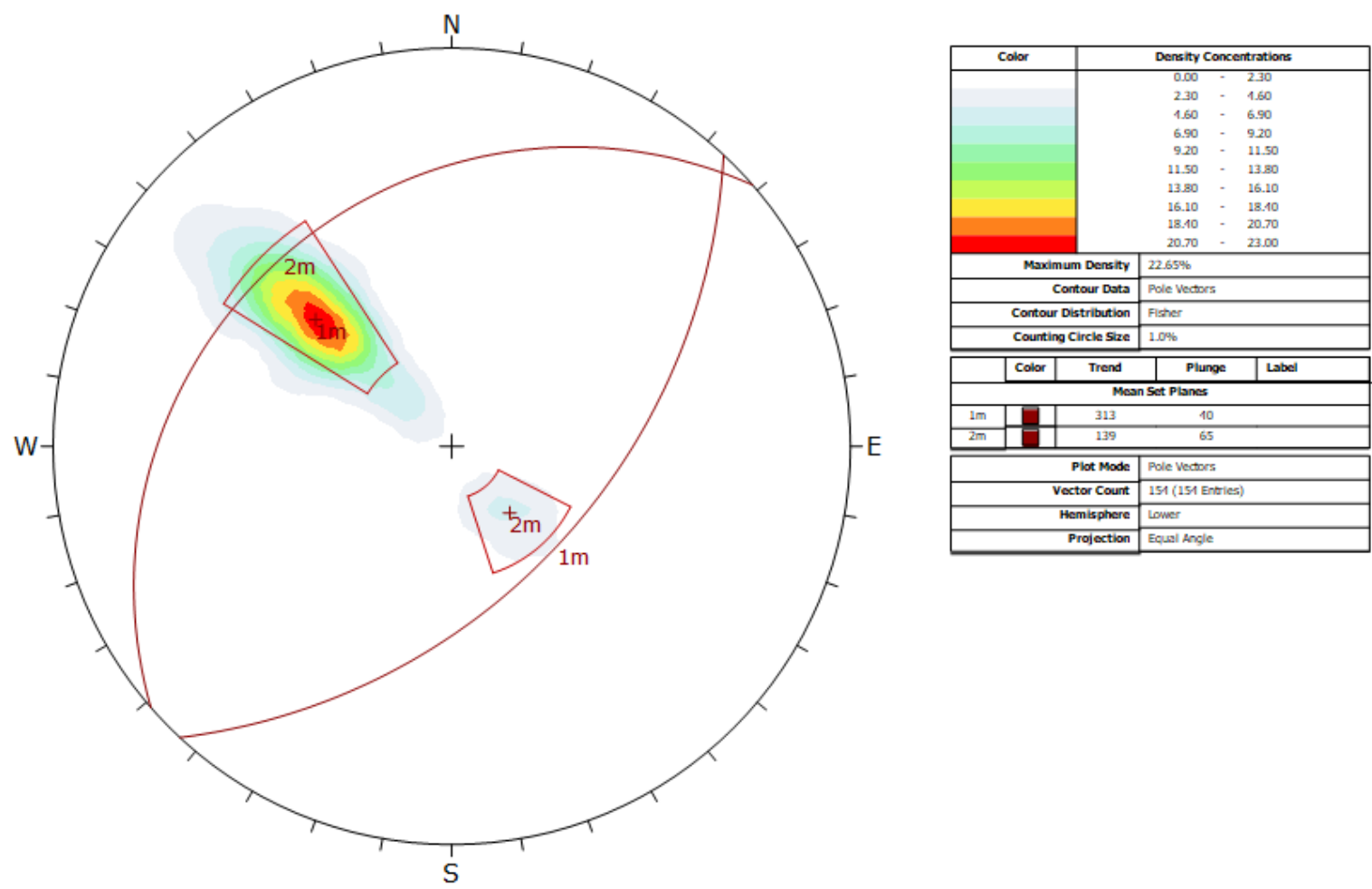


\section{$\underline{\text { SM-4596 }}$}

A perfilagem ótica iniciou-se com 28,20 metros e terminou com 49,74 metros, perfazendo 21,54 metros de aquisição de imagem, a rocha foi classificada como um gnaisse de granulação grossa.

O quadro 24 apresenta a classificação geomecânica do material, que segundo Bieniawsk (1993) não possui tempo de auto sustentação. O estereograma apresenta as descontinuidades presentes na classificação do televisamento (Figura 28), bem como as famílias de fraturas presentes $1 \mathrm{~m}(117 / 73)$ e $2 \mathrm{~m}(135 / 14)$.

\section{Quadro 24 - Classificação da SM-4596 com base em Bieniawski (1989) modificada}

\begin{tabular}{|l|c|c|}
\hline Sondagem & \multicolumn{2}{|c|}{ SM-4596 } \\
\hline Parâmetro & Classificação & Peso \\
\hline Resistência (Mpa) & 5 & 3 \\
\hline RQD (\%) & 37 & 6 \\
\hline Espaçamento das descontinuidades & F4 & 5 \\
\hline Condição das descontinuidades & S1 a P3 & 15 \\
\hline Ação da água subterrânea & F4 & 0 \\
\hline Classificação & IV - Pobre (29) \\
\hline
\end{tabular}

Figura 28 - Estereograma SM-4597
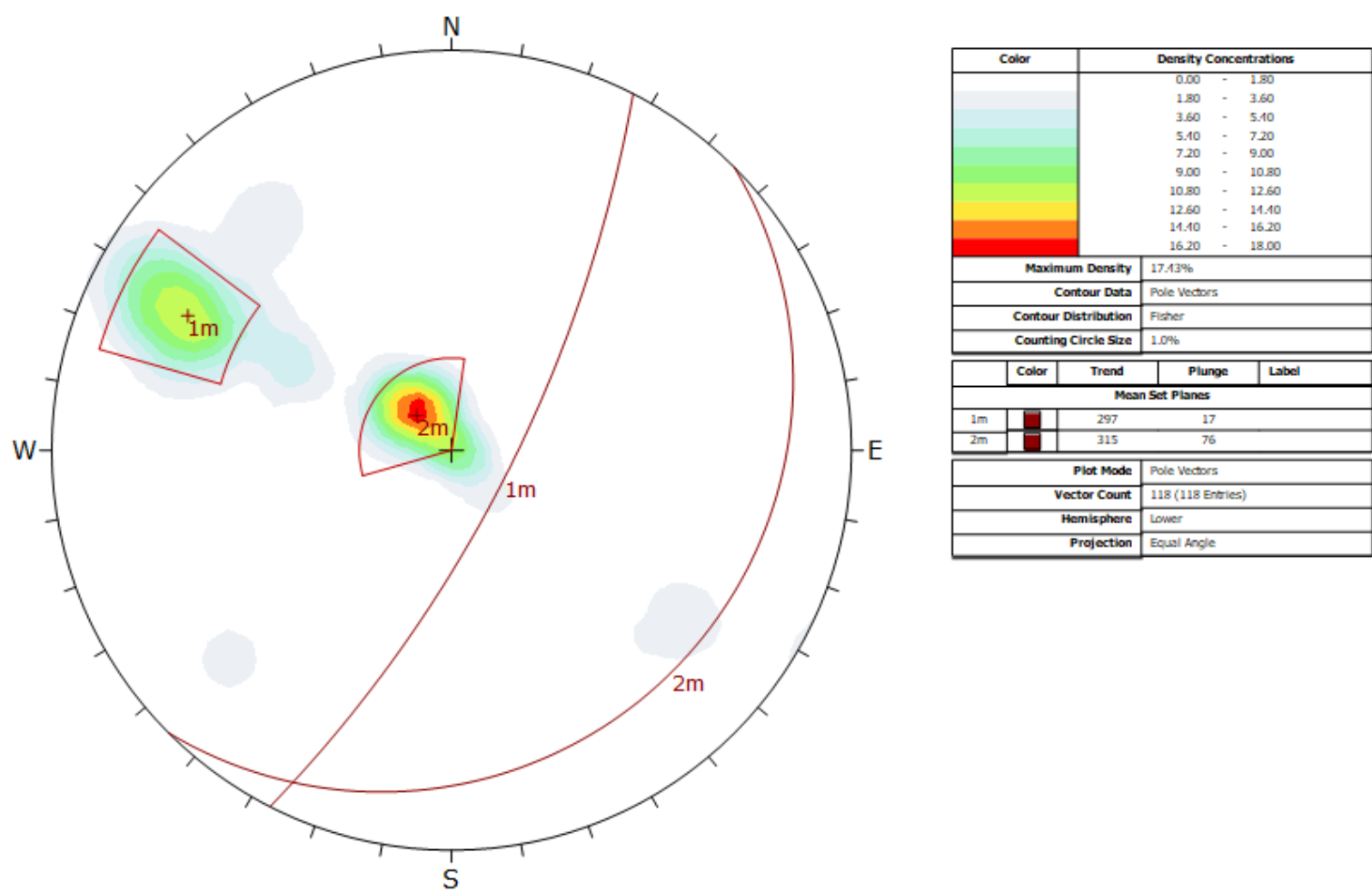


\section{$\underline{\mathrm{SM}-4597}$}

A perfilagem ótica iniciou-se com 18,60 metros e terminou com 45,60 metros, perfazendo 27,00 metros de aquisição de imagem, a rocha foi classificada como um gnaisse de granulação fina a grossa.

O quadro 25 apresenta a classificação geomecânica do material, que segundo Bieniawsk (1993) possui tempo de auto sustentação de 15 a 30 dias. O estereograma apresenta as descontinuidades presentes na classificação do televisamento (Figura 29), bem como as famílias de fraturas presentes $1 \mathrm{~m}$ (150/70), 2m (159/37), 3m 130/78 e $4 \mathrm{~m}(46 / 70)$.

Figura 29 - Estereograma SM-4597
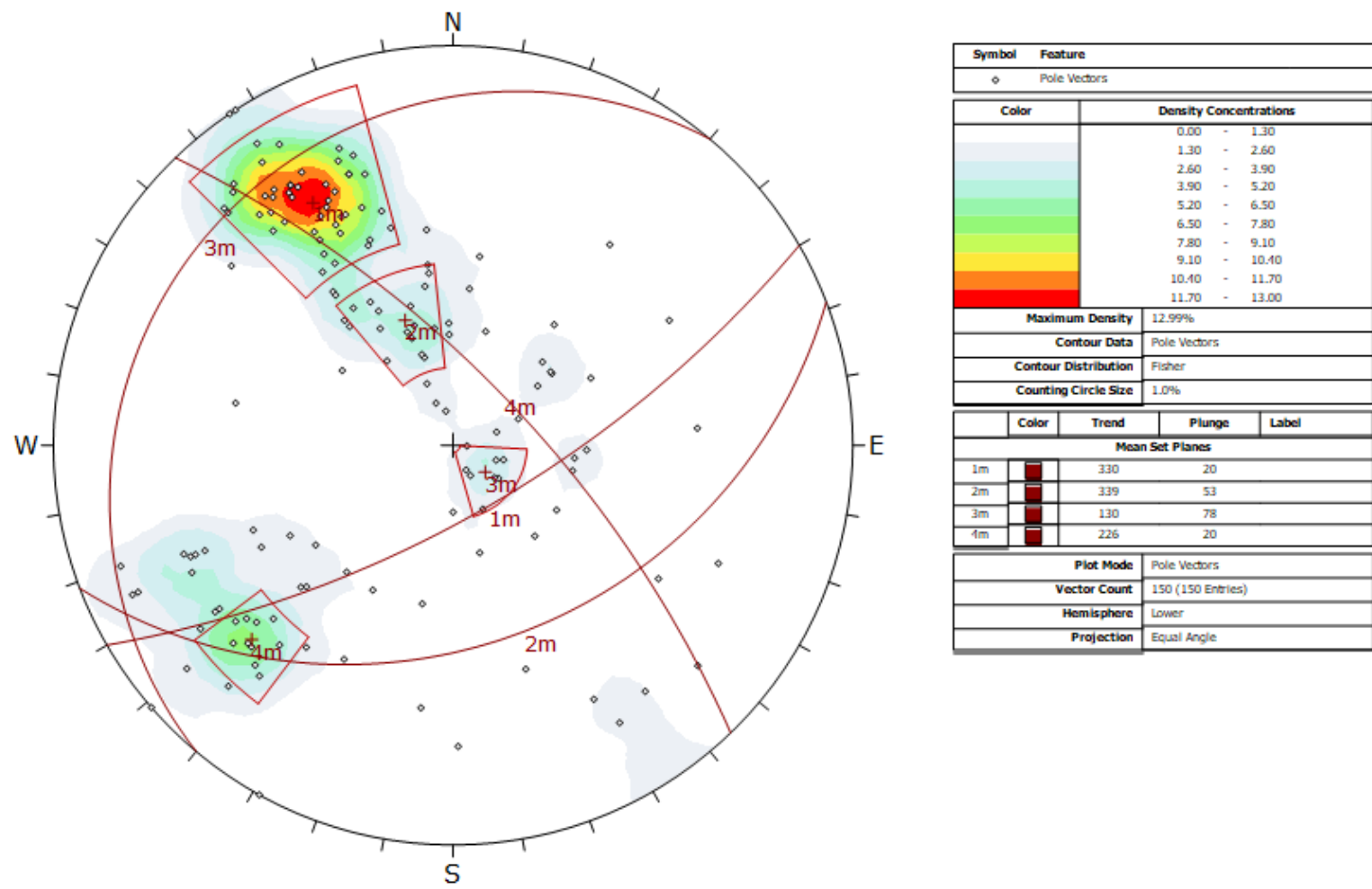


\subsection{Modelo Geológico}

A geologia da área de estudo foi dividida de acordo com a descrição da unidade estratigráfica, sendo dividida em aterro $(A T)$, aluvião $(A L)$, solo de alteração de rocha (SAR) e rocha, como exemplificado no Quadro 25, e demonstrado no Apêndice III.

\section{Quadro 25 - exemplo de classificação para exportar em arquivo BIM}

\begin{tabular}{|c|c|c|c|c|}
\hline $\begin{array}{c}\text { Numero da } \\
\text { sondagem } \\
(\mathbf{m})\end{array}$ & $\begin{array}{c}\text { Nivel de } \\
\text { Água } \\
(\mathrm{m})\end{array}$ & Topo & Base & Geologia \\
\hline 4503 & 4,95 & 0 & 5 & AT \\
\hline & & 5 & 21,4 & SAR \\
\hline & & 21,4 & 45 & ROCHA \\
\hline
\end{tabular}

O modelo geológico foi dividido em 3 perfis, a Figura 34 apresenta a divisão utilizada, enquanto a Figuras 35 mostra os perfis, que também estão apresentados no Apêndice IV. É possível perceber que o substrato rochoso, seja pela rocha, seja por sua alteração, é predominante em todo o trecho estudado, mostrando a importância da compreensão das características do maciço.

Quando analisado o traçado, é possível perceber um adelgaçamento da camada de alteração no meio do perfil, inclusive com rocha aflorante. Existem pequenos depósitos aluvionares e uma camada de aterro persistente em quase todo o traçado, est devido a intensa ocupação urbana da região.

Figura 30 - Traçado das sondagens com a divisão dos perfis realizados

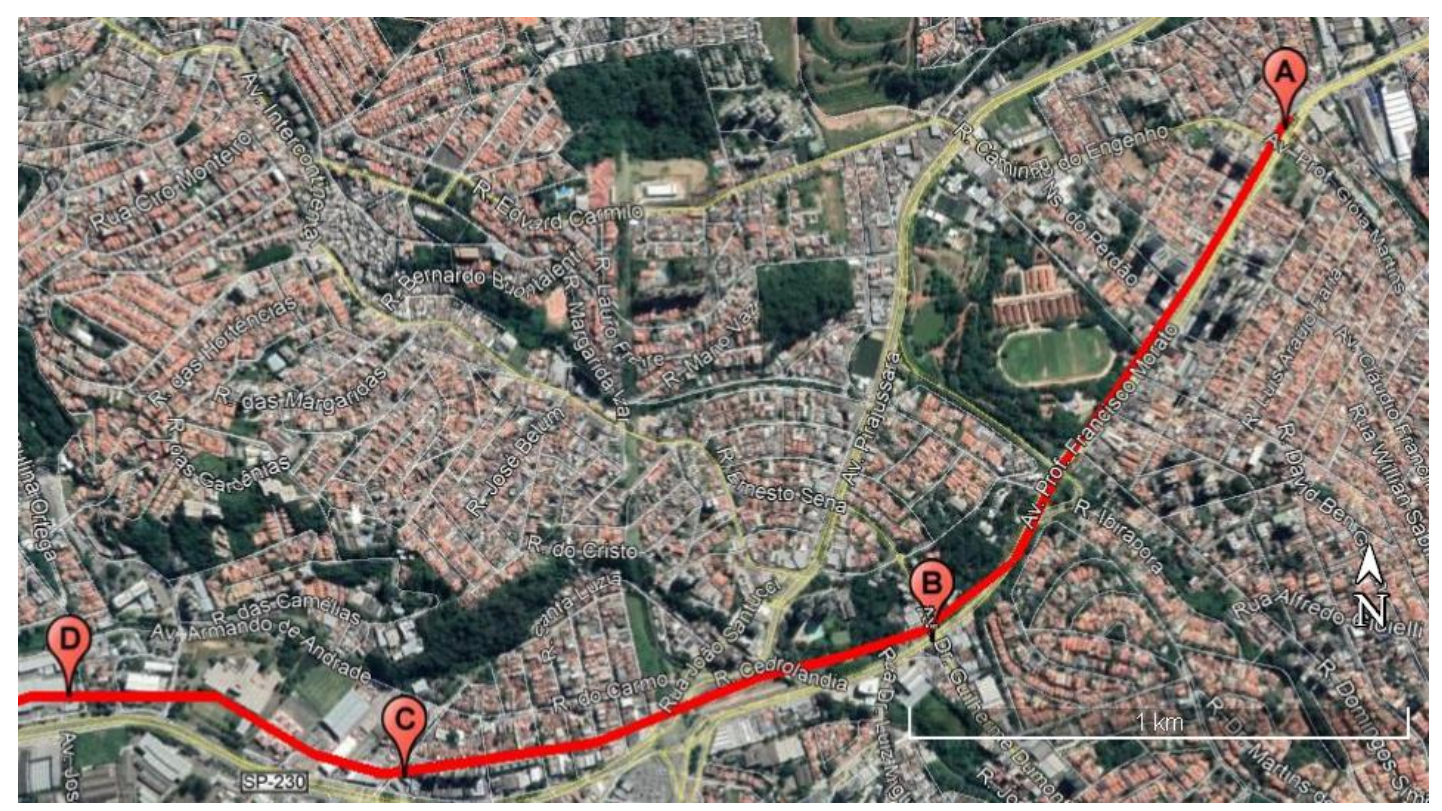


Figura 31 - Perfis Geológicos do traçado
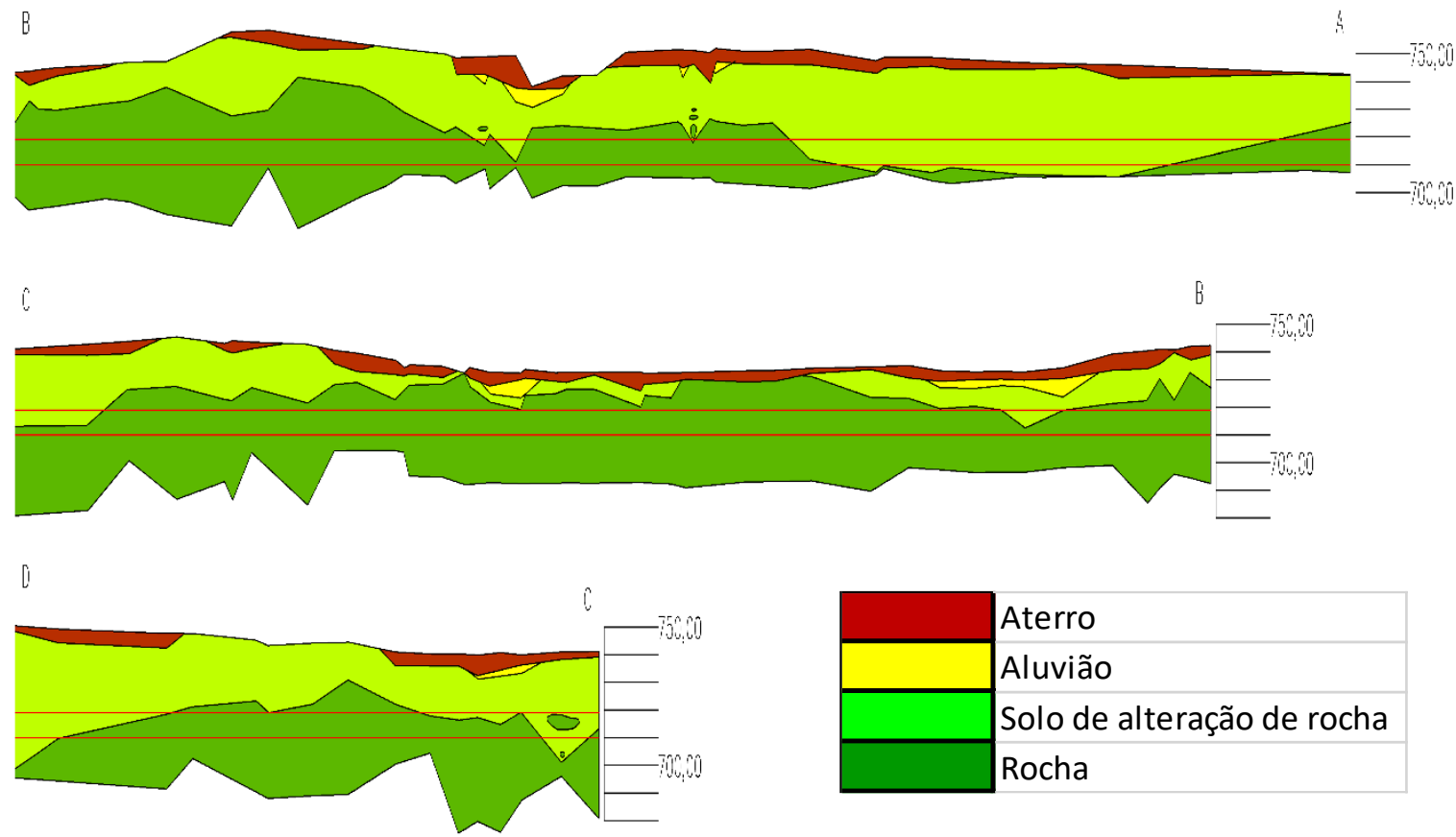

\begin{tabular}{|l|l|}
\hline & Aterro \\
\hline & Aluvião \\
\hline Solo de alteração de rocha \\
Rocha
\end{tabular}

\subsection{Modelo Geotécnico do maciço rochoso}

O modelo geotécnico foi dividido de acordo com a proposta de BIENIAWSKI (1990), como exemplificado no quadro 26. O Apêndice III exibe as características de todas as sondagens utilizadas. 
Quadro 26 - exemplo de classificação para exportar em arquivo BIM

\begin{tabular}{|c|c|c|c|c|c|c|}
\hline $\begin{array}{c}\text { Numero da } \\
\text { sondagem } \\
\text { (m) }\end{array}$ & $\begin{array}{c}\text { Topo } \\
\text { (m, 2DP) }\end{array}$ & $\begin{array}{c}\text { Base } \\
\text { (m, 2DP) }\end{array}$ & $\begin{array}{c}\text { Classe de } \\
\text { maciço }\end{array}$ & $\begin{array}{c}\text { Grau } \\
\text { Fratur. } \\
\text { (lista) }\end{array}$ & $\begin{array}{c}\text { RQD } \\
\text { (\%) }\end{array}$ & $\begin{array}{c}\text { Recuperação } \\
\text { (\%) }\end{array}$ \\
\hline 4503 & 21.40 & 24.40 & III - Regular & 4 & 52 & 79 \\
\hline & 24.40 & 27.40 & III - Regular & 4 & 47 & 100 \\
\hline & 27.40 & 30.40 & III - Regular & 4 & 44 & 100 \\
\hline & 30.40 & 33.40 & II - Bom & 4 & 87 & 100 \\
\hline & 33.40 & 36.40 & III - Regular & 4 & 75 & 100 \\
\hline & 36.40 & 39.40 & III - Regular & 4 & 78 & 100 \\
\hline & 39.40 & 42.40 & III - Regular & 4 & 78 & 100 \\
\hline & 42.40 & 45.00 & II - Bom & 3 & 69 & 95 \\
\hline
\end{tabular}

Os perfis geotécnicos (Figura 36 e Apêndice IV) estão divididos da mesma forma que os perfis geológicos (Figura 34). Pode-se perceber que embora existam trechos de homogeneidade vertical e horizontal, não existe um padrão no comportamento geomecânico do maciço. Existe predominância de classificação de maciço 2 e 3, Bom a Regular.

Figura 32 - Perfis Geotécnicos
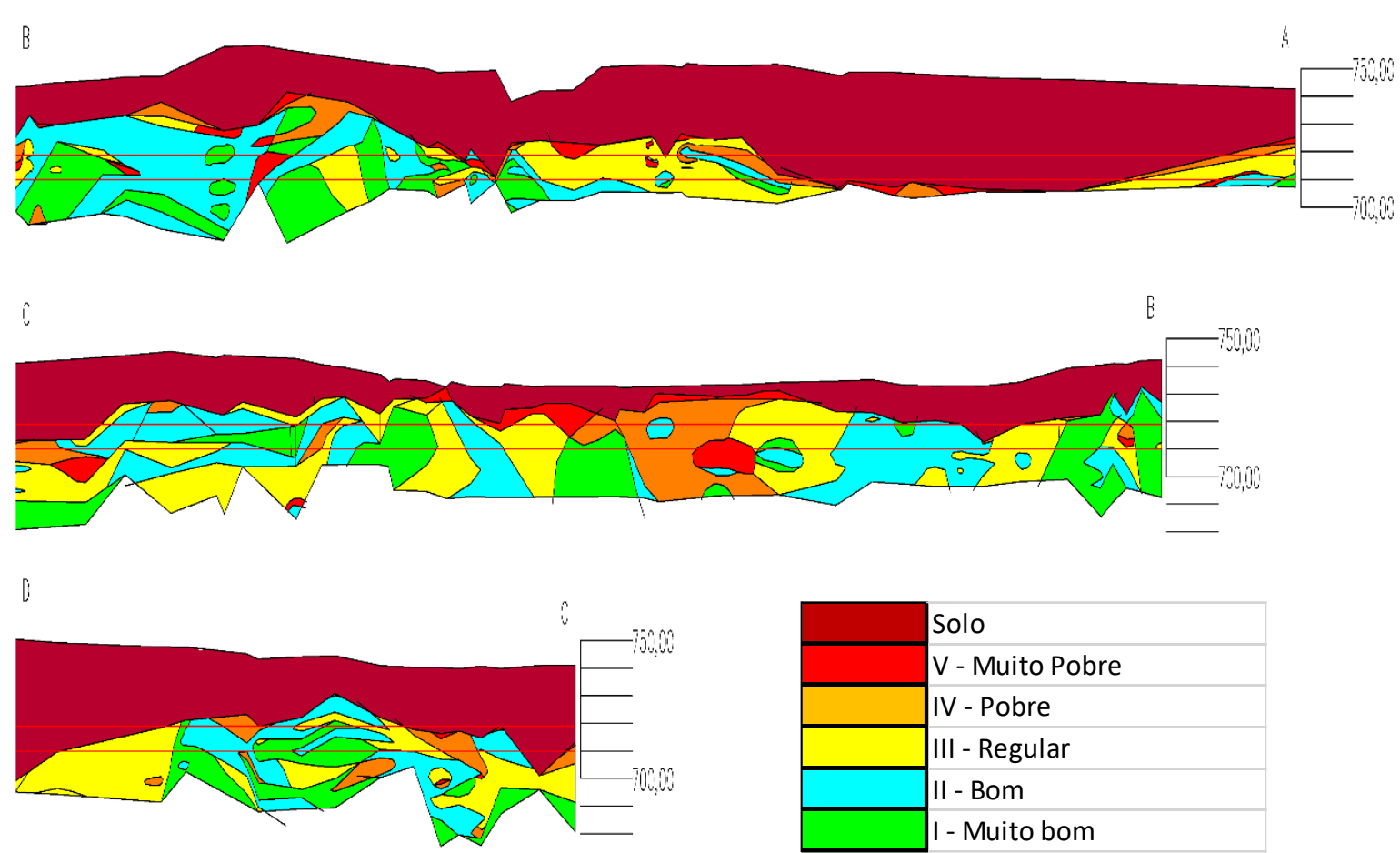

\begin{tabular}{|l|l|}
\hline Solo \\
V - Muito Pobre \\
IV - Pobre \\
III - Regular \\
II - Bom \\
I - Muito bom
\end{tabular}




\subsection{Modelo de blocos do túnel}

Para a criação de um modelo de blocos em túneis são utilizados as famílias de fraturas encontradas numa determinada região e a direção do túnel que as atravessam.

Como a direção da escavação também influencia a formação de blocos, o trecho estudado foi segmentado da mesma forma utilizada no modelo geológicogeotécnico, gerando direções de 40,70 e $110^{\circ}$. Os televisamentos de cada trecho foram isolados de forma a utilizar apenas as famílias encontradas em determinado segmento.

As figuras abaixo apresentam os blocos encontrados, bem como seus respectivos fatores de segurança para as diferentes direções do túnel, segmento $A B$ que se encontrava a $40^{\circ}$ (figura 37 ), segmento $B C, 70^{\circ}$ (figura 38 ) e segmento $C D$, $110^{\circ}$ (figura 39).

Figura 33 - Segmento $A B(40 / 00)$

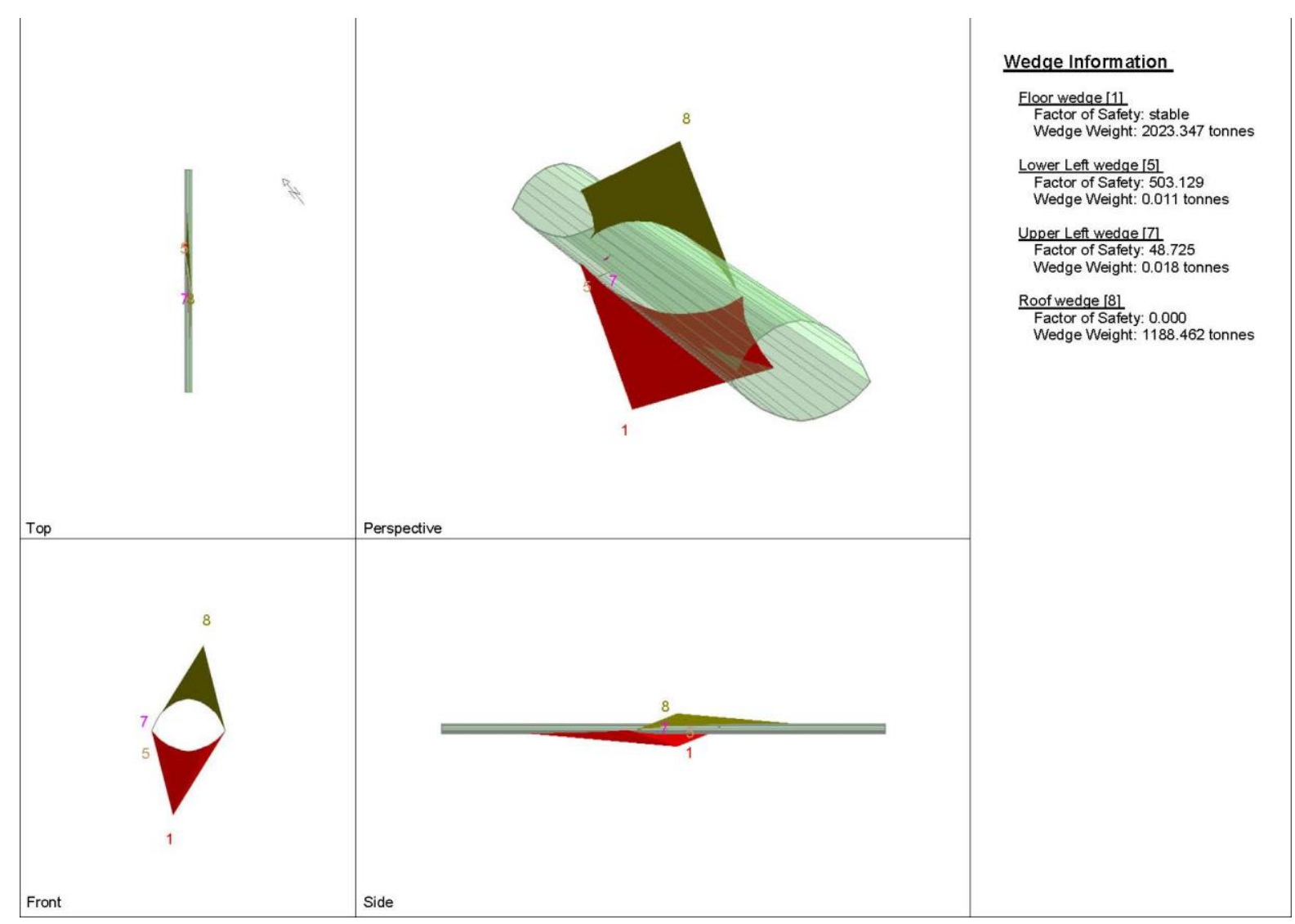


Figura 34 - Segmento BC (70/00)

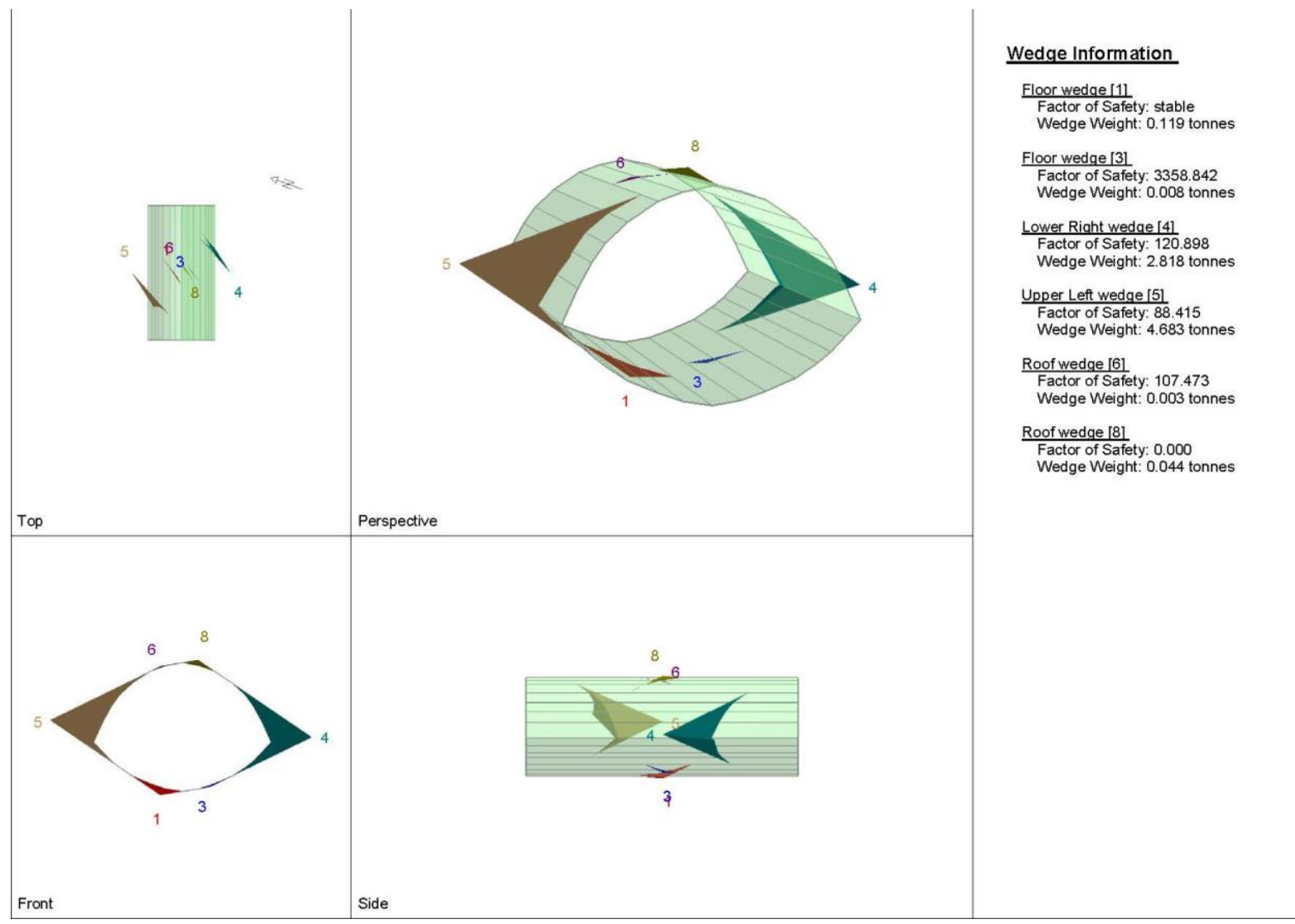

Figura 35 - Segmento CD (110/10)

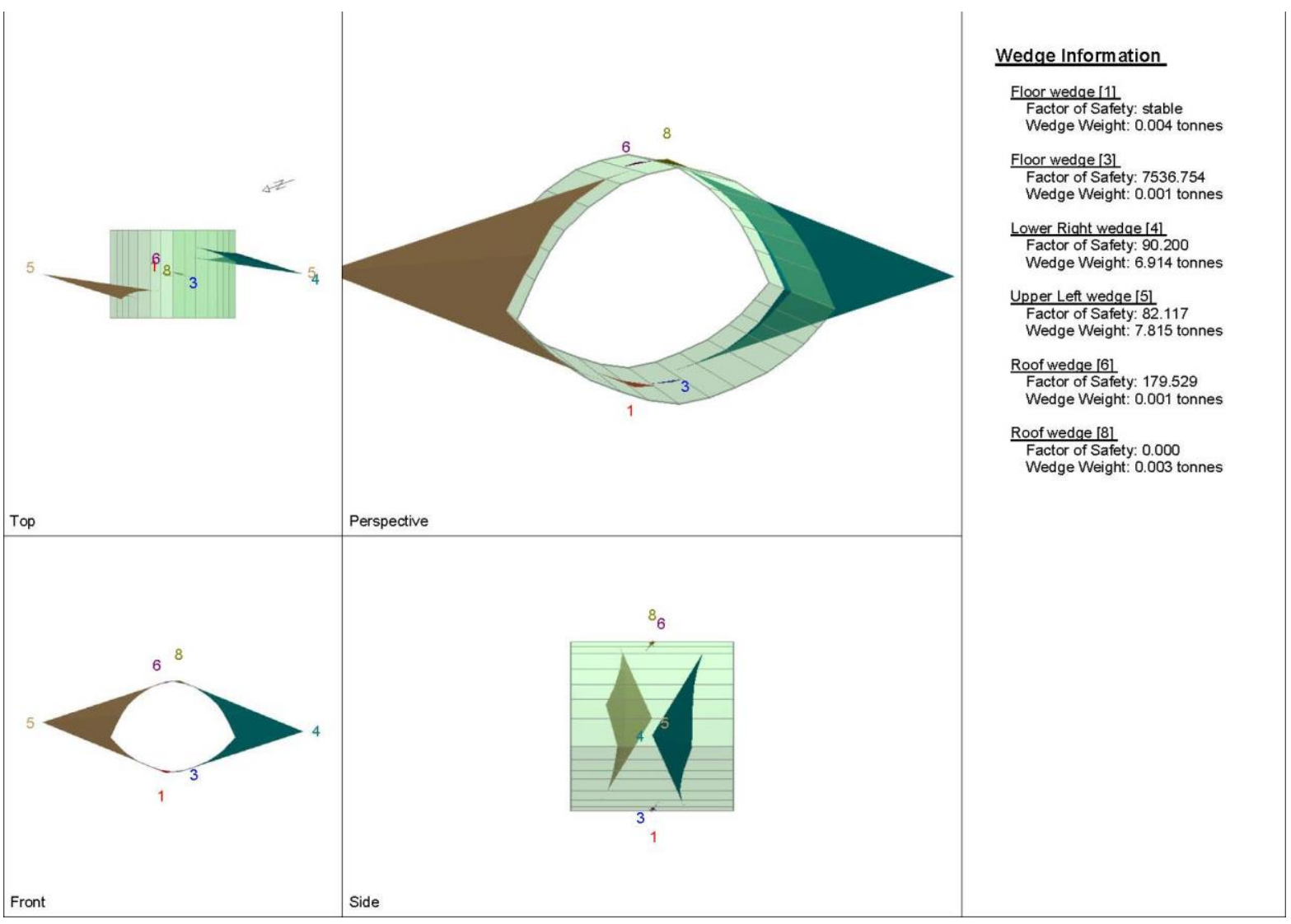




\section{DISCUSSÃO}

\subsection{Geologia da área}

O local estudado, situado dentro da Região Metropolitana de São Paulo, possui rochas classificadas como gnaisses, de granulação média a grossa, foliação subhorizontal a subvertical e textura migmatítica e migmatitos, de granulação média a grossa, podendo apresentar porções miloníticas localizadas, esta classificação condiz com as rochas do Complexo Embu como descreve JULIANI (1992).

Apesar de não ter sido realizada a classificação tátil-visual dos testemunhos de sondagem, foi possível visualizar as características da rocha na perfilagem ótica, tais como, gnaisse com fratura parcialmente soldada (Figura 40), gnaisse migmatizados (Figura 41) e enclaves presentes no gnaisse (Figura 42)

Figura 36 - Gnaisse de granulação fina a média, com fratura parcialmente soldada entre 27 e 28 metros de profundidade na SM-4528

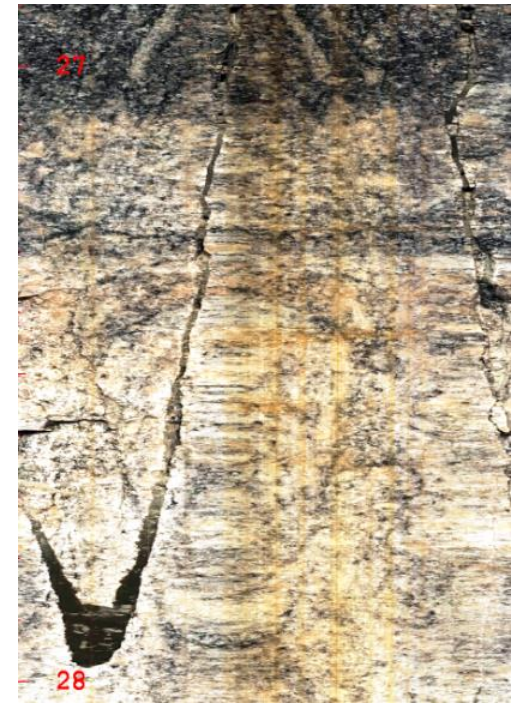


Figura 37 - Gnaisse migmatizado, presente entre 34 e 35 metros de profundidade na SM-4515

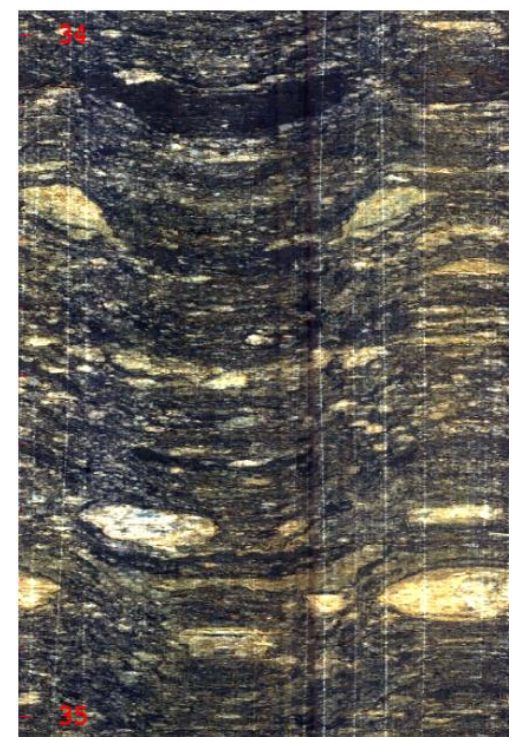

Figura 38 - Gnaisse, com enclave, presente entre 7 e 8 metros de profundidade na SM-4544

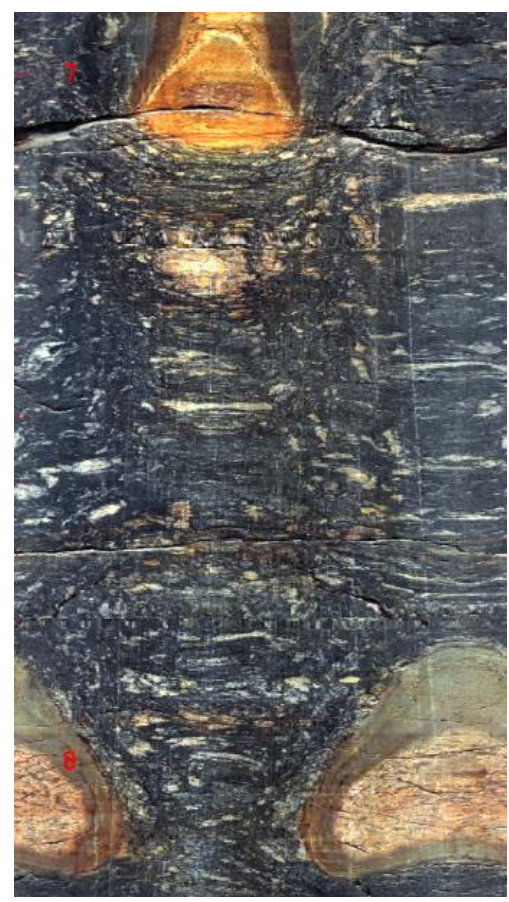

Os perfis geológicos mostram, além do maciço rochoso, as camadas de solo perfuradas para alcança-lo. Percebe-se uma camada de aterro quase constante, esta camada de aterro é resultante da extensa ocupação urbana no entorno da Rodovia Régis Bittencourt e Avenida Professor Francisco Morato. O solo de alteração de rocha presente no perfil exibe grandes profundidades tanto na parte Sul do traçado (49 metros), como na parte Norte (40 metros), porém na região central sofre um 
adelgaçamento que faz até com que se encontre rocha quase aflorante. Foram identificadas 3 presenças de material aluvionar nas sondagens.

\subsection{Análise das descontinuidades}

Ao analisar separadamente cada estereograma percebe-se um alinhamento das descontinuidades no eixo NE-SW, este fica mais evidente quando todas as descontinuidades são colocadas no mesmo estereograma (figura 30). É possível perceber na Figura 31 o alinhamento polar, que é condizente com a direção 220/88, também pode ser observado que os pontos podem ser agrupados em 6 conjuntos de famílias, 1m (310/27), 2m (311/56), 3m (301/82), 4m (127/83), 5m (130/60) e $6 \mathrm{~m}$ (130/28) que são complementares entre si ( $1 \mathrm{~m}$ e $6 \mathrm{~m}, 2 \mathrm{~m}$ e $5 \mathrm{~m}, 3 \mathrm{~m}$ e $4 \mathrm{~m})$. 
Figura 39 - Estereograma com a distribuição de descontinuidades

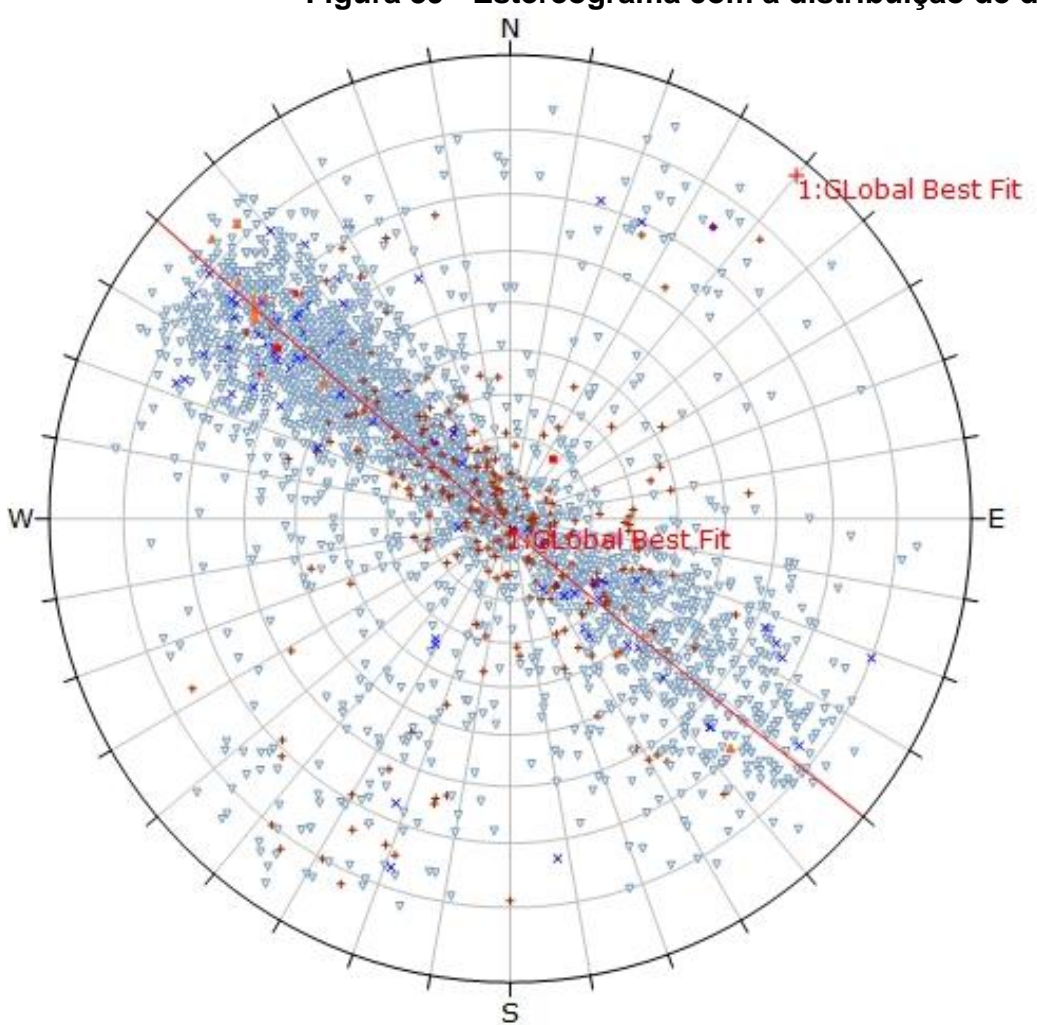

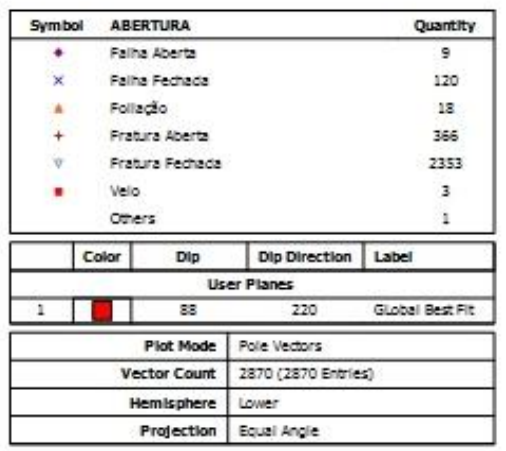

Figura 40 - Distribuição de descontinuidades e famílias

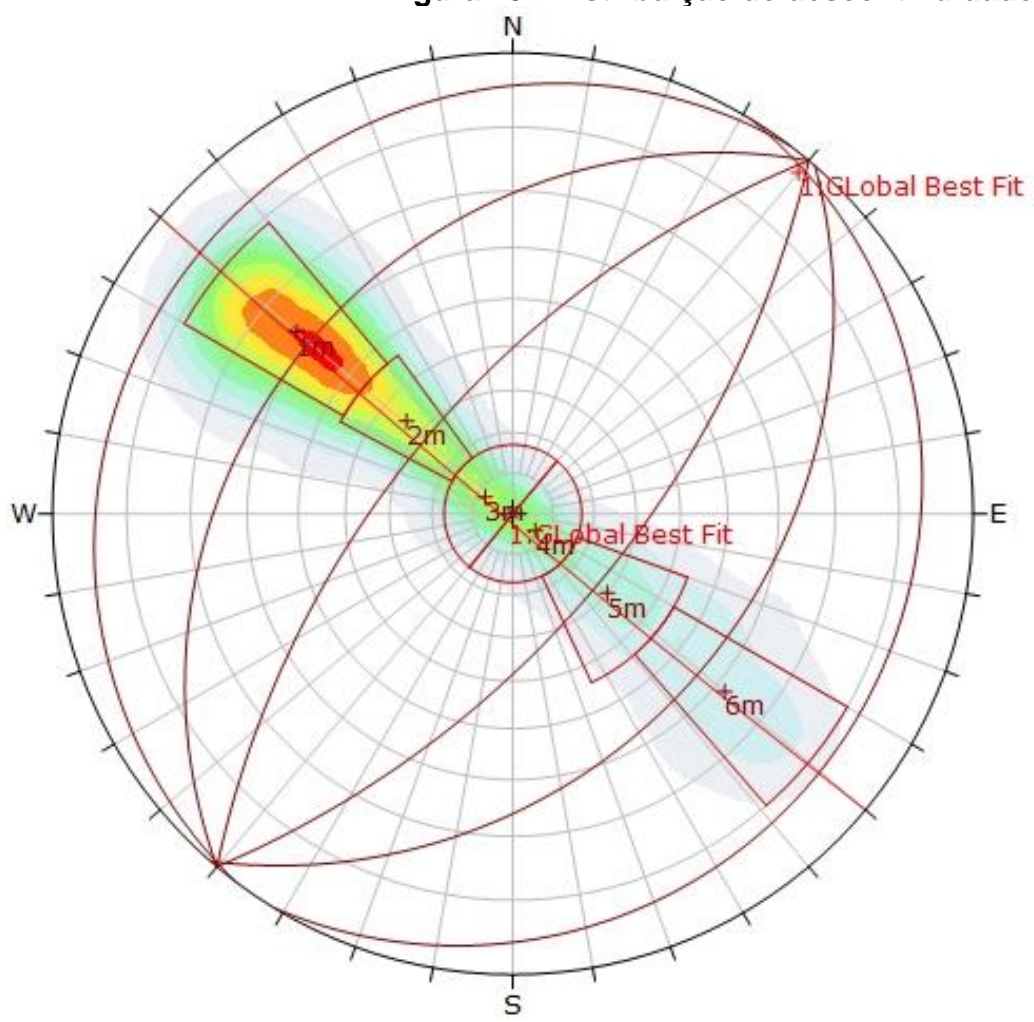

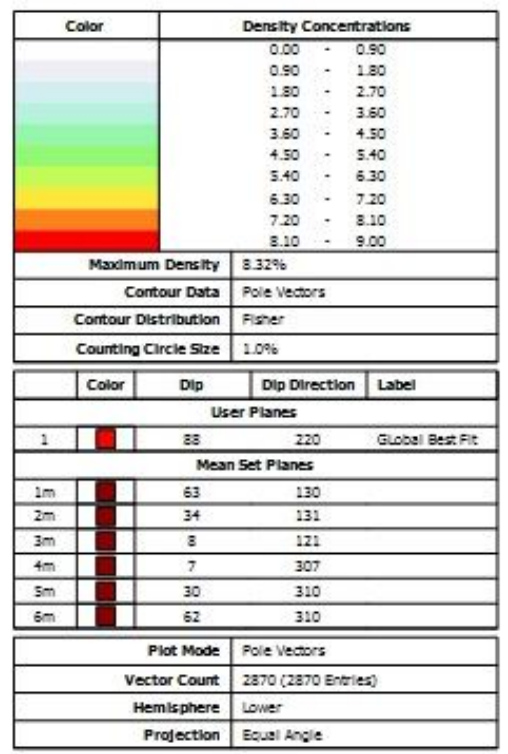


Quando se relaciona as descontinuidades com a profundidade percebe-se um comportamento inversamente proporcional e que com o aumento da profundidade as descontinuidades tendem a assumir as direções próximas daquelas propostas na literatura, NE/SW. Além disto o mergulho acaba por convergir às medidas centrais, onde as descontinuidades são sub-horizontais, inclinadas e subverticais (figura 32). Estas relações não são percebidas quando correlacionados a cota e as descontinuidades.

Figura 41 - profundidade por mergulho e direção

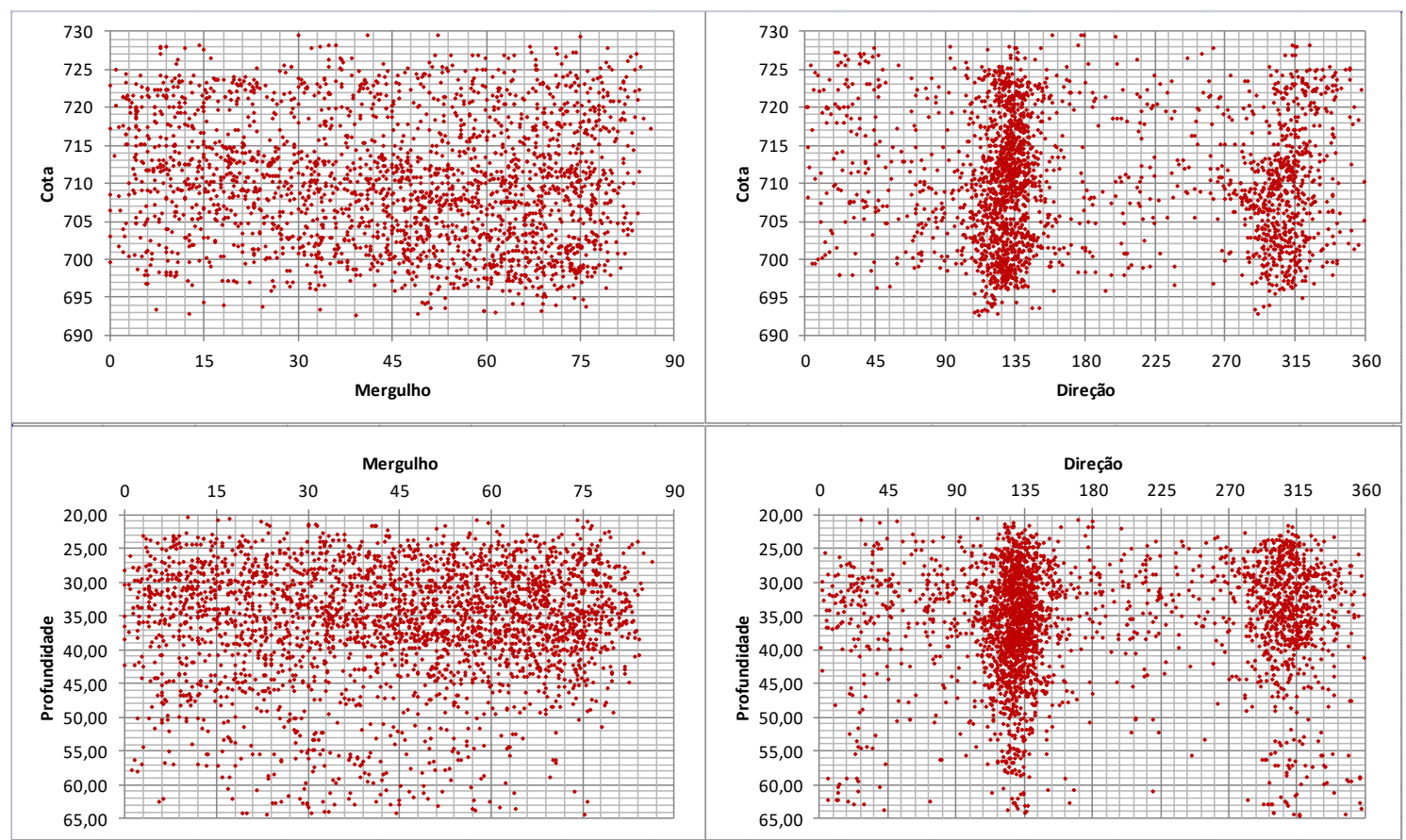

Ao estabelecer uma frequência de fraturas abertas e fechadas, com relação ao mergulho, percebe-se que as fraturas abertas apresentam mais de $60 \%$ de frequência de baixo ângulo (horizontais, sub-horizontais), e apenas 15\% de fraturas com alto ângulo, assumindo o formato de uma meia parábola. As fraturas fechadas, no entanto, assumem o formato de uma função do primeiro grau, não existindo uma tendência predominante, mas da mesma forma que as abertas, apresenta frequência muito baixa de fraturas subverticais (Figura 33 ). 
Figura 42 - frequência acumulada $X$ mergulho

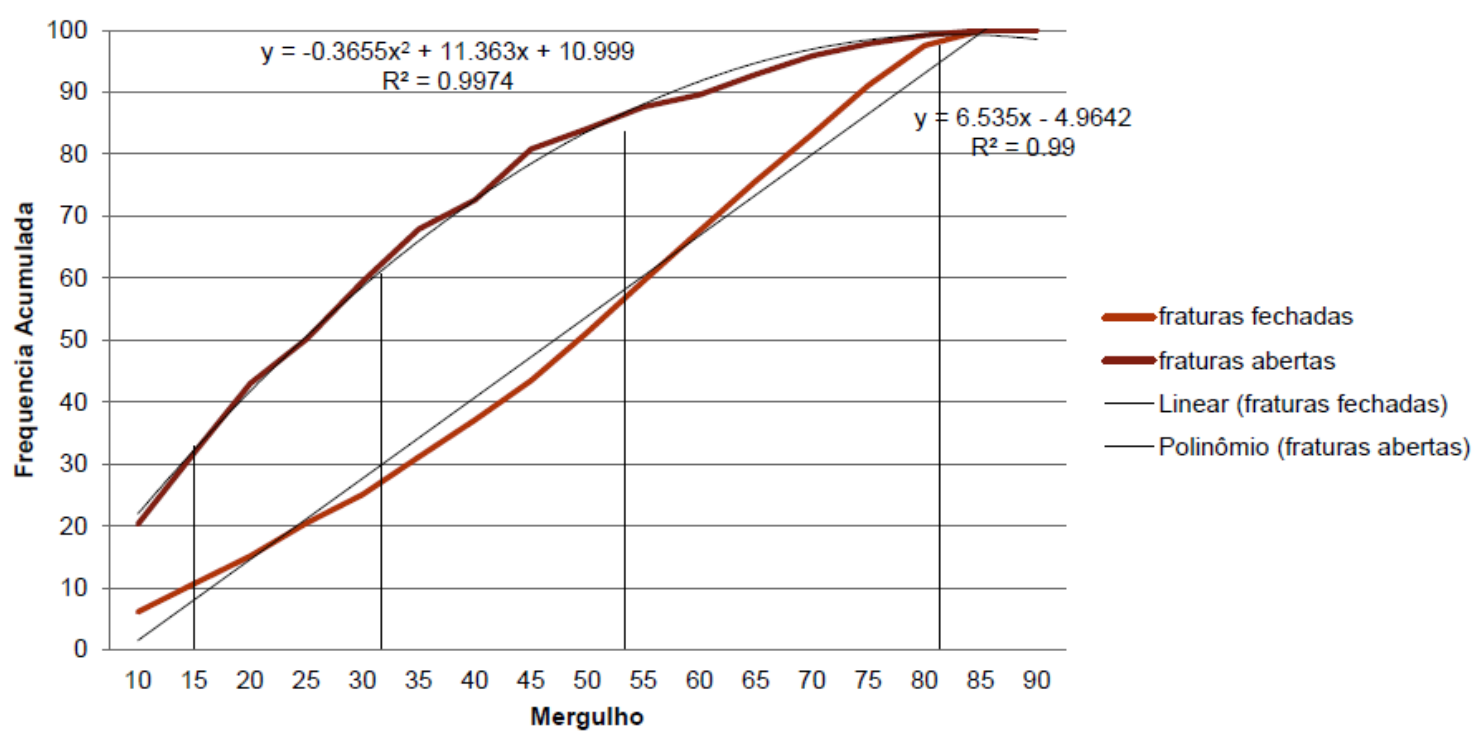

\subsection{Classificação RMR}

A classificação do maciço rochoso foi realizada usando uma adaptação de BIENIAWSKI (1990), proposta pela Companhia do Metropolitano de São Paulo. Ela se utilizou dos perfis de testemunhos de sondagem realizados na área de estudo a fim de classificar o maciço geomecanicamente e mensurando sua qualidade e condições de estabilidade durante e após o tunelamento.

A região que dá continuidade a linha já existente, próxima do ponto $A$ apresenta os piores parâmetros de qualidade, isso ocorre devido a predominância de solo na região que é gradualmente substituída por uma rocha intermediária de classe III.

Não foram observados grandes trechos críticos na rocha, com baixa qualidade, em sua maioria a escavação do túnel irá atingir rochas de classe II (Bom) e classe III (Regular).

A diferença entre as classes de maciço no trecho se deu principalmente pelas fraturas presentes na rocha e suas qualidades (ex: oxidação, presença de argilominerais), pouco influenciando sua alteração ou coerência. 


\subsection{Perfilagem Ótica}

Uma vez realizada a perfilagem ótica de um furo de sondagem a imagem gerada será a base de todos os dados gerados, desta forma a aquisição de imagens é o processo mais importante. O primeiro fator a ser pensado é a turbidez da água que pode impedir a visualização das paredes com boa definição (Figura 43).

Para isso deve-se iniciar com a lavagem do furo, de forma a remover a maior quantidade de particulado, com subsequente utilização de floculante, para a decantação do material fino excedente. Furos inclinados, por sua natureza, acabam por perder parte da informação pois a decantação faz com que a argila se deposite na parede inferior da perfuração (Figura 44).

Figura 43 - Perfilagem com problemas de definição devido a turbidez na água, trecho entre 42 e 43 metros de profundidade na SM-4505

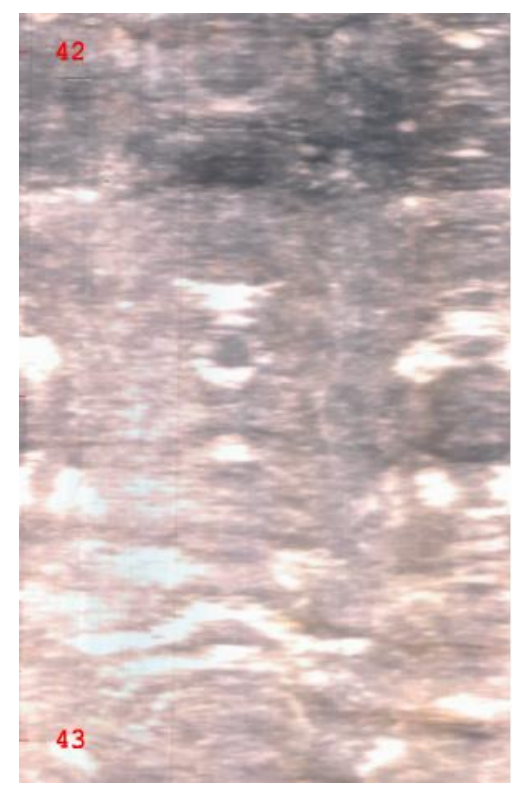


Figura 44 - Marca da sedimentação e arraste da sonda entre 27 e 28 metros da SM-4539

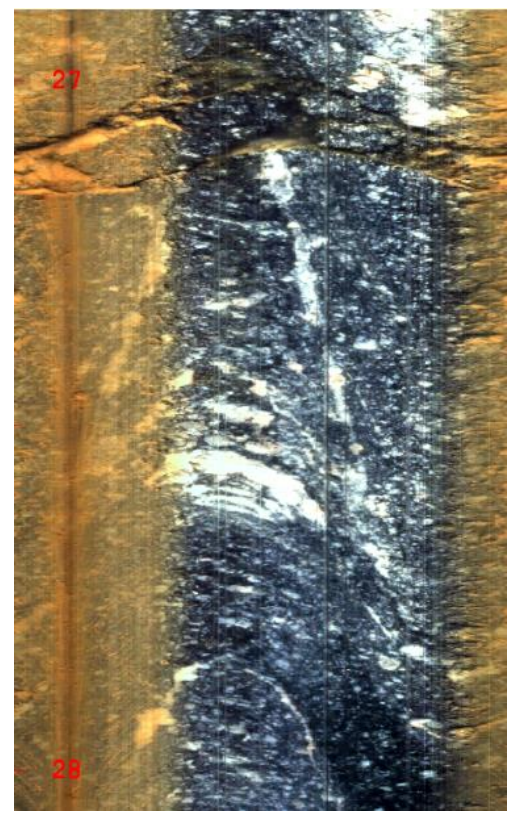

Da mesma forma que uma fotografia, para a obtenção de uma boa imagem é necessária uma quantidade de luz utilizada e captada adequada ao que se espera obter, assim para cada tipo de material é preciso realizar testes para verificar o nível correto de exposição a luz caso contrário pode-se perder dados, seja pelo excesso como pela falta de iluminação (Figura 45).

Figura 45 - Problema de iluminação prejudicando a visualização das estruturas, entre 13 e 14 metros da SM-4532

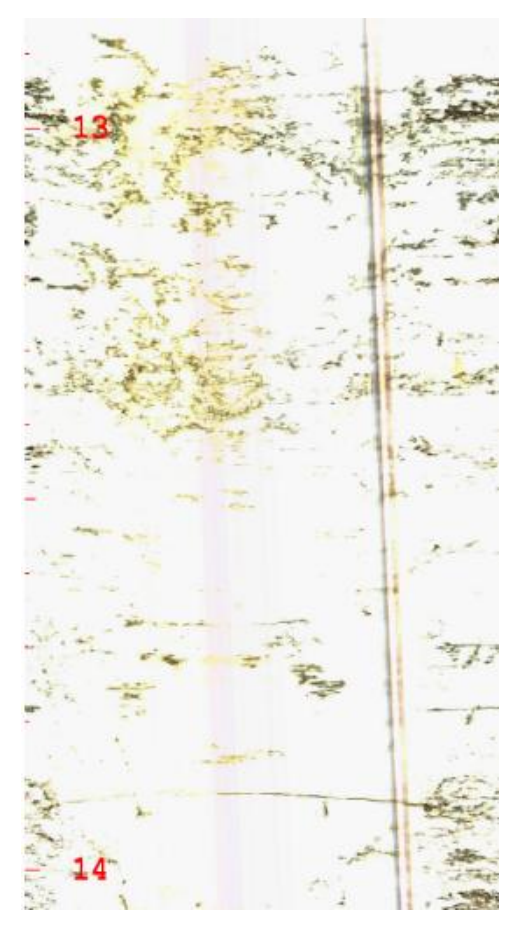


Uma das maiores vantagens da perfilagem ótica, além da determinação da orientação dos testemunho de sondagem é o fato de possibilitar a obtenção de imagens em trechos que sofreram baixa recuperação de testemunhos de sondagem, devido a fragmentação excessiva, ou alteração do maciço (Figura 46).

Figura 46 - Trecho de baixa recuperação, muito fraturado e alterado, entre 17 e 18 metros da SM-4536

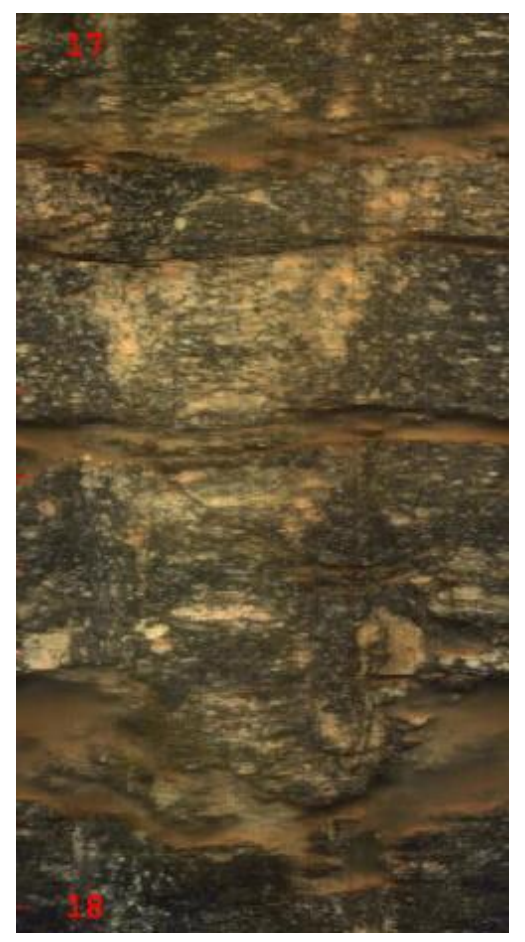

Para obtenção de orientações das descontinuidades foram realizadas 18 perfilagens óticas. A análise dos televisionamentos possibilitou perceber um alinhamento no eixo NW-SE dos polos das descontinuidades presentes no maciço rochoso, estas foram agrupadas em 6 conjuntos de famílias, $1 \mathrm{~m}$ (130/63), $2 \mathrm{~m}$ (131/34), 3m (121/08), $4 m$ (307/07), 5m (310/30) e $6 m$ (310/62), complementares entre si $(1 \mathrm{~m}$ e $6 \mathrm{~m}, 2 \mathrm{~m}$ e $5 \mathrm{~m}, 3 \mathrm{~m}$ e $4 \mathrm{~m})$. Este alinhamento é esperado na região estudada, a literatura mostra que o Complexo Embu fez parte do evento de construção da Gondwana Ocidental, exibindo descontinuidades na direção aproximada de NNESSW.

Com relação ao comportamento das descontinuidades com relação a profundidade, quanto maior a profundidade ocorre uma diminuição do número de descontinuidades, elas tendem a assumir as direções próximas daquelas propostas na literatura e o mergulho acaba por convergir às medidas centrais (sub-horizontais, 
inclinadas e subverticais). As fraturas abertas apresentam mais de $60 \%$ de frequência de baixo ângulo (horizontais, sub-horizontais), e apenas 15\% de fraturas com alto ângulo. As fraturas fechadas, não exibem uma tendência predominante, mas da mesma forma que as abertas, apresenta frequência muito baixa de fraturas subverticais.

\subsection{Formação de blocos}

Para realizar a análise de blocos foram utilizadas as atitudes das descontinuidades obtidas na perfilagem ótica de cada segmento estudado.

$O$ trecho identificado com blocos mais suscetíveis a colapso foi o segmento $A B$ que apresentou um bloco com fator de segurança 0 e quase 1200 toneladas. Como apresentado anteriormente todas as famílias principais de descontinuidades possuem as direções de mergulho com orientações de 130 e $310^{\circ}$, que por sua vez são perpendiculares a direção do segmento $A B$ do túnel $\left(40^{\circ}\right)$, justificando a formação de blocos instáveis. Esta relação é apresentada no estereograma abaixo (figura 47).

Nos outros trechos, não foram identificados blocos que associavam baixo fator de segurança com alta tonelagem, oferecendo risco mais baixo de problemas durante a execução do túnel.

Este favorecimento da estabilidade se deve em parte devido as fraturas estarem na mesma direção, mas principalmente pelo direcionamento do túnel que modifica a forma como os blocos são cortados. 

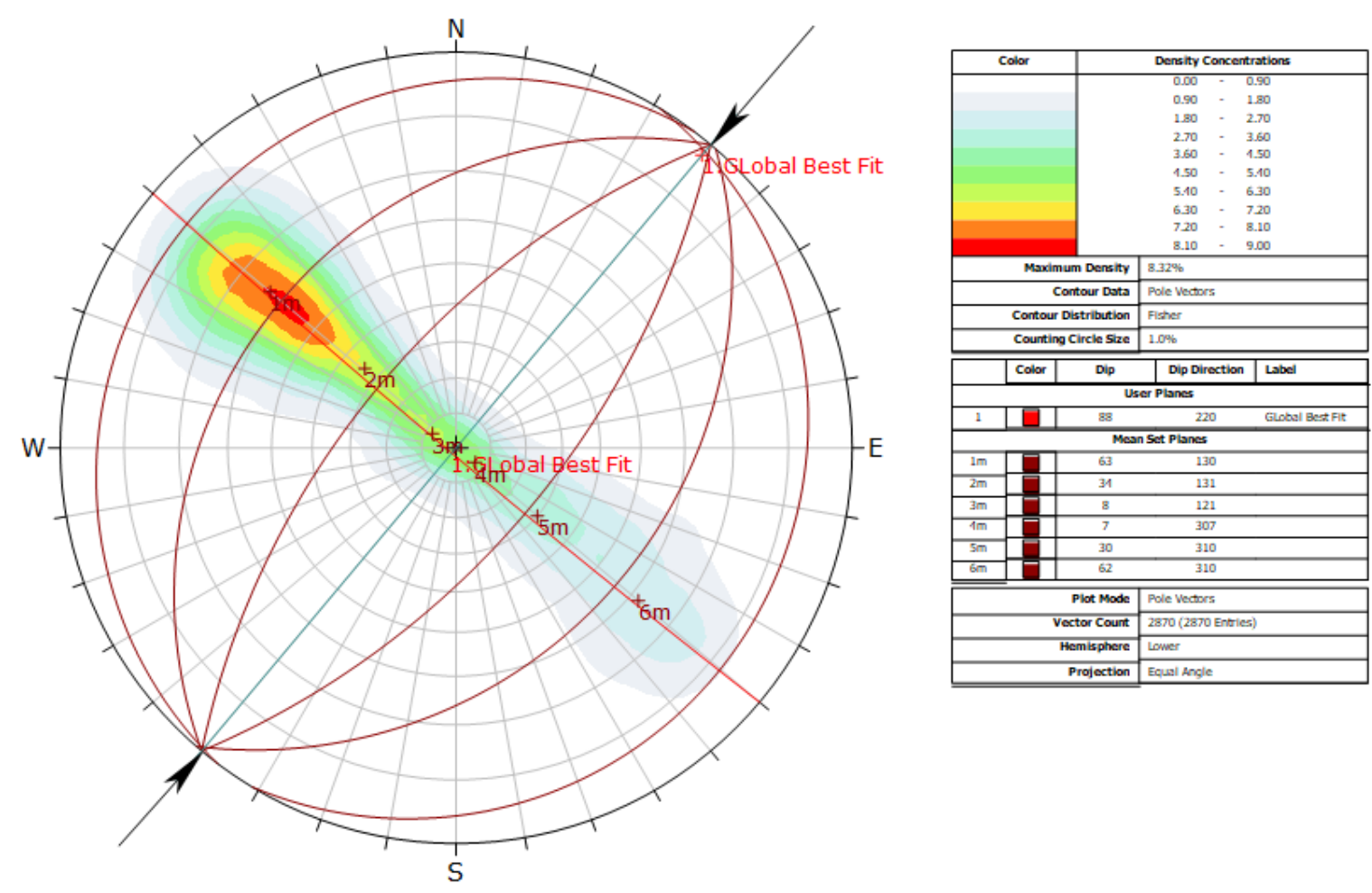

\section{CONSIDERAÇÕES FINAIS}

Com a ocupação dos grandes centros urbanos torna-se fundamental a utilização escavações subterrâneas, em especial túneis para projetos de mobilidade urbana e para isso faz-se necessário entender o substrato rochoso no qual estão inseridos.

Em obras de engenharia que envolvam construções em rocha, a obtenção de testemunhos de sondagem com subsequente caracterização da rocha e classificação de maciços rochosos fazem parte da rotina de escritórios de engenharia. Este trabalho demonstra que embora subjetivas, tanto a caracterização como a classificação, servem como forma de apresentar a qualidade do maciço ajudando a prever pontos críticos devido a rochas de baixa qualidade que podem prejudicar o andamento da obra.

Como forma complementar a investigação tradicional, a perfilagem ótica consegue observar trechos de baixa recuperação de testemunhos de sondagem, mas tem como função principal detectar a orientação de fraturas, permitindo que sejam 
criados estereogramas e modelos de blocos do maciço rochoso, estes que se tornam fundamentais para entender a dinâmica do maciço rochoso quando das solicitações das escavações subterrâneas.

A compreensão do comportamento geomecânico do maciço, frente a escavação a que está sendo submetido, é fundamental para que sejam diminuídas as incertezas e consequentemente o risco associado ao tunelamento, favorecendo cronogramas, planejamento financeiro e segurança da obra. 


\section{BIBLIOGRAFIA}

AGUILAR, A. P.; JULIANI, C.; ANDRADE, M. R. M.; OLIVEIRA A. M. Geoparque Ciclo do Ouro, Guarulhos (SP): Proposta. In: Geoparques propostas do Brasil: Propostas. Rio de janeiro: CPRM, 2012. p. 748.

BARTON, N. Predicting the behaviour of underground openings in jointed rock. 4th Manual Rocha Memorial Lecture, Lisbon. Anais...Lisboa: 1987

BARTON, N.; LIEN, R.; LUNDE, J. Engineering Classifaction of Rock Masses for the Design of Tunnel Support.pdf. Rock Mechanics Felsmechanik Mécanique des Roches, v. 6, n. 4, p. 189-236, 1974.

BERGMANN, M. Caracterização estratigráfica e estrutural da sequência vulcanosedimentar do grupo São Roque - na região de Pirapora do Bom Jesus - Estado de São Paulo. São Paulo: Universidade de São Paulo, 7 jul. 1988.

BIENIAWSKI, Z. T. Estimating the strength of rock materials. International Journal of Rock Mechanics and Mining Sciences Geomechanics Abstracts, 1974.

BIENIAWSKI, Z. Classification of Rock Masses for Engineering: The RMR System and Future Trends. In: Rock Testing and Site Characterization. [s.I.] Pergamon, 1993. p. 553-573.

BIENIAWSKI, Z. T. Tunnel design by rock mass classifications.Pennsylvania State Univ University Park Dept of Mineral Engineering, 1990.

CHOI, S. Y.; PARK, H. D. Comparison among different criteria of RMR and Q-system for rock mass classification for tunnelling in Korea. Tunnelling and Underground Space Technology, v. 17, n. 4, p. 391-401, 1 out. 2002.

CPRM. Mapa Geológico do Estado de São Paulo: Escala 1:750000. Breve descrição das unidades litoestratigráficas aflorantes no Estado de São Paulo. São Paulo: CPRM, 2006.

DANTAS, A. S. L. Geologia da faixa são roque e intrusivas associadas na região entre São Paulo e Mairiporã, Norte de São Paulo - SP. São Paulo: Universidade de São Paulo, 16 maio 1991.

DE FREDRICK, F. NGUYEN, T.; SEYMOUR, C.; DEMPERS, G. Geotechnical data from optical and acoustic televiewer surveys. AusIMM Bulletin, v. Oct, n. 5, p. 64-66, 2014.

DEERE, D. The rock quality designation (RQD) index in practice. In: INTERNATIONAL, A. (Ed.). . Rock classification systems for engineering purposes. NY: ASTM International, 1988. p. $91-101$

ELLEDGE, B. S.; DUBEAU, M.; HEENAN, D. M. Modeling Grout Injection Volume in Fractured Rock Using Borehole Imagery. Grouting and Deep Mixing 2012. Anais...Reston: American Society of Civil Engineers, 2012

FOOKES, P. G.; GOURLEY, C. S.; OHIKERE, C. Rock weathering in engineering time Naturally occurring weathering processes. Quaterly Journal of Engineering Geology, v. 21, p. 33-57, 1988.

GAILLOT, P. Brewer, T.; Pezard, P.; Yeh, E. Supplement 1: Borehole Imaging Tools Principles and Applications. Scientific Drilling, n. 5, p. 50-53, 2007.

GANERØD, G. V.; RØNNING, J. S.; DALSEGG, E.; ELVEBAKK, H.; HOLMØY, K.; NILSEN, B.; BRAATHEN, A. Comparison of geophysical methods for sub-surface mapping of faults and fracture zones in a section of the Viggja road tunnel, Norway. Bulletin of Engineering Geology and the Environment, v. 65, n. 3, p. 231-243, 26 ago. 2006.

GUIDICINI, G. OLIVEIRA, A. M. S.; CAMARGO, F. P.; KAJI, N. Um método de classificação 
geotécnica preliminar de meios rochosos. Semana Paulista de Geologia Aplicada 4. Anais...São Paulo: 1972

GURGUEIRA, M. D. Correlação de dados geológicos e tectônicos na Bacia de São Paulo. [s.I.] Universidade de São Paulo, 2013.

GWYNN, X. P.; M.C. BROWN; P.J. MOHR SRK. Combined use of traditional core logging and televiewer imaging for practical geotechnical data collection Combined use of traditional core logging and televiewer imaging for practical geotechnical data collection. Slope Stability, n. September, p. 14, 2013.

HASUI, Y. Geologia Estrutural das rochas da linha 4: avaliação e síntese dos conhecimentos. relatório interno da Companhia do Metropolitano de São Paulo. São Paulo: Relatório interno da Companhia do Metropolitano de São Paulo - Metrô SP, 1994.

HASUI, Y. A grande colisão pré-cambriana do sudeste brasileiro e a estruturação regional. Geociencias, v. 29, n. 2, p. 141-169, 2010.

HASUI, Y.; CARNEIRO, C. D. R.; COIMBRA, A. M. The Ribeira Folded Belt. Revista Brasileira de Geociências, v. 5, p. 257-266, 29 ago. 1975.

HOLCOMBE, R. ORIENTED DRILLCORE: MEASUREMENT, CONVERSION, AND QA/QC PROCEDURES FOR STRUCTURAL AND EXPLORATION GEOLOGISTS. Mudgeeraba: HCOV Global, 2000.

HOLM $\varnothing Y, K . H$. Significance of geological parameters for predicting water leakage in hard rock tunnels Kristin Hilde Holmøy Significance of geological parameters for predicting water leakage in hard rock tunnels Thesis for the degree of philosophiae. Trondheim: Norwegian University of science and Technology, 2008.

HUBBARD, B. ROBERSON, S.; SAMYN, D.; MERTON-LYN, D. Digital optical televiewing of ice boreholes. Journal of Glaciology, v. 54, n. 188, p. 823-830, 8 set. 2008.

HUBBARD, B. TISON, J. L.; PATTYN, F.; DIERCKX, M.; BOEREBOOM, T.; SAMYN, D. Optical-televiewer-based identification and characterization of material facies associated with an antarctic ice-shelf rift. Annals of Glaciology, v. 53, n. 60, p. 137-146, nov. 2012.

IPT. Estudos Geológico- Geotécnicos para Caracterização e Classificação de Maciços Rochosos para Projetos de Engenharia (Túneis, Lavra a Céu Aberto e Barragens). São Paulo: IPT, 1984.

JULIANI, C. O embasamento Pré-Cambriano da Bacia de São Paulo. Seminário Problemas Geológicos e Geotécnicos na região Metropolitana de São Paulo. Anais...1992

JULIANI, C. Geologia, petrogênese e aspectos metalogenéticos dos grupos Serra do Itaberaba e São Roque na região das Serras do Itaberaba e da Pedra Branca, NE da Cidade de São Paulo, SP. São Paulo: Universidade de São Paulo, 29 abr. 1993.

JULIANI, C.; BELJAVSKIS, P. Revisão da litoestratigrafia da faixa São Roque/Serra do Itaberaba (SP). Revista do Instituto Geológico, v. 16, n. 1-2, p. 33-58, 1 dez. 1995.

LAFRONZ, N. J. PETERSON, D. E.; TURTON, R. D.; ANDERSON, S. Geologic Characterization, Colorado River Bridge Foundations, Hoover Dam Bypass. Geotechnical Engineering for Transportation Projects. Anais...Reston, VA: American Society of Civil Engineers, 21 jul. 2004

MADDOX, S. D. Application of Downhole Video Technology to Multilateral Well Completions. Offshore Europe. Anais...Society of Petroleum Engineers, 1997

MALONE, T.; HUBBARD, B.; MERTON-LYN, D.; WORTHINGTON, P.; ZWIGGELAAR, R. 
Borehole and Ice Feature Annotation Tool (BIFAT): A program for the automatic and manual annotation of glacier borehole images. Computers \& Geosciences, v. 51, p. 381-389, 1 fev. 2013.

MATULA, M. Rock and soil description and classification for engineering geological mapping report by IAEG Comission on Engineering Geological Mapping. Bulletin of Engineering Geology and the Environment, v. 24, p. 235-274, 1981.

MEIRA, V. T. Evolução Tectono-Metamórfica Neoproterozoica dos Complexos Embu e Costeiro no Contexto de Formação do Gondwana Ocidental (Leste do Estado de São Paulo). São Paulo: Universidade de São Paulo, 6 nov. 2014.

MONTEIRO, M. D. CONTRIBUIÇÃO À CARACTERIZAÇÃO HIDROGEOLÓGICA DE MACIÇOS FRATURADOS E SOLOS RESIDUAIS EM PROJETOS DE OBRAS SUBTERRÂNEAS NA REGIÃO METROPOLITANA DE SÃO PAULO. São Paulo: Universidade de São Paulo, 2016.

MONTEIRO, M. D.; GURGUEIRA, M. D.; ROCHA, H. C. Geologia da Região Metropolitana de São Paulo. In: TWIN CITIES - Solos das Regiões Metropolitanas de São Paulo e Curitiba. 12. ed. São Paulo: ABMS, 2012. p. 512.

OLIVEIRA, A. M. S.; BRITO, S. N. A.. Geologia de Engenharia. 1. ed. São Paulo: ABGE, 1998.

OLIVEIRA, D. G. G. TELEVISIONAMENTO ÓPTICO DE SONDAGENS - PROPOSTA METODOLÓGICA PARA EXECUÇÃO E SUAS APLICAÇÕES PARA OBRAS SUBTERRÂNEAS. São Paulo: Universidade de São Paulo, 2015.

PASTORE, E. L.; CRUZ, P. T.; FREITAS JR, M. S. Fundações de Barragens e Estruturas em Arenitos: Natureza dos Maciços e Controle de Fluxo de Erosões. XXX Seminário Nacional de Grandes Barragens, p. 1-18, 2015.

RICCOMINI, C. Rift Continental Do Sudeste. São PAulo: Universidade de São Paulo, 1989.

ROBERSON, S.; HUBBARD, B. Application of borehole optical televiewing to investigating the 3-D structure of glaciers: implications for the formation of longitudinal debris ridges, midre Lovénbreen, Svalbard. Journal of Glaciology, v. 56, n. 195, p. 143-156, 8 set. 2010.

SAUMUR, B. M. CRUDEN, A. R.; EVANS-LAMSWOOD, D.; LIGHTFOOT, P. C. Wall-Rock Structural Controls on the Genesis of the Voisey's Bay Intrusion and its Ni-Cu-Co Magmatic Sulfide Mineralization (Labrador, Canada). Economic Geology, v. 110, n. 3, p. 691-711, 1 maio 2015.

STUMM, F. CHU, A.; JOESTEN, P. K.; NOLL, M. L.; COMO, M. Delineation of Fractures , Foliation, and Groundwater-flow Zones of the Bedrock at the Harlem River Tunnel in Northern New York County , New York. 20th Conference on Geology of Long Island and Metropolitan New York. Anais...2013

THOMAS, R.; NEILSEN, J. M.; WILSON, H. F.; LAMB, P. Structural interpretation from Televiewer surveysNinth International Symposium on Field Measurements in Geomechanics, 2015 9-11 September, SydneyAustralian Centre for Geomechanics, , 9 set. 2015.

VAVRO, M.; SOUČEK, K.; STAŠ, L.; WACLAWIK, P.; VAVRO, L.; KONICEK, P.; PTÁČEK, J. Application of alternative methods for determination of rock quality designation (RQD) index: a case study from the Rožná I uranium mine, Strážek Moldanubicum, Bohemian Massif, Czech Republic. Canadian Geotechnical Journal, v. 52, n. 10, p. 1466-1476, out. 2015.

WEIR, F. M. The future of structural data from boreholes. International Journal of 
Geotechnical Engineering, v. 9, n. 3, p. 223-228, 5 jun. 2015. 
APÊNDICE I - TABELAS DE DESCONTINUIDADES 


\begin{tabular}{|c|c|c|c|c|c|c|c|c|c|c|}
\hline 4503 & Depth & $A z$ & Dip & Dec. & Apert & Depth & $\mathrm{Az}$ & Dip & Dec. & Apert \\
\hline & 21,69 & 179,92 & 30,11 & 159,03 & 0 & 27,6 & 135,08 & 55,44 & 114,19 & 0 \\
\hline & 21,72 & 200,32 & 52,39 & 179,43 & 0 & 27,69 & 149,08 & 42,49 & 128,19 & 0 \\
\hline & 21,78 & 198 & 40,96 & 177,11 & 0 & 27,8 & 280,45 & 11,03 & 259,56 & 0 \\
\hline & 21,9 & 220 & 75 & 199,11 & 0 & 27,91 & 142 & 82 & 121,11 & 0 \\
\hline & 22,98 & 345,28 & 35,98 & 324,39 & 0 & 27,96 & 143,91 & 19,54 & 123,02 & 0 \\
\hline & 23 & 334,3 & 34,84 & 313,41 & 0 & 28,05 & 149 & 11 & 128,11 & 0 \\
\hline & 23,1 & 195,92 & 14,25 & 175,03 & 0 & 28,09 & 156 & 33 & 135,11 & 0 \\
\hline & 23,16 & 335,95 & 67 & 315,06 & 0 & 28,12 & 146,72 & 40,23 & 125,83 & 0 \\
\hline & 23,18 & 336,72 & 33,5 & 315,83 & 0 & 28,16 & 323 & 46 & 302,11 & 0 \\
\hline & 23,22 & 113,9 & 8,87 & 93,01 & 0 & 28,44 & 163,53 & 59,97 & 142,64 & 0 \\
\hline & 23,24 & 152 & 8 & 131,11 & 0 & 28,67 & 322 & 40 & 301,11 & 0 \\
\hline & 23,38 & 283 & 8 & 262,11 & 0 & 28,71 & 357 & 16 & 336,11 & 0 \\
\hline & 23,43 & 65 & 12 & 44,11 & 0 & 28,8 & 98 & 6 & 77,11 & 0 \\
\hline & 23,45 & 172 & 71 & 151,11 & 0 & 28,87 & 241 & 6 & 220,11 & 0 \\
\hline & 23,48 & 155,59 & 79,47 & 134,7 & 0 & 28,89 & 26,54 & 9,2 & 5,65 & 0 \\
\hline & 23,5 & 156 & 32 & 135,11 & 0 & 28,89 & 32,56 & 9 & 11,67 & 0 \\
\hline & 23,59 & 138 & 15 & 117,11 & 0 & 28,91 & 340,54 & 15,22 & 319,65 & 2,12 \\
\hline & 24,03 & 157,19 & 67,31 & 136,3 & 12,73 & 28,91 & 93 & 9 & 72,11 & 0,97 \\
\hline & 24,18 & 276 & 8 & 255,11 & 0 & 28,93 & 347,49 & 23 & 326,6 & 0 \\
\hline & 24,19 & 58 & 84 & 37,11 & 0 & 28,93 & 323,4 & 7,63 & 302,51 & 0 \\
\hline & 24,32 & 329,19 & 51,91 & 308,3 & 0 & 28,96 & 3 & 8 & 342,11 & 0 \\
\hline & 24,42 & 336,06 & 62,92 & 315,17 & 0 & 28,98 & 18 & 7 & 357,11 & 0,28 \\
\hline & 24,46 & 334 & 58,81 & 313,11 & 0 & 29,02 & 349 & 19 & 328,11 & 0 \\
\hline & 24,46 & 152,69 & 54,38 & 131,8 & 0 & 29,11 & 347 & 62 & 326,11 & 0 \\
\hline & 24,5 & 56,51 & 83 & 35,62 & 0 & 29,3 & 192 & 31 & 171,11 & 0 \\
\hline & 24,67 & 156,61 & 59,94 & 135,72 & 0 & 29,52 & 161,09 & 70,2 & 140,2 & 0 \\
\hline & 24,77 & 114 & 16 & 93,11 & 0 & 29,57 & 157,22 & 64,58 & 136,33 & 0 \\
\hline & 24,82 & 161,6 & 36,8 & 140,71 & 0 & 29,65 & 155,23 & 62,29 & 134,34 & 0 \\
\hline & 24,84 & 152,62 & 38,52 & 131,73 & 0 & 29,78 & 161 & 9 & 140,11 & 0 \\
\hline & 24,9 & 156,95 & 36,94 & 136,06 & 0 & 29,81 & 280 & 5 & 259,11 & 0 \\
\hline & 25,03 & 59 & 82,51 & 38,11 & 0 & 29,81 & 178 & 9 & $\mathbf{1 5 7 , 1 1}$ & 0 \\
\hline & 25,63 & 24 & 68 & 3,11 & 0 & 29,84 & 236 & 2 & 215,11 & 0 \\
\hline & 25,73 & 81,02 & 27,65 & 60,13 & 0 & 30,02 & 327,6 & 2,52 & 306,71 & 0 \\
\hline & 25,89 & 134,22 & 28,81 & 113,33 & 0 & 30,18 & 150,93 & 66,11 & 130,04 & 0 \\
\hline & 25,94 & 145,64 & 28,9 & 124,75 & 0 & 30,28 & 155 & 26 & 134,11 & 0 \\
\hline & 25,99 & 151,07 & 23,27 & 130,18 & 0 & 30,28 & 152,89 & 60,03 & 132 & 0 \\
\hline & 26,11 & 152,29 & 36,72 & 131,4 & 0 & 30,32 & 170 & 29 & 149,11 & 0 \\
\hline & 26,21 & 176 & 1 & 155,11 & 0 & 30,34 & 186,43 & 57,8 & 165,54 & 0 \\
\hline & 26,24 & 159 & 62 & 138,11 & 0 & 30,55 & 159,72 & 73,04 & 138,83 & 0 \\
\hline & 26,35 & 147 & 36,87 & 126,11 & 0 & 30,64 & 105 & 12 & 84,11 & 0 \\
\hline & 26,37 & 323,53 & 56,66 & 302,64 & 0 & 30,65 & 128 & 11 & 107,11 & 0 \\
\hline & 26,46 & 142,87 & 53,87 & 121,98 & 0 & 30,72 & 159,88 & 64,37 & 138,99 & 0 \\
\hline & 26,46 & 349 & 27 & 328,11 & 0 & 30,79 & 151,35 & 26,57 & 130,46 & 0 \\
\hline & 26,53 & 336,5 & 39,76 & 315,61 & 0 & 30,89 & 152,46 & 42 & 131,57 & 0 \\
\hline & 26,53 & 145,2 & 44,19 & 124,31 & 0 & 31,11 & 348,64 & 4 & 327,75 & 2,16 \\
\hline & 26,61 & 146,2 & 27,92 & 125,31 & 0 & 31,12 & 22,78 & 3,21 & 1,89 & 0,6 \\
\hline & 26,64 & 147,97 & 46,99 & 127,08 & 0 & 31,17 & 160 & 7 & 139,11 & 0 \\
\hline & 26,7 & 143,31 & 52,98 & 122,42 & 0 & 31,18 & 285,65 & 9,98 & 264,76 & 1,38 \\
\hline & 26,75 & 153,4 & 50,19 & 132,51 & 0 & 31,18 & 148,98 & 11,2 & 128,09 & 1,37 \\
\hline & 26,78 & 150,85 & 48,79 & 129,96 & 0 & 31,19 & 136,51 & 11 & 115,62 & 0,45 \\
\hline & 26,95 & 1 & 11 & 340,11 & 0 & 31,27 & 43 & 4 & 22,11 & 0 \\
\hline & 27,04 & 142 & 51 & 121,11 & 0 & 31,32 & 154 & 72 & 133,11 & 0 \\
\hline & 27,24 & 162,38 & 43,71 & 141,49 & 0 & 31,36 & 155 & 36 & 134,11 & 0 \\
\hline & 27,27 & 151,07 & 60,95 & 130,18 & 0 & 31,57 & 292 & 19 & 271,11 & 0 \\
\hline & 27,28 & 333,59 & 49,72 & 312,7 & 0 & 31,63 & 163 & 14 & 142,11 & 0 \\
\hline & 27,39 & 149,85 & 77,76 & 128,96 & 0 & 31,78 & 122,84 & 7,97 & 101,95 & 0 \\
\hline & 27,42 & 349 & 49 & 328,11 & 0 & 31,8 & 152,8 & 72,7 & 131,91 & 0 \\
\hline
\end{tabular}




\begin{tabular}{|c|c|c|c|c|c|c|c|c|c|c|}
\hline 4503 & Depth & $\mathrm{Az}$ & Dip & Dec. & Apert & Depth & $A z$ & Dip & Dec. & Apert \\
\hline & 31,84 & 106,07 & 11,2 & 85,18 & 0 & 36,82 & 152 & 58 & 131,11 & 0 \\
\hline & 31,9 & 115 & 12 & 94,11 & 0 & 36,94 & 154,06 & 54,65 & 133,17 & 0 \\
\hline & 32,08 & 349 & 4 & 328,11 & 0 & 37,01 & 337 & 63 & 316,11 & 0 \\
\hline & 32,19 & 342,12 & 7 & 321,23 & 4,31 & 37,43 & 151,86 & 62,3 & 130,97 & 0 \\
\hline & 32,23 & 159,32 & 57,44 & 138,43 & 0 & 37,5 & 146,2 & 64,54 & 125,31 & 0 \\
\hline & 32,39 & 153,87 & 53,27 & 132,98 & 0 & 37,76 & 149,39 & 58,22 & 128,5 & 0 \\
\hline & 32,5 & 293,34 & 4,12 & 272,45 & 1,4 & 37,89 & 150,37 & 57,57 & 129,48 & 0 \\
\hline & 32,51 & 99,81 & 10,2 & 78,92 & 1,38 & 38 & 45 & 0 & 24,11 & 0 \\
\hline & 32,7 & 49,89 & 12,63 & 29 & 0 & 38,22 & 145,48 & 22,59 & \begin{tabular}{l|}
124,59 \\
\end{tabular} & 0 \\
\hline & 32,95 & 158,46 & 81,33 & 137,57 & 0 & 38,33 & 334,85 & 5,14 & 313,96 & 0 \\
\hline & 33,23 & 153,87 & 69,4 & 132,98 & 0 & 38,36 & 147,46 & 20,61 & 126,57 & 1,32 \\
\hline & 33,32 & 157,36 & 64,02 & 136,47 & 0 & 38,37 & 147,3 & 18,98 & 126,41 & 1,32 \\
\hline & 33,37 & 159,74 & 65,4 & 138,85 & 0 & 38,39 & 155,09 & 26,2 & 134,2 & 0,54 \\
\hline & 33,46 & 155,52 & 56,31 & 134,63 & 0 & 38,43 & 136,04 & 23,36 & 115,15 & 0,55 \\
\hline & 33,56 & 154,06 & 62,3 & 133,17 & 0 & 38,45 & 59,68 & 26 & 38,79 & 0 \\
\hline & 33,64 & 326,88 & 9,65 & 305,99 & 0,79 & 38,56 & 144 & 11 & 123,11 & 1,37 \\
\hline & 33,64 & 133 & 13 & 112,11 & 0,59 & 38,58 & 149,21 & 33 & 128,32 & 1,17 \\
\hline & 33,68 & 91 & 2 & 70,11 & 0 & 38,61 & 145,9 & 25,36 & 125,01 & 1,27 \\
\hline & 33,69 & 318,96 & 4 & 298,07 & \begin{tabular}{|l|l|}
3,12 \\
\end{tabular} & 38,67 & 165 & 33 & 144,11 & 1,81 \\
\hline & 33,71 & 141,01 & 12,3 & 120,12 & 2,15 & 38,69 & 335,68 & 11,97 & 314,79 & 1,37 \\
\hline & 33,71 & 328 & 22,19 & 307,11 & 2,59 & 38,74 & 155,32 & 64,75 & 134,43 & 0 \\
\hline & 33,78 & 151,35 & 1,26 & 130,46 & 0 & 38,87 & 149,81 & 58,63 & 128,92 & 0 \\
\hline & 33,83 & 146,02 & 4 & 125,13 & 0,6 & 39,26 & 158,46 & 39,01 & 137,57 & 0 \\
\hline & 33,85 & 136,02 & 6 & 115,13 & 1,39 & 39,34 & 143,35 & 16,91 & 122,46 & 0 \\
\hline & 33,87 & 142,07 & 11 & 121,18 & 0 & 39,35 & 137,4 & 57,75 & 116,51 & 0 \\
\hline & 33,94 & 326,88 & 2,86 & 305,99 & 0 & 39,85 & 59 & 80 & 38,11 & 0,49 \\
\hline & 34 & 342 & 13,28 & 321,11 & 1,36 & 39,88 & 152 & 74 & 131,11 & 0 \\
\hline & 34 & 146,2 & 35,19 & 125,31 & 0 & 39,99 & 151,04 & 70 & 130,15 & 0 \\
\hline & 34,11 & 338,69 & 51 & 317,8 & 0 & 40,21 & 156,98 & 51,12 & 136,09 & 0 \\
\hline & 34,12 & 330,93 & 4,46 & 310,04 & 0 & 40,65 & 359,44 & 12,3 & 338,55 & 0 \\
\hline & 34,13 & 92 & 20 & 71,11 & 0 & 40,68 & 150 & 42,86 & 129,11 & 1,47 \\
\hline & 34,14 & 25 & 17 & 4,11 & 0 & 40,73 & 151,75 & 42,36 & 130,86 & 1,48 \\
\hline & 34,18 & 170,08 & 63,23 & 149,19 & 0 & 40,76 & 148,35 & 47,73 & 127,46 & $\overline{0}$ \\
\hline & 34,22 & 336 & 56 & 315,11 & 0 & 40,79 & 148 & 45,34 & 127,11 & 0 \\
\hline & 34,29 & 152,8 & 45,14 & 131,91 & 0 & 40,89 & 143 & 46 & 122,11 & 0 \\
\hline & 34,4 & 158,9 & 60,26 & 138,01 & 0 & 41,05 & 20 & 27 & 359,11 & 0 \\
\hline & 34,58 & 154,06 & 75,74 & 133,17 & 0 & 41,18 & 340,71 & 2,86 & 319,82 & 0 \\
\hline & 34,81 & 332,9 & 18,78 & 312,01 & \begin{tabular}{l|l|}
0,57 \\
\end{tabular} & 41,74 & 151,86 & 56,31 & 130,97 & 0 \\
\hline & 34,82 & 336 & 56 & 315,11 & 0 & 42,06 & 96 & 5 & 75,11 & 1,06 \\
\hline & 34,97 & 327,09 & 59 & 306,2 & 0 & 42,07 & 74,49 & 11,2 & 53,6 & 1,37 \\
\hline & 34,99 & 167,14 & 61,21 & 146,25 & 0 & 42,17 & 155,26 & 62,73 & 134,37 & 0 \\
\hline & 34,99 & 271,26 & 10,09 & 250,37 & 1,18 & 42,27 & 140,03 & 42,36 & 119,14 & 0 \\
\hline & 34,99 & 59,25 & 6,05 & 38,36 & 1,39 & 42,35 & 334 & 23 & 313,11 & 0 \\
\hline & 35,04 & 330,45 & 37,95 & 309,56 & 0 & 42,39 & 330 & 18 & 309,11 & 0 \\
\hline & 35,2 & 165,19 & 55,85 & 144,3 & 0 & 42,41 & 306 & 10 & 285,11 & 0 \\
\hline & 35,5 & 153,27 & 60,06 & 132,38 & 0 & 42,43 & 145,9 & 69,88 & 125,01 & 0 \\
\hline & 35,62 & 125,68 & 17,37 & 104,79 & 0 & 42,69 & 138,07 & 56,49 & 117,18 & 0 \\
\hline & 35,65 & 125 & 15 & 104,11 & 0 & 42,71 & 131 & 3 & 110,11 & 0 \\
\hline & 35,94 & 150,37 & \begin{tabular}{l|}
40,7 \\
\end{tabular} & 129,48 & 0 & 42,91 & 153,42 & 50,84 & 132,53 & 0 \\
\hline & 36,05 & 321,64 & \begin{tabular}{l|}
10,2 \\
\end{tabular} & 300,75 & 0 & 42,93 & 337,22 & 50,01 & 316,33 & 0 \\
\hline & 36,1 & 324,92 & 2,4 & 304,03 & 0 & 43,12 & 148,42 & 58,31 & 127,53 & 0 \\
\hline & 36,34 & 343 & 73,95 & 322,11 & 0,97 & 43,42 & 145,48 & 58,81 & 124,59 & 0 \\
\hline & 36,35 & 349 & 70 & 328,11 & 0 & 43,49 & 146 & 48 & 125,11 & 0 \\
\hline & 36,39 & 333,66 & 19 & 312,77 & 2,15 & 43,72 & 153,7 & 63,2 & 132,81 & 0 \\
\hline & 36,42 & 338,2 & 18,16 & 317,31 & 2,13 & 43,85 & 143,85 & 71 & 122,96 & 0 \\
\hline & 36,67 & 166 & 58 & 145,11 & 0 & 43,92 & 107,93 & 23 & 87,04 & 0 \\
\hline & 36,69 & 159 & 57 & 138,11 & 0 & 44 & 132,2 & 16,49 & 111,31 & 0 \\
\hline
\end{tabular}




\begin{tabular}{|c|c|c|c|c|c|c|c|c|c|c|}
\hline 4505 & Depth & $\mathrm{Az}$ & Dip & Dec. & Apert & Depth & $\mathrm{Az}$ & Dip & Dec. & Apert \\
\hline & 26,87 & 352 & 24,6 & 331,11 & 0 & 31,35 & 340 & 69,2 & \begin{tabular}{|l|}
319,11 \\
\end{tabular} & 0,5 \\
\hline & 27,11 & 182,1 & 13,2 & 161,21 & 0 & 31,36 & 351,05 & 61,84 & 330,16 & 0,66 \\
\hline & 27,11 & 124 & 8 & 103,11 & 1,98 & 31,39 & 262 & 5,2 & 241,11 & 0 \\
\hline & 27,26 & 337,21 & 8,87 & 316,32 & 1,38 & 31,42 & 10 & 13,6 & 349,11 & 0 \\
\hline & 27,35 & 176 & 16,4 & 155,11 & 1,34 & 31,49 & 331,65 & 41,67 & 310,76 & 0 \\
\hline & 27,67 & 189 & 34,2 & 168,11 & 0,5 & 31,6 & 350 & 17,3 & 329,11 & 0 \\
\hline & 27,83 & 255,84 & 11,53 & 234,95 & 0,78 & 31,7 & 253 & 4,4 & 232,11 & 0 \\
\hline & 27,93 & 164,69 & 42,55 & 143,8 & 0,44 & 31,72 & 89 & 4,1 & 68,11 & 0 \\
\hline & 27,95 & 164,27 & 40,83 & 143,38 & 0,61 & 31,73 & 257,8 & 38,31 & 236,91 & 0 \\
\hline & 28,01 & 340,71 & 2,4 & 319,82 & 1,4 & 31,89 & 182,45 & 10,76 & 161,56 & 0,79 \\
\hline & 28,01 & 174,48 & 12,74 & 153,59 & 1,37 & 31,89 & 32,02 & 3,21 & 11,13 & 0 \\
\hline & 28,02 & 164,14 & 23,36 & 143,25 & 0,73 & 31,91 & 173,5 & 22,98 & 152,61 & 1,29 \\
\hline & 28,05 & 155,32 & 30,96 & 134,43 & 0,52 & 32 & 359 & 26,2 & 338,11 & 0 \\
\hline & 28,22 & 335,5 & 43,95 & 314,61 & 1,01 & 32,08 & 164 & 8,3 & 143,11 & 0 \\
\hline & 28,23 & 333,64 & 30,46 & 312,75 & 1,21 & 32,23 & 36,91 & 26,29 & 16,02 & 0 \\
\hline & 28,24 & 171,12 & 49,53 & 150,23 & 0 & 32,54 & 337,27 & 63,55 & 316,38 & 0 \\
\hline & 28,25 & 343,58 & 40,56 & 322,69 & 1,07 & 32,8 & 224,39 & 68,12 & 203,5 & 0 \\
\hline & 28,35 & 168,61 & 24,7 & 147,72 & 0 & 32,84 & 295 & 82,1 & 274,11 & 0 \\
\hline & 28,36 & 334,83 & 20,51 & 313,94 & 0 & 33,23 & 41 & 7,4 & 20,11 & 0 \\
\hline & 28,46 & 150,99 & 14,25 & 130,1 & 0 & 33,61 & 347,43 & 33,43 & 326,54 & 0 \\
\hline & 28,47 & 344 & 22,6 & 323,11 & 0 & 33,97 & 156,82 & 80,31 & 135,93 & 0 \\
\hline & 28,63 & 176,02 & 5,14 & 155,13 & 0,8 & 34,06 & 159,74 & 49,14 & 138,85 & 0 \\
\hline & 28,64 & 186,92 & 9,98 & 166,03 & 0,79 & 34,38 & 9 & 4,6 & 348,11 & 0 \\
\hline & 28,71 & 349,65 & 61,94 & 328,76 & 0,94 & 34,41 & 332 & 58 & 311,11 & 0 \\
\hline & 28,75 & 170,64 & 62,12 & 149,75 & 0 & 34,51 & 50,3 & 79,68 & 29,41 & 0,68 \\
\hline & 28,99 & 348,12 & 63,39 & 327,23 & 0,63 & 35,1 & 154,06 & 21,31 & 133,17 & 0 \\
\hline & 29,02 & 165,67 & 21,5 & 144,78 & 0 & 35,14 & 154,87 & 8,08 & 133,98 & 2,77 \\
\hline & 29,06 & 173,08 & 39,76 & 152,19 & 0 & 35,16 & 158,29 & 4 & 137,4 & 2,79 \\
\hline & 29,18 & 342,66 & 67,91 & 321,77 & 0 & 35,68 & 161,81 & 53,06 & 140,92 & 0 \\
\hline & 29,24 & 341,69 & 66,75 & 320,8 & 0 & 35,73 & 158,85 & 56,93 & 137,96 & 0 \\
\hline & 29,35 & 355 & 41,5 & 334,11 & 0 & 35,9 & 152,42 & 53,83 & 131,53 & 0 \\
\hline & 29,47 & 166,44 & 55,3 & 145,55 & 0 & 36,03 & 359 & 16,7 & 338,11 & 4,02 \\
\hline & 29,53 & 352,59 & 63,8 & 331,7 & 0 & 36,21 & 161,23 & 77,98 & 140,34 & 0 \\
\hline & 29,54 & 162,43 & 34,99 & 141,54 & 0 & 36,5 & 109,42 & 26,29 & 88,53 & 0 \\
\hline & 29,65 & 178,95 & 7,63 & 158,06 & 3,57 & 36,59 & 133,61 & 37,81 & 112,72 & 0 \\
\hline & 29,68 & 174,06 & 9,98 & 153,17 & 2,15 & 36,93 & 184,93 & 39,28 & 164,04 & 0 \\
\hline & 29,68 & 342,52 & 14,57 & 321,63 & 2,9 & 37,02 & 169,62 & 22,19 & 148,73 & 0 \\
\hline & 29,7 & 311,21 & 6,05 & 290,32 & 1,39 & 37,14 & 158,78 & 20,1 & 137,89 & 0 \\
\hline & 29,71 & 155,74 & 8,42 & 134,85 & 1,38 & 37,2 & 161,23 & 67,65 & 140,34 & 0 \\
\hline & 29,72 & 281,01 & 2,75 & 260,12 & 0,4 & 37,27 & 337,84 & 21,5 & 316,95 & 0 \\
\hline & 29,72 & 91,71 & 3,66 & 70,82 & 0 & 37,49 & 323,5 & 29,42 & 302,61 & 0 \\
\hline & 29,74 & 124,29 & 8,87 & 103,4 & 1,38 & 37,9 & 302,32 & 26,93 & 281,43 & 0 \\
\hline & 29,81 & 288 & 11,5 & 267,11 & 0 & 37,99 & 327 & 18,98 & 306,11 & 2,03 \\
\hline & 30,03 & 327,84 & 20,51 & 306,95 & 0 & 38,1 & 157,27 & 26,57 & 136,38 & 0 \\
\hline & 30,07 & 336,79 & 22 & 315,9 & 0 & 38,21 & 161 & 22,39 & 140,11 & 2,04 \\
\hline & 30,5 & 134,21 & 27,29 & 113,32 & 0 & 38,33 & 158 & 42,24 & 137,11 & 1,63 \\
\hline & 30,7 & 345,74 & 48,44 & 324,85 & 0 & 38,52 & 155,13 & 29,25 & 134,24 & 0 \\
\hline & 30,82 & 337,27 & 68,12 & 316,38 & 0 & 38,63 & 166,36 & 19,29 & 145,47 & 0 \\
\hline & 30,9 & 168,19 & 20,2 & 147,3 & 0 & 38,74 & 148,44 & 25,64 & 127,55 & 0 \\
\hline & 31,05 & 306,17 & 0,8 & 285,28 & 0 & 38,84 & 170 & 25,27 & 149,11 & 0,9 \\
\hline & 31,06 & 344,76 & 45 & 323,87 & 0 & 38,89 & 147 & 25,27 & 126,11 & 1,99 \\
\hline & 31,25 & 45,38 & 7,07 & 24,49 & 1,39 & 39,21 & 346,09 & 31,3 & 325,2 & 0 \\
\hline & 31,25 & 48,23 & 9,31 & 27,34 & 1,37 & 39,45 & 44,35 & 53,18 & 23,46 & 0 \\
\hline & 31,26 & 34,53 & 14,68 & 13,64 & 1,35 & 39,47 & 130 & 6,9 & 109,11 & 0 \\
\hline & 31,29 & 205,65 & 5,14 & 184,76 & 1,39 & 39,48 & 106 & 9,5 & 85,11 & 0 \\
\hline & 31,3 & 14 & 37 & 353,11 & 0 & 40,19 & 128,69 & 16,49 & 107,8 & 0 \\
\hline & 31,35 & 354,97 & 29,16 & 334,08 & 1,75 & 40,24 & 166,69 & 72,59 & 145,8 & 0 \\
\hline
\end{tabular}




\begin{tabular}{|c|c|c|c|c|c|c|c|c|c|c|}
\hline 4505 & Depth & $A z$ & Dip & Dec. & Apert & & & & & \\
\hline & 40,47 & 229 & 24,5 & 208,11 & 2 & 31,06 & 144,93 & 65,1 & 124,04 & 0 \\
\hline & 40,48 & 223 & 21,8 & 202,11 & 0,93 & 31,21 & 149,45 & 65,69 & 128,56 & 0 \\
\hline & 40,56 & 153,87 & 73,14 & 132,98 & 0 & 31,27 & 147,99 & 68,86 & 127,1 & 11,25 \\
\hline & 40,73 & 133,12 & 66,88 & 112,23 & 0 & 31,4 & 147,99 & 68,45 & 127,1 & 0 \\
\hline & 40,81 & 128 & 19,7 & 107,11 & 3,01 & 31,49 & 341,8 & 60,62 & 320,91 & 0 \\
\hline & 40,84 & 132 & 17,6 & 111,11 & 2,09 & 31,49 & 145,46 & 63,97 & 124,57 & 0 \\
\hline & 41,17 & 161,25 & 83,44 & 140,36 & 0 & 31,59 & 156,49 & 68,68 & 135,6 & 0 \\
\hline & 41,82 & 128,23 & 46,23 & 107,34 & 0 & 31,95 & 147,99 & 67,31 & 127,1 & 0 \\
\hline & 41,94 & 149,9 & 33,02 & 129,01 & 0 & 32,14 & 153,3 & 64,26 & 132,41 & $\overline{0}$ \\
\hline & 42,15 & 329,45 & 41,15 & 308,56 & 0 & 32,2 & 151,97 & 66,26 & 131,08 & 0 \\
\hline & 42,28 & 154,87 & 51,12 & 133,98 & 0 & 32,29 & 332,37 & 29,25 & 311,48 & 0 \\
\hline & 42,4 & 265,51 & 15,64 & 244,62 & 0 & 32,46 & 313,38 & 11 & 292,49 & 0 \\
\hline & 42,57 & 320,57 & 28,81 & 299,68 & 0 & 32,48 & 146,92 & 59,33 & 126,03 & $\overline{0}$ \\
\hline & 42,83 & 319,59 & 39,28 & 298,7 & 0 & 32,59 & 155,29 & 61,79 & 134,4 & 0 \\
\hline & 43,13 & 22 & 19,5 & 1,11 & 0 & 32,8 & 150,38 & 55,92 & 129,49 & 0 \\
\hline & 43,25 & 137,12 & 41,09 & 116,23 & 0 & 32,92 & 215 & 10 & 194,11 & 0,59 \\
\hline & 43,46 & 248,05 & 25,27 & 227,16 & 0 & 32,92 & 167,65 & 63,5 & 146,76 & 0 \\
\hline & 43,53 & 57,95 & 79,72 & 37,06 & 0 & 32,94 & 84 & 4 & 63,11 & 2,2 \\
\hline & 43,55 & 150,9 & 54,66 & 130,01 & 0 & 33,06 & 147,45 & 38,52 & 126,56 & 0 \\
\hline & 43,6 & 144,47 & 79,83 & 123,58 & 0 & 33,17 & 331,04 & 41,99 & 310,15 & 0 \\
\hline & 43,72 & 50,28 & 9,76 & 29,39 & 0 & 33,2 & 156,35 & 28,72 & 135,46 & 0 \\
\hline & 43,92 & 235,26 & 22,88 & 214,37 & 0 & 33,24 & 150,38 & 30,11 & 129,49 & 0 \\
\hline 4515 & Depth & Azimuth & Dip & Declinado & Aperture & Depth & Azimuth & Dip & Declinado & Aperture \\
\hline & 26,92 & 173,58 & 41,35 & 152,69 & 0 & 33,34 & 166,72 & 58,53 & 145,83 & 0 \\
\hline & 27,01 & 76,33 & 13,17 & 55,44 & 0 & 33,46 & 124 & 25 & 103,11 & 1,27 \\
\hline & 27,04 & 148,02 & 58,41 & 127,13 & 0 & 33,47 & 143,06 & 61,41 & 122,17 & 0 \\
\hline & 27,06 & 311 & 62,39 & 290,11 & 0 & 33,54 & 137,57 & 51,12 & 116,68 & 0 \\
\hline & 27,09 & 152,8 & 57,51 & 131,91 & 0 & 33,64 & 320,43 & 20,81 & 299,54 & 0 \\
\hline & 27,16 & 335,87 & 53,02 & 314,98 & 0 & 33,66 & 165,67 & 33,02 & 144,78 & 0 \\
\hline & 27,24 & 327,9 & 56,8 & 307,01 & 0 & 33,71 & 156,72 & 54,23 & 135,83 & 0 \\
\hline & 27,32 & 330,4 & 12,63 & 309,51 & 1,56 & 33,72 & 156,3 & 54,11 & 135,41 & 0 \\
\hline & 27,49 & 326 & 4,23 & 305,11 & 0 & 33,8 & 149,31 & 56,97 & 128,42 & 0 \\
\hline & 27,9 & 151,35 & 67,36 & 130,46 & 0 & 33,85 & 150,6 & 57,83 & 129,71 & 0 \\
\hline & 28,21 & 59,23 & 59,53 & 38,34 & 0 & 33,86 & 147,36 & 24,99 & 126,47 & 0 \\
\hline & 28,25 & 235,79 & 2,06 & 214,9 & 0,8 & 33,93 & 150,43 & 44,48 & 129,54 & 1 \\
\hline & 28,25 & 96,58 & 6,73 & 75,69 & 1,39 & 33,99 & 144,42 & 16,91 & 123,53 & 1,34 \\
\hline & 28,26 & 142,94 & 3,89 & 122,05 & 0,8 & 34 & 150,43 & 55,44 & 129,54 & 0 \\
\hline & 28,36 & 154,36 & 47,93 & 133,47 & 0 & 34,08 & 95,46 & 21 & 74,57 & 0 \\
\hline & 28,39 & 231,68 & 69,5 & 210,79 & 0 & 34,11 & 149,87 & 45,68 & 128,98 & 0 \\
\hline & 28,65 & 76 & 3 & 55,11 & 0 & 34,21 & 328,4 & 22 & 307,51 & 0 \\
\hline & 28,84 & 143,47 & 69,91 & 122,58 & 0 & 34,29 & 152,39 & 46,99 & 131,5 & 0 \\
\hline & 29,42 & 165,65 & 53,19 & 144,76 & 0 & 34,33 & 346,52 & 24,51 & 325,63 & 0 \\
\hline & 29,48 & 161,8 & 53,67 & 140,91 & 0 & 34,41 & 339,31 & 33,02 & 318,42 & 0 \\
\hline & 29,64 & 164,12 & 67,21 & 143,23 & 0 & 34,5 & 311,63 & 48,44 & 290,74 & 0 \\
\hline & 29,81 & 220,92 & 17,33 & 200,03 & 0 & 34,56 & 145,26 & 57,17 & 124,37 & 0 \\
\hline & 29,92 & 143,47 & 50,24 & 122,58 & 0 & 34,62 & 149,87 & 51,21 & 128,98 & 0 \\
\hline & 30,12 & 145,99 & 60,51 & 125,1 & 1,08 & 34,65 & 158,82 & 50,47 & 137,93 & 0 \\
\hline & 30,13 & 322,14 & 46,34 & 301,25 & 0 & 34,76 & 149,45 & 15,43 & 128,56 & 1,35 \\
\hline & 30,19 & 142,54 & 43,83 & 121,65 & 1,15 & 34,84 & 333,86 & 28,19 & 312,97 & 0 \\
\hline & 30,19 & 152,9 & 61,4 & 132,01 & 0,77 & \begin{tabular}{|l|}
34,88 \\
\end{tabular} & 325 & 6 & 304,11 & 1,39 \\
\hline & 30,21 & 151,84 & 60,78 & 130,95 & 0 & 34,99 & 159,8 & 49,86 & 138,91 & 0 \\
\hline & 30,24 & 160,21 & 55,88 & 139,32 & 0 & 35,05 & 144 & 43,08 & 123,11 & 0 \\
\hline & 30,29 & 157,28 & 57,7 & 136,39 & 0 & 35,15 & 243 & 12 & 222,11 & 0 \\
\hline & 30,44 & 155,82 & 67,05 & 134,93 & 0 & 35,2 & 330,78 & 36,28 & 309,89 & 0 \\
\hline & 30,62 & 147,99 & 46,12 & 127,1 & 0 & 35,27 & 68 & 12 & 47,11 & 0 \\
\hline & 30,7 & 139,08 & 48,14 & 118,19 & 0 & 35,36 & 326,04 & 22,78 & 305,15 & $\overline{0}$ \\
\hline & 30,82 & 117,96 & 71,61 & 97,07 & 0 & 35,42 & 168,19 & 39,56 & 147,3 & 0 \\
\hline
\end{tabular}




\begin{tabular}{|c|c|c|c|c|c|c|c|c|c|c|}
\hline 4515 & Depth & Azimuth & Dip & Declinado & Aperture & Depth & Azimuth & Dip & Declinado & Aperture \\
\hline & 35,62 & 152,5 & 36,5 & 131,61 & 0 & 39,54 & 52,27 & 70,47 & 31,38 & 0 \\
\hline & 35,69 & 25,03 & 47,73 & 4,14 & 0 & 39,55 & 104,62 & 40,83 & 83,73 & 0 \\
\hline & 35,75 & 153 & 34 & 132,11 & 0 & 39,77 & 158,17 & 66,3 & 137,28 & 1,21 \\
\hline & 35,77 & 356 & 44 & 335,11 & 0 & 39,8 & 155,24 & 30,28 & 134,35 & 2,59 \\
\hline & 35,85 & 342 & 15 & 321,11 & 0 & 39,86 & 35,92 & 63,39 & 15,03 & 1,34 \\
\hline & 35,92 & 51 & 83 & 30,11 & 0 & 39,87 & 353,05 & 59 & 332,16 & 0 \\
\hline & 35,92 & 344 & 58 & 323,11 & 0 & 40,06 & 41,4 & 76,87 & 20,51 & 0 \\
\hline & 36,01 & 346,53 & 19,8 & 325,64 & 1,51 & 40,12 & 141,44 & 63,04 & 120,55 & 0 \\
\hline & 36,05 & 176,48 & 65,26 & 155,59 & 0 & 40,24 & 143,98 & 20,41 & 123,09 & 0 \\
\hline & 36,09 & 335,84 & 71,8 & 314,95 & 0 & 40,27 & 145,97 & 30,03 & 125,08 & 4,5 \\
\hline & 36,09 & 56,65 & 81,73 & 35,76 & 2,01 & 40,28 & 288,45 & 22 & 267,56 & 1,86 \\
\hline & 36,11 & 34,99 & 21,01 & 14,1 & 0 & 40,45 & 314,58 & 26,75 & 293,69 & 0 \\
\hline & 36,13 & 304,36 & 15,32 & 283,47 & 0,77 & 40,6 & 141 & 37 & 120,11 & 0 \\
\hline & 36,31 & 224 & 17 & 203,11 & 0 & 40,76 & 153,35 & 18,47 & 132,46 & 2,46 \\
\hline & 36,36 & 322,49 & 7,18 & 301,6 & 0 & 40,81 & 124,71 & 13,82 & 103,82 & 0 \\
\hline & 36,43 & 315,67 & 43,68 & 294,78 & 0 & 40,86 & 47 & 61,74 & 26,11 & 0,57 \\
\hline & 36,47 & 46,31 & 81,43 & 25,42 & 1,04 & 40,88 & 99,96 & 23,94 & 79,07 & 0,55 \\
\hline & 36,95 & 148 & 69,02 & 127,11 & 0 & 40,88 & 178,53 & 22,98 & 157,64 & 0,55 \\
\hline & 37 & 146,9 & 54,5 & 126,01 & 0 & 40,91 & 97,58 & 15,22 & 76,69 & 1,35 \\
\hline & 37,13 & 151,43 & 50,93 & 130,54 & 0 & 41,06 & 149,87 & 29,25 & 128,98 & 0 \\
\hline & 37,26 & 151,86 & 52,54 & 130,97 & 0 & 41,13 & 144 & 27,56 & 123,11 & 0 \\
\hline & 37,36 & 152,31 & 41,28 & 131,42 & 0 & 41,26 & 155,74 & 30,96 & 134,85 & 0 \\
\hline & 37,38 & 345,27 & 48,09 & 324,38 & 0 & 41,32 & 151,83 & 36,8 & 130,94 & 0 \\
\hline & 37,43 & 336,93 & 52,94 & 316,04 & 0 & 41,42 & 316,52 & 26,93 & 295,63 & 0 \\
\hline & 37,43 & 150,6 & 48,87 & 129,71 & 0 & 41,55 & 136,59 & 23,94 & 115,7 & 0 \\
\hline & 37,51 & 160,74 & 50,57 & 139,85 & 0 & 41,59 & 150,85 & 22,98 & 129,96 & 0,74 \\
\hline & 37,6 & 244,2 & 0,69 & 223,31 & 0 & 41,64 & 153,37 & 56,03 & 132,48 & 1,56 \\
\hline & 37,66 & 343 & 23 & 322,11 & 0 & 41,77 & 248,99 & 32,7 & 228,1 & 1,18 \\
\hline & 37,73 & 151,93 & 51,25 & 131,04 & 0 & 41,88 & 302,82 & 9,2 & 281,93 & 0 \\
\hline & 37,76 & 325,89 & 55,07 & 305 & 0 & 41,97 & 167,63 & 11,09 & 146,74 & 0 \\
\hline & 37,8 & 159,24 & 33,27 & 138,35 & 0 & 42,04 & 332,32 & 2,4 & 311,43 & 0 \\
\hline & 37,85 & 148,89 & 50,29 & 128 & 0 & 42,11 & 325,89 & 23,94 & 305 & 0 \\
\hline & 37,87 & 180 & 33 & 159,11 & 0 & 42,13 & 148 & 23 & 127,11 & 0 \\
\hline & 37,95 & 153,37 & 58,38 & 132,48 & 0 & 42,14 & 147,46 & 64,32 & 126,57 & 0 \\
\hline & 38,07 & 147,36 & 56,35 & 126,47 & 0 & 42,22 & 148,33 & 9,31 & 127,44 & 1,38 \\
\hline & 38,15 & 148,89 & 71,87 & 128 & 0 & 42,22 & 149,87 & 30,63 & 128,98 & 1,2 \\
\hline & 38,19 & 151,41 & 48,99 & 130,52 & 0 & 42,3 & 134 & 24 & 113,11 & 0 \\
\hline & 38,22 & 151,41 & 69,4 & 130,52 & 0 & 42,45 & 147,91 & 1,6 & 127,02 & 0 \\
\hline & 38,22 & 341,69 & 54,54 & 320,8 & 0 & 42,5 & 153,79 & 44,25 & 132,9 & 0 \\
\hline & 38,46 & 136,59 & 12,74 & 115,7 & 0 & 42,6 & 152,81 & 50,47 & 131,92 & 0 \\
\hline & 38,49 & 1,4 & 52,98 & 340,51 & 0 & 42,76 & 329,8 & 67,43 & 308,91 & 0 \\
\hline & 38,58 & 152,81 & 50,19 & 131,92 & 0 & 42,77 & 149,87 & 67,43 & 128,98 & 0 \\
\hline & 38,76 & 154,35 & 49,33 & 133,46 & 0 & 42,89 & 322,97 & 50,29 & 302,08 & 0 \\
\hline & 38,78 & 333,59 & 64,69 & 312,7 & 0 & 42,91 & 157,74 & 70,83 & 136,85 & 0 \\
\hline & 38,9 & 131 & 14 & 110,11 & 0 & 43,02 & 149,35 & 47,31 & 128,46 & 1,22 \\
\hline & 39,09 & 144 & 4,46 & 123,11 & 0 & 43,05 & 151,28 & 39,31 & 130,39 & 0,62 \\
\hline & 39,09 & 339,59 & 59,53 & 318,7 & 0 & 43,05 & 154,27 & 39,01 & 133,38 & 0,78 \\
\hline & 39,1 & 155 & 35,9 & 134,11 & 1,78 & 43,06 & 153,26 & 38,45 & 132,37 & 0,63 \\
\hline & 39,16 & 337,77 & 53,02 & 316,88 & 0 & 43,09 & 142,41 & 27,11 & 121,52 & 0,71 \\
\hline & 39,21 & 155,27 & 67,75 & 134,38 & 0 & 43,1 & 148,9 & 52,73 & 128,01 & 0 \\
\hline & 39,25 & 325,52 & 54,69 & 304,63 & 0 & 43,22 & 147,89 & 25,83 & 127 & 0 \\
\hline & 39,27 & 144,45 & 48,89 & 123,56 & 0 & 43,29 & 155,28 & 33,1 & 134,39 & 0,84 \\
\hline & 39,3 & 153,73 & 63,62 & 132,84 & 0 & 43,33 & 160,76 & 35,83 & 139,87 & 0 \\
\hline & 39,42 & 156,26 & 77,27 & 135,37 & 0 & 43,48 & 151,81 & 51,61 & 130,92 & 0 \\
\hline & 39,45 & 132,05 & 40,37 & 111,16 & 0 & 43,59 & 152,37 & 57,07 & 131,48 & 0 \\
\hline & 39,45 & 340,82 & 67,8 & 319,93 & 0 & 43,62 & 151,81 & 18,16 & 130,92 & 0 \\
\hline & 39,47 & 9,79 & 54,46 & 348,9 & 0 & 43,75 & 332 & 19 & 311,11 & 0,75 \\
\hline
\end{tabular}




\begin{tabular}{|c|c|c|c|c|c|c|c|c|c|c|}
\hline 4515 & Depth & Azimuth & Dip & Declinado & Aperture & Depth & Azimuth & Dip & Declinado & Aperture \\
\hline & 43,84 & 171,05 & 27,92 & 150,16 & 0 & 47,49 & 137,57 & 37,31 & 116,68 & 0 \\
\hline & 43,89 & 156,26 & 55,68 & 135,37 & 0 & 47,51 & 145,26 & 49,84 & 124,37 & 0 \\
\hline & 43,9 & 143,42 & 22,88 & 122,53 & 0 & 47,53 & 122,78 & 22,69 & 101,89 & 0 \\
\hline & 43,92 & 295,67 & 36,87 & 274,78 & 0 & 47,57 & 150,92 & 50,19 & 130,03 & 0 \\
\hline & 43,93 & 157,74 & 53,79 & 136,85 & 0 & 47,58 & 127,64 & 10,87 & 106,75 & 0 \\
\hline & 44,01 & 154,38 & 59,42 & 133,49 & 0 & 47,66 & 78,85 & 10,42 & 57,96 & 0 \\
\hline & 44,16 & 149,41 & 67,88 & 128,52 & 0 & 47,71 & 103,88 & 14,68 & 82,99 & 0 \\
\hline & 44,35 & 153,38 & 57,34 & 132,49 & 0 & 47,84 & 164,13 & 53,87 & 143,24 & 0 \\
\hline & 44,71 & 155,28 & 29,07 & 134,39 & \begin{tabular}{l|l}
0 \\
\end{tabular} & 47,98 & 148,89 & 35,22 & 128 & 1,14 \\
\hline & 44,71 & 159,75 & 59,56 & 138,86 & 0 & 47,99 & 160,78 & 54,15 & 139,89 & 0 \\
\hline & 44,78 & 350 & 37,67 & 329,11 & 0,63 & 48,11 & 30,81 & 6,28 & 9,92 & 0 \\
\hline & 44,89 & 146,1 & 57 & 125,21 & 0 & 48,13 & 174,48 & 17,54 & 153,59 & 1,53 \\
\hline & 45,05 & 321,55 & 6,84 & 300,66 & 0 & 48,16 & 179,09 & 66,46 & 158,2 & 0 \\
\hline & 45,24 & 170 & 55 & 149,11 & 0 & 48,17 & 148,47 & 49,33 & 127,58 & 1,3 \\
\hline & 45,34 & 134,63 & 25,92 & 113,74 & 0 & 48,22 & 162,31 & 36,28 & 141,42 & 0 \\
\hline & 45,36 & 145,96 & 62,73 & 125,07 & 0 & 48,24 & 162,59 & 38,38 & 141,7 & 1,1 \\
\hline & 45,42 & 227,32 & 59,94 & 206,43 & 0 & 48,32 & 305,76 & 37,81 & 284,87 & 0 \\
\hline & 45,52 & 153,79 & 41,86 & 132,9 & 0 & 48,33 & 150,71 & 53,91 & 129,82 & 0 \\
\hline & 45,56 & 151,97 & 43,41 & 131,08 & 0 & 48,41 & 148,33 & 38,59 & 127,44 & 2,34 \\
\hline & 45,57 & 324,91 & 27,56 & 304,02 & 0 & 48,5 & 331,9 & 4,46 & 311,01 & 0 \\
\hline & 45,64 & 103,04 & 13,49 & 82,15 & 0 & 48,51 & 143,44 & 25,45 & 122,55 & 0 \\
\hline & 45,67 & 144,98 & 59,86 & 124,09 & 0 & 48,59 & 141,9 & 63,71 & 121,01 & 0 \\
\hline & 45,71 & 352,45 & 79,11 & 331,56 & \begin{tabular}{l|l}
0 \\
\end{tabular} & 48,67 & 153,79 & 54,69 & 132,9 & 0 \\
\hline & 45,79 & 161 & 52,77 & 140,11 & \begin{tabular}{l|l}
0 \\
\end{tabular} & 48,82 & 49,21 & 65,4 & 28,32 & 0 \\
\hline & 45,86 & 326,87 & 20,51 & 305,98 & \begin{tabular}{l|l}
0 \\
\end{tabular} & 48,84 & 147,91 & 60,34 & 127,02 & 0 \\
\hline & 45,98 & 150,43 & 36,28 & 129,54 & 0 & 48,88 & 147,91 & 21,6 & 127,02 & 0 \\
\hline & 46,05 & 156,3 & 30,63 & 135,41 & 0 & 48,93 & 147,91 & 46,45 & 127,02 & 0 \\
\hline & 46,09 & 163,58 & 21,01 & 142,69 & 0 & 49,08 & 302,6 & 25,27 & 281,71 & 0 \\
\hline & 46,11 & 154,35 & 25,27 & 133,46 & 0 & 49,16 & 335,25 & 23,36 & 314,36 & 0 \\
\hline & 46,18 & 153,79 & 27,83 & 132,9 & 0 & 49,16 & 162,73 & 29,42 & 141,84 & 0 \\
\hline & 46,26 & 149,45 & 22,59 & 128,56 & 1,29 & 49,19 & 148,4 & 75,79 & 127,51 & 0 \\
\hline & 46,26 & 322,95 & 9,2 & 302,06 & 0 & 49,29 & 147,91 & 22,29 & 127,02 & 0 \\
\hline & 46,29 & 146,48 & 32,94 & 125,59 & 0 & 49,32 & 46,83 & 52,56 & 25,94 & 0 \\
\hline & 46,32 & 156,67 & 61,48 & 135,78 & \begin{tabular}{l|l}
0,38 \\
\end{tabular} & 49,44 & 142,11 & 56,04 & 121,22 & 0 \\
\hline & 46,36 & 161,22 & 60,26 & 140,33 & 0,4 & 49,46 & 155,88 & 45,62 & 134,99 & 0 \\
\hline & 46,4 & 163,24 & 65,63 & 142,35 & \begin{tabular}{l|l}
0,33 \\
\end{tabular} & 49,53 & 152,81 & 58,78 & 131,92 & 0 \\
\hline & 46,41 & 40,42 & 6,16 & 19,53 & 0,8 & 49,63 & 163 & 26,93 & 142,11 & 1,96 \\
\hline & 46,47 & 169,06 & 68,69 & 148,17 & \begin{tabular}{l|l}
0,58 \\
\end{tabular} & 49,72 & 149,45 & 60,76 & 128,56 & 0 \\
\hline & 46,51 & 147,9 & 23,75 & 127,01 & 0 & 49,9 & 172 & 7 & 151,11 & 0,79 \\
\hline & 46,54 & 169,34 & 62,86 & 148,45 & 0,36 & 50,04 & 229 & 9 & 208,11 & 0 \\
\hline & 46,54 & 159,19 & 19,7 & 138,3 & 0 & 50,1 & 155 & 18 & 134,11 & 0 \\
\hline & 46,62 & 161,69 & 12,19 & 140,8 & \begin{tabular}{l|l}
0 \\
\end{tabular} & 50,16 & 146 & 29 & 125,11 & 0 \\
\hline & 46,65 & 156,82 & 35,53 & 135,93 & \begin{tabular}{l|l}
0 \\
\end{tabular} & 50,24 & 229 & 10 & 208,11 & 0 \\
\hline & 46,74 & 143,02 & 21,9 & 122,13 & 0 & 50,24 & 343 & 28 & 322,11 & 0 \\
\hline & 46,77 & 83,74 & 11,97 & 62,85 & 0 & 50,26 & 161 & 12 & 140,11 & 0 \\
\hline & 46,86 & 157,28 & 54,69 & 136,39 & 0 & 50,28 & 153 & 27,83 & 132,11 & 0 \\
\hline & 46,91 & 158,26 & 54,38 & 137,37 & 0 & 50,31 & 135 & 25,45 & 114,11 & 0 \\
\hline & 46,95 & 152,81 & 47,36 & 131,92 & 0 & 50,35 & 159,8 & 57,57 & 138,91 & 0 \\
\hline & 47,05 & 133,1 & 38,59 & 112,21 & 0 & 50,35 & 241 & 4 & 220,11 & 0 \\
\hline & 47,08 & 111,29 & 41,48 & 90,4 & 0 & 50,37 & 80 & 2 & 59,11 & 0 \\
\hline & 47,15 & 301,28 & 10,87 & 280,39 & 0 & 50,39 & 80 & 6 & 59,11 & 0 \\
\hline & 47,16 & 135,61 & 16,59 & 114,72 & 0 & 50,44 & 72 & 7 & 51,11 & 0 \\
\hline & 47,18 & 162,73 & 15,75 & 141,84 & 1,35 & 50,5 & 135 & 27 & 114,11 & 0 \\
\hline & 47,28 & 147,5 & 44,01 & 126,61 & 0 & 50,57 & 120 & 13 & 99,11 & 0 \\
\hline & 47,33 & 150,43 & 55,99 & 129,54 & \begin{tabular}{l|l}
0,78 \\
\end{tabular} & 50,62 & 119 & 10 & 98,11 & 0 \\
\hline & 47,37 & 144,42 & 52,39 & 123,53 & 0 & 50,66 & 199 & 26,75 & 178,11 & 0 \\
\hline & 47,44 & 11,32 & 6,5 & 350,43 & 0 & 50,67 & 96 & 17 & 75,11 & 0 \\
\hline
\end{tabular}




\begin{tabular}{|c|c|c|c|c|c|c|c|c|c|c|}
\hline 4515 & Depth & Azimuth & Dip & Declinado & Aperture & Depth & Azimuth & Dip & Declinado & Aperture \\
\hline & 50,84 & 142 & 16,17 & 121,11 & 0 & 54,63 & 55,13 & 57,21 & 34,24 & 0 \\
\hline & 50,92 & 152 & 34,84 & 131,11 & 0 & 54,66 & 151,8 & 62,49 & 130,91 & 0 \\
\hline & 51,02 & 149,59 & 42,24 & 128,7 & 2,66 & 54,73 & 151,8 & 53,91 & 130,91 & 0 \\
\hline & 51,05 & 144,42 & 40,23 & 123,53 & 0 & 54,77 & 150,92 & 49,77 & 130,03 & 0 \\
\hline & 51,31 & 131,7 & 47,57 & 110,81 & 0 & 54,95 & 151,8 & 30,8 & 130,91 & 0 \\
\hline & 51,45 & 174,48 & 44,01 & 153,59 & 0 & 54,98 & 155,83 & 31,05 & 134,94 & 0 \\
\hline & 51,51 & 46,31 & 78,14 & 25,42 & 0 & 55 & 152,31 & 32,37 & 131,42 & 0 \\
\hline & 51,55 & 151,8 & 19,39 & 130,91 & 0 & 55,03 & 145,89 & 30,11 & 125 & 0 \\
\hline & 51,58 & 159,73 & 26,2 & 138,84 & 0 & 55,07 & 140,71 & 29 & \begin{tabular}{|l|}
119,82 \\
\end{tabular} & 0 \\
\hline & 51,65 & 160,24 & 58,22 & 139,35 & 0 & 55,1 & 321 & 16 & 300,11 & 0 \\
\hline & 51,75 & 157,34 & 12,73 & 136,45 & 0,78 & 55,16 & 144,5 & 7,18 & 123,61 & 0 \\
\hline & 51,8 & 161,24 & 49,82 & 140,35 & 0,52 & 55,25 & 155,41 & 53,67 & 134,52 & 0 \\
\hline & 51,81 & 159,1 & 51,65 & 138,21 & 0,5 & 55,38 & 170,06 & 54,65 & 149,17 & 0,46 \\
\hline & 51,83 & 331,93 & 4,92 & 311,04 & 0 & 55,4 & 150 & 40,16 & 129,11 & 0,61 \\
\hline & 51,83 & 154,32 & 56,13 & 133,43 & 0 & 55,42 & 159,23 & 33,66 & 138,34 & 0 \\
\hline & 51,96 & 151,86 & 27,7 & 130,97 & 0 & 55,43 & 359 & 29,94 & 338,11 & 1,39 \\
\hline & 52 & 145,51 & 52,64 & 124,62 & 0,48 & 55,49 & 44 & 13,71 & 23,11 & 0,78 \\
\hline & 52,04 & 170,56 & 38,87 & 149,67 & 3,11 & 55,49 & 318,41 & 13,28 & 297,52 & 1,57 \\
\hline & 52,16 & 226,2 & 7,18 & 205,31 & 1,59 & 55,51 & 266 & 32 & 245,11 & 0 \\
\hline & 52,22 & 244,57 & 44,65 & 223,68 & 0 & 55,59 & 117,31 & 21,01 & 96,42 & 0 \\
\hline & 52,25 & 161,24 & 28,1 & 140,35 & 1,41 & 55,59 & 345,37 & 23,94 & 324,48 & 0 \\
\hline & 52,26 & 351,57 & 13,71 & 330,68 & 0 & 55,61 & 352,91 & 22,2 & 332,02 & 0 \\
\hline & 52,32 & 158,85 & 32,46 & 137,96 & 0 & 55,63 & 352,04 & 24,51 & 331,15 & 0 \\
\hline & 52,4 & 145,94 & 45,34 & 125,05 & 0 & 55,65 & 10 & 37 & 349,11 & 0 \\
\hline & 52,45 & 140,02 & 31,3 & 119,13 & 0 & 55,66 & 151 & 46 & 130,11 & 0 \\
\hline & 52,47 & 40,53 & 70,53 & 19,64 & 0 & 55,72 & 155 & 63 & 134,11 & 0 \\
\hline & 52,47 & 136,07 & 32,13 & 115,18 & 0 & 55,84 & 142,05 & 35 & 121,16 & 0 \\
\hline & 52,5 & 113,54 & 28,01 & 92,65 & 0 & 55,95 & 146 & 38 & 125,11 & 0 \\
\hline & 52,56 & 57,65 & 31,13 & 36,76 & 0 & 56,02 & 150 & 37 & 129,11 & 0 \\
\hline & 52,63 & 147,4 & 64,02 & 126,51 & 0 & 56,04 & 153 & 40 & 132,11 & 0 \\
\hline & 52,7 & 149,92 & 63,44 & 129,03 & 0 & 56,1 & 146,9 & 56,27 & 126,01 & 0 \\
\hline & 52,78 & 339,86 & 28,72 & 318,97 & 0 & 56,15 & 315,57 & 38,1 & 294,68 & 0 \\
\hline & 52,8 & 155,33 & 61,61 & 134,44 & 0 & 56,22 & 100 & 28 & 79,11 & 0 \\
\hline & 52,9 & 153,99 & 43,59 & 133,1 & 0 & 56,26 & 101 & 30 & 80,11 & 0 \\
\hline & 53,11 & 149,92 & 17,01 & 129,03 & 0 & 56,29 & 313 & 19 & 292,11 & 0 \\
\hline & 53,17 & 333,74 & 53,83 & 312,85 & 0 & 56,33 & 331 & 36,8 & 310,11 & 0 \\
\hline & 53,18 & 275,29 & 17,12 & 254,4 & 0 & 56,33 & 314,69 & 1,72 & 293,8 & 0 \\
\hline & 53,24 & 170,18 & 65,28 & 149,29 & 0 & 56,4 & 138 & 55,15 & 117,11 & 0 \\
\hline & 53,26 & 155,83 & 41,28 & 134,94 & 0 & 56,44 & 143,37 & 70,49 & 122,48 & 0 \\
\hline & 53,33 & 154,99 & 50,19 & 134,1 & 0 & 56,44 & 334,39 & 54,69 & 313,5 & 0 \\
\hline & 53,36 & 138,46 & 31,72 & 117,57 & 0 & 56,49 & 143,01 & 25,64 & 122,12 & 0 \\
\hline & 53,36 & 133,05 & 30,8 & 112,16 & 0 & 56,51 & 140,62 & 70,11 & 119,73 & 0 \\
\hline & 53,42 & 154,83 & 30,96 & 133,94 & 0 & 56,59 & 147,48 & 39,08 & 126,59 & 0 \\
\hline & 53,44 & 350,11 & 16,28 & 329,22 & 0 & 56,64 & 148,41 & 41,99 & 127,52 & 0 \\
\hline & 53,52 & 337,34 & 45,9 & 316,45 & 0 & 56,67 & 144 & 25,55 & 123,11 & 0 \\
\hline & 53,58 & 321,31 & 49,24 & 300,42 & 0 & 56,74 & 143,9 & 50,52 & 123,01 & 0 \\
\hline & 53,59 & 45,08 & 17,33 & 24,19 & 0 & 56,78 & 138,08 & 70,64 & 117,19 & 0 \\
\hline & 53,72 & 324 & 56 & 303,11 & 0 & 56,79 & 131,52 & 49,96 & 110,63 & 0 \\
\hline & 53,78 & 329 & 28,01 & 308,11 & \begin{tabular}{l|}
0,7 \\
\end{tabular} & 56,93 & 64 & 6,62 & 43,11 & 0 \\
\hline & 53,82 & 339 & 18,16 & 318,11 & 2,09 & 57 & 321,57 & 38,8 & 300,68 & 0 \\
\hline & 54,05 & 325,51 & 44,19 & 304,62 & 0 & 57,03 & 323,02 & 2,75 & 302,13 & 0,6 \\
\hline & 54,15 & 145,89 & 11,09 & 125 & 0 & 57,05 & 332,83 & 7,97 & 311,94 & 1,19 \\
\hline & 54,26 & 51,73 & 58,84 & 30,84 & 0 & 57,09 & 354 & 12 & 333,11 & 1,18 \\
\hline & 54,28 & 46,32 & 55,99 & 25,43 & 0 & 57,15 & 341,67 & 37,74 & 320,78 & 0 \\
\hline & 54,37 & 124,24 & 20,61 & 103,35 & 0 & 57,21 & 329,93 & 38,52 & 309,04 & 0 \\
\hline & 54,45 & 148,41 & 3,09 & 127,52 & 0 & 57,27 & 145,83 & 32,78 & 124,94 & 0 \\
\hline & 54,5 & 146,9 & 63,16 & 126,01 & 0 & 57,28 & 346,09 & 13,28 & 325,2 & 0 \\
\hline
\end{tabular}




\begin{tabular}{|c|c|c|c|c|c|c|c|c|c|c|}
\hline 4515 & Depth & Azimuth & Dip & Declinado & Aperture & Depth & Azimuth & Dip & Declinado & Aperture \\
\hline & 57,33 & 155,22 & 15,22 & 134,33 & 0 & 62,54 & 329,29 & 25,55 & 308,4 & 0 \\
\hline & 57,47 & 331 & 30,96 & 310,11 & 0 & 62,55 & 149,66 & 75,79 & 128,77 & 0 \\
\hline & 57,69 & 149,37 & 53,27 & 128,48 & 0 & 62,56 & 185,39 & 41,09 & 164,5 & 0 \\
\hline & 57,81 & 142,46 & 46,78 & 121,57 & 0 & 62,61 & 17 & 32,46 & 356,11 & 1,52 \\
\hline & 57,89 & 152,26 & 50,93 & 131,37 & 0 & 62,68 & 148,89 & 59,8 & 128 & 0 \\
\hline & 57,92 & 147,92 & 1,03 & 127,03 & 0 & 62,78 & 316,11 & 24,7 & 295,22 & 0 \\
\hline & 58,01 & 142,46 & 52,56 & 121,57 & 0 & 62,82 & 319,48 & 24,13 & 298,59 & 0 \\
\hline & 58,07 & 329,29 & 2,06 & 308,4 & 0 & 62,86 & 318,03 & 29,94 & 297,14 & 0 \\
\hline & 58,2 & 144,39 & 30,79 & 123,5 & 0 & 62,88 & 313,53 & 29,16 & 292,64 & 0 \\
\hline & 58,25 & 147,92 & 39,21 & 127,03 & 0 & 62,94 & 49,68 & 44,83 & 28,79 & 0 \\
\hline & 58,38 & 150,82 & 42,8 & 129,93 & 0 & 62,94 & 42,93 & 34,29 & 22,04 & 0 \\
\hline & 58,44 & 155,32 & 48,64 & 134,43 & 0 & 62,99 & 158,21 & 43,41 & 137,32 & 0 \\
\hline & 58,58 & 153,23 & 40,03 & 132,34 & 0 & 63,06 & 156,28 & 37,67 & 135,39 & 0 \\
\hline & 58,6 & 153,61 & 42,36 & 132,72 & 0,94 & 63,12 & 330 & 29,77 & 309,11 & 1,22 \\
\hline & 58,61 & 328,81 & 24,42 & 307,92 & 1,09 & 63,14 & 150,82 & 51,38 & 129,93 & 0 \\
\hline & 58,74 & 342,64 & 23,56 & 321,75 & 0 & 63,46 & 18 & 30,11 & 357,11 & 1,56 \\
\hline & 58,75 & 159,02 & 58,93 & 138,13 & 0 & 63,52 & 151,78 & 61,4 & 130,89 & 0 \\
\hline & 58,91 & 17,2 & 16,07 & 356,31 & 0 & 63,7 & 63,35 & 57 & 42,46 & 0 \\
\hline & 58,98 & 26,05 & 17,12 & 5,16 & 0 & 63,76 & 144,87 & 64 & 123,98 & 0 \\
\hline & 59,06 & 38,91 & 38,59 & 18,02 & 0 & 63,92 & 156,77 & 57,51 & 135,88 & 0 \\
\hline & 59,08 & 182,81 & 69,68 & 161,92 & 0 & 64,09 & 155,8 & 32,78 & 134,91 & 0 \\
\hline & 59,1 & 45,34 & 58,31 & 24,45 & 0 & 64,11 & 320,45 & 33,5 & 299,56 & 0 \\
\hline & 59,12 & 16,93 & 35 & 356,04 & 0 & 64,21 & 320,13 & 19,9 & 299,24 & 1,13 \\
\hline & 59,14 & 9,16 & 23,56 & 348,27 & 0 & 64,25 & 7,88 & 19,29 & 346,99 & 1,13 \\
\hline & 59,36 & 10 & 42,11 & 349,11 & 0 & 64,29 & 333,31 & 30,54 & 312,42 & 1,72 \\
\hline & 59,41 & 12 & 34 & 351,11 & 0 & 64,35 & 337,81 & 44,42 & 316,92 & 1,71 \\
\hline & 59,51 & 46 & 53,43 & 25,11 & 0,72 & 64,47 & 337,81 & 75,33 & 316,92 & 0 \\
\hline & 59,68 & 355,34 & 39,83 & 334,45 & 0 & 64,56 & 337,33 & 23,17 & 316,44 & 0 \\
\hline & 59,74 & 317,09 & 40,7 & 296,2 & 0 & & & & & \\
\hline & 59,83 & 33,93 & 62,41 & 13,04 & 0,56 & & & & & \\
\hline & 59,85 & 338,29 & 29,6 & 317,4 & 0 & & & & & \\
\hline & 59,91 & 353,57 & 34,68 & 332,68 & 0,98 & & & & & \\
\hline & 60,2 & 33 & 48,84 & 12,11 & 0 & & & & & \\
\hline & 60,26 & 60,29 & 45,23 & 39,4 & 0 & & & & & \\
\hline & 60,47 & 141,81 & 56,73 & 120,92 & 0 & & & & & \\
\hline & 60,73 & 188,76 & 16,91 & 167,87 & 0 & & & & & \\
\hline & 60,78 & 171,56 & 29,42 & 150,67 & 0,52 & & & & & \\
\hline & 60,86 & 241,02 & 21,6 & 220,13 & 0 & & & & & \\
\hline & 60,91 & 46 & 42,74 & 25,11 & 0 & & & & & \\
\hline & 61,08 & 32,48 & 46,67 & 11,59 & 0 & & & & & \\
\hline & 61,13 & 155,32 & 73,7 & 134,43 & 0 & & & & & \\
\hline & 61,19 & 0 & 51,91 & 339,11 & 0 & & & & & \\
\hline & 61,23 & 134,58 & 63,73 & 113,69 & 0 & & & & & \\
\hline & 61,29 & 153,2 & 33,74 & 132,31 & 0 & & & & & \\
\hline & 61,41 & 336 & 37 & 315,11 & 0 & & & & & \\
\hline & 61,42 & 155 & 48,99 & 134,11 & 0 & & & & & \\
\hline & 61,52 & 334,88 & 41,86 & 313,99 & 1,79 & & & & & \\
\hline & 61,79 & 324,95 & 26,75 & 304,06 & 0 & & & & & \\
\hline & 61,9 & 147,92 & 47,2 & 127,03 & 0 & & & & & \\
\hline & 62,08 & 151 & 49,53 & 130,11 & 0 & & & & & \\
\hline & 62,14 & 303 & 6,39 & 282,11 & 0 & & & & & \\
\hline & 62,23 & 26,53 & 17,64 & 5,64 & 0 & & & & & \\
\hline & 62,25 & 31,51 & 36,58 & 10,62 & 0,48 & & & & & \\
\hline & 62,26 & 32,96 & 28,63 & 12,07 & 1,05 & & & & & \\
\hline & 62,4 & 39 & 57,27 & 18,11 & 0 & & & & & \\
\hline & 62,48 & 327,84 & 44,83 & 306,95 & 0 & & & & & \\
\hline & 62,5 & 93,58 & 5,5 & 72,69 & 0 & & & & & \\
\hline
\end{tabular}




\begin{tabular}{|c|c|c|c|c|c|c|c|c|c|c|}
\hline 4528 & Depth & Azimuth & Dip & Declinado & Aperture & Depth & Azimuth & Dip & Declinado & Aperture \\
\hline & 20,44 & 124,66 & 10,31 & 103,77 & 0 & 26,62 & 156,13 & 77,54 & 135,24 & 0 \\
\hline & 20,68 & 47,73 & 17,22 & 26,84 & 0 & 26,94 & 340,4 & 77 & 319,51 & 0 \\
\hline & 20,81 & 191,04 & 57,77 & 170,15 & 0 & 27,08 & 331,31 & 79,03 & 310,42 & 0 \\
\hline & 20,94 & 200,39 & 74,16 & 179,5 & 0 & 27,11 & 55,5 & 86,29 & 34,61 & 0 \\
\hline & 20,94 & 72,1 & 15,38 & 51,21 & 0 & 27,25 & 334,71 & 78,22 & 313,82 & 0 \\
\hline & 21,15 & 148,67 & 75,72 & 127,78 & 0 & 27,34 & 343 & 45 & 322,11 & 0 \\
\hline & 21,2 & 60,17 & 22,29 & 39,28 & 0 & 27,44 & 161,77 & 23,36 & 140,88 & 0 \\
\hline & 21,43 & 142,86 & 59,46 & 121,97 & 0 & 27,56 & 172,14 & 62,27 & 151,25 & 0 \\
\hline & 21,51 & 148,67 & 23,27 & 127,78 & 0 & 27,62 & 255,03 & 44 & 234,14 & 0 \\
\hline & 21,57 & 330,17 & 31,38 & 309,28 & 0 & 28,12 & 151,95 & 38,45 & 131,06 & 0 \\
\hline & 21,59 & 158,67 & 30,11 & 137,78 & 0 & 28,27 & 148,41 & 48,29 & 127,52 & 0 \\
\hline & 21,7 & 332,65 & 61,86 & 311,76 & 0 & 28,42 & 156,45 & 77,27 & 135,56 & 0 \\
\hline & 21,71 & 148,5 & 31,47 & 127,61 & 0 & 28,6 & 156,63 & 71,36 & 135,74 & 0 \\
\hline & 21,73 & 147,91 & 23,85 & 127,02 & 0 & 28,75 & 68,62 & 12,95 & 47,73 & 0 \\
\hline & 21,74 & 148,8 & 41,15 & 127,91 & 0 & 28,84 & 341,04 & 21,06 & 320,15 & 0 \\
\hline & 21,79 & 145,07 & 40,36 & 124,18 & 0 & 28,97 & 160,74 & 37,6 & 139,85 & 0 \\
\hline & 21,81 & 142,86 & 76,55 & 121,97 & 0 & 29,06 & 287,39 & 29,25 & 266,5 & 1,75 \\
\hline & 22,26 & 156,39 & 50,98 & 135,5 & 0 & 29,08 & 273 & 21,41 & 252,11 & 1,12 \\
\hline & 22,28 & 145,07 & 76,15 & 124,18 & 0 & 29,09 & 343 & 15 & 322,11 & 1,16 \\
\hline & 22,44 & 329,97 & 43,08 & 309,08 & 0 & 29,32 & 142,86 & 52,11 & 121,97 & 0 \\
\hline & 22,59 & 153,87 & 61,03 & 132,98 & 0 & 29,48 & 149,5 & 67,8 & 128,61 & 0 \\
\hline & 22,62 & 143,7 & 79,35 & 122,81 & 0 & 29,67 & 160,88 & 64,32 & 139,99 & 0 \\
\hline & 22,86 & 152,35 & 78,58 & 131,46 & 0 & 29,84 & 149,5 & 66,77 & 128,61 & 0 \\
\hline & 23,09 & 159,93 & 65,94 & 139,04 & 0 & 30,13 & 44,88 & 19,55 & 23,99 & 0 \\
\hline & 23,25 & 0,56 & 19,19 & 339,67 & 0 & 30,13 & 340,4 & 55,68 & 319,51 & 0 \\
\hline & 23,28 & 161,78 & 2,98 & 140,89 & 0 & 30,15 & 119,47 & 30,54 & 98,58 & 0 \\
\hline & 23,32 & 144,96 & 52,35 & 124,07 & 0 & 30,23 & 1,26 & 21,06 & 340,37 & 0 \\
\hline & 23,32 & 144,4 & 42,86 & 123,51 & 0 & 30,37 & 338,19 & 14,84 & 317,3 & 0 \\
\hline & 23,42 & 147,43 & 17,12 & 126,54 & 0 & 30,58 & 67,96 & 0,69 & 47,07 & 0 \\
\hline & 23,42 & 142,21 & 56,31 & 121,32 & 0 & 30,67 & 334,79 & 41,48 & 313,9 & 0 \\
\hline & 23,64 & 348,07 & 3,43 & 327,18 & 0 & 30,76 & 330,85 & 69,34 & 309,96 & 0 \\
\hline & 23,66 & 145,48 & 74,5 & 124,59 & 0 & 30,85 & 179,25 & 3,89 & 158,36 & 0 \\
\hline & 23,68 & 321,88 & 57,37 & 300,99 & 0 & 30,86 & 245,23 & 9,65 & 224,34 & 0 \\
\hline & 23,91 & 331,38 & 22,59 & 310,49 & 0 & 31,07 & 39,1 & 26,66 & 18,21 & 2,5 \\
\hline & 23,92 & 145,48 & 78 & 124,59 & 0 & 31,21 & 335,62 & 15,43 & 314,73 & 1,93 \\
\hline & 24,15 & 154,3 & 61,21 & 133,41 & 0 & 31,25 & 264,01 & 9,98 & 243,12 & 2,76 \\
\hline & 24,27 & 149,91 & 54,66 & 129,02 & 0 & 31,45 & 308,57 & 24,32 & 287,68 & 0 \\
\hline & 24,28 & 315,13 & 14,9 & 294,24 & 0 & 31,67 & 335,64 & 67,63 & 314,75 & 0 \\
\hline & 24,45 & 151,71 & 68,12 & 130,82 & 0 & 31,7 & 11,49 & 34,14 & 350,6 & 0 \\
\hline & 24,58 & 331,55 & 61,15 & 310,66 & 0 & 31,77 & 320,18 & 40,86 & 299,29 & 0 \\
\hline & 24,6 & 150,95 & 76,5 & 130,06 & 0 & 31,84 & 152 & 8 & 131,11 & 1,39 \\
\hline & 24,66 & 324,89 & 33,74 & 304 & 0 & 31,85 & 146 & 12,41 & 125,11 & 1,16 \\
\hline & 24,75 & 153,15 & 77,36 & 132,26 & 0 & 31,94 & 328,67 & 45,57 & 307,78 & 0 \\
\hline & 25,13 & 325,95 & 72,23 & 305,06 & 0 & 32,05 & 267,09 & 7,97 & 246,2 & 0 \\
\hline & 25,77 & 221,55 & 81,57 & 200,66 & 0 & 32,21 & 341,35 & 37,95 & 320,46 & 0 \\
\hline & 25,78 & 56 & 84,99 & 35,11 & 0 & 32,32 & 331,13 & 54,69 & 310,24 & 0 \\
\hline & 25,81 & 333,15 & 58,31 & 312,26 & 0 & 32,33 & 157,62 & 73,33 & 136,73 & 0 \\
\hline & 25,83 & 153,15 & 76,28 & 132,26 & 0 & 32,39 & 97 & 27,11 & 76,11 & 0 \\
\hline & 25,88 & 16,05 & 56 & 355,16 & 0 & 32,41 & 280,83 & 14,68 & 259,94 & 0 \\
\hline & 25,99 & 159,12 & 77,98 & 138,23 & 0 & 32,52 & 151,71 & 28,59 & 130,82 & 0 \\
\hline & 26,1 & 159 & 53,27 & 138,11 & 1,44 & 32,54 & 147,84 & 44,19 & 126,95 & 0 \\
\hline & 26,13 & 271,63 & 77,54 & 250,74 & 0 & 32,61 & 155,19 & 51 & 134,3 & 0 \\
\hline & 26,2 & 295 & 45 & 274,11 & 0 & 32,62 & 159,61 & 68,78 & 138,72 & 0 \\
\hline & 26,21 & 325,92 & 62 & 305,03 & 0 & 32,7 & 144,7 & 71,85 & 123,81 & 0 \\
\hline & 26,27 & 33,98 & 75,06 & 13,09 & 0 & 32,78 & 128,32 & 66,9 & 107,43 & 0 \\
\hline & 26,43 & 239 & 47,41 & 218,11 & 0 & 32,99 & 30,77 & 78,86 & 9,88 & 0 \\
\hline & 26,44 & 325,19 & 73,43 & 304,3 & 0 & 33,06 & 319,23 & 9,09 & 298,34 & 0 \\
\hline
\end{tabular}




\begin{tabular}{|c|c|c|c|c|c|c|c|c|c|c|}
\hline 4528 & Depth & Azimuth & Dip & Declinado & Aperture & Depth & Azimuth & Dip & Declinado & Aperture \\
\hline & 33,39 & 142,06 & 48,84 & 121,17 & 0 & 27,43 & 140,44 & 61,07 & 119,55 & 0 \\
\hline & 33,59 & 332,67 & 79,22 & 311,78 & 0 & 27,53 & 153,76 & 61,19 & 132,87 & 0 \\
\hline & 33,9 & 152,1 & 78,23 & 131,21 & 0 & 27,66 & 163,41 & 60,45 & 142,52 & $\underline{0}$ \\
\hline & 33,9 & 334,12 & 58,25 & 313,23 & 0 & 27,78 & 165,32 & 64,6 & 144,43 & 0 \\
\hline & 33,92 & 348 & 32,46 & 327,11 & 0 & 27,92 & 347,08 & 31,96 & 326,19 & 0 \\
\hline & 33,95 & 334,77 & 32,13 & 313,88 & 0 & 28 & 3,98 & 62,73 & 343,09 & 0 \\
\hline & 34 & 224 & 26 & 203,11 & 0 & 28,15 & 159,06 & 73,65 & 138,17 & 0 \\
\hline & 34,03 & 149 & 16 & 128,11 & 0 & 28,35 & 168,58 & 34,49 & 147,69 & 0 \\
\hline & 34,17 & 324,8 & 8,53 & 303,91 & 0 & 28,36 & 324,92 & 34,49 & 304,03 & 0 \\
\hline & 34,32 & 124,21 & 13,22 & 103,32 & 0 & 28,43 & 325,88 & 27,83 & 304,99 & 0 \\
\hline & 34,44 & 91,66 & 17,74 & 70,77 & 0 & 28,52 & 154,17 & 64,73 & 133,28 & 0 \\
\hline & 34,7 & 160,78 & 81,3 & 139,89 & 0 & 28,61 & 152,27 & 68,75 & 131,38 & 0 \\
\hline & 34,76 & 159,35 & 73,03 & 138,46 & 0 & 28,78 & 307,25 & 10,7 & 286,36 & 0 \\
\hline & 34,76 & 321,47 & 54,69 & 300,58 & 0 & 28,81 & 140,85 & 23,94 & 119,96 & 0 \\
\hline & 34,84 & 147,94 & 75,17 & 127,05 & 0 & 28,81 & 147,43 & 77,75 & 126,54 & 0 \\
\hline & 35 & 146,87 & 36,2 & 125,98 & 0 & 28,88 & 101,56 & 12,52 & 80,67 & 0 \\
\hline & 35,05 & 151,35 & 33,58 & 130,46 & 0 & 29,04 & 153,35 & 71,04 & 132,46 & 0 \\
\hline & 35,05 & 149,79 & 70,93 & 128,9 & 0 & 29,11 & 148,65 & 74,1 & 127,76 & 0 \\
\hline & 35,07 & 139,02 & 52,17 & 118,13 & 0 & 29,3 & 337,43 & 63,68 & 316,54 & 0 \\
\hline & 35,18 & 136,56 & 31,63 & 115,67 & 0 & 29,33 & 159,47 & 38,8 & 138,58 & 0 \\
\hline & 35,32 & 94,96 & 39,08 & 74,07 & 0 & 29,43 & 146,08 & 79,23 & 125,19 & 0 \\
\hline & 35,32 & 274,9 & 21,7 & 254,01 & 0 & 29,62 & 143,16 & 44,89 & 122,27 & 0 \\
\hline & 35,4 & 109,87 & 7,52 & 88,98 & 0 & 29,72 & 155,99 & 74,9 & 135,1 & 0 \\
\hline & 35,41 & 333,77 & 48,69 & 312,88 & 0 & 30,06 & 174,83 & 16,07 & 153,94 & 0 \\
\hline & 35,49 & 330,29 & 45,11 & 309,4 & 0 & 30,11 & 290,39 & 11,86 & 269,5 & 0 \\
\hline & 35,49 & 309,55 & 44,3 & 288,66 & 0 & 30,24 & 67,43 & 76,88 & 46,54 & 0 \\
\hline & 35,67 & 341,73 & 60,7 & 320,84 & 0 & 30,33 & 153,25 & 72,59 & 132,36 & 0 \\
\hline & 35,88 & 318,41 & 21,6 & 297,52 & 0 & 30,52 & 59,82 & 67,63 & 38,93 & 0 \\
\hline 4532 & Depth & Azimuth & Dip & Declinado & Aperture & 30,53 & 175,32 & 77,25 & 154,43 & 0 \\
\hline & Depth & Azimuth & Dip & Declinado & Aperture & 30,6 & 180,14 & 57,34 & 159,25 & 0 \\
\hline & $\mathrm{m}$ & deg & deg & deg & $\mathrm{mm}$ & 30,75 & 156,62 & 41,7 & 135,73 & 0 \\
\hline & 25,06 & 137,64 & 64,32 & 116,75 & 0 & 30,76 & 346,57 & 78,87 & 325,68 & 0 \\
\hline & 25,13 & 351,44 & 74,9 & 330,55 & 0 & 30,8 & 161,37 & 52,41 & 140,48 & 0 \\
\hline & 25,22 & 83,77 & 75,99 & 62,88 & 0,94 & 30,89 & 146,51 & 49,36 & 125,62 & 0 \\
\hline & 25,35 & 303,72 & 25,41 & 282,83 & 0 & 30,94 & 325,88 & 53,16 & 304,99 & 0 \\
\hline & 25,46 & 307,09 & 47,47 & 286,2 & 0 & 30,98 & 160,97 & 60,62 & 140,08 & 0 \\
\hline & 25,56 & 330,17 & 44,89 & 309,28 & 0 & 31,16 & 156,62 & 55,22 & 135,73 & $\underline{0}$ \\
\hline & 25,66 & 162,44 & 35,64 & 141,55 & 0 & 31,54 & 157,57 & 49,84 & 136,68 & 0 \\
\hline & 25,73 & 158,02 & 43,74 & 137,13 & 0 & 31,59 & 157,87 & 76,66 & 136,98 & 0,83 \\
\hline & 25,86 & 163,44 & 25,36 & 142,55 & 0 & 31,9 & 351,44 & 73,95 & 330,55 & 0 \\
\hline & 25,96 & 155,16 & 39,93 & 134,27 & 0 & 31,93 & 345 & 17 & 324,11 & 0 \\
\hline & 26,06 & 326,66 & 63,55 & 305,77 & 0 & 31,94 & 162,8 & 82,25 & 141,91 & 0 \\
\hline & 26,13 & 147,96 & 73,54 & 127,07 & 0 & 32,01 & 337,97 & 84,1 & 317,08 & 0 \\
\hline & 26,16 & 331,59 & 50,82 & 310,7 & 0 & 32,04 & 343 & 29 & 322,11 & 0 \\
\hline & 26,2 & 155,02 & 45,9 & 134,13 & 0 & 32,15 & 177,15 & 66,26 & 156,26 & 2,05 \\
\hline & 26,27 & 330,45 & 23,36 & 309,56 & 0 & 32,22 & 177,27 & 73,7 & 156,38 & 0 \\
\hline & 26,32 & 150,45 & 58,03 & 129,56 & 0 & 32,44 & 86,47 & 7,18 & 65,58 & 0 \\
\hline & 26,36 & 331,74 & 47,44 & 310,85 & 0 & 32,5 & 271,22 & 4,12 & 250,33 & 0 \\
\hline & 26,4 & 334,02 & 69,34 & 313,13 & 0 & 32,53 & 128,88 & 24,51 & 107,99 & 0 \\
\hline & 26,53 & 333,02 & 43,2 & 312,13 & 0 & 32,64 & 253,54 & 82,03 & 232,65 & 0 \\
\hline & 26,64 & 161,87 & 51,83 & 140,98 & 0 & 32,68 & 160,02 & 18,26 & 139,13 & 0 \\
\hline & 26,82 & 157,59 & 35,3 & 136,7 & 0 & 33,06 & 318,26 & 32,33 & 297,37 & 0 \\
\hline & 26,9 & 151,88 & 37,74 & 130,99 & 0 & 33,27 & 157,57 & 49,62 & 136,68 & 0 \\
\hline & 26,9 & 335,22 & 76,66 & 314,33 & 0 & 33,41 & 156,62 & 68,66 & 135,73 & 0 \\
\hline & 26,98 & 144,46 & 25 & 123,57 & 0 & 33,45 & 329,27 & 54,6 & 308,38 & 0 \\
\hline & 27,13 & 171,98 & 71,95 & 151,09 & 0 & 33,52 & 152,35 & 66,12 & 131,46 & 0 \\
\hline & 27,13 & 336,14 & 43,53 & 315,25 & 0 & 33,58 & 148,93 & 66,21 & 128,04 & 0 \\
\hline
\end{tabular}




\begin{tabular}{|c|c|c|c|c|c|c|c|c|c|c|}
\hline 4532 & Depth & Azimuth & Dip & Declinado & Aperture & Depth & Azimuth & Dip & Declinado & Aperture \\
\hline & 33,67 & 150,39 & 44,97 & 129,5 & 0 & 37,21 & 305,18 & 21 & 284,29 & 0 \\
\hline & 33,7 & 147,13 & 55,17 & 126,24 & 0 & 37,24 & 332,45 & 23 & 311,56 & 0 \\
\hline & 33,77 & 149,9 & 53,29 & 129,01 & 0 & 37,27 & 325,41 & 30 & 304,52 & 0 \\
\hline & 33,88 & 146,97 & 31,34 & 126,08 & 0 & 37,39 & 181,32 & 62,74 & 160,43 & 0 \\
\hline & 33,91 & 150,39 & 33,9 & 129,5 & 0 & 37,47 & 169,01 & 60,99 & 148,12 & 0 \\
\hline & 34,05 & 333,9 & 14,47 & 313,01 & 0 & 37,62 & 167,47 & 50,41 & 146,58 & 0 \\
\hline & 34,1 & 147,95 & 25,92 & 127,06 & 0 & 37,7 & 325,71 & 51,76 & 304,82 & 1,49 \\
\hline & 34,22 & 149,9 & 58,5 & 129,01 & 0 & 37,73 & 157,8 & 45,4 & 136,91 & 0 \\
\hline & 34,26 & 150,39 & 44,88 & 129,5 & 0 & 37,78 & 155,16 & 47,04 & 134,27 & 0 \\
\hline & 34,3 & 149,42 & 46,4 & 128,53 & 0 & 37,82 & 150,79 & 45,14 & 129,9 & 0 \\
\hline & 34,34 & 153,33 & 71,14 & 132,44 & 0 & 37,87 & 162,64 & 47,52 & 141,75 & 0 \\
\hline & 34,51 & 157,16 & 76,91 & 136,27 & 0 & 37,93 & 157,36 & 49,11 & \begin{tabular}{l|}
136,47 \\
\end{tabular} & 0 \\
\hline & 34,64 & 164,23 & 64,15 & 143,34 & 0 & 38,01 & 322,2 & 62,34 & 301,31 & 0 \\
\hline & 34,75 & 160,42 & 44,89 & 139,53 & 0 & 38,02 & 156,26 & 49,48 & 135,37 & 0 \\
\hline & 34,81 & 162,46 & 47,12 & 141,57 & 0 & 38,13 & 154,51 & 64,22 & 133,62 & 0 \\
\hline & 34,87 & 160,02 & 43,47 & 139,13 & 0 & 38,19 & 338,24 & 67,02 & 317,35 & 0 \\
\hline & 34,94 & 156,62 & 37,95 & 135,73 & 0 & 38,2 & 159,35 & 63,77 & 138,46 & 0 \\
\hline & 35,07 & 164,77 & 42,74 & 143,88 & 0 & 38,32 & 333,08 & 64,16 & 312,19 & 0 \\
\hline & 35,08 & 336,89 & 58,97 & 316 & 0 & 38,36 & 158,46 & 46,8 & 137,57 & 0 \\
\hline & 35,15 & 161,92 & 58,97 & 141,03 & 0 & 38,42 & 337,58 & 37,74 & 316,69 & 0 \\
\hline & 35,18 & 345,48 & 33,42 & 324,59 & 0 & 38,44 & 178,68 & 42,65 & 157,79 & 0 \\
\hline & 35,3 & 347,9 & 35,3 & 327,01 & 0 & 38,46 & 183,96 & 36,43 & 163,07 & 0 \\
\hline & 35,31 & 170,62 & 49,04 & 149,73 & 0 & 38,56 & 164,84 & 54,77 & 143,95 & 0 \\
\hline & 35,45 & 165,73 & 44,27 & 144,84 & 0 & 38,62 & 150,33 & 48,14 & 129,44 & 0 \\
\hline & 35,45 & 331,72 & 49,84 & 310,83 & 0 & 38,68 & 318,24 & 21,45 & 297,35 & 0 \\
\hline & 35,51 & 167,59 & 76,01 & 146,7 & 0 & 38,77 & 335,82 & 50,96 & 314,93 & 0 \\
\hline & 35,52 & 343,69 & 50,47 & 322,8 & 0 & 38,82 & 161,5 & 61,61 & 140,61 & 0 \\
\hline & 35,59 & 169,53 & 33,66 & 148,64 & 0 & 38,85 & 314,51 & 6,33 & 293,62 & 0 \\
\hline & 35,62 & 341,6 & 38 & 320,71 & 0 & 38,88 & 160 & 57,24 & 139,11 & 0 \\
\hline & 35,68 & 167,23 & 65,1 & 146,34 & 0 & 38,94 & 353,41 & 49,11 & 332,52 & 0 \\
\hline & 35,81 & 158,18 & 79,2 & 137,29 & 0 & 38,95 & 177,58 & 37,95 & 156,69 & 0 \\
\hline & 35,86 & 160,42 & 46,32 & 139,53 & 0 & 39,03 & 177,8 & 41,89 & 156,91 & 0 \\
\hline & 35,91 & 163,64 & 54,07 & 142,75 & 0 & & & & & \\
\hline & 36,15 & 164,55 & 48,74 & 143,66 & 0 & & & & & \\
\hline & 36,23 & 167 & 39,01 & 146,11 & 0 & & & & & \\
\hline & 36,27 & 160,97 & 33,31 & 140,08 & 0 & & & & & \\
\hline & 36,38 & 333,35 & 32,46 & 312,46 & 0 & & & & & \\
\hline & 36,39 & 329,55 & 30,71 & 308,66 & 0 & & & & & \\
\hline & 36,4 & 331,18 & 30,71 & 310,29 & 0 & & & & & \\
\hline & 36,41 & 170,08 & 55,39 & 149,19 & 0 & & & & & \\
\hline & 36,44 & 341,78 & 40,93 & 320,89 & \begin{tabular}{l|}
2,49 \\
\end{tabular} & & & & & \\
\hline & 36,48 & 173,47 & 39,21 & 152,58 & 0 & & & & & \\
\hline & 36,49 & 122,08 & 9,03 & 101,19 & 0 & & & & & \\
\hline & 36,52 & 176,74 & 36,54 & 155,85 & 0 & & & & & \\
\hline & 36,67 & 353,75 & 68,75 & 332,86 & 0 & & & & & \\
\hline & 36,68 & 353,34 & 48,14 & 332,45 & 0 & & & & & \\
\hline & 36,72 & 336,48 & 35,75 & 315,59 & 0 & & & & & \\
\hline & 36,79 & 322,21 & 22,93 & 301,32 & 0 & & & & & \\
\hline & 36,84 & 164,55 & 46,67 & 143,66 & 0 & & & & & \\
\hline & 36,86 & 352,25 & 58,46 & 331,36 & 2,2 & & & & & \\
\hline & 36,9 & 158,11 & 57,24 & 137,22 & 0 & & & & & \\
\hline & 37 & 160,88 & 65,25 & 139,99 & 0 & & & & & \\
\hline & 37,01 & 165,49 & 44,27 & 144,6 & 0 & & & & & \\
\hline & 37,1 & 158,46 & 26,47 & 137,57 & 0 & & & & & \\
\hline & 37,19 & 160 & 72,79 & 139,11 & 0 & & & & & \\
\hline & 37,2 & 330,55 & 8,87 & 309,66 & 0 & & & & & \\
\hline & 37,21 & 336,04 & 33,18 & 315,15 & 0 & & & & & \\
\hline
\end{tabular}




\begin{tabular}{|c|c|c|c|c|c|c|c|c|c|c|}
\hline 4536 & Depth & Azimuth & Dip & Declinado & Aperture & Depth & Azimuth & Dip & Declinado & Aperture \\
\hline & 24,02 & 242,56 & 65,24 & 221,67 & 0 & 28,14 & 152,37 & 57,8 & 131,48 & 0 \\
\hline & 24,07 & 333,85 & 64,95 & 312,96 & 0 & 28,34 & 157,82 & 48,99 & 136,93 & 0 \\
\hline & 24,25 & 152,81 & 68,62 & 131,92 & 0 & 28,44 & 150,51 & 53,63 & 129,62 & $\underline{0}$ \\
\hline & 24,27 & 340,31 & 41,48 & 319,42 & 0 & 28,55 & 348,18 & 61,5 & 327,29 & 0 \\
\hline & 24,33 & 165,2 & 52,04 & 144,31 & 0 & 28,61 & 340,34 & 62,9 & 319,45 & 0 \\
\hline & 24,44 & 350,16 & 53,67 & 329,27 & 0 & 28,64 & 348,31 & 64,39 & 327,42 & 0 \\
\hline & 24,61 & 336,31 & 73,36 & 315,42 & 0 & 28,69 & 356,01 & 63,06 & 335,12 & 0 \\
\hline & 24,67 & 329,98 & 8,08 & 309,09 & 0 & 28,79 & 342,73 & 66,57 & 321,84 & 0 \\
\hline & 24,68 & 333,83 & 61,79 & 312,94 & 0 & 28,92 & 337,35 & 54,42 & 316,46 & 0 \\
\hline & 24,69 & 164,72 & 46,51 & 143,83 & 0 & 28,94 & 156,86 & 54,11 & 135,97 & 0 \\
\hline & 24,74 & 160,74 & 32,62 & 139,85 & 0 & 28,99 & 345,74 & 43,59 & 324,85 & 0 \\
\hline & 24,77 & 158,75 & 45,11 & 137,86 & 0 & 29,06 & 330,36 & 38,31 & 309,47 & 0 \\
\hline & 24,83 & 154,23 & 19,19 & 133,34 & 0 & 29,1 & 145,96 & 10,42 & 125,07 & 0 \\
\hline & 24,87 & 198,33 & 20,71 & 177,44 & 1,31 & 29,14 & 161,76 & 22,88 & 140,87 & 0 \\
\hline & 24,96 & 226,76 & 67,81 & 205,87 & 0,6 & 29,27 & 332,32 & 59,24 & 311,43 & 0 \\
\hline & 24,99 & 320,55 & 18,47 & 299,66 & 0 & 29,31 & 154,38 & 64,43 & 133,49 & 0 \\
\hline & 25,21 & 156,75 & 64,73 & 135,86 & 0 & 29,42 & 149,87 & 64,54 & 128,98 & 0 \\
\hline & 25,22 & 331,84 & 26,84 & 310,95 & 0 & 29,51 & 324,91 & 37,6 & 304,02 & 0 \\
\hline & 25,22 & 342,19 & 69,76 & 321,3 & 0 & 29,53 & 341,13 & 60,03 & 320,24 & 0 \\
\hline & 25,32 & 151,83 & 17,64 & 130,94 & 0 & 29,65 & 139,11 & 31,3 & 118,22 & 0 \\
\hline & 25,46 & 330,78 & 64,26 & 309,89 & 0 & 29,68 & 319,88 & 43,59 & 298,99 & 0 \\
\hline & 25,48 & 151,65 & 76,35 & 130,76 & 0 & 29,74 & 200,2 & 1,6 & 179,31 & 0 \\
\hline & 25,58 & 335,25 & 47,2 & 314,36 & 0 & 29,79 & 319,18 & 52,85 & 298,29 & 0 \\
\hline & 25,68 & 153,23 & 64,99 & 132,34 & 0 & 29,94 & 102,52 & 27,56 & 81,63 & 0 \\
\hline & 25,76 & 340,29 & 32,13 & 319,4 & 0 & 30,12 & 333,92 & 76,71 & 313,03 & 0 \\
\hline & 25,86 & 331,34 & 32,94 & 310,45 & 0 & 30,32 & 335,37 & 70,28 & 314,48 & 0 \\
\hline & 25,95 & 156,27 & 77,95 & 135,38 & 0 & 30,39 & 161,2 & 66,75 & 140,31 & 0 \\
\hline & 26,08 & 326,03 & 73,61 & 305,14 & 0 & 30,45 & 161,76 & 68,72 & 140,87 & 0 \\
\hline & 26,1 & 166,66 & 57,21 & 145,77 & 0 & 30,63 & 334,83 & 79,47 & 313,94 & 0 \\
\hline & 26,18 & 168,19 & 59,12 & 147,3 & 0 & 30,72 & 321,55 & 50,19 & 300,66 & 0 \\
\hline & 26,21 & 155,32 & 63,71 & 134,43 & 0 & 30,76 & 163,74 & 52,17 & 142,85 & 0 \\
\hline & 26,21 & 163,57 & 41,35 & 142,68 & 0 & 30,87 & 159,27 & 49,91 & 138,38 & 0 \\
\hline & 26,45 & 334,95 & 70,56 & 314,06 & 0 & 30,92 & 150,43 & 58,81 & 129,54 & 0 \\
\hline & 26,52 & 326,44 & 35,22 & 305,55 & 0 & 30,99 & 162,14 & 66,09 & 141,25 & 0 \\
\hline & 26,53 & 149,87 & 66,79 & 128,98 & 0 & 31,43 & 334,73 & 75,38 & 313,84 & 0 \\
\hline & 26,56 & 339,87 & 69,21 & 318,98 & 0 & 31,49 & 152,35 & 63,8 & 131,46 & 0 \\
\hline & 26,57 & 161,23 & 31,8 & 140,34 & 0,85 & 31,6 & 149,31 & 67,36 & 128,42 & $\underline{0}$ \\
\hline & 26,71 & 323,93 & 67 & 303,04 & 0 & 31,77 & 179,37 & 41,22 & 158,48 & 0 \\
\hline & 26,72 & 147,91 & 63,8 & 127,02 & 0 & 31,82 & 148,89 & 39,56 & 128 & 0 \\
\hline & 26,86 & 157,36 & 65,87 & 136,47 & 0 & 31,92 & 155,74 & 53,87 & 134,85 & 0 \\
\hline & 27,01 & 336,28 & 70,14 & 315,39 & 0 & 32,06 & 159,32 & 69,54 & 138,43 & 0 \\
\hline & 27,06 & 328,92 & 69,08 & 308,03 & 0 & 32,24 & 162,17 & 9,2 & 141,28 & 0 \\
\hline & 27,11 & 135,05 & 6,05 & 114,16 & 0 & 32,51 & 332,32 & 67,38 & 311,43 & 0 \\
\hline & 27,11 & 129,24 & 21,31 & 108,35 & 0 & 32,53 & 163,7 & 79,36 & 142,81 & 0 \\
\hline & 27,14 & 337,82 & 72,21 & 316,93 & 0 & 32,75 & 155,82 & 47,15 & 134,93 & 0 \\
\hline & 27,31 & 212 & 6,5 & 191,11 & 0 & 32,88 & 323 & 70,48 & 302,11 & 0 \\
\hline & 27,39 & 235,79 & 61,68 & 214,9 & 0,66 & 32,99 & 318,5 & 52,85 & 297,61 & 0 \\
\hline & 27,4 & 330,35 & 71,45 & 309,46 & 0 & 32,99 & 317,52 & 27,2 & 296,63 & 0 \\
\hline & 27,47 & 340,74 & 69,4 & 319,85 & 0 & 33,26 & 320,66 & 33,66 & 299,77 & 0 \\
\hline & 27,52 & 34,54 & 26,47 & 13,65 & 0 & 33,3 & 155,58 & 64,91 & 134,69 & 0 \\
\hline & 27,57 & 153,83 & 3,89 & 132,94 & 0 & 33,33 & 322,51 & 11,97 & 301,62 & 0 \\
\hline & 27,61 & 89,27 & 40,96 & 68,38 & 1,21 & 33,34 & 326,37 & 35,15 & 305,48 & 0 \\
\hline & 27,75 & 158,35 & 54,5 & 137,46 & 0 & 33,42 & 319,97 & 28,19 & 299,08 & 0 \\
\hline & 27,85 & 153,3 & 27,2 & 132,41 & 0 & 33,48 & 327,41 & 29,94 & 306,52 & 0 \\
\hline & 27,93 & 161,27 & 1,26 & 140,38 & 0 & 33,69 & 329,46 & 68,81 & 308,57 & 0 \\
\hline & 27,99 & 335,42 & 56,03 & 314,53 & 0 & 33,84 & 342,13 & 67,38 & 321,24 & 0 \\
\hline & 28,06 & 347,25 & 50,29 & 326,36 & 0 & 34,02 & 334,95 & 70,41 & 314,06 & 0 \\
\hline
\end{tabular}




\begin{tabular}{|c|c|c|c|c|c|c|c|c|c|c|}
\hline 4536 & Depth & Azimuth & Dip & Declinado & Aperture & Depth & Azimuth & Dip & Declinado & Aperture \\
\hline & 34,3 & \begin{tabular}{|l|}
325,05 \\
\end{tabular} & 74,76 & 304,16 & 0 & 39,35 & 347,69 & 54,88 & 326,8 & 0 \\
\hline & 34,34 & 147,9 & 59 & 127,01 & 0 & 39,41 & 330,92 & 54,46 & 310,03 & 0 \\
\hline & 34,55 & 326,43 & 51,56 & 305,54 & 0 & 39,48 & 152,39 & 31,88 & 131,5 & $\underline{0}$ \\
\hline & 34,56 & 163,16 & 70,03 & 142,27 & 0 & 39,57 & 257,84 & 56,45 & 236,95 & 0 \\
\hline & 34,7 & 172,07 & 71,53 & 151,18 & 0 & 39,59 & 335,82 & 73,79 & 314,93 & 0 \\
\hline & 35,01 & 338,27 & 73,36 & 317,38 & 0 & 39,65 & 162,31 & 42,11 & 141,42 & 0 \\
\hline & 35,33 & 326,53 & 63,5 & 305,64 & 0 & 39,78 & 74,89 & 68,84 & 54 & 0 \\
\hline & 35,35 & 149,85 & 10,87 & 128,96 & 0 & 39,81 & 333,37 & 58,78 & 312,48 & 0 \\
\hline & 35,41 & 226,79 & 74,17 & 205,9 & \begin{tabular}{l|l}
0 \\
\end{tabular} & 39,89 & 333,82 & 46,51 & 312,93 & 0 \\
\hline & 35,43 & 225,81 & 71,87 & 204,92 & 0 & 39,94 & 157,7 & 60,4 & 136,81 & 0 \\
\hline & 35,5 & 93,85 & 6,62 & 72,96 & 0 & 39,96 & 66,98 & 79,02 & 46,09 & 0 \\
\hline & 35,5 & 227,28 & 46,88 & 206,39 & 0 & 39,98 & 327,91 & 71,78 & 307,02 & 0 \\
\hline & 35,67 & 95,63 & 32,7 & 74,74 & 0 & 40,08 & 150,87 & 52,26 & 129,98 & 0 \\
\hline & 35,96 & 90,17 & 32,94 & 69,28 & 0 & 40,26 & 213,33 & 63,66 & 192,44 & 0 \\
\hline & 36,01 & 79,69 & 26,57 & 58,8 & 0 & & & & & \\
\hline & 36,12 & 134,73 & 6,61 & 113,84 & 0 & & & & & \\
\hline & 36,38 & 3,01 & 79,46 & 342,12 & 0 & & & & & \\
\hline & 36,55 & 336,26 & 66,81 & 315,37 & 0 & & & & & \\
\hline & 36,66 & 26,57 & 43,35 & 5,68 & 0 & & & & & \\
\hline & 36,69 & 25,1 & 35,15 & 4,21 & 0 & & & & & \\
\hline & 36,72 & 79,41 & 41,8 & 58,52 & 0 & & & & & \\
\hline & 36,93 & 336,48 & 77,97 & 315,59 & 0 & & & & & \\
\hline & 37,06 & 332,32 & 66,37 & 311,43 & \begin{tabular}{l|l}
0 \\
\end{tabular} & & & & & \\
\hline & 37,22 & 146,15 & 73,43 & 125,26 & \begin{tabular}{l|l}
0 \\
\end{tabular} & & & & & \\
\hline & 37,23 & 343,3 & 77,55 & 322,41 & \begin{tabular}{l|l}
0 \\
\end{tabular} & & & & & \\
\hline & 37,26 & 228,77 & 74,7 & 207,88 & 0 & & & & & \\
\hline & 37,32 & 237,65 & 77,16 & 216,76 & 0 & & & & & \\
\hline & 37,37 & 338,19 & 59,74 & 317,3 & 0 & & & & & \\
\hline & 37,37 & 90,68 & 74,91 & 69,79 & 0 & & & & & \\
\hline & 37,56 & 153,32 & 74,08 & 132,43 & 0 & & & & & \\
\hline & 37,63 & 159,27 & 73,35 & 138,38 & 0 & & & & & \\
\hline & 37,76 & 335,39 & 78,86 & 314,5 & 0 & & & & & \\
\hline & 37,77 & 155,32 & 72,32 & 134,43 & 0 & & & & & \\
\hline & 37,87 & 163,32 & 63,64 & 142,43 & 0 & & & & & \\
\hline & 37,96 & 336,26 & 74,17 & 315,37 & 0 & & & & & \\
\hline & 37,97 & 155,32 & 68,99 & 134,43 & 0 & & & & & \\
\hline & 38,07 & 155,78 & 74,31 & 134,89 & 0 & & & & & \\
\hline & 38,22 & 152,33 & 39,9 & 131,44 & 0 & & & & & \\
\hline & 38,3 & 331,92 & 39,15 & 311,03 & 0 & & & & & \\
\hline & 38,42 & 342,28 & 48,74 & 321,39 & 0 & & & & & \\
\hline & 38,42 & 329,92 & 72,31 & 309,03 & \begin{tabular}{l|l}
0 \\
\end{tabular} & & & & & \\
\hline & 38,44 & 151,87 & 51,3 & 130,98 & \begin{tabular}{l|l}
0 \\
\end{tabular} & & & & & \\
\hline & 38,5 & 150,29 & 55,22 & 129,4 & \begin{tabular}{l|l}
0 \\
\end{tabular} & & & & & \\
\hline & 38,58 & 154,78 & 60,06 & 133,89 & 0 & & & & & \\
\hline & 38,7 & 334,46 & 52,22 & 313,57 & 0 & & & & & \\
\hline & 38,71 & 155,78 & 53,75 & 134,89 & 0 & & & & & \\
\hline & 38,74 & 155,32 & 56,59 & 134,43 & 0 & & & & & \\
\hline & 38,84 & 150,87 & 48,19 & 129,98 & 0 & & & & & \\
\hline & 38,9 & 160 & 60 & 139,11 & 0 & & & & & \\
\hline & 38,96 & 340,82 & 44,89 & 319,93 & 0 & & & & & \\
\hline & 39 & 342,73 & 38,38 & 321,84 & 0 & & & & & \\
\hline & 39,06 & 331,37 & 57,57 & 310,48 & 0 & & & & & \\
\hline & 39,09 & 160,78 & 60,81 & 139,89 & \begin{tabular}{l|l}
0 \\
\end{tabular} & & & & & \\
\hline & 39,11 & 334,37 & 12,3 & 313,48 & 0 & & & & & \\
\hline & 39,11 & 156,78 & 63,41 & 135,89 & 0 & & & & & \\
\hline & 39,15 & 158,78 & 65,48 & 137,89 & 0 & & & & & \\
\hline & 39,17 & 334,39 & 75,14 & 313,5 & \begin{tabular}{l|l}
0 \\
\end{tabular} & & & & & \\
\hline
\end{tabular}




\begin{tabular}{|c|c|c|c|c|c|c|c|c|c|c|}
\hline 4540 & Depth & Azimuth & Dip & Declinado & Aperture & Depth & Azimuth & Dip & Declinado & Aperture \\
\hline & 25,19 & 324,49 & 59,72 & 303,6 & 0 & 30,57 & 143,56 & 76,71 & 122,67 & 0 \\
\hline & 25,22 & 147,5 & 60,86 & 126,61 & 0 & 30,77 & 139,6 & 38,06 & 118,71 & 0 \\
\hline & 25,35 & 150,43 & 25,5 & 129,54 & 0 & 30,87 & 147,41 & 40,23 & 126,52 & 0 \\
\hline & 25,42 & 141,06 & 53,59 & 120,17 & 0 & 31,05 & 346,59 & 62,34 & 325,7 & 0 \\
\hline & 25,49 & 324,49 & 70,51 & 303,6 & 0 & 31,09 & 80,26 & 64,69 & 59,37 & 0 \\
\hline & 25,5 & 144,98 & 63,79 & 124,09 & 0 & 31,11 & 238 & 11 & 217,11 & 0 \\
\hline & 25,71 & 328,82 & 71,36 & 307,93 & 0 & 31,18 & 303,82 & 71,7 & 282,93 & 0 \\
\hline & 25,78 & 129,74 & 37,31 & 108,85 & 0 & 31,3 & 131,65 & 50,75 & 110,76 & 0 \\
\hline & 25,99 & 151,42 & 62,99 & 130,53 & 0 & 31,32 & 158,82 & 73,93 & 137,93 & 0 \\
\hline & 26,08 & 324,56 & 74,92 & 303,67 & 0 & 31,41 & 328,4 & 72 & 307,51 & 0 \\
\hline & 26,11 & 135,17 & 38,38 & 114,28 & 1,14 & 31,54 & 323,92 & 77,36 & 303,03 & 0 \\
\hline & 26,12 & 140,09 & 39,52 & 119,2 & 0 & 31,55 & 172,1 & 47,2 & 151,21 & 0 \\
\hline & 26,23 & 323,93 & 46,4 & 303,04 & 0 & 31,57 & 202,41 & 53 & 181,52 & 0 \\
\hline & 26,32 & 316 & 54 & 295,11 & 0 & 31,59 & 2,94 & 4,12 & 342,05 & 0,34 \\
\hline & 26,46 & 300,86 & 62,49 & 279,97 & 0 & 31,59 & 196,71 & 48,59 & 175,82 & 0 \\
\hline & 26,57 & 152,89 & 77,69 & 132 & 0 & 31,6 & 176,99 & 2,4 & 156,1 & 3 \\
\hline & 26,76 & 168,62 & 58,6 & 147,73 & 0 & 31,6 & 137,99 & 4,12 & 117,1 & 0 \\
\hline & 26,91 & 156,26 & 23,07 & 135,37 & 0 & 31,67 & 143,86 & 28,1 & 122,97 & 1,87 \\
\hline & 26,94 & 315,22 & 74,11 & 294,33 & 0 & 31,68 & 121 & 82 & 100,11 & 0 \\
\hline & 27,05 & 324,56 & 74,35 & 303,67 & 0 & 31,71 & 95,72 & 20 & 74,83 & 0 \\
\hline & 27,1 & 315,64 & 54,13 & 294,75 & 0 & 31,72 & 245,08 & 20,86 & 224,19 & 0 \\
\hline & 27,12 & 319,13 & 44,54 & 298,24 & 0 & 31,72 & 147 & 81 & 126,11 & 0 \\
\hline & 27,2 & 320,57 & 37,31 & 299,68 & 0 & 31,76 & 323,64 & 24,51 & 302,75 & 0 \\
\hline & 27,46 & 147,44 & 74,11 & 126,55 & 0 & 31,78 & 175,46 & 17,95 & 154,57 & 2 \\
\hline & 27,48 & 329,5 & 75,29 & 308,61 & 0 & 31,78 & 303,48 & 26,2 & 282,59 & 0,81 \\
\hline & 27,75 & 319 & 79,22 & 298,11 & 0 & 31,81 & 150,29 & 5,48 & 129,4 & 2,99 \\
\hline & 27,77 & 143,45 & 80,88 & 122,56 & 0 & 31,82 & 144,42 & 67,12 & 123,53 & 0 \\
\hline & 27,86 & 150,9 & 65,58 & 130,01 & 0 & 31,98 & 321,55 & 47,2 & 300,66 & 0 \\
\hline & 27,9 & 322,14 & 64,69 & 301,25 & 0 & 32,1 & 127,64 & 20,41 & 106,75 & 0 \\
\hline & 28,04 & 130,66 & 72,82 & 109,77 & 0 & 32,23 & 147,36 & 57,93 & 126,47 & 0 \\
\hline & 28,04 & 326,04 & 43,92 & 305,15 & 0 & 32,36 & 357 & 2 & 336,11 & 0 \\
\hline & 28,07 & 320,05 & 31,72 & 299,16 & 0 & 32,43 & 145,55 & 61,58 & 124,66 & 0 \\
\hline & 28,18 & 313,65 & 26,2 & 292,76 & 0 & 32,48 & 323,09 & 68,9 & \begin{tabular}{|c|}
302,2 \\
\end{tabular} & 0 \\
\hline & 28,22 & 148,49 & 52,73 & 127,6 & 0 & 32,92 & 153,93 & 62,92 & 133,04 & 0 \\
\hline & 28,28 & 161,92 & 49,04 & 141,03 & 0 & 32,96 & 152,39 & 64,47 & 131,5 & 0 \\
\hline & 28,38 & 324,45 & 29,42 & 303,56 & 0 & 32,99 & 328,24 & 67,93 & 307,35 & 0 \\
\hline & 28,42 & 143,98 & 48,89 & 123,09 & 0 & 33,11 & 325,47 & 53,59 & 304,58 & 0 \\
\hline & 28,49 & 143,04 & 77,21 & 122,15 & 0 & 33,3 & 165,25 & 41,99 & 144,36 & 0 \\
\hline & 28,59 & 316,69 & 35,18 & 295,8 & 0 & 33,37 & 342,1 & 73,14 & 321,21 & 0 \\
\hline & 28,7 & 327,49 & 28,77 & 306,6 & 0 & 33,48 & 162,17 & 4,8 & 141,28 & 0 \\
\hline & 28,72 & 143,56 & 73,21 & 122,67 & 0 & 33,63 & 343,64 & 28,77 & 322,75 & 0 \\
\hline & 28,77 & 330,45 & 33,66 & 309,56 & 0 & 33,75 & 343,02 & 49,19 & 322,13 & 0 \\
\hline & 28,8 & 143,04 & 65,16 & 122,15 & 0 & 33,83 & 144 & 28,37 & 123,11 & 0 \\
\hline & 29,05 & 229,47 & 77,45 & 208,58 & 0 & 34,03 & 89,76 & 76,44 & 68,87 & 1,48 \\
\hline & 29,05 & 30,98 & 65,52 & 10,09 & 0 & 34,28 & 9,75 & 32,82 & 348,86 & 0 \\
\hline & 29,22 & 205,22 & 22,93 & \begin{tabular}{|l|}
184,33 \\
\end{tabular} & 0 & 34,31 & 0,94 & 31,59 & 340,05 & 0 \\
\hline & 29,31 & 147,46 & 73,45 & 126,57 & 0 & 34,55 & 322,95 & 74,55 & 302,06 & 0 \\
\hline & 29,32 & 236 & 82 & 215,11 & 0 & 34,78 & 172,1 & 1,37 & 151,21 & 0,9 \\
\hline & 29,56 & 65,96 & 47,98 & 45,07 & 0 & 34,79 & 153,37 & 74,55 & 132,48 & 0 \\
\hline & 29,58 & 58,19 & 47 & \begin{tabular}{l|}
37,3 \\
\end{tabular} & 0 & 35,01 & 151,41 & 66,37 & 130,52 & 0 \\
\hline & 29,89 & 142,93 & 70,32 & 122,04 & 0 & 35,11 & 13,84 & 72,74 & 352,95 & 0 \\
\hline & 29,9 & 329,9 & 68,63 & 309,01 & 0 & 35,21 & 164,69 & 72,95 & 143,8 & 0 \\
\hline & 30,05 & 149,34 & 71,48 & 128,45 & 0 & 35,31 & 155,32 & 64,6 & 134,43 & 0 \\
\hline & 30,11 & 171,66 & 15,75 & 150,77 & 0 & 35,37 & 155,74 & 56,36 & 134,85 & 0 \\
\hline & 30,29 & 328,02 & 67,35 & 307,13 & 0 & 35,45 & 153,23 & 69,51 & 132,34 & 0 \\
\hline & 30,35 & 141,57 & 76,7 & 120,68 & 0 & 35,53 & 144,42 & 66,46 & 123,53 & 0 \\
\hline & 30,36 & 324,98 & 66,86 & 304,09 & 0 & 35,69 & 53,27 & 33,31 & 32,38 & 0 \\
\hline
\end{tabular}




\begin{tabular}{|c|c|c|c|c|c|c|c|c|c|c|}
\hline 4540 & Depth & Azimuth & Dip & Declinado & Aperture & Depth & Azimuth & Dip & Declinado & Aperture \\
\hline & 35,86 & 338,33 & 40,83 & 317,44 & 0 & 39,93 & 155,82 & 73,18 & 134,93 & 0 \\
\hline & 35,91 & 157,42 & 3,78 & 136,53 & 2,1 & 39,97 & 163,79 & 72,03 & 142,9 & 0 \\
\hline & 35,93 & 346,58 & 22,93 & 325,69 & 0 & 40 & 160,34 & 26,06 & 139,45 & 0 \\
\hline & 35,94 & 205,51 & 17,64 & 184,62 & 2,29 & 40,08 & 161,27 & 52,47 & 140,38 & 0 \\
\hline & 36,04 & 112 & 3 & 91,11 & 0 & 40,12 & 150,51 & 31,96 & 129,62 & 0 \\
\hline & 36,05 & 108 & 5 & 87,11 & 0 & 40,13 & 149,85 & 55,39 & 128,96 & 0 \\
\hline & 36,14 & 155,46 & 15,43 & 134,57 & 0 & 40,16 & 145,99 & 68,4 & 125,1 & 0 \\
\hline & 36,19 & 144 & 66,18 & 123,11 & 0 & 40,23 & 143,47 & 66,32 & 122,58 & 0 \\
\hline & 36,21 & 306,17 & 24,94 & 285,28 & 0 & 40,3 & 325,46 & 71,32 & 304,57 & 0 \\
\hline & 36,25 & 146,38 & 72,94 & 125,49 & 0 & & & & & \\
\hline & 36,29 & 316,1 & 25,36 & 295,21 & 0 & & & & & \\
\hline & 36,42 & 334,83 & 44,8 & 313,94 & 0 & & & & & \\
\hline & 36,47 & 136,45 & 62,81 & 115,56 & 0 & & & & & \\
\hline & 36,61 & 151,27 & 70,57 & 130,38 & 0 & & & & & \\
\hline & 36,69 & 162,17 & 66,75 & 141,28 & 0 & & & & & \\
\hline & 36,74 & 162,73 & 68,75 & 141,84 & 0 & & & & & \\
\hline & 36,85 & 321,55 & 12,52 & 300,66 & 0 & & & & & \\
\hline & 36,91 & 147,91 & 73,45 & 127,02 & 0 & & & & & \\
\hline & 37,07 & 152,39 & 70,78 & 131,5 & 0 & & & & & \\
\hline & 37,18 & 146,94 & 60,62 & 126,05 & 0 & & & & & \\
\hline & 37,29 & 140,5 & 61,35 & 119,61 & 0 & & & & & \\
\hline & 37,34 & 157,28 & 52,66 & 136,39 & 0 & & & & & \\
\hline & 37,39 & 144,56 & 57,44 & 123,67 & \begin{tabular}{l|l}
0 \\
\end{tabular} & & & & & \\
\hline & 37,46 & 146,38 & 50,89 & 125,49 & \begin{tabular}{l|l}
0 \\
\end{tabular} & & & & & \\
\hline & 37,61 & 147,45 & 60,74 & 126,56 & \begin{tabular}{l|l}
0 \\
\end{tabular} & & & & & \\
\hline & 37,75 & 147,78 & 73,84 & 126,89 & 0 & & & & & \\
\hline & 37,83 & 149,37 & 63,95 & 128,48 & 0 & & & & & \\
\hline & 37,92 & 111,82 & 5,65 & 90,93 & 0 & & & & & \\
\hline & 38,04 & 317,62 & 45,4 & 296,73 & 0 & & & & & \\
\hline & 38,11 & 152,31 & 63,48 & 131,42 & 0 & & & & & \\
\hline & 38,14 & 196 & 9 & 175,11 & 0 & & & & & \\
\hline & 38,14 & 200,77 & 9,54 & 179,88 & 0 & & & & & \\
\hline & 38,15 & 207,69 & 10,54 & 186,8 & 0 & & & & & \\
\hline & 38,17 & 151,68 & 7,86 & 130,79 & 0 & & & & & \\
\hline & 38,4 & 225,83 & 69,3 & 204,94 & 0 & & & & & \\
\hline & 38,43 & 42,91 & 66,21 & 22,02 & 0 & & & & & \\
\hline & 38,48 & 217,46 & 70,61 & 196,57 & 0 & & & & & \\
\hline & 38,66 & 147,99 & 66,23 & 127,1 & 0 & & & & & \\
\hline & 38,8 & 153,83 & 60,7 & 132,94 & 0 & & & & & \\
\hline & 38,87 & 142,94 & 64,73 & 122,05 & 0 & & & & & \\
\hline & 38,95 & 148,38 & 59,59 & 127,49 & 0 & & & & & \\
\hline & 38,98 & 149,85 & 58,78 & 128,96 & \begin{tabular}{l|l}
0 \\
\end{tabular} & & & & & \\
\hline & 39,12 & 146,92 & 65,4 & 126,03 & \begin{tabular}{l|l}
0 \\
\end{tabular} & & & & & \\
\hline & 39,21 & 327,99 & 25,92 & 307,1 & 0 & & & & & \\
\hline & 39,24 & 147,99 & 19,65 & 127,1 & 0 & & & & & \\
\hline & 39,3 & 149,85 & 17,95 & 128,96 & 0 & & & & & \\
\hline & 39,32 & 144,4 & 18,88 & 123,51 & 0 & & & & & \\
\hline & 39,36 & 146,92 & 29,03 & 126,03 & 0 & & & & & \\
\hline & 39,38 & 149,85 & 28,1 & 128,96 & 0 & & & & & \\
\hline & 39,43 & 142,54 & 20,25 & 121,65 & 0 & & & & & \\
\hline & 39,5 & 310,72 & 22,34 & 289,83 & 0 & & & & & \\
\hline & 39,62 & 140,01 & 56,93 & 119,12 & 0 & & & & & \\
\hline & 39,66 & 319,62 & 5,66 & 298,73 & \begin{tabular}{l|l}
0 \\
\end{tabular} & & & & & \\
\hline & 39,72 & 156,35 & 70,89 & 135,46 & 0 & & & & & \\
\hline & 39,75 & 148,92 & 34,14 & 128,03 & 0 & & & & & \\
\hline & 39,85 & 323,6 & 33,31 & 302,71 & 0 & & & & & \\
\hline & 39,87 & 144,31 & 47,12 & 123,42 & \begin{tabular}{l|l}
0 \\
\end{tabular} & & & & & \\
\hline
\end{tabular}




\begin{tabular}{|c|c|c|c|c|c|c|c|c|c|c|}
\hline 4544 & Depth & Azimuth & Dip & Declinado & Aperture & Depth & Azimuth & Dip & Declinado & Aperture \\
\hline & 23,67 & 316,52 & 49,62 & 295,63 & 0 & 25,35 & 309,77 & 6,84 & 288,88 & 0 \\
\hline & 23,69 & 329 & 26 & 308,11 & 4,9 & 25,39 & 55,14 & 77,12 & 34,25 & 0 \\
\hline & 23,69 & 319,46 & 13,01 & 298,57 & 0 & 25,5 & 324 & 70 & 303,11 & 0 \\
\hline & 23,71 & 158,12 & 12,84 & 137,23 & 3,22 & 25,52 & 158,49 & 29,94 & 137,6 & 0 \\
\hline & 23,73 & 324,49 & 6,67 & 303,6 & 0 & 25,53 & 256 & 19 & 235,11 & 0 \\
\hline & 23,74 & 322,53 & 8,36 & 301,64 & 0 & 25,53 & 164 & 59,86 & 143,11 & 0 \\
\hline & 23,82 & 112,82 & 7,86 & 91,93 & 0 & 25,59 & 324,43 & 3,78 & 303,54 & 0 \\
\hline & 23,87 & 354 & 19,8 & 333,11 & 2,82 & 25,64 & 141 & 33,18 & 120,11 & 0 \\
\hline & 23,89 & 328,82 & 47,2 & 307,93 & 0 & 25,68 & 146,21 & 40 & 125,32 & 0 \\
\hline & 23,9 & 84,3 & 66,48 & 63,41 & 0 & 25,71 & 153 & 40 & 132,11 & 0 \\
\hline & 23,91 & 330,92 & 36,09 & 310,03 & 0 & 25,74 & 154 & 32 & 133,11 & 0 \\
\hline & 23,92 & 150,01 & 34,95 & 129,12 & 0 & 25,76 & 145,44 & 30,71 & 124,55 & 0 \\
\hline & 23,93 & 325,89 & 34,14 & 305 & 0 & 25,77 & 152 & 24,23 & 131,11 & 1,92 \\
\hline & 23,93 & 89,2 & 66,48 & 68,31 & 0 & 25,8 & 147,58 & 26 & 126,69 & 0 \\
\hline & 23,96 & 314,56 & 34,02 & 293,67 & 0 & 25,89 & 141,06 & 26,34 & 120,17 & 0 \\
\hline & 24 & 75,91 & 18,73 & 55,02 & 2,84 & 25,96 & 333,08 & 19,8 & 312,19 & 0 \\
\hline & 24,01 & 178,11 & 14,14 & 157,22 & 0 & 26,01 & 168,61 & 48,44 & 147,72 & 0 \\
\hline & 24,02 & 314,14 & 31,96 & 293,25 & 0,76 & 26,04 & 237 & 18 & 216,11 & 0 \\
\hline & 24,04 & 314,98 & 29,81 & 294,09 & 1,82 & 26,07 & 136,59 & 28,9 & 115,7 & 0 \\
\hline & 24,07 & 337,21 & 32,82 & 316,32 & 0 & 26,1 & 120,79 & 20,25 & 99,9 & 0 \\
\hline & 24,09 & 168,75 & 38,8 & 147,86 & 0 & 26,11 & 335,45 & 54 & 314,56 & 0 \\
\hline & 24,11 & 320,43 & 20,1 & 299,54 & 0 & 26,18 & 142,04 & 4,12 & 121,15 & 0 \\
\hline & 24,12 & 148,47 & 32,46 & 127,58 & 0 & 26,18 & 135,05 & 46,64 & 114,16 & 0 \\
\hline & 24,15 & 156,3 & 25,36 & 135,41 & 1,9 & 26,22 & 141 & 41 & 120,11 & 0 \\
\hline & 24,16 & 163,71 & 21,31 & 142,82 & 0 & 26,23 & 143 & 61,89 & 122,11 & 0 \\
\hline & 24,17 & 326,87 & 42,65 & 305,98 & 0 & 26,3 & 142,46 & 44,01 & 121,57 & 1,51 \\
\hline & 24,25 & 150,29 & 32,7 & 129,4 & 0 & 26,31 & 319,48 & 35,75 & 298,59 & 0,73 \\
\hline & 24,27 & 327,98 & 15,91 & 307,09 & 0 & 26,31 & 144,42 & 40,92 & 123,53 & 0 \\
\hline & 24,42 & 331,45 & 54 & 310,56 & 0 & 26,33 & 133,1 & 41,61 & 112,21 & 0 \\
\hline & 24,42 & 312 & 11 & 291,11 & \begin{tabular}{|l|}
2,93 \\
\end{tabular} & 26,4 & 143,44 & 58,27 & 122,55 & 0 \\
\hline & 24,45 & 127 & 19 & 106,11 & 0 & 26,47 & 293,87 & 7,18 & 272,98 & 0 \\
\hline & 24,49 & 149,31 & 32,7 & 128,42 & 0 & 26,54 & 285,48 & 15,27 & 264,59 & 0 \\
\hline & 24,5 & 331,76 & 47,98 & 310,87 & 0,8 & 26,54 & 137,99 & 74,6 & 117,1 & 0 \\
\hline & 24,52 & 337,21 & 8,36 & 316,32 & 0 & 26,57 & 94,65 & 16,54 & 73,76 & 0 \\
\hline & 24,53 & 148,89 & 53,95 & 128 & 0 & 26,62 & 198,66 & 11,86 & 177,77 & 0 \\
\hline & 24,54 & 326,81 & 51,16 & 305,92 & 0,75 & 26,63 & 175,46 & 11,86 & 154,57 & 0 \\
\hline & 24,61 & 237,04 & 10 & 216,15 & 0 & 26,66 & 219,91 & 4,97 & 199,02 & 0 \\
\hline & 24,75 & 332,32 & 15,91 & 311,43 & 0 & 26,7 & 235,71 & 21,45 & 214,82 & 0 \\
\hline & 24,76 & 161,62 & 18,73 & 140,73 & 0 & 26,71 & 97,58 & 20,25 & 76,69 & 1,13 \\
\hline & 24,77 & 314,98 & 46,56 & 294,09 & 0 & 26,8 & 324,07 & 32,82 & 303,18 & 0 \\
\hline & 24,84 & 323,93 & 50,19 & 303,04 & 0 & 26,8 & 310,09 & 59,77 & 289,2 & 0 \\
\hline & 24,88 & 264,79 & 3,6 & 243,9 & 0 & 26,88 & 301 & 30,96 & 280,11 & 1,8 \\
\hline & 24,92 & 155,74 & 9,03 & 134,85 & 0 & 26,9 & 294 & 28,1 & 273,11 & 1,85 \\
\hline & 24,93 & 61,04 & 54 & 40,15 & 0 & 26,91 & 311,07 & 57,78 & 290,18 & 0 \\
\hline & 25 & 143 & 32 & 122,11 & 0 & 26,92 & 127,64 & 63,89 & 106,75 & 0 \\
\hline & 25,11 & 332,88 & 55,44 & 311,99 & 0 & 27,03 & 293,31 & 15,91 & 272,42 & 0,87 \\
\hline & 25,16 & 175,46 & 5,99 & 154,57 & 0 & 27,05 & 130,58 & 12,52 & 109,69 & 1,17 \\
\hline & 25,16 & 319,46 & 53,59 & 298,57 & 0 & 27,08 & 321,55 & 12,03 & 300,66 & 1,17 \\
\hline & 25,19 & 320,96 & 8,36 & 300,07 & 0 & 27,08 & 40,35 & 76,82 & 19,46 & 0,21 \\
\hline & 25,19 & 315,54 & 47,98 & 294,65 & 0 & 27,13 & 133,1 & 14,14 & 112,21 & 0,29 \\
\hline & 25,21 & 311,65 & 44,01 & 290,76 & 1,51 & 27,16 & 289,4 & 9,7 & 268,51 & 0,89 \\
\hline & 25,23 & 88,08 & 58,41 & 67,19 & 0 & 27,19 & 171,12 & 54,6 & 150,23 & 0 \\
\hline & 25,23 & 138,64 & 46,72 & 117,75 & 0 & 27,19 & 166,65 & 28,9 & 145,76 & 0 \\
\hline & 25,27 & 324 & 48 & 303,11 & 0 & 27,19 & 320,16 & 19,8 & 299,27 & 1,98 \\
\hline & 25,29 & 345 & 14 & 324,11 & 0 & 27,24 & 38,94 & 78 & 18,05 & 0 \\
\hline & 25,33 & 116,23 & 45,57 & 95,34 & 0 & 27,34 & 234,17 & 36,09 & 213,28 & 0 \\
\hline & 25,34 & 318,55 & 65,75 & 297,66 & 0 & 27,45 & 149,45 & 26,88 & 128,56 & 0 \\
\hline
\end{tabular}




\begin{tabular}{|c|c|c|c|c|c|c|c|c|c|c|}
\hline 4544 & Depth & Azimuth & Dip & Declinado & Aperture & Depth & Azimuth & Dip & Declinado & Aperture \\
\hline & 27,49 & 307,29 & \begin{tabular}{|r|}
58,78 \\
\end{tabular} & 286,4 & 0 & 29,81 & 147,96 & 5,65 & 127,07 & 0 \\
\hline & 27,53 & 323 & 23,07 & 302,11 & 1,1 & 29,87 & 306,73 & 44,19 & 285,84 & 0 \\
\hline & 27,59 & 309,79 & 21,01 & 288,9 & 0 & 29,87 & 134,12 & 18,11 & 113,23 & 0 \\
\hline & 27,62 & 270,66 & 7,18 & 249,77 & 1,19 & 29,94 & 109 & 23 & 88,11 & 0 \\
\hline & 27,63 & 323,78 & 15,11 & 302,89 & 0 & 29,98 & 310 & 69 & 289,11 & 0 \\
\hline & 27,63 & 41,55 & 54,65 & 20,66 & 0 & 30,04 & 134 & 22 & 113,11 & 0 \\
\hline & 27,67 & 43,26 & 80,42 & 22,37 & 0 & 30,08 & 139 & 15 & 118,11 & 3,05 \\
\hline & 27,7 & 301,28 & 43,29 & 280,39 & 0 & 30,09 & 120 & 13 & 99,11 & 0 \\
\hline & 27,74 & 202,16 & 3,6 & 181,27 & 0 & 30,14 & 143 & 18,57 & 122,11 & 0 \\
\hline & 27,75 & 125,27 & 56,93 & 104,38 & 0 & 30,21 & 97 & 30 & 76,11 & 0 \\
\hline & 27,81 & 172,52 & 16,54 & 151,63 & 0 & 30,22 & 92 & 37 & 71,11 & 0 \\
\hline & 27,81 & 303,24 & 20,86 & 282,35 & 0 & 30,25 & 308,72 & 52,41 & 287,83 & 0 \\
\hline & 27,81 & 119,81 & 63,31 & 98,92 & 0 & 30,26 & 105 & 14,79 & 84,11 & 2,93 \\
\hline & 27,81 & 147,5 & 21,9 & 126,61 & 0 & 30,28 & 108,53 & 17,33 & 87,64 & 0 \\
\hline & 28 & 314,14 & 49,84 & 293,25 & 0 & 30,29 & 319,63 & 63,45 & 298,74 & 0 \\
\hline & 28,01 & 142,46 & 23,37 & \begin{tabular}{|l|}
121,57 \\
\end{tabular} & 0 & 30,38 & 318,58 & 47,04 & 297,69 & 0 \\
\hline & 28,06 & 104,97 & 32,46 & 84,08 & 0 & 30,42 & 312,94 & 17,01 & 292,05 & 0 \\
\hline & 28,16 & 146,92 & 14,31 & 126,03 & 0 & 30,5 & 68 & 24 & 47,11 & 0 \\
\hline & 28,17 & 266,84 & 58,41 & 245,95 & 0 & 30,5 & 322,04 & 55,99 & 301,15 & 0 \\
\hline & 28,2 & 114,41 & 19,49 & 93,52 & 0 & 30,54 & 315,12 & 76,13 & 294,23 & 0 \\
\hline & 28,26 & 0 & 0 & 339,11 & 0 & 30,59 & 66,06 & 10,37 & 45,17 & 1,47 \\
\hline & 28,27 & 54,26 & 76,81 & 33,37 & 0 & 30,61 & 132,13 & 27,02 & 111,24 & 2,43 \\
\hline & 28,27 & 292,89 & 39,83 & 272 & 0 & 30,66 & 132,13 & 30,58 & 111,24 & 2,32 \\
\hline & 28,3 & 313,13 & 34,14 & 292,24 & 0 & 30,71 & 224,86 & 68 & 203,97 & 0 \\
\hline & 28,33 & 133,98 & 53,23 & 113,09 & 0 & 30,71 & 144,88 & 78,75 & 123,99 & 0 \\
\hline & 28,41 & 326,87 & 53,77 & 305,98 & 0 & 30,79 & 145 & 22,49 & 124,11 & 1,39 \\
\hline & 28,45 & 220 & 17,01 & 199,11 & 0 & 30,95 & 318,58 & 56,26 & 297,69 & 0 \\
\hline & 28,5 & 150 & 68,26 & 129,11 & 0 & 31,02 & 137 & 20 & 116,11 & 0 \\
\hline & 28,52 & 327,01 & 74,81 & 306,12 & 0 & 31,09 & 184,04 & 24,94 & 163,15 & 0 \\
\hline & 28,53 & 156,88 & 68,72 & 135,99 & 0 & 31,1 & 336,93 & 44,19 & 316,04 & 0 \\
\hline & 28,65 & 200 & 12 & 179,11 & 0 & 31,16 & 146,92 & 10,37 & 126,03 & 0 \\
\hline & 28,7 & 139,95 & 30,71 & 119,06 & 0 & 31,27 & 141 & 25,92 & 120,11 & 4,87 \\
\hline & 28,7 & 204,7 & 8,87 & 183,81 & 0 & 31,27 & 332,84 & 48,52 & 311,95 & 0 \\
\hline & 28,73 & 206 & 73 & 185,11 & 0 & 31,35 & 244,58 & 66,15 & 223,69 & 0 \\
\hline & 28,79 & 257 & 19 & 236,11 & 0 & 31,39 & 52 & 34,37 & 31,11 & 0 \\
\hline & 28,82 & 242,13 & 23,65 & 221,24 & 0 & 31,4 & 307 & 18,88 & 286,11 & 0 \\
\hline & 28,82 & 115,88 & 56,73 & 94,99 & 0 & 31,41 & 177 & 14,47 & 156,11 & 0 \\
\hline & 28,87 & 339 & 46,72 & 318,11 & 0 & 31,46 & 181 & 6 & 160,11 & 0 \\
\hline & 28,88 & 204 & 9 & 183,11 & 0 & 31,5 & 58 & 13,17 & 37,11 & 0 \\
\hline & 28,9 & 344 & 43,47 & 323,11 & 0 & 31,54 & 152,52 & 76,5 & 131,63 & 0 \\
\hline & 28,92 & 301,28 & 24,94 & 280,39 & 0 & 31,58 & 161 & 18 & 140,11 & 2,57 \\
\hline & 28,95 & 294,43 & 43,56 & 273,54 & 0 & 31,59 & 129 & 14 & 108,11 & 0 \\
\hline & 28,97 & 283,55 & 21,6 & 262,66 & 0 & 31,65 & 332 & 78,16 & 311,11 & 0 \\
\hline & 29,02 & 304,74 & 31,22 & 283,85 & 0 & 31,72 & 20 & 17 & 359,11 & 0 \\
\hline & 29,09 & 312 & 46,72 & 291,11 & 0 & 31,91 & 46,83 & 7,86 & 25,94 & 0 \\
\hline & 29,11 & 305,79 & 39,73 & 284,9 & 0 & 32,02 & 73 & 43,83 & 52,11 & 0 \\
\hline & 29,15 & 307,25 & 45,9 & 286,36 & 0 & 32,04 & 72,41 & 40 & 51,52 & 0 \\
\hline & 29,2 & 301,8 & 62,49 & 280,91 & 0 & 32,07 & 150 & 22 & 129,11 & 0 \\
\hline & 29,26 & 49,32 & 68,72 & 28,43 & 0 & 32,07 & 321,41 & 36,09 & 300,52 & 0 \\
\hline & 29,29 & 52,33 & 57,74 & 31,44 & 0 & 32,21 & 324,49 & 33,66 & 303,6 & 0 \\
\hline & 29,3 & 305,26 & 63,65 & 284,37 & 0 & 32,29 & 148,9 & 59,42 & 128,01 & 0 \\
\hline & 29,36 & 319,52 & 64,08 & 298,63 & 0 & 32,33 & 160,2 & 34,02 & 139,31 & 0 \\
\hline & 29,39 & 315,64 & 62,49 & 294,75 & 0 & 32,43 & 174,48 & 31,22 & 153,59 & 0 \\
\hline & 29,41 & 49,4 & 79,47 & 28,51 & 0 & 32,5 & 145,88 & 26,75 & 124,99 & 0 \\
\hline & 29,61 & 308,72 & 66,23 & 287,83 & 0 & 32,5 & 312,12 & 13,49 & 291,23 & 0 \\
\hline & 29,61 & 321 & 7 & 300,11 & 0 & 32,61 & 328,34 & 56,68 & 307,45 & 0 \\
\hline & 29,78 & 308,2 & 52,98 & 287,31 & 0 & 32,69 & 158,74 & 26,61 & 137,85 & 0 \\
\hline
\end{tabular}




\begin{tabular}{|c|c|c|c|c|c|c|c|c|c|c|}
\hline 4544 & Depth & Azimuth & Dip & Declinado & Aperture & Depth & Azimuth & Dip & Declinado & Aperture \\
\hline & 32,71 & 329,79 & 64,41 & 308,9 & 0 & 35,83 & 103,48 & 44,01 & 82,59 & 0 \\
\hline & 32,82 & 316,59 & 63,85 & 295,7 & 0 & 35,89 & 149,92 & 74,48 & 129,03 & 0 \\
\hline & 32,89 & 311,67 & 27,29 & 290,78 & 0 & 35,91 & 36 & 30,96 & 15,11 & $\underline{0}$ \\
\hline & 32,95 & 314,58 & 58,41 & 293,69 & 0 & 35,91 & 95 & 50 & 74,11 & 0 \\
\hline & 32,99 & 310,67 & 60,74 & 289,78 & 0 & 35,93 & 327,9 & 65,75 & 307,01 & 0 \\
\hline & 33,04 & 319,61 & 62,15 & 298,72 & 0 & 36,19 & 121,74 & 43,11 & 100,85 & 0 \\
\hline & 33,18 & 329 & 23,94 & 308,11 & 1,37 & 36,36 & 148,97 & 41,22 & 128,08 & 0 \\
\hline & 33,2 & 4,54 & 50,61 & 343,65 & 0 & 36,65 & 146 & 33,18 & 125,11 & 2,18 \\
\hline & 33,22 & 340,33 & 37,95 & 319,44 & 0 & 36,72 & 31,62 & 68,4 & 10,73 & 0 \\
\hline & 33,3 & 329 & 42,55 & 308,11 & 1,99 & 36,72 & 321,48 & 66,51 & 300,59 & 0 \\
\hline & 33,32 & 332 & 9,87 & 311,11 & 1,18 & 36,81 & 148,97 & 56,31 & 128,08 & 0 \\
\hline & 33,35 & 315,14 & 21,01 & 294,25 & 0 & 36,89 & 153,37 & 73,26 & 132,48 & 0 \\
\hline & 33,42 & 148,55 & 77 & 127,66 & 0 & 36,91 & 326,95 & 42,27 & 306,06 & 0 \\
\hline & 33,43 & 150 & 66,21 & 129,11 & 0 & 37,12 & 130 & 47,67 & 109,11 & 1,82 \\
\hline & 33,44 & 350,6 & 40,63 & 329,71 & 0 & 37,18 & 147,42 & 71,99 & 126,53 & 0 \\
\hline & 33,44 & 335,62 & 78,84 & 314,73 & 0 & 37,27 & 147,9 & 62,3 & 127,01 & 0 \\
\hline & 33,46 & 38 & 68,21 & 17,11 & 0 & 37,35 & 147,31 & 56,83 & 126,42 & 0 \\
\hline & 33,5 & 159,3 & 46,96 & 138,41 & 0 & 37,51 & 137,56 & 52,09 & 116,67 & 0 \\
\hline & 33,52 & 135,34 & 66,97 & 114,45 & 0 & 37,54 & 230 & 68,21 & 209,11 & 0 \\
\hline & 33,53 & 64,01 & 50,89 & 43,12 & 0 & 37,59 & 322,07 & 65,1 & 301,18 & 0 \\
\hline & 33,62 & 152,82 & 77,64 & 131,93 & 0 & 37,71 & 149,92 & 70,81 & 129,03 & 0 \\
\hline & 33,76 & 143,91 & 77,77 & 123,02 & 0 & 37,75 & 132,56 & 52,6 & 111,67 & 0 \\
\hline & 33,77 & 162,66 & 76,01 & 141,77 & 0 & 37,8 & 258 & 75 & 237,11 & 0 \\
\hline & 33,95 & 307,15 & 30,2 & 286,26 & 0 & 37,87 & 327,42 & 74,91 & 306,53 & 0 \\
\hline & 34,02 & 165,67 & 14,79 & 144,78 & 0 & 37,92 & 107,38 & 75,38 & 86,49 & 0 \\
\hline & 34,21 & 311,63 & 38,8 & 290,74 & 0 & 38,05 & 163,24 & 53,83 & 142,35 & 0 \\
\hline & 34,22 & 142,91 & 74,73 & 122,02 & 0 & 38,08 & 158,72 & 55,99 & 137,83 & 0 \\
\hline & 34,29 & 316,52 & 12,52 & 295,63 & 0 & 38,19 & 158,72 & 58,27 & 137,83 & 0 \\
\hline & 34,44 & 320,53 & 57,88 & 299,64 & 0 & 38,31 & 148,38 & 74,3 & 127,49 & 0 \\
\hline & 34,5 & 33,05 & 62,71 & 12,16 & 0 & 38,33 & 63,49 & 28,24 & 42,6 & 0 \\
\hline & 34,53 & 140,41 & 76,48 & 119,52 & 0 & 38,44 & 339,79 & 55,28 & 318,9 & 0 \\
\hline & 34,62 & 331,94 & 58,07 & 311,05 & 0 & 38,46 & 142,31 & 76,2 & 121,42 & 0 \\
\hline & 34,73 & 156,22 & 33,42 & 135,33 & 0 & 38,47 & 144,33 & 61,54 & 123,44 & 0 \\
\hline & 34,87 & 356,55 & 19,8 & 335,66 & 0 & & & & & \\
\hline & 34,91 & 16,64 & 13,33 & 355,75 & 0 & & & & & \\
\hline & 34,93 & 191,77 & 21,16 & 170,88 & 0 & & & & & \\
\hline & 34,97 & 134 & 13 & 113,11 & 0 & & & & & \\
\hline & 34,99 & 149,92 & 77,25 & 129,03 & 0 & & & & & \\
\hline & 35,01 & 156,82 & 7,86 & 135,93 & 0 & & & & & \\
\hline & 35,07 & 166,57 & 64,85 & 145,68 & 0 & & & & & \\
\hline & 35,08 & 338,84 & 20,41 & 317,95 & 0 & & & & & \\
\hline & 35,12 & 324,45 & 12,68 & 303,56 & 0 & & & & & \\
\hline & 35,2 & 172,51 & 24,8 & 151,62 & 0 & & & & & \\
\hline & 35,24 & 327,78 & 39,83 & 306,89 & 0 & & & & & \\
\hline & 35,24 & 153,37 & 27,56 & 132,48 & 0 & & & & & \\
\hline & 35,31 & 199,26 & 75,07 & 178,37 & 0 & & & & & \\
\hline & 35,32 & 186,9 & 67,61 & 166,01 & 1,49 & & & & & \\
\hline & 35,36 & 180,48 & 30,33 & 159,59 & 2,33 & & & & & \\
\hline & 35,37 & 41,02 & 29,16 & 20,13 & 3,4 & & & & & \\
\hline & 35,46 & 184,4 & 23,51 & 163,51 & 0 & & & & & \\
\hline & 35,5 & 154,8 & 36,32 & 133,91 & 0 & & & & & \\
\hline & 35,58 & 153,73 & 22,78 & 132,84 & 0 & & & & & \\
\hline & 35,6 & 326,12 & 23,65 & 305,23 & 0 & & & & & \\
\hline & 35,63 & 136,49 & 47,04 & 115,6 & 0 & & & & & \\
\hline & 35,7 & 118,94 & 53 & 98,05 & 0 & & & & & \\
\hline & 35,74 & 121,76 & 52 & 100,87 & 0 & & & & & \\
\hline & 35,77 & 147,45 & 41,61 & 126,56 & 0 & & & & & \\
\hline
\end{tabular}




\begin{tabular}{|c|c|c|c|c|c|c|c|c|c|c|}
\hline 4545 & Depth & Azimuth & Dip & Declinado & Aperture & Depth & Azimuth & Dip & Declinado & Aperture \\
\hline & 22,74 & 301,28 & 26,47 & 280,39 & 0 & 27,86 & 115,34 & 11,36 & 94,45 & 0 \\
\hline & 22,74 & 145,96 & 10,2 & 125,07 & 0 & 27,88 & 172,52 & 23,94 & 151,63 & 0 \\
\hline & 22,75 & 139,53 & 32,46 & 118,64 & 0 & 27,9 & 314,7 & 67,48 & 293,81 & 0 \\
\hline & 22,86 & 333,16 & 56,36 & 312,27 & 0 & 27,96 & 297,29 & 80,29 & 276,4 & 0 \\
\hline & 22,9 & 82,35 & 23,51 & 61,46 & 0 & 28,09 & 61 & 15,11 & 40,11 & 0 \\
\hline & 22,93 & 163,71 & 56,57 & 142,82 & 0 & 28,26 & 141,96 & 43,2 & 121,07 & 0 \\
\hline & 22,94 & 151,41 & 74,24 & 130,52 & 0 & 28,33 & 156,73 & 51,23 & 135,84 & 4,13 \\
\hline & 23,08 & 324,63 & 61,5 & 303,74 & 0 & 28,35 & 296,46 & 35,53 & 275,57 & 0 \\
\hline & 23,11 & 324,91 & 71,6 & 304,02 & 0 & 28,35 & 149,24 & 30,2 & 128,35 & 0 \\
\hline & 23,21 & 101,92 & 67,58 & 81,03 & 0 & 28,35 & 156,28 & 50,54 & 135,39 & 0 \\
\hline & 23,28 & 161,34 & 43,29 & 140,45 & 0 & 28,5 & 303,73 & 48,06 & 282,84 & 0 \\
\hline & 23,42 & 281,57 & 43,29 & 260,68 & 0 & 28,58 & 297,8 & 28,1 & 276,91 & 2,38 \\
\hline & 23,78 & 148,89 & 70,08 & 128 & 0 & 28,79 & 300,26 & 63,41 & 279,37 & 0 \\
\hline & 23,88 & 95,63 & 4,12 & 74,74 & 0 & 28,87 & 302,82 & 33,66 & 281,93 & 0 \\
\hline & 23,88 & 259,9 & 46,4 & 239,01 & 0 & 28,88 & 304,22 & 31,59 & 283,33 & 1,79 \\
\hline & 24,15 & 159,24 & 64,02 & 138,35 & 0 & 28,9 & 128,2 & 77,13 & 107,31 & 0 \\
\hline & 24,32 & 59 & 8,87 & 38,11 & 2 & 29,05 & 140,64 & 55,44 & 119,75 & 0 \\
\hline & 24,38 & 51 & 5,3 & 30,11 & 0 & 29,08 & 143,02 & 55 & 122,13 & 0 \\
\hline & 24,46 & 122 & 11,8 & 101,11 & 0 & 29,19 & 172,1 & 39,62 & 151,21 & 0 \\
\hline & 24,56 & 260,88 & 12,52 & 239,99 & 0 & 29,25 & 149,03 & 55,99 & 128,14 & 0 \\
\hline & 24,7 & 288,98 & 14,31 & 268,09 & 0 & 29,45 & 330,78 & 39,21 & 309,89 & 0 \\
\hline & 24,94 & 327,43 & 7,52 & 306,54 & 0 & 29,49 & 151,27 & 52,02 & 130,38 & 0 \\
\hline & 24,96 & 144,56 & 70,02 & 123,67 & 0 & 29,56 & 146,94 & 53,53 & 126,05 & 0 \\
\hline & 25,05 & 142,46 & 70,36 & 121,57 & 0,71 & 29,62 & 148,75 & 45,23 & 127,86 & 0 \\
\hline & 25,06 & 285,48 & 54,42 & 264,59 & \begin{tabular}{l|l}
0,52 \\
\end{tabular} & 29,69 & 144,42 & 55,11 & 123,53 & 0 \\
\hline & 25,07 & 308,13 & 28,9 & 287,24 & 0 & 29,77 & 301,87 & 32,21 & 280,98 & 0 \\
\hline & 25,23 & 291,91 & 38,38 & 271,02 & 0 & 29,79 & 315,54 & 13,66 & 294,65 & 0 \\
\hline & 25,42 & 148,33 & 62,41 & 127,44 & 0 & 29,85 & 123 & 17,2 & 102,11 & 0 \\
\hline & 25,57 & 121,21 & 72,39 & 100,32 & 0 & 29,89 & 92,69 & 76,83 & 71,8 & 0 \\
\hline & 25,63 & 318,06 & 52,22 & 297,17 & 0 & 29,92 & 135,05 & 49,77 & 114,16 & 0 \\
\hline & 25,73 & 142,46 & 75,93 & 121,57 & 0 & 30,02 & 310,51 & 69,25 & 289,62 & 0 \\
\hline & 25,8 & 163,15 & 74,3 & 142,26 & 0 & 30,03 & 310,74 & 40,83 & 289,85 & 2,27 \\
\hline & 25,98 & 245,08 & \begin{tabular}{|c|}
35,07 \\
\end{tabular} & 224,19 & 0 & 30,04 & 72,94 & 75,16 & 52,05 & 0 \\
\hline & 26,14 & 152,33 & \begin{tabular}{|l|}
69,8 \\
\end{tabular} & 131,44 & 0 & 30,08 & 60,19 & 76,83 & 39,3 & $\overline{0}$ \\
\hline & 26,14 & 289,02 & 49,55 & 268,13 & 0 & 30,12 & 149,45 & 22,93 & 128,56 & 0 \\
\hline & 26,16 & 137,06 & 14,63 & 116,17 & 0 & 30,19 & 122,19 & 43,92 & 101,3 & 0 \\
\hline & 26,2 & 286,56 & 46,56 & 265,67 & 0 & 30,3 & 146,42 & 76,03 & 125,53 & 0 \\
\hline & 26,2 & 154,32 & 69,12 & 133,43 & 0 & 30,36 & 155,32 & 41,02 & 134,43 & 0 \\
\hline & 26,25 & 288,02 & 47,52 & 267,13 & 0 & 30,43 & 148,96 & 76,07 & 128,07 & 0 \\
\hline & 26,45 & 325,89 & 37,74 & 305 & 0 & 30,48 & 312,61 & 35,75 & 291,72 & 1,7 \\
\hline & 26,55 & 162 & 41,02 & 141,11 & 2 & 30,5 & 146,38 & 19,19 & 125,49 & 1,98 \\
\hline & 26,69 & 151,33 & 74,86 & 130,44 & 0 & 30,55 & 0 & 0 & 339,11 & 0 \\
\hline & 26,74 & 153,32 & 74,67 & 132,43 & 0 & 30,61 & 312,47 & 33,9 & 291,58 & 1,74 \\
\hline & 26,74 & 171,14 & 22,93 & 150,25 & 0 & 30,62 & 136,06 & 55,39 & 115,17 & 0 \\
\hline & 26,92 & 323,01 & 36,65 & 302,12 & 0 & 30,69 & 128,06 & 43,92 & 107,17 & 0 \\
\hline & 26,95 & 320,56 & 34,37 & 299,67 & 0 & 30,7 & 296,39 & 49,33 & 275,5 & 0 \\
\hline & 27,05 & 140,06 & 49,48 & 119,17 & 1,95 & 30,8 & 314,14 & 36,2 & 293,25 & 1,69 \\
\hline & 27,15 & 351,64 & 41,89 & 330,75 & 0 & 30,8 & 357,48 & 49,62 & 336,59 & 1,36 \\
\hline & 27,37 & 162,14 & 75,6 & 141,25 & 0 & 30,81 & 297,37 & 10,54 & 276,48 & 2,06 \\
\hline & 27,49 & 147,91 & 52,28 & 127,02 & 2,02 & 30,83 & 126,66 & 52,47 & 105,77 & 1,28 \\
\hline & 27,52 & 121,21 & 13,82 & 100,32 & 0 & 30,96 & 110,46 & 14,1 & 89,57 & 0 \\
\hline & 27,58 & 100,1 & 17,64 & 79,21 & 0 & 30,99 & 92,02 & 8,3 & 71,13 & 0 \\
\hline & 27,59 & 177,55 & 13,01 & 156,66 & 2,05 & 31 & 4,58 & 37,09 & 343,69 & 0 \\
\hline & 27,66 & 150,85 & 43,56 & 129,96 & 0 & 31,07 & 128,32 & 11,7 & 107,43 & 0 \\
\hline & 27,68 & 152,09 & 41,99 & 131,2 & 0 & 31,2 & 143,55 & 44,54 & 122,66 & 1,5 \\
\hline & 27,76 & 148,33 & 67,23 & 127,44 & 0 & 31,45 & 144 & 66,32 & 123,11 & 0 \\
\hline & 27,77 & 142,04 & 10,87 & 121,15 & 0 & 31,53 & 109 & 51,83 & 88,11 & 0 \\
\hline
\end{tabular}




\begin{tabular}{|c|c|c|c|c|c|c|c|c|c|c|}
\hline 4545 & Depth & Azimuth & Dip & Declinado & Aperture & Depth & Azimuth & Dip & Declinado & Aperture \\
\hline & 31,57 & 105,11 & 48,74 & 84,22 & 0 & 35,1 & 154,32 & 78,24 & 133,43 & 0 \\
\hline & 31,65 & 100 & 50,4 & 79,11 & 0 & 35,11 & 156,82 & 36,2 & 135,93 & 0 \\
\hline & 31,68 & 191,91 & 32,94 & 171,02 & 0 & 35,25 & 134,23 & 41,51 & 113,34 & 0 \\
\hline & 31,73 & 142,51 & 74,98 & 121,62 & 0 & 35,26 & 320,05 & 75,25 & 299,16 & 0 \\
\hline & 31,74 & 154,35 & 7,86 & 133,46 & 0 & 35,36 & 152,3 & 72,05 & 131,41 & 0 \\
\hline & 31,8 & 108,01 & 41,8 & 87,12 & 0 & 35,59 & 326,47 & 77,29 & 305,58 & 0 \\
\hline & 31,84 & 141,57 & 74,74 & 120,68 & 0 & 35,63 & 158,66 & 61,81 & 137,77 & 0 \\
\hline & 31,93 & 133,83 & 67,33 & 112,94 & 0 & 35,66 & 151,35 & 73,54 & 130,46 & 0 \\
\hline & 31,95 & 122,09 & 38,59 & 101,2 & 0 & 35,69 & 323,03 & 78,15 & 302,14 & 0 \\
\hline & 31,96 & 340,29 & 45,57 & 319,4 & 0 & 35,78 & 201 & 5,9 & 180,11 & 0 \\
\hline & 32,04 & 31 & 5,82 & 10,11 & 0 & 35,91 & 289 & 55,6 & 268,11 & 0 \\
\hline & 32,17 & 182,31 & 40,43 & \begin{tabular}{l|}
161,42 \\
\end{tabular} & 0 & 35,98 & 334,32 & 79,25 & 313,43 & 0 \\
\hline & 32,17 & 104,85 & 57,78 & 83,96 & 0 & 36,03 & 345,06 & 63,62 & 324,17 & 0 \\
\hline & 32,19 & 337,98 & 25,92 & 317,09 & 0 & 36,12 & 85,24 & 5,65 & 64,35 & 0 \\
\hline & 32,37 & 98,56 & 42,74 & 77,67 & 0 & 36,12 & 293,9 & 9,87 & 273,01 & 0 \\
\hline & 32,46 & 93,39 & 49,62 & 72,5 & 0 & 36,15 & 150,87 & 80,96 & 129,98 & 0 \\
\hline & 32,53 & 130,02 & 45,8 & 109,13 & 0 & 36,28 & 150,87 & 82,05 & 129,98 & 0 \\
\hline & 32,57 & 130,5 & 40,83 & 109,61 & 0 & 36,31 & 248,96 & 71,63 & 228,07 & 0 \\
\hline & 32,66 & 116,74 & 50,54 & 95,85 & 0 & 36,32 & 150,4 & 51,56 & 129,51 & 0 \\
\hline & 32,76 & 159,38 & 35,98 & 138,49 & 0 & 36,4 & 319,1 & 62,3 & 298,21 & 0 \\
\hline & 32,8 & 147,36 & 38,38 & 126,47 & 0 & 36,4 & 33,05 & 75,95 & 12,16 & 0 \\
\hline & 32,85 & 124,71 & 68,17 & 103,82 & 0 & 36,62 & 144,98 & 35,75 & 124,09 & 0 \\
\hline & 32,88 & 105,97 & 50,61 & 85,08 & 0 & 36,69 & 335,67 & 18,11 & 314,78 & 0 \\
\hline & 32,91 & 96,75 & 45,23 & 75,86 & 0 & 36,78 & 127,64 & 33,78 & 106,75 & 0 \\
\hline & 33,1 & 151,35 & 82,62 & 130,46 & 0 & 36,78 & 305,2 & 57,93 & 284,31 & 0 \\
\hline & 33,14 & 331,9 & 56,2 & 311,01 & 0 & 36,94 & 164,83 & 58,22 & 143,94 & 0 \\
\hline & 33,17 & 153,37 & 45,82 & 132,48 & 0 & 36,96 & 28,52 & 24,8 & 7,63 & 0 \\
\hline & 33,18 & 149,87 & 56,73 & 128,98 & 0 & 37,16 & 148,33 & 63,75 & 127,44 & 0 \\
\hline & 33,3 & 12,3 & 46,88 & 351,41 & 0 & 37,18 & 110,45 & 14,14 & 89,56 & 0 \\
\hline & 33,45 & 92,62 & 48,89 & 71,73 & 0 & 37,21 & 290,94 & 65,16 & 270,05 & 0 \\
\hline & 33,6 & 150,87 & 59,64 & 129,98 & 0 & 37,23 & 95,21 & 71,04 & 74,32 & 0 \\
\hline & 33,7 & 162,66 & 82,64 & 141,77 & 0 & 37,48 & 2,52 & 60,62 & 341,63 & 0 \\
\hline & 33,72 & 340,74 & 59,28 & 319,85 & 0 & 37,56 & 117,72 & 56,88 & 96,83 & 0 \\
\hline & 33,74 & 167,16 & 60,16 & 146,27 & 0 & 37,57 & 121,21 & 56,88 & 100,32 & 0 \\
\hline & 33,82 & 159,79 & 66,29 & 138,9 & 0 & 37,68 & 154,35 & 61,35 & 133,46 & 0 \\
\hline & 33,89 & 336,82 & 63,79 & 315,93 & 0 & 37,77 & 133,51 & 78,86 & 112,62 & 0 \\
\hline & 33,92 & 91,19 & 2,23 & \begin{tabular}{l|l|}
70,3 \\
\end{tabular} & 0 & 37,78 & 185,94 & 52,22 & 165,05 & 0 \\
\hline & 33,94 & 161,22 & 67,53 & 140,33 & 0 & 37,87 & 242,56 & 69,21 & 221,67 & 0 \\
\hline & 34,02 & 177,03 & 69,94 & 156,14 & 0 & 37,89 & 178,39 & 32,82 & 157,5 & 0 \\
\hline & 34,09 & 160,15 & 73,92 & 139,26 & 0 & 37,91 & 144,42 & 70,44 & 123,53 & 0 \\
\hline & 34,11 & 333,37 & 56,62 & 312,48 & 0 & 38,2 & 332,38 & 81,39 & 311,49 & 0 \\
\hline & 34,2 & 167,64 & 47,6 & 146,75 & 0 & 38,23 & 155,32 & 39,21 & 134,43 & 0 \\
\hline & 34,2 & 155,27 & 74,15 & 134,38 & 0 & 38,25 & 155,74 & 38,8 & 134,85 & 0 \\
\hline & 34,3 & 311,73 & 27,29 & 290,84 & 0 & 38,29 & 151 & 37,95 & 130,11 & 0 \\
\hline & 34,34 & 314,58 & 37,31 & 293,69 & 0 & 38,34 & 142,88 & 41,41 & 121,99 & 0 \\
\hline & 34,36 & 133,51 & 63,34 & \begin{tabular}{|l|}
112,62 \\
\end{tabular} & 0 & 38,43 & 331,34 & 75,09 & 310,45 & 0 \\
\hline & 34,37 & 316,13 & 46,96 & 295,24 & 0 & 38,44 & 137,71 & 74,52 & 116,82 & 0 \\
\hline & 34,4 & 134,11 & 53,95 & 113,22 & 0 & 38,66 & 327,84 & 77,26 & 306,95 & 0 \\
\hline & 34,49 & 145,88 & 77,32 & 124,99 & 0 & 38,69 & 330,36 & 32,82 & 309,47 & 0 \\
\hline & 34,5 & 142,43 & 60,45 & 121,54 & 0 & 38,73 & 149,87 & 47,44 & 128,98 & 0 \\
\hline & 34,59 & 135,06 & 16,7 & 114,17 & 0 & 38,83 & 124 & 47,67 & 103,11 & 0 \\
\hline & 34,59 & 239,09 & 77,55 & 218,2 & 0 & 38,88 & 155,32 & 71,16 & 134,43 & 0 \\
\hline & 34,64 & 331,47 & 16,7 & 310,58 & 0 & 38,98 & 151,83 & 74,2 & 130,94 & 0 \\
\hline & 34,65 & 143,86 & 77,01 & 122,97 & 0 & 39,07 & 150,29 & 79,89 & 129,4 & 0 \\
\hline & 34,68 & 142,91 & 76,97 & 122,02 & 0 & 39,16 & 148,47 & 66,09 & 127,58 & 0 \\
\hline & 34,81 & 152,89 & 80,71 & 132 & 0 & 39,18 & 152,95 & 76,11 & 132,06 & 0 \\
\hline & 34,82 & 322,07 & 50,05 & 301,18 & 0 & 39,2 & 329,52 & 76,81 & 308,63 & 0 \\
\hline
\end{tabular}




\begin{tabular}{|c|c|c|c|c|c|c|c|c|c|c|}
\hline 4548 & Depth & Azimuth & Dip & Declinado & Aperture & Depth & Azimuth & Dip & Declinado & Aperture \\
\hline & 30,35 & 146,77 & 46,88 & 125,88 & 0 & 35,16 & 312,71 & 49,62 & 291,82 & 0 \\
\hline & 30,5 & 148,17 & 68,26 & 127,28 & 0 & 35,19 & 146,77 & 50,82 & 125,88 & 0 \\
\hline & 30,62 & 135,86 & 51,03 & 114,97 & 0 & 35,21 & 140,89 & 52,41 & 120 & 0 \\
\hline & 30,69 & 133,48 & 63,55 & 112,59 & 0 & 35,24 & 323,27 & 32 & 302,38 & 0 \\
\hline & 30,78 & 142,85 & 68,9 & 121,96 & 0 & 35,26 & 129,69 & 55,11 & 108,8 & 0 \\
\hline & 31,04 & 316,49 & 66,81 & 295,6 & 0 & 35,33 & 129 & 63,48 & 108,11 & 0 \\
\hline & 31,04 & 139,49 & 68,1 & 118,6 & 0 & 35,34 & 310,05 & 42,64 & 289,16 & 0 \\
\hline & 31,11 & 137,4 & 64,6 & 116,51 & 0 & 35,36 & 126,96 & 60,7 & 106,07 & 0 \\
\hline & 31,21 & 142,29 & 58,27 & 121,4 & 0 & 35,39 & 124 & 60 & 103,11 & 0 \\
\hline & 31,25 & 143,27 & 57,74 & 122,38 & 0 & 35,4 & 305 & 33,9 & 284,11 & 0 \\
\hline & 31,34 & 70,66 & 74,81 & 49,77 & 0 & 35,44 & 129,98 & 60,62 & 109,09 & 0 \\
\hline & 31,36 & 153,21 & 50,12 & 132,32 & 0 & 35,55 & 133,9 & 55,83 & 113,01 & 0 \\
\hline & 31,47 & 315,65 & 58,5 & 294,76 & 0 & 35,56 & 129 & 55 & 108,11 & 0 \\
\hline & 31,48 & 136,98 & 60,95 & 116,09 & 0 & 35,67 & 134,46 & 37,31 & 113,57 & 0 \\
\hline & 31,62 & 316,91 & 54,37 & 296,02 & 0 & 35,82 & 130,4 & 37,31 & 109,51 & 0 \\
\hline & 31,69 & 137,82 & 47,44 & 116,93 & 0 & 35,84 & 317,05 & 6,5 & 296,16 & 0 \\
\hline & 31,71 & 306,55 & 40,23 & 285,66 & 0 & 35,91 & 131,52 & 46,56 & 110,63 & 0 \\
\hline & 31,87 & 141,73 & 55,39 & 120,84 & 0 & 35,98 & 128,44 & 45,74 & 107,55 & 0 \\
\hline & 31,94 & 142,71 & 59,15 & 121,82 & 0 & 36,15 & 223,58 & 68 & 202,69 & 0 \\
\hline & 31,95 & 0 & 4,8 & 339,11 & 0 & 36,21 & 144,25 & 47,44 & 123,36 & 0 \\
\hline & 32,13 & 139,91 & 68,59 & 119,02 & 0 & 36,26 & 138,8 & 44,19 & 117,91 & 0 \\
\hline & 32,14 & 309,49 & 31,09 & 288,6 & 0 & 36,29 & 134,4 & 73,48 & 113,51 & 0 \\
\hline & 32,24 & 312,15 & 57,09 & 291,26 & 0 & 36,31 & 135,86 & 47,67 & 114,97 & 0 \\
\hline & 32,36 & 136,84 & 60,95 & 115,95 & 0 & 36,45 & 141,31 & 71,84 & 120,42 & 0 \\
\hline & 32,42 & 130,96 & 60,2 & \begin{tabular}{|l|}
110,07 \\
\end{tabular} & 0 & 36,59 & 137,82 & 72,89 & 116,93 & 0 \\
\hline & 32,53 & 330,76 & 27,02 & 309,87 & 0 & 36,63 & 315,51 & 62,04 & 294,62 & 0 \\
\hline & 32,57 & 135,44 & 62,15 & 114,55 & 0 & 36,67 & 139 & 75,27 & 118,11 & 0 \\
\hline & 32,61 & 136,42 & 62,04 & 115,53 & 0 & 36,81 & 314,48 & 44,01 & 293,59 & 0 \\
\hline & 32,67 & 118,87 & 45 & 97,98 & 0 & 36,89 & 130,96 & 48,29 & 110,07 & 0 \\
\hline & 32,77 & 126,48 & 35,75 & 105,59 & 0 & 36,96 & 318,03 & 47,44 & 297,14 & 0 \\
\hline & 32,83 & 137,82 & 34,14 & 116,93 & 0 & 37,01 & 145,23 & 58,97 & 124,34 & 0 \\
\hline & 32,93 & 161,6 & 13,17 & 140,71 & 0 & 37,08 & 131,94 & 64,15 & 111,05 & 0 \\
\hline & 33,09 & 314,53 & 62,71 & 293,64 & 0 & 37,26 & 204 & 2 & 183,11 & 0 \\
\hline & 33,24 & 140,33 & 48,82 & 119,44 & 0 & 37,3 & 143,83 & 67,85 & 122,94 & 0 \\
\hline & 33,34 & 141,38 & 79,9 & 120,49 & 0 & 37,39 & 137,4 & 67,2 & 116,51 & 0 \\
\hline & 33,36 & 148,31 & 41,22 & 127,42 & 0 & 37,56 & 139,42 & 72,83 & 118,53 & 0 \\
\hline & 33,49 & 225,73 & 78,4 & 204,84 & 0 & 37,58 & 316,4 & 37 & 295,51 & 0 \\
\hline & 33,58 & 207,01 & 82,93 & 186,12 & 0 & 37,6 & 141,87 & 57,04 & 120,98 & 0 \\
\hline & 33,61 & 135,54 & 52,02 & 114,65 & 0 & 37,64 & 309,07 & 44,54 & 288,18 & 0 \\
\hline & 33,65 & 316 & 62,41 & 295,11 & 0 & 37,74 & 147,75 & 49,55 & 126,86 & 0 \\
\hline & 33,87 & 148 & 38,59 & 127,11 & 0 & 37,79 & 312,57 & 41,99 & 291,68 & 0 \\
\hline & 33,88 & 138 & 39,62 & 117,11 & 0 & 37,79 & 137,26 & 60,95 & 116,37 & 0 \\
\hline & 33,91 & 318,48 & 47,83 & 297,59 & 0 & 37,88 & 309,19 & 43,11 & 288,3 & 0 \\
\hline & 34,06 & 139,8 & 63,82 & 118,91 & 0 & 38,04 & 134,46 & 62,45 & 113,57 & 0 \\
\hline & 34,07 & 314,6 & 43,83 & 293,71 & 0 & 38,1 & 141,31 & 58,03 & 120,42 & 0 \\
\hline & 34,33 & 137,26 & 50,41 & \begin{tabular}{|l|}
116,37 \\
\end{tabular} & 0 & 38,17 & 315,09 & 33,66 & 294,2 & 0 \\
\hline & 34,41 & 37 & 81,79 & 16,11 & 0 & 38,19 & 133,9 & 54,6 & 113,01 & 0 \\
\hline & 34,42 & 325,02 & 83,15 & 304,13 & 0 & 38,26 & 326 & 44,54 & 305,11 & 0 \\
\hline & 34,43 & 136,98 & 63,48 & 116,09 & 0 & 38,3 & 148,17 & 47,2 & 127,28 & 0 \\
\hline & 34,53 & 142 & 51 & 121,11 & 0 & 38,35 & 345 & 61,27 & 324,11 & 0 \\
\hline & 34,61 & 322,92 & 50,61 & 302,03 & 0 & 38,42 & 146,21 & 52,47 & 125,32 & 0 \\
\hline & 34,7 & 140,75 & 54,54 & 119,86 & 0 & 38,47 & 338,31 & 49,62 & 317,42 & 0 \\
\hline & 34,93 & 133,34 & 63,69 & 112,45 & 0 & 38,51 & 150,13 & 37,74 & 129,24 & 0 \\
\hline & 34,96 & 318,59 & 60,28 & 297,7 & 0 & 38,62 & 306,13 & 36,87 & 285,24 & 0 \\
\hline & 34,99 & 132,5 & 65,75 & 111,61 & 0 & 38,65 & 0 & 0 & 339,11 & 0 \\
\hline & 35,1 & 122,98 & 50,61 & 102,09 & 0 & 38,69 & 65 & 23 & 44,11 & 0 \\
\hline & 35,13 & 0 & 0 & 339,11 & 0 & 38,77 & 133,06 & 46,07 & 112,17 & 0 \\
\hline
\end{tabular}




\begin{tabular}{|c|c|c|c|c|c|c|c|c|c|c|}
\hline 4548 & Depth & Azimuth & Dip & Declinado & Aperture & Depth & Azimuth & Dip & Declinado & Aperture \\
\hline & 38,82 & 140,73 & \begin{tabular}{|r|}
73,73 \\
\end{tabular} & 119,84 & 0 & 44,35 & 319,42 & 18,11 & 298,53 & 0 \\
\hline & 38,97 & 316,98 & 31,47 & 296,09 & 0 & 44,35 & 140,33 & 71,04 & 119,44 & 0 \\
\hline & 38,99 & 323,48 & 59,77 & 302,59 & 0 & 44,51 & 140,75 & 75,86 & 119,86 & 0 \\
\hline & 39,09 & 142,43 & 61,07 & 121,54 & 0 & 44,56 & 315,93 & 24,37 & 295,04 & 0 \\
\hline & 39,24 & 315,09 & 62,3 & 294,2 & 0 & 44,71 & 171,4 & 51,03 & 150,51 & 0 \\
\hline & 39,24 & 145,23 & 63,92 & 124,34 & 0 & 44,74 & 167,06 & 53,35 & 146,17 & 0 \\
\hline & 39,27 & 94 & 16 & 73,11 & 0 & 44,84 & 309,63 & 7,35 & 288,74 & 0 \\
\hline & 39,42 & 137,96 & 68,5 & 117,07 & 0 & 44,9 & 135,72 & 33,42 & 114,83 & 0 \\
\hline & 39,58 & 146,35 & 39,21 & 125,46 & 0 & 44,97 & 137,96 & 59,59 & 117,07 & 0 \\
\hline & 39,58 & 320,4 & 4,29 & 299,51 & 0 & 45,05 & 134,32 & 59,59 & 113,43 & 0 \\
\hline & 39,68 & 145,65 & 28,63 & 124,76 & 0 & 45,09 & 131,94 & 68,75 & 111,05 & 0 \\
\hline & 39,72 & 336,21 & 42,55 & \begin{tabular}{l|}
315,32 \\
\end{tabular} & 0 & 45,2 & 129,42 & 61,5 & 108,53 & 0 \\
\hline & 39,81 & 131,52 & 47,44 & 110,63 & 0 & 45,35 & 312,15 & 12,52 & 291,26 & 0 \\
\hline & 39,87 & 147,75 & 48,29 & 126,86 & 0 & 45,4 & 144,25 & 49,19 & 123,36 & 0 \\
\hline & 39,97 & 134,51 & 74,75 & 113,62 & 0 & 45,55 & 132,36 & 39,11 & 111,47 & 0 \\
\hline & 40,05 & 316,07 & 64,69 & 295,18 & 0 & & & & & \\
\hline & 40,11 & 139,77 & 61,89 & 118,88 & 0 & & & & & \\
\hline & 40,22 & 314,53 & 61,81 & 293,64 & 0 & & & & & \\
\hline & 40,3 & 138,38 & 63,62 & 117,49 & 0 & & & & & \\
\hline & 40,37 & 147,75 & 65,58 & 126,86 & 0 & & & & & \\
\hline & 40,48 & 141,87 & 64,38 & 120,98 & 0 & & & & & \\
\hline & 40,48 & 317,05 & 33,66 & 296,16 & 0 & & & & & \\
\hline & 40,62 & 146,77 & 63,58 & 125,88 & 0 & & & & & \\
\hline & 40,7 & 140,75 & 68,1 & 119,86 & 0 & & & & & \\
\hline & 40,79 & 314 & 55,66 & 293,11 & 1,19 & & & & & \\
\hline & 40,9 & 142,85 & 70,3 & 121,96 & 0 & & & & & \\
\hline & 40,9 & 318,03 & 66,65 & 297,14 & 0 & & & & & \\
\hline & 41,05 & 148,73 & 67,04 & 127,84 & 0 & & & & & \\
\hline & 41,14 & 135 & 63,68 & 114,11 & 0 & & & & & \\
\hline & 41,16 & 139,35 & 64,28 & 118,46 & 0 & & & & & \\
\hline & 41,28 & 140,89 & 65,69 & 120 & 0 & & & & & \\
\hline & 41,51 & 307,67 & 60,78 & 286,78 & 0 & & & & & \\
\hline & 41,65 & 321,1 & 48,59 & 300,21 & 0 & & & & & \\
\hline & 41,69 & 144,81 & 13,17 & 123,92 & 0 & & & & & \\
\hline & 41,77 & 137,26 & 67,38 & 116,37 & 0 & & & & & \\
\hline & 41,77 & 146,77 & 28,77 & 125,88 & 0 & & & & & \\
\hline & 42,03 & 142,85 & 54,83 & 121,96 & 0 & & & & & \\
\hline & 42,28 & 328,8 & 32,7 & 307,91 & 0 & & & & & \\
\hline & 42,33 & 180,91 & 25,64 & 160,02 & 0 & & & & & \\
\hline & 42,45 & 134,46 & 62,56 & 113,57 & 0 & & & & & \\
\hline & 42,47 & 319,42 & 45,4 & 298,53 & 0 & & & & & \\
\hline & 42,7 & 129,42 & 69,38 & 108,53 & 0 & & & & & \\
\hline & 42,72 & 322,5 & 51,16 & 301,61 & 0 & & & & & \\
\hline & 42,84 & 137,44 & 65,1 & 116,55 & 0 & & & & & \\
\hline & 42,99 & 140,33 & 68,02 & 119,44 & 0 & & & & & \\
\hline & 43,07 & 136,42 & 68,97 & 115,53 & 0 & & & & & \\
\hline & 43,14 & 141,87 & 69,45 & 120,98 & 0 & & & & & \\
\hline & 43,4 & 340,69 & 53,35 & 319,8 & 0 & & & & & \\
\hline & 43,42 & 141,37 & 73,99 & 120,48 & 0 & & & & & \\
\hline & 43,54 & 142,83 & 75,37 & 121,94 & 0 & & & & & \\
\hline & 43,84 & 156,14 & 14,79 & 135,25 & 0 & & & & & \\
\hline & 43,96 & 146,77 & 50,61 & 125,88 & 0 & & & & & \\
\hline & 43,99 & 137,82 & 49,84 & 116,93 & 0 & & & & & \\
\hline & 44,1 & 139,35 & 50,19 & 118,46 & 0 & & & & & \\
\hline & 44,12 & 142,29 & 68,99 & 121,4 & 0 & & & & & \\
\hline & 44,16 & 141,31 & 64,25 & 120,42 & 0 & & & & & \\
\hline & 44,19 & 142 & 65,92 & 121,11 & 0 & & & & & \\
\hline
\end{tabular}




\begin{tabular}{|c|c|c|c|c|c|c|c|c|c|c|}
\hline 4559 & Depth & Azimuth & Dip & Declinado & Aperture & Depth & Azimuth & Dip & Declinado & Aperture \\
\hline & 29,91 & 22 & 7 & 1,11 & 7,49 & 48,28 & 123,28 & 9,2 & 102,39 & 2,35 \\
\hline & 30,8 & 307 & 4 & 286,11 & 0 & 48,33 & 356,55 & 10,87 & 335,66 & 2,08 \\
\hline & 32,58 & 22,98 & 14 & 2,09 & 9,14 & 48,35 & 130,58 & 15,75 & 109,69 & 2,31 \\
\hline & 34,08 & 26,7 & 13,82 & 5,81 & 1,17 & 48,49 & 143,47 & 71,34 & 122,58 & 0 \\
\hline & 34,1 & 75,91 & 9,7 & 55,02 & 3,25 & 48,53 & 144,13 & 70,1 & 123,24 & 0 \\
\hline & 35,06 & 260 & 41,99 & 239,11 & 3,69 & 48,6 & 144,93 & 69,94 & 124,04 & 0 \\
\hline & 35,46 & 290,88 & 28,37 & 269,99 & 5,31 & 48,89 & 145,46 & 76,22 & 124,57 & 0 \\
\hline & 36,03 & 281,02 & 38,59 & 260,13 & 4,35 & 49,09 & 150,85 & 68,99 & 129,96 & 0 \\
\hline & 38 & 304,41 & 23,94 & 283,52 & 1,92 & 49,37 & 151,83 & 68,02 & 130,94 & 0 \\
\hline & 38,13 & 313 & 38 & 292,11 & 0 & 49,64 & 146,52 & 69,04 & 125,63 & 1,18 \\
\hline & 39,34 & 286 & 16,7 & 265,11 & 0 & 49,7 & 135,33 & 33,42 & 114,44 & 0 \\
\hline & 41,31 & 95 & 22,78 & 74,11 & 0 & 50,43 & 156,72 & 74,34 & 135,83 & 0 \\
\hline & 41,93 & 150,92 & 71,07 & 130,03 & 0 & & & & & \\
\hline & 42,31 & 147,9 & 66,32 & 127,01 & 0 & & & & & \\
\hline & 43,08 & 147,9 & 73,93 & 127,01 & 0 & & & & & \\
\hline & 43,41 & 315,51 & 41,41 & 294,62 & 0 & & & & & \\
\hline & 43,9 & 311 & 44,71 & 290,11 & 0 & & & & & \\
\hline & 43,95 & 292,98 & 27,56 & 272,09 & 5,67 & & & & & \\
\hline & 45,33 & 149,41 & 73,66 & 128,52 & 0 & & & & & \\
\hline & 45,4 & 133,68 & 75,47 & 112,79 & 0 & & & & & \\
\hline & 45,58 & 146,94 & 72,13 & 126,05 & 0 & & & & & \\
\hline & 45,69 & 152,81 & 70,98 & 131,92 & 0 & & & & & \\
\hline & 45,88 & 138,97 & 73,5 & 118,08 & 0 & & & & & \\
\hline & 46,14 & 146,94 & 67,85 & 126,05 & 0 & & & & & \\
\hline & 46,75 & 359,86 & 10,54 & 338,97 & 0 & & & & & \\
\hline & 46,76 & 42,36 & 9,54 & 21,47 & 1,19 & & & & & \\
\hline & 46,77 & 301,28 & 9,03 & 280,39 & 1,19 & & & & & \\
\hline & 46,77 & 329,38 & 9,54 & 308,49 & 2,07 & & & & & \\
\hline & 46,79 & 50,75 & 5,48 & 29,86 & 2,09 & & & & & \\
\hline & 46,8 & 319,46 & 6 & 298,57 & 1,2 & & & & & \\
\hline & 46,89 & 323,62 & 10,2 & 302,73 & 5,56 & & & & & \\
\hline & 47,89 & 283,53 & 6 & 262,64 & 8,36 & & & & & \\
\hline 4564 & Depth & Azimuth & Dip & Declinado & Aperture & & & & & \\
\hline & 43,98 & 154 & 9 & 133,11 & 0 & & & & & \\
\hline & 44,59 & 112 & 23,94 & 91,11 & 0 & & & & & \\
\hline & 44,69 & 174 & 27 & 153,11 & 0 & & & & & \\
\hline & 44,71 & 142 & 31 & 121,11 & 0 & & & & & \\
\hline & 44,74 & 122,48 & 33 & 101,59 & 0 & & & & & \\
\hline & 44,8 & 329,45 & 12,52 & 308,56 & 0 & & & & & \\
\hline & 45 & 143,47 & 56,93 & 122,58 & 0 & & & & & \\
\hline & 45,01 & 142,54 & 29,16 & 121,65 & 0 & & & & & \\
\hline & 45,13 & 102,42 & 42,74 & 81,53 & 0 & & & & & \\
\hline & 45,17 & 145,99 & 12,03 & 125,1 & 0 & & & & & \\
\hline & 45,22 & 323,47 & 53,89 & 302,58 & 0 & & & & & \\
\hline & 45,23 & 134,17 & 15,59 & 113,28 & 0 & & & & & \\
\hline & 45,37 & 139,78 & 61,97 & 118,89 & 0 & & & & & \\
\hline & 45,71 & 149,85 & 69,01 & 128,96 & 0 & & & & & \\
\hline & 46,42 & 200,47 & 72,67 & 179,58 & 0 & & & & & \\
\hline & 46,58 & 148,38 & 51,56 & 127,49 & 0 & & & & & \\
\hline & 46,85 & 149,53 & 51 & 128,64 & 0 & & & & & \\
\hline & 46,97 & 149 & 48 & 128,11 & 0 & & & & & \\
\hline & 47,23 & 190 & 74 & 169,11 & 0 & & & & & \\
\hline & 47,33 & 134,17 & 35,98 & 113,28 & 0 & & & & & \\
\hline & 47,43 & 135 & 32 & 114,11 & 0 & & & & & \\
\hline & 47,53 & 144,07 & 30,96 & 123,18 & 0 & & & & & \\
\hline & 47,71 & 141,08 & 70,51 & 120,19 & 0 & & & & & \\
\hline & 47,95 & 133,11 & 59,59 & 112,22 & 0 & & & & & \\
\hline
\end{tabular}




\begin{tabular}{|c|c|c|c|c|c|c|c|c|c|c|}
\hline 4572 & Depth & Azimuth & Dip & Declinado & Aperture & Depth & Azimuth & Dip & Declinado & Aperture \\
\hline & 27,34 & 358,04 & 52,92 & 337,15 & 0 & 35,55 & 158,66 & 75,95 & 137,77 & 0 \\
\hline & 27,44 & 10,8 & 53,77 & 349,91 & 0 & 35,66 & 159,17 & 76,03 & 138,28 & 0 \\
\hline & 27,56 & 11,22 & 59,33 & 350,33 & 0 & 35,88 & 160,61 & 83,31 & 139,72 & $\underline{0}$ \\
\hline & 27,7 & 345,13 & 68,17 & 324,24 & 0 & 36,17 & 359,44 & 2,4 & 338,55 & 1,2 \\
\hline & 27,7 & 349,76 & 59,94 & 328,87 & 0 & 36,18 & 0 & 2,4 & 339,11 & 1,2 \\
\hline & 27,72 & 353,41 & 58,41 & 332,52 & 0 & 36,68 & 151,28 & 80,85 & 130,39 & 0 \\
\hline & 28,08 & 1,26 & 73,44 & 340,37 & 0 & 37,02 & 152,23 & 80,42 & 131,34 & 0 \\
\hline & 28,38 & 319,89 & 71 & 299 & 0 & 37,43 & 151,32 & 77,93 & 130,43 & 0 \\
\hline & 28,41 & 145,43 & 4,8 & 124,54 & 28,5 & 37,72 & 154,16 & 82,62 & 133,27 & 0 \\
\hline & 28,42 & 327,46 & 38,48 & 306,57 & 0 & 37,87 & 77 & 15,43 & 56,11 & 1,15 \\
\hline & 28,58 & 151,4 & 82,45 & 130,51 & 0 & 37,88 & 91,54 & 21,01 & 70,65 & 0 \\
\hline & 28,59 & 354,61 & 21,6 & 333,72 & 3,19 & 38,26 & 156,63 & 83,57 & 135,74 & 0 \\
\hline & 28,75 & 88,52 & 29,94 & 67,63 & 0 & 38,69 & 153,7 & 70,02 & 132,81 & 0 \\
\hline & 28,86 & 352,56 & 40,63 & 331,67 & 0 & 38,86 & 153,14 & 69,08 & 132,25 & 0 \\
\hline & 29,32 & 324,38 & 8,36 & 303,49 & 115,16 & 39,02 & 150,2 & 70,24 & 129,31 & 0 \\
\hline & 29,43 & 342,61 & 34,49 & 321,72 & 0 & 39,2 & 164,08 & 59,9 & 143,19 & 0 \\
\hline & 29,46 & 343,59 & 20,86 & 322,7 & 0 & 39,69 & $\mathbf{1 5 5 , 1 1}$ & 34,14 & 134,22 & 0 \\
\hline & 29,64 & 156,09 & 74,85 & 135,2 & 0 & 39,94 & 153,7 & 76,74 & 132,81 & 0 \\
\hline & 29,66 & 1,54 & 39,83 & 340,65 & 0 & 40,09 & 160,16 & 74,6 & 139,27 & 0 \\
\hline & 29,9 & 356 & 50 & 335,11 & 0 & 40,27 & 151,74 & 73,74 & 130,85 & 0 \\
\hline & 30,02 & 5,3 & 56 & 344,41 & 0 & 40,85 & 167,45 & 6,16 & 146,56 & 0,31 \\
\hline & 30,1 & 356 & 70 & 335,11 & 0 & 40,86 & 118,23 & 5,82 & 97,34 & 1,3 \\
\hline & 30,21 & 41,44 & 48 & 20,55 & \begin{tabular}{l|l}
0 \\
\end{tabular} & 40,95 & 153,92 & 73 & 133,03 & 0 \\
\hline & 30,31 & 224,46 & 84,42 & 203,57 & \begin{tabular}{l|l}
0 \\
\end{tabular} & 40,98 & 156,69 & 84,35 & 135,8 & 0 \\
\hline & 30,36 & 147,75 & 78,56 & 126,86 & \begin{tabular}{l|l}
0 \\
\end{tabular} & 41,01 & 145,79 & 71,09 & 124,9 & 0 \\
\hline & 30,43 & 29,45 & 58 & 8,56 & 0 & 41,6 & 161,63 & 74,51 & 140,74 & 0 \\
\hline & 30,62 & 326,9 & 50,82 & 306,01 & 0 & 42,05 & 168 & 76 & 147,11 & 0 \\
\hline & 30,64 & 190,84 & 77,88 & 169,95 & 0 & 42,33 & 162 & 28 & 141,11 & 0 \\
\hline & 30,7 & 342,33 & 15,43 & 321,44 & 0 & 42,35 & 146,28 & 74,48 & 125,39 & 0 \\
\hline & 31,21 & 214,01 & 25,08 & 193,12 & 0 & 42,56 & 154,69 & 81,82 & 133,8 & 0 \\
\hline & 31,24 & 1,26 & 61,62 & 340,37 & 0 & 42,7 & 162,58 & 79,65 & 141,69 & 0 \\
\hline & 31,32 & 174,46 & 29,42 & 153,57 & 0 & 42,98 & 153,63 & 73,67 & 132,74 & 0 \\
\hline & 31,43 & 207,51 & 38,8 & 186,62 & 0 & 43,08 & 158,1 & 71,29 & 137,21 & 0 \\
\hline & 31,78 & 206,16 & 20,25 & 185,27 & 0 & 43,31 & 158,1 & 71,53 & 137,21 & 0 \\
\hline & 31,8 & 172,9 & 81,17 & 152,01 & 0 & 43,57 & 171,37 & 26 & 150,48 & 0 \\
\hline & 32,01 & 179,37 & 14,79 & 158,48 & \begin{tabular}{l|l}
2,03 \\
\end{tabular} & 43,67 & 149,29 & 49,55 & 128,4 & 0 \\
\hline & 32,2 & 190,45 & 29,94 & 169,56 & 0 & 43,9 & 151,67 & 74,24 & 130,78 & 0 \\
\hline & 32,23 & 246,68 & 62,92 & 225,79 & 0 & 44,03 & 156,56 & 40,23 & 135,67 & 0 \\
\hline & 32,42 & 244,16 & 73,99 & 223,27 & 0 & & & & & \\
\hline & 32,6 & 41,93 & 49,04 & 21,04 & 0 & & & & & \\
\hline & 32,65 & 243,05 & 77,34 & 222,16 & 1,94 & & & & & \\
\hline & 32,7 & 35,48 & 43,92 & 14,59 & \begin{tabular}{l|l}
0 \\
\end{tabular} & & & & & \\
\hline & 32,75 & 34,5 & 43,92 & 13,61 & \begin{tabular}{l|l}
0 \\
\end{tabular} & & & & & \\
\hline & 33,06 & 141,36 & 44,89 & 120,47 & 0 & & & & & \\
\hline & 33,1 & 236,58 & 74,43 & 215,69 & 2,67 & & & & & \\
\hline & 33,21 & 145 & 55 & 124,11 & 0 & & & & & \\
\hline & 33,37 & 127,35 & 28,9 & 106,46 & 10,06 & & & & & \\
\hline & 33,53 & 308,95 & 50,54 & 288,06 & 0 & & & & & \\
\hline & 33,7 & 160,72 & 41,99 & 139,83 & 0 & & & & & \\
\hline & 33,93 & 160,69 & 79,81 & 139,8 & 0 & & & & & \\
\hline & 34,23 & 158,65 & 81,39 & 137,76 & 0 & & & & & \\
\hline & 34,51 & 152,23 & 75,38 & 131,34 & 0 & & & & & \\
\hline & 34,83 & 13,11 & 9,2 & 352,22 & 0 & & & & & \\
\hline & 34,84 & 153,18 & 45,9 & 132,29 & 0 & & & & & \\
\hline & 34,96 & 209,56 & 34,49 & 188,67 & 0 & & & & & \\
\hline & 35,1 & 153,18 & 78,76 & 132,29 & 0 & & & & & \\
\hline & 35,22 & 150,76 & 65,46 & 129,87 & 0 & & & & & \\
\hline
\end{tabular}




\begin{tabular}{|c|c|c|c|c|c|c|c|c|c|c|}
\hline 4581 & Depth & Azimuth & Dip & Declinado & Aperture & Depth & Azimuth & Dip & Declinado & Aperture \\
\hline & 28,6 & 2,91 & 17,01 & 342,02 & 0 & 34,41 & 157 & 39 & 136,11 & 0 \\
\hline & 28,63 & 10,87 & 20,56 & 349,98 & 0 & 34,47 & 158,47 & 11,86 & 137,58 & 2,04 \\
\hline & 28,67 & 340 & 77 & 319,11 & 0 & 34,49 & 125,66 & 9,2 & 104,77 & 2,96 \\
\hline & 28,68 & 160,41 & 22,93 & 139,52 & 0 & 34,63 & 148,97 & 67,93 & 128,08 & 0 \\
\hline & 28,72 & 159,4 & 21,31 & 138,51 & 0 & 34,68 & 155,43 & 55,88 & 134,54 & 0 \\
\hline & 28,77 & 340 & 82 & 319,11 & 0 & 34,71 & 351,44 & 36,65 & 330,55 & 0 \\
\hline & 28,84 & 147,51 & 40,63 & 126,62 & 0 & 34,83 & 163,85 & 69,66 & 142,96 & 0 \\
\hline & 28,95 & 153,46 & 12,84 & 132,57 & 2,05 & 35,09 & 156,27 & 67,68 & 135,38 & 0 \\
\hline & 29,01 & 150,94 & 52,85 & 130,05 & 0 & 35,25 & 138,02 & 67,83 & 117,13 & 0 \\
\hline & 29,05 & 151,9 & 78,51 & 131,01 & 0 & 35,34 & 148,95 & 81 & 128,06 & 0 \\
\hline & 29,07 & 152,34 & 45,74 & 131,45 & 0 & 35,53 & 152,61 & 74,1 & 131,72 & 0 \\
\hline & 29,18 & 152,48 & 36,98 & 131,59 & 0 & 35,55 & 319 & 14,47 & 298,11 & 0 \\
\hline & 29,18 & 163,85 & 4,12 & 142,96 & 2,09 & 35,55 & 149,95 & 14,79 & 129,06 & 0 \\
\hline & 29,25 & 148,41 & 23,36 & 127,52 & 0 & 35,74 & 150,94 & 52,66 & 130,05 & 0 \\
\hline & 29,31 & 159,36 & 20,86 & 138,47 & 0 & 35,82 & 151,5 & 58,03 & 130,61 & 1,11 \\
\hline & 29,32 & 160,34 & 41,89 & 139,45 & 0 & 35,89 & 154,45 & 53,35 & 133,56 & 0 \\
\hline & 29,39 & 148,97 & 39,83 & 128,08 & 0 & 36,05 & 269,02 & 37,52 & 248,13 & 0 \\
\hline & 29,51 & 151,92 & 36,87 & 131,03 & 0 & 36,05 & 151,92 & 46,72 & 131,03 & 0 \\
\hline & 29,68 & 329,81 & 31,09 & 308,92 & 0 & 36,09 & 338 & 27,56 & 317,11 & 1,86 \\
\hline & 29,69 & 329,8 & 81,41 & 308,91 & 0 & 36,09 & 150,37 & 58,41 & 129,48 & 0 \\
\hline & 29,82 & 147,99 & 67,41 & 127,1 & 0 & 36,17 & 153,46 & 60,03 & 132,57 & 0 \\
\hline & 30,06 & 324,34 & 46,07 & 303,45 & 0 & 36,21 & 1 & 37,95 & 340,11 & 0,71 \\
\hline & 30,07 & 156,41 & 22,49 & 135,52 & 0 & 36,31 & 329,48 & 34,14 & 308,59 & 1,74 \\
\hline & 30,09 & 151,5 & 20,25 & 130,61 & 0 & 36,47 & 160,9 & 33,19 & 140,01 & 0 \\
\hline & 30,25 & 205,41 & 28,77 & 184,52 & 0 & 36,56 & 160,9 & 41,7 & 140,01 & 0 \\
\hline & 30,37 & 329,25 & 22,93 & 308,36 & 0 & 36,56 & 327,29 & 25,5 & 306,4 & 4,6 \\
\hline & 30,54 & 322,79 & 27,83 & 301,9 & 0 & 36,71 & 158,94 & 46,64 & 138,05 & 0 \\
\hline & 30,55 & 158,38 & 42,55 & 137,49 & 0 & 36,78 & 344,7 & 28,1 & 323,81 & 2,64 \\
\hline & 30,64 & 147,43 & 44,01 & 126,54 & 0 & 36,85 & 154,45 & 67,98 & 133,56 & 0 \\
\hline & 30,77 & 164,27 & 38,8 & 143,38 & 0 & 37,02 & 151,5 & 62,56 & 130,61 & 0 \\
\hline & 30,81 & 159,36 & 42,27 & 138,47 & 0 & 37,25 & 149,95 & 71,53 & 129,06 & 0 \\
\hline & 30,91 & 151,5 & 53,16 & 130,61 & 0 & 37,57 & 157,39 & 29,29 & 136,5 & 1,83 \\
\hline & 30,94 & 152,48 & 53,35 & 131,59 & 0 & 37,59 & 150,51 & 26,88 & 129,62 & 1,61 \\
\hline & 30,97 & 152,9 & 51,56 & 132,01 & 0 & 37,65 & 342,59 & 16,38 & 321,7 & 0 \\
\hline & 30,99 & 98,99 & 15,43 & 78,1 & 0 & 37,69 & 154,87 & 46,23 & 133,98 & 1,45 \\
\hline & 30,99 & 154,45 & 55,05 & 133,56 & 0 & 37,79 & 156,41 & 41,02 & 135,52 & 0 \\
\hline & 31,36 & 335,15 & 45,23 & 314,26 & 0 & 37,89 & 157,82 & 47,98 & 136,93 & 0 \\
\hline & 31,43 & 151,48 & 80,31 & 130,59 & 0 & 38,02 & 343,57 & 51,03 & 322,68 & 0 \\
\hline & 31,51 & 149,95 & 61,89 & 129,06 & 0 & 38,18 & 148,41 & 52,02 & 127,52 & 0 \\
\hline & 31,73 & 153,46 & 56,31 & 132,57 & 0 & 38,33 & 155,85 & 71,04 & 134,96 & 0 \\
\hline & 31,74 & 155,95 & 63 & 135,06 & 0 & 38,38 & 351,58 & 36,87 & 330,69 & 0 \\
\hline & 31,87 & 157,39 & 40,03 & 136,5 & 0 & 38,5 & 146,02 & 45,14 & 125,13 & 0 \\
\hline & 32,48 & 156,97 & 59,9 & 136,08 & 0 & 38,55 & 322,65 & 55,77 & 301,76 & 0 \\
\hline & 32,64 & 345,96 & 71,84 & 325,07 & 0 & 38,55 & 124,68 & 52,92 & 103,79 & 0 \\
\hline & 32,88 & 166,94 & 69,08 & 146,05 & 0 & 38,66 & 135,21 & 68,49 & 114,32 & 0 \\
\hline & 32,94 & 350,06 & 81,85 & 329,17 & 0 & 38,72 & 135,63 & 49,19 & 114,74 & 0 \\
\hline & 33,1 & 158,94 & 65,52 & 138,05 & 0 & 38,83 & 134,79 & 45,9 & 113,9 & 1,46 \\
\hline & 33,21 & 159,78 & 57,44 & 138,89 & 0 & 38,86 & 139,14 & 47,44 & 118,25 & 2,84 \\
\hline & 33,41 & 163,85 & 39,83 & 142,96 & 0 & 38,88 & 147,43 & 42,92 & 126,54 & 1,54 \\
\hline & 33,48 & 165,26 & 29,29 & 144,37 & 0 & 38,98 & 146,02 & 33,31 & 125,13 & 1,76 \\
\hline & 33,56 & 335,71 & 42,36 & 314,82 & 0 & 39,01 & 140,97 & 30,58 & 120,08 & 0,78 \\
\hline & 33,6 & 155,85 & 66,48 & 134,96 & 0 & 39,04 & 135,63 & 39,83 & 114,74 & 1,61 \\
\hline & 33,8 & 304,4 & 35,41 & 283,51 & 0 & 39,07 & 151,92 & 43,65 & 131,03 & 1,74 \\
\hline & 33,8 & 256 & 4 & 235,11 & 0 & 39,08 & 154,31 & 43,83 & 133,42 & 0,66 \\
\hline & 34,02 & 336,69 & 7,18 & 315,8 & 0 & 39,08 & 151,5 & 43,83 & 130,61 & 1,53 \\
\hline & 34,03 & 173,26 & 15,27 & 152,37 & 0 & 39,09 & 152,9 & 43,29 & 132,01 & 1,53 \\
\hline & 34,1 & 157,54 & 34,49 & 136,65 & 0 & 39,14 & 145,04 & 43,47 & 124,15 & 3,05 \\
\hline
\end{tabular}




\begin{tabular}{|c|c|c|c|c|c|c|c|c|c|c|}
\hline 4581 & Depth & Azimuth & Dip & Declinado & Aperture & Depth & Azimuth & Dip & Declinado & Aperture \\
\hline & 39,27 & 161,89 & 18,26 & 141 & 0 & 36,34 & 129,71 & 69,15 & 108,82 & 0 \\
\hline & 39,47 & 146,02 & 49,11 & 125,13 & 0 & 36,48 & 140,54 & 68,59 & 119,65 & 0 \\
\hline & 39,6 & 143,49 & 60,49 & 122,6 & 0 & 36,58 & 0 & 0 & 339,11 & 0 \\
\hline & 39,82 & 167,5 & 34,14 & 146,61 & 0 & 36,65 & 160,52 & 73,59 & 139,63 & 0 \\
\hline & 40,02 & 152,81 & 43,65 & 131,92 & 0 & 36,83 & 106,35 & 10,7 & 85,46 & 2,07 \\
\hline & 40,16 & 157,93 & 45,65 & 137,04 & 0 & 36,84 & 169,94 & 69,68 & 149,05 & 0 \\
\hline & 40,33 & 147,07 & 52,6 & 126,18 & 0 & 37,36 & 138,63 & 83,78 & 117,74 & 0 \\
\hline & 40,48 & 148,99 & 64,47 & 128,1 & 0 & 37,54 & 113,42 & 19,19 & 92,53 & 2,5 \\
\hline & 40,65 & 334,12 & 74,05 & 313,23 & 0 & 37,69 & 138,12 & 79,4 & 117,23 & 0 \\
\hline & 40,77 & 153,85 & 59,15 & 132,96 & 0 & 37,94 & 149,1 & 55,99 & 128,21 & 0 \\
\hline & 40,94 & 160,83 & 56,15 & 139,94 & 0 & 38,1 & 104,77 & 6,16 & 83,88 & 12,23 \\
\hline & 41,1 & 156,43 & 51,83 & 135,54 & 0 & 38,15 & 132,64 & 15,75 & 111,75 & 1,73 \\
\hline & 41,16 & 155,52 & 52,09 & 134,63 & 0 & 38,16 & 158,47 & 18,42 & 137,58 & 1,71 \\
\hline & 41,27 & 155,52 & 59,77 & 134,63 & 0 & 38,18 & 145,55 & 18,26 & 124,66 & 3,42 \\
\hline & 41,35 & 344,27 & 26,47 & 323,38 & 0 & 38,25 & 146,82 & 2 & 125,93 & 3,01 \\
\hline & 41,39 & 351,29 & 21,9 & 330,4 & 3,34 & 38,26 & 138,06 & 82,48 & 117,17 & 0 \\
\hline & 41,76 & 327,76 & 55,55 & 306,87 & 0 & 38,37 & 131 & 12 & 110,11 & 0 \\
\hline & 41,92 & 280,97 & 19,49 & 260,08 & 0 & 38,46 & 328 & 9 & 307,11 & 0 \\
\hline & 41,95 & 161,56 & 46 & 140,67 & 0 & 38,48 & 143,55 & 84,26 & 122,66 & 0 \\
\hline & 42,08 & 155,85 & 58,69 & 134,96 & 0 & 39,16 & 126,67 & 53,23 & 105,78 & 0 \\
\hline & 42,17 & 155,43 & 57,64 & 134,54 & 0 & 39,39 & 140,1 & 49,33 & 119,21 & 0 \\
\hline & 42,27 & 158,94 & 51,29 & 138,05 & 0 & 39,59 & 21,53 & 78,63 & 0,64 & 1,01 \\
\hline & 42,31 & 160,95 & 53 & 140,06 & 0 & 39,86 & 193,26 & 78,09 & 172,37 & 0 \\
\hline & 42,61 & 145,46 & 62,49 & 124,57 & 0 & 40,12 & 356,03 & 78,82 & 335,14 & 0 \\
\hline & 42,66 & 146,44 & 30,71 & 125,55 & 0 & 40,22 & 161,51 & 69,17 & 140,62 & 0 \\
\hline & 42,92 & 152,48 & 41,41 & 131,59 & 5,4 & 40,48 & 165,39 & 77,97 & 144,5 & 0 \\
\hline & 43,09 & 159,92 & 37,74 & 139,03 & 0 & 40,82 & 131,31 & 21,9 & 110,42 & 1,84 \\
\hline & 43,39 & 162,31 & 33,18 & 141,42 & 0 & 40,99 & 127,23 & 25,92 & 106,34 & 5 \\
\hline & 43,57 & 158,38 & 61,11 & 137,49 & 0 & 41,05 & 140,15 & 39,83 & 119,26 & 0 \\
\hline & 43,76 & 163,56 & 48 & 142,67 & 0 & 41,17 & 142,65 & 51,76 & 121,76 & 2,04 \\
\hline & 43,86 & 348,07 & 19,8 & 327,18 & 3,1 & 41,28 & 155,42 & 61,5 & 134,53 & 0 \\
\hline & 43,87 & 0,15 & 20,41 & 339,26 & 1,97 & 41,3 & 141,16 & 76,43 & 120,27 & 0 \\
\hline & 43,99 & 172,51 & 52,09 & 151,62 & 0 & 41,3 & 317,28 & 22,93 & 296,39 & 0 \\
\hline & 44,11 & 168,77 & 49,84 & 147,88 & 0 & 41,81 & 329,19 & 71,41 & 308,3 & 0 \\
\hline & 44,26 & 162,73 & 51,36 & 141,84 & 0 & 41,81 & 143,63 & 69,36 & 122,74 & 0 \\
\hline & 44,41 & 163,69 & 52,47 & 142,8 & 0 & 41,89 & 142,09 & 62,41 & 121,2 & 0 \\
\hline & 44,44 & 163,97 & 55 & 143,08 & 0 & 42,11 & 133,22 & 67,48 & 112,33 & 0 \\
\hline & 44,57 & 169 & 57 & 148,11 & 0 & 42,2 & 138,57 & 72,02 & 117,68 & 0 \\
\hline & 44,73 & 148,88 & 50,89 & 127,99 & 0 & 42,35 & 0 & 0 & 339,11 & 0 \\
\hline & 44,79 & 217,21 & 58,69 & 196,32 & 0 & 42,37 & 80,05 & 57,98 & 59,16 & 1,59 \\
\hline 4596 & Depth & Azimuth & Dip & Declinado & Aperture & 42,45 & 65,13 & 70,4 & 44,24 & 0,7 \\
\hline & 33,86 & 202,58 & 10,54 & 181,69 & 3,04 & 42,57 & 112,4 & 67,88 & 91,51 & 0 \\
\hline & 34,16 & 145,13 & 79,67 & 124,24 & 0 & 42,75 & 234,79 & 74,5 & 213,9 & 0 \\
\hline & 34,45 & 125,23 & 78,29 & 104,34 & 0 & 42,95 & 307,81 & 52,47 & 286,92 & 0 \\
\hline & 34,47 & 116,5 & 47,36 & 95,61 & 0 & 43,14 & 136,74 & 71,63 & 115,85 & 0 \\
\hline & 34,8 & 136,1 & 76,09 & 115,21 & 0 & 43,26 & 129,28 & 68,02 & 108,39 & 0 \\
\hline & 34,85 & 343,54 & 64,51 & 322,65 & 0 & 43,53 & 336,08 & 55,77 & 315,19 & 0 \\
\hline & 35,16 & 332,71 & 2,41 & 311,82 & 0 & 43,56 & 169 & 11 & 148,11 & 0 \\
\hline & 35,23 & 139,09 & 49,91 & 118,2 & 0 & 43,57 & 191 & 19 & 170,11 & 0 \\
\hline & 35,34 & 138,16 & 74,38 & 117,27 & 0 & 43,62 & 174,87 & 8,87 & 153,98 & 3,25 \\
\hline & 35,48 & 150,53 & 72,36 & 129,64 & 0 & 43,64 & 236,91 & 6,16 & 216,02 & 2,09 \\
\hline & 35,71 & 132,59 & 74,46 & 111,7 & 0 & 43,64 & 137,87 & 66,75 & 116,98 & 0 \\
\hline & 35,8 & 340,59 & 34,14 & 319,7 & 0 & 43,75 & 133,22 & 66,29 & 112,33 & 0 \\
\hline & 35,88 & 134,51 & 18 & 113,62 & 3 & 44 & 142,09 & 65,34 & 121,2 & 0 \\
\hline & 35,97 & 145,04 & 16,7 & 124,15 & 0 & 44,36 & 290,5 & 5,48 & 269,61 & 2,09 \\
\hline & 36,01 & 152,07 & 9,87 & 131,18 & 0,89 & 44,37 & 297,4 & 4,8 & 276,51 & 2,09 \\
\hline & 36,09 & 305,43 & 36 & 284,54 & 0 & 44,38 & 302,18 & 5,14 & 281,29 & 5,38 \\
\hline
\end{tabular}




\begin{tabular}{|c|c|c|c|c|c|c|c|c|c|c|}
\hline 4596 & Depth & Azimuth & Dip & Declinado & Aperture & Depth & Azimuth & Dip & Declinado & Aperture \\
\hline & 44,39 & 153,48 & 2,75 & 132,59 & 4,7 & 30,35 & 43,3 & 79,19 & 22,41 & 0 \\
\hline & 44,4 & 66,26 & 74,84 & 45,37 & 0 & 30,39 & 124,16 & 37,09 & 103,27 & 0 \\
\hline & 44,46 & 164,45 & 27,83 & 143,56 & 1,86 & 30,52 & 55,49 & 72,13 & 34,6 & $\underline{0}$ \\
\hline & 44,57 & 181,76 & 17,95 & 160,87 & 3,8 & 30,58 & 220,99 & 43,56 & 200,1 & 0 \\
\hline & 44,59 & 146,17 & 21,31 & 125,28 & 0 & 30,72 & 46,1 & 54,6 & 25,21 & 0 \\
\hline & 44,63 & 159,53 & 10,2 & 138,64 & 0 & 30,75 & 41,62 & 67,83 & 20,73 & 0 \\
\hline & 44,65 & 138,57 & 4,12 & 117,68 & 0 & 30,96 & 188,9 & 51,3 & 168,01 & 0 \\
\hline & 44,67 & 143,63 & 7,86 & 122,74 & 0 & 31,03 & 147,39 & 84,69 & 126,5 & 0 \\
\hline & 44,75 & 199 & 14 & 178,11 & 0 & 31,05 & 318,94 & 34,84 & 298,05 & 0 \\
\hline & 44,8 & 147,57 & 12,52 & 126,68 & 0 & 31,17 & 146 & 90 & 125,11 & 0 \\
\hline & 44,82 & 149,12 & 19,8 & 128,23 & 0 & 31,32 & 70,23 & 83,66 & 49,34 & 0 \\
\hline & 44,86 & 182,74 & 15,75 & 161,85 & 0 & 31,39 & 7,99 & 67,83 & 347,1 & 0 \\
\hline & 44,88 & 166,85 & 18,26 & 145,96 & 0 & 31,39 & 139,02 & 80,07 & 118,13 & 0 \\
\hline & 44,91 & 159,95 & 18,57 & 139,06 & 0 & 31,81 & 27,2 & 62,81 & 6,31 & 0 \\
\hline & 44,94 & 153,48 & 19,19 & 132,59 & 0 & 32,04 & 29,23 & 45,9 & 8,34 & 3,76 \\
\hline & 45,32 & 343 & 6 & 322,11 & 0 & 32,06 & 244,84 & 42,92 & 223,95 & 0 \\
\hline & 45,46 & 151 & 30 & 130,11 & 0 & 32,21 & 294,18 & 72,83 & 273,29 & 0 \\
\hline & 45,58 & 41 & 30 & 20,11 & 0 & 32,25 & 0 & 19,8 & 339,11 & 0 \\
\hline & 45,64 & 345 & 11 & 324,11 & 0 & 32,25 & 136,54 & 78,2 & 115,65 & 0 \\
\hline & 45,7 & 340,59 & 23,51 & 319,7 & 0 & 32,51 & 101,92 & 58,12 & 81,03 & 0 \\
\hline & 45,74 & 160,52 & 17,01 & 139,63 & 0 & 32,61 & 157,78 & 19,8 & 136,89 & 1,97 \\
\hline & 45,86 & 356,48 & 18,73 & 335,59 & 0 & 32,72 & 142,52 & 30,46 & 121,63 & 0 \\
\hline & 45,97 & 167,34 & 24,51 & 146,45 & 0 & 32,75 & 36,59 & 64,28 & 15,7 & 1,82 \\
\hline & 46,06 & 168,43 & 14,95 & 147,54 & 1,74 & 32,76 & 67,78 & 68,21 & 46,89 & 0,78 \\
\hline & 46,1 & 183,29 & 17,64 & 162,4 & 1,72 & 32,88 & 303,64 & 63,95 & 282,75 & 0 \\
\hline & 46,16 & 187,26 & 14,79 & 166,37 & 3,19 & 33,19 & 62,31 & 57,78 & 41,42 & 0 \\
\hline & 46,2 & 144,12 & 22,78 & 123,23 & 1,66 & 33,23 & 50,96 & 68,99 & 30,07 & 1,51 \\
\hline & 46,25 & 170,38 & 19,34 & 149,49 & 1,7 & 33,29 & 46,52 & 71,48 & 25,63 & 1,72 \\
\hline & 46,28 & 154 & 22,93 & 133,11 & 1,66 & 33,34 & 248,76 & 20,1 & 227,87 & 0 \\
\hline & 46,43 & 140,07 & 47,52 & 119,18 & 0 & 33,37 & 68,76 & 72,82 & 47,87 & 0 \\
\hline & 46,85 & 335,26 & 71,04 & 314,37 & 0 & 33,56 & 48,43 & 73,48 & 27,54 & 0,6 \\
\hline & 47,1 & 326,74 & 69,3 & 305,85 & 0 & 33,6 & 171,17 & 33,42 & 150,28 & 0 \\
\hline & 47,36 & 134,66 & 42,55 & 113,77 & 0 & 33,71 & 67,29 & 71,23 & 46,4 & 0 \\
\hline & 47,51 & 72,61 & 76,38 & 51,72 & 0 & 33,9 & 173,55 & 57,54 & 152,66 & 17,23 \\
\hline & 47,67 & 139,64 & 77,21 & 118,75 & 0 & 33,92 & 65,33 & 82,11 & 44,44 & 0 \\
\hline & 47,72 & 184,57 & 6,84 & 163,68 & 2,09 & 34,13 & 306,1 & 16,54 & 285,21 & 0 \\
\hline & 47,73 & 180,77 & 11,53 & 159,88 & 3,25 & 34,22 & 359,44 & 74,2 & 338,55 & $\underline{0}$ \\
\hline & 47,91 & 142,56 & 78,76 & 121,67 & 0 & 34,31 & 276,45 & 34,84 & 255,56 & 1,72 \\
\hline & 48,11 & 134,12 & 73,45 & 113,23 & 0 & 34,35 & 253,25 & 13,17 & 232,36 & $\underline{0}$ \\
\hline & 48,32 & 321,3 & 78,62 & 300,41 & 0 & 34,4 & 158,76 & 58,78 & 137,87 & 0 \\
\hline & 48,81 & 135,67 & 62,56 & 114,78 & 0 & 34,46 & 162,69 & 26,2 & 141,8 & 5,73 \\
\hline & 49,06 & 321,79 & 62,56 & 300,9 & 0 & 34,46 & 196,82 & 33,18 & 175,93 & 1,64 \\
\hline & 49,32 & 140,1 & 80,04 & 119,21 & 0 & 34,51 & 233,9 & 34,84 & 213,01 & 0 \\
\hline & 49,39 & 143,07 & 64,79 & 122,18 & 0 & 34,72 & 159,33 & 32,46 & 138,44 & 2,78 \\
\hline & 49,68 & 97,29 & 47,98 & 76,4 & 2,16 & 34,78 & 29 & 90 & 8,11 & 0 \\
\hline 4597 & Depth & Azimuth & Dip & Declinado & Aperture & 35,01 & 67,29 & 70,59 & 46,4 & 0 \\
\hline & 29,05 & 42,07 & 73,78 & 21,18 & 1,01 & 35,1 & 286,89 & 15,27 & 266 & 0 \\
\hline & 29,11 & 40,16 & 74,41 & 19,27 & 1,05 & 35,2 & 54,39 & 46,07 & 33,5 & 0 \\
\hline & 29,32 & 55,89 & 71,29 & 35 & 0 & 35,23 & 178,04 & 34,14 & 157,15 & 0 \\
\hline & 29,45 & 46 & 64,47 & 25,11 & 0 & 35,49 & 151,4 & 76,44 & 130,51 & 0 \\
\hline & 29,53 & 67,26 & 57,74 & 46,37 & 0 & 35,58 & 136,05 & 79,85 & 115,16 & $\underline{0}$ \\
\hline & 29,57 & 64,23 & 72,7 & 43,34 & 0 & 35,82 & 240,42 & 64,47 & 219,53 & 0 \\
\hline & 29,81 & 266,53 & 63,55 & 245,64 & 0 & 35,88 & 150,35 & 82,07 & 129,46 & 0 \\
\hline & 30,03 & 234,02 & 34,95 & 213,13 & 0 & 35,89 & 159,74 & 72,53 & 138,85 & 0 \\
\hline & 30,06 & 168,02 & 10,7 & 147,13 & 0 & 35,95 & 51,45 & 70,85 & 30,56 & 0 \\
\hline & 30,07 & 48,63 & 67,93 & 27,74 & 0 & 35,99 & 40,4 & 45,23 & 19,51 & 3,32 \\
\hline & 30,33 & 61,38 & 50,82 & 40,49 & 0 & 35,99 & 147 & 90 & 126,11 & 0 \\
\hline
\end{tabular}




\begin{tabular}{|c|c|c|c|c|c|c|c|c|c|c|}
\hline 4597 & Depth & Azimuth & Dip & Declinado & Aperture & Depth & Azimuth & Dip & Declinado & Aperture \\
\hline & 36,05 & 148,39 & 75,2 & 127,5 & 0 & 41,61 & 152,32 & 62,71 & 131,43 & 0 \\
\hline & 36,1 & 49 & 90 & 28,11 & 0 & 41,82 & 147 & 74,48 & 126,11 & 0 \\
\hline & 36,29 & 159,25 & 77,08 & 138,36 & 0 & 42,14 & 143,47 & 76,85 & 122,58 & 0 \\
\hline & 36,45 & 302,24 & 34,84 & 281,35 & 0 & 42,3 & 342,2 & 61,5 & 321,31 & 0 \\
\hline & 36,52 & 272,76 & 37,95 & 251,87 & 3,82 & 42,32 & 158,24 & 75,23 & 137,35 & 0 \\
\hline & 36,57 & 273,47 & 4 & 252,58 & 0 & 42,32 & 172,08 & 47,52 & 151,19 & 0 \\
\hline & 36,76 & 154,84 & 72,94 & 133,95 & 0 & 42,4 & 147,88 & 73,48 & 126,99 & 0 \\
\hline & 36,77 & 308,48 & 15 & 287,59 & 3,91 & 42,67 & 346,13 & 31,47 & 325,24 & 0 \\
\hline & 37,08 & 155,82 & 70,3 & 134,93 & 0 & 42,87 & 329,83 & 78,44 & 308,94 & 0 \\
\hline & 37,22 & 148,81 & 75,6 & 127,92 & 0 & 42,88 & 152,88 & 68,02 & 131,99 & 0 \\
\hline & 37,27 & 289,7 & 13,5 & 268,81 & 0 & 43,13 & 140,95 & 81,96 & 120,06 & 0 \\
\hline & 37,37 & 47,52 & 55,22 & 26,63 & 0 & 43,15 & 152,88 & 64,6 & 131,99 & 0 \\
\hline & 37,41 & 148,88 & 38,06 & 127,99 & 0 & 43,32 & 147,42 & 65,16 & 126,53 & 0 \\
\hline & 37,51 & 146,43 & 60,62 & 125,54 & 0 & 43,57 & 146,97 & 81,87 & 126,08 & 0 \\
\hline & 37,52 & 11,36 & 44,89 & 350,47 & 0 & 43,78 & 144,9 & 46,32 & 124,01 & 0 \\
\hline & 37,57 & 65,82 & 83,64 & 44,93 & 0 & 44,01 & 147,42 & 63,55 & 126,53 & 0 \\
\hline & 37,62 & 170,68 & 44,27 & 149,79 & 0 & 44,2 & 150,92 & 45,06 & 130,03 & 0 \\
\hline & 37,76 & 178,04 & 31,59 & 157,15 & 5,36 & 44,42 & 331 & 72 & 310,11 & 0 \\
\hline & 37,83 & 218,06 & 65,52 & 197,17 & 0 & 44,46 & 149,37 & 74,2 & 128,48 & 0 \\
\hline & 38,12 & 227,43 & 34,14 & 206,54 & 8,69 & 44,65 & 312,06 & 79,74 & 291,17 & 0 \\
\hline & 38,16 & 172,08 & 49,48 & 151,19 & 0 & 44,71 & 148,88 & $\begin{array}{l}75,37 \\
\end{array}$ & 127,99 & 0 \\
\hline & 38,29 & 129,06 & 71,65 & 108,17 & 0 & 44,83 & 142,22 & 73 & 121,33 & 0 \\
\hline & 38,37 & 235,98 & 29,94 & 215,09 & 0 & 44,87 & 322,57 & 76,61 & 301,68 & 0 \\
\hline & 38,41 & 45,96 & 71,25 & 25,07 & 0 & 45,04 & 50,02 & 82,6 & 29,13 & 0 \\
\hline & 38,42 & 153,87 & 69,36 & 132,98 & 0 & 45,34 & 140,96 & 74,4 & 120,07 & 0 \\
\hline & 38,53 & 282,37 & 34,14 & 261,48 & 0 & & & & & \\
\hline & 38,56 & 159,75 & 72,57 & 138,86 & 0 & & & & & \\
\hline & 38,77 & 162,83 & 35,3 & 141,94 & 0 & & & & & \\
\hline & 38,81 & 162,27 & 71,7 & 141,38 & 0 & & & & & \\
\hline & 38,97 & 158,35 & 13,17 & 137,46 & 0 & & & & & \\
\hline & 38,97 & 161,29 & 75,02 & 140,4 & 0 & & & & & \\
\hline & 39,22 & 161,67 & 27,02 & 140,78 & 0 & & & & & \\
\hline & 39,23 & 335,2 & 20,41 & 314,31 & 0 & & & & & \\
\hline & 39,27 & 150,78 & 67,48 & 129,89 & 0 & & & & & \\
\hline & 39,49 & 164,24 & 59,5 & 143,35 & 0 & & & & & \\
\hline & 39,59 & 144,34 & 75,9 & 123,45 & 0 & & & & & \\
\hline & 39,95 & 54,09 & 76,13 & 33,2 & 0 & & & & & \\
\hline & 40,01 & 186,08 & 43,47 & 165,19 & 0 & & & & & \\
\hline & 40,06 & 145,04 & 76,75 & 124,15 & 0 & & & & & \\
\hline & 40,24 & 154,71 & 65,98 & 133,82 & 0 & & & & & \\
\hline & 40,31 & 163,81 & 63,48 & 142,92 & 0 & & & & & \\
\hline & 40,33 & 157,23 & 57,78 & 136,34 & 0 & & & & & \\
\hline & 40,48 & 143,5 & 57,29 & 122,61 & 0 & & & & & \\
\hline & 40,52 & 143,08 & 70,65 & 122,19 & 0 & & & & & \\
\hline & 40,68 & 140,41 & 70,1 & 119,52 & 0 & & & & & \\
\hline & 40,71 & 142,51 & 52,98 & 121,62 & 0 & & & & & \\
\hline & 40,8 & 147,42 & 57,44 & 126,53 & 0 & & & & & \\
\hline & 40,91 & 151,9 & 42,18 & 131,01 & 0 & & & & & \\
\hline & 41 & 155,27 & 65,92 & 134,38 & 0 & & & & & \\
\hline & 41,07 & 163,67 & 40,33 & 142,78 & 0 & & & & & \\
\hline & 41,22 & 158,75 & 34,37 & 137,86 & 0 & & & & & \\
\hline & 41,23 & 159,33 & 65,98 & 138,44 & 0 & & & & & \\
\hline & 41,36 & 142,51 & 51,3 & 121,62 & 0 & & & & & \\
\hline & 41,38 & 330,59 & 10 & 309,7 & 4,98 & & & & & \\
\hline & 41,4 & 332,25 & 8,87 & 311,36 & 0 & & & & & \\
\hline & 41,46 & 139,57 & 43,65 & 118,68 & 0 & & & & & \\
\hline & 41,47 & 139,57 & 45,4 & 118,68 & 0 & & & & & \\
\hline
\end{tabular}


APÊNDICE II - TABELAS DE GEOLOGIA E RMR 


\begin{tabular}{|c|c|c|c|c|c|c|c|c|c|c|}
\hline $\begin{array}{c}\text { Numero da } \\
\text { sondagem }(\mathrm{m})\end{array}$ & $\begin{array}{c}\text { Nivel de Água } \\
\text { (m) }\end{array}$ & Topo & Base & Geologia & $\begin{array}{c}\text { Topo } \\
\text { (m, 2DP) }\end{array}$ & $\begin{array}{c}\text { Base } \\
(\mathrm{m}, 2 \mathrm{DP})\end{array}$ & Classe de maciço & $\begin{array}{l}\text { Grau } \\
\text { Fratur. } \\
\text { (lista) }\end{array}$ & $\begin{array}{r}\text { RQD } \\
(\%)\end{array}$ & $\begin{array}{c}\text { Recuperação } \\
\text { (\%) }\end{array}$ \\
\hline \multirow[t]{3}{*}{4500} & 11.35 & 0.00 & 2.00 & AT & 51.25 & 55.00 & V-Muito Pobre & $\mathrm{F} 4$ & 22 & 79 \\
\hline & & 2.00 & 51.25 & SAR & 53.00 & 55.34 & III-Regular & F2 & 92 & 100 \\
\hline & & 51.25 & 55.34 & ROCHA & & & & & & \\
\hline \multirow[t]{4}{*}{\begin{tabular}{l|l}
4501 \\
\end{tabular}} & 7.61 & 0.00 & 5.00 & AT & 39.55 & 42.50 & III-Regular & 4 & 50 & 75 \\
\hline & & 5.00 & 39.55 & SAR & 53.00 & 48.80 & III - Regular & 4 & 78 & 100 \\
\hline & & 39.55 & 55.00 & ROCHA & 48.80 & 51.90 & II-Bom & 3 & 78 & 92 \\
\hline & & & & & 51.90 & 55.00 & II-Bom & 3 & 68 & 81 \\
\hline \multirow{8}{*}{4503} & 4.95 & 0.00 & 5.00 & AT & 21.40 & 24.40 & III - Regular & 4 & 52 & 79 \\
\hline & & 5.00 & 21.40 & SAR & 24.40 & 27.40 & III - Regular & 4 & 47 & 100 \\
\hline & & 21.40 & 45.00 & ROCHA & 27.40 & 30.40 & III - Regular & 4 & 44 & 100 \\
\hline & & & & & 30.40 & 33.40 & II-Bom & 4 & 87 & 100 \\
\hline & & & & & 33.40 & 36.40 & III-Regular & 4 & 75 & 100 \\
\hline & & & & & 36.40 & 39.40 & III-Regular & 4 & 78 & 100 \\
\hline & & & & & 39.40 & 42.40 & III - Regular & 4 & 78 & 100 \\
\hline & & & & & 42.40 & 45.00 & II - Bom & 3 & 69 & 95 \\
\hline \multirow[t]{10}{*}{4504} & 7.40 & 0.00 & 5.15 & AT & 27.15 & 30.00 & III - Regular & 4 & 39 & 67 \\
\hline & & 5.15 & 27.15 & SAR & 30.00 & 33.00 & III-Regular & 3 & 53 & 77 \\
\hline & & 27.15 & 55.00 & ROCHA & 33.00 & 36.00 & III-Regular & 4 & 80 & 100 \\
\hline & & & & & 36.00 & 39.00 & III-Regular & 3 & 69 & 82 \\
\hline & & & & & 39.00 & 42.00 & III - Regular & 4 & 90 & 100 \\
\hline & & & & & 42.00 & 45.00 & III - Regular & 4 & 89 & 100 \\
\hline & & & & & 45.00 & 48.00 & IV-Pobre & 4 & 87 & 100 \\
\hline & & & & & 48.00 & 51.00 & III - Regular & 3 & 94 & 100 \\
\hline & & & & & 51.00 & 54.00 & III-Regular & 2 & 99 & 99 \\
\hline & & & & & 54.00 & 55.00 & III-Regular & 2 & 93 & 100 \\
\hline \multirow[t]{7}{*}{4505} & 9.09 & 0.00 & 26.56 & SAR & 26.56 & 29.56 & I-Muito Bom & 1 & 85 & 100 \\
\hline & & 26.56 & 45.30 & ROCHA & 29.56 & 32.56 & II-Bom & 2 & 79 & 98 \\
\hline & & & & & 32.56 & 35.56 & II - Bom & 2 & 69 & 98 \\
\hline & & & & & 35.56 & 38.56 & I-Muito Bom & 1 & 98 & 100 \\
\hline & & & & & 38.56 & 41.56 & I-Muito Bom & 1 & 95 & 100 \\
\hline & & & & & 41.56 & 44.56 & II-Bom & 2 & 82 & 99 \\
\hline & & & & & 44.56 & 45.30 & I-Muito Bom & 1 & 100 & 100 \\
\hline \multirow[t]{13}{*}{4507} & 2.47 & 0.00 & 22.05 & & 22.05 & 23.00 & IV-Pobre & 3 & 33 & 95 \\
\hline & & 22.05 & 55.00 & & 23.00 & 26.10 & IV-Pobre & 2 & 68 & 98 \\
\hline & & & & & 26.10 & 28.90 & IV-Pobre & 2 & 75 & 99 \\
\hline & & & & & 28.90 & 32.00 & III-Regular & 1 & 82 & 98 \\
\hline & & & & & 32.00 & 32.40 & V-Muito Pobre & 4 & 23 & 77 \\
\hline & & & & & 32.40 & 35.55 & II - Bom & 2 & 80 & 99 \\
\hline & & & & & 35.55 & 38.55 & IV-Pobre & 3 & 55 & 100 \\
\hline & & & & & 38.55 & 41.50 & I- Muito Bom & 1 & 90 & 100 \\
\hline & & & & & 41.50 & 44.50 & II-Bom & 1 & 100 & 100 \\
\hline & & & & & 44.50 & 47.50 & III-Regular & 2 & 80 & 100 \\
\hline & & & & & 47.50 & 50.50 & III-Regular & 1 & 95 & 100 \\
\hline & & & & & 50.50 & 53.50 & I-Muito Bom & 1 & 95 & 100 \\
\hline & & & & & 53.50 & 55.00 & III - Regular & 2 & 60 & 97 \\
\hline \multirow[t]{10}{*}{4508} & 3.41 & 0.00 & 24.35 & SAR & 24.35 & 26.00 & IV-Pobre & 3 & 53 & 91 \\
\hline & & 24.35 & 55.32 & ROCHA & 26.00 & 29.05 & II-Bom & 1 & 95 & 100 \\
\hline & & & & & 29.05 & 30.95 & III-Regular & 2 & 75 & 100 \\
\hline & & & & & 30.95 & 37.25 & I-Muito Bom & 1 & 95 & 100 \\
\hline & & & & & 37.25 & 39.90 & II - Bom & 2 & 85 & 100 \\
\hline & & & & & 39.90 & 43.00 & II - Bom & 1 & 90 & 100 \\
\hline & & & & & 43.00 & 45.10 & IV-Pobre & 3 & 58 & 100 \\
\hline & & & & & 45.10 & 51.20 & I-Muito Bom & 1 & 93 & 100 \\
\hline & & & & & 51.20 & 53.82 & II-Bom & 1 & 95 & 100 \\
\hline & & & & & 53.82 & 55.32 & III - Regular & 2 & 85 & 100 \\
\hline \multirow[t]{6}{*}{\begin{tabular}{l|l}
4509 \\
\end{tabular}} & 1.80 & 0.00 & 20.19 & SAR & 22.04 & 24.00 & II - Bom & 2 & 68 & 78 \\
\hline & & 20.19 & 21.00 & ROCHA & 24.00 & 25.40 & III - Regular & 4 & 20 & 65 \\
\hline & & 21.00 & 22.04 & SAR & 25.40 & 27.00 & III-Regular & 3 & 50 & 73 \\
\hline & & 22.04 & 55.20 & ROCHA & 27.00 & 29.15 & II-Bom & 2 & 82 & 100 \\
\hline & & & & & 29.15 & 29.95 & II-Bom & 2 & 65 & 100 \\
\hline & & & & & 29.95 & 32.95 & I-Muito Bom & 1 & 100 & 100 \\
\hline
\end{tabular}




\begin{tabular}{|c|c|c|c|c|c|c|c|c|c|c|}
\hline $\begin{array}{c}\text { Numero da } \\
\text { sondagem }(\mathrm{m})\end{array}$ & $\begin{array}{c}\text { Nivel de Água } \\
(\mathrm{m})\end{array}$ & Topo & Base & Geologia & $\begin{array}{c}\text { Topo } \\
\text { (m, 2DP) }\end{array}$ & $\begin{array}{c}\text { Base } \\
\text { (m, 2DP) }\end{array}$ & Classe de maciço & $\begin{array}{l}\text { Grau } \\
\text { Fratur. } \\
\text { (lista) }\end{array}$ & $\begin{array}{r}\text { RQD } \\
(\%)\end{array}$ & $\begin{array}{c}\text { Recuperação } \\
\text { (\%) }\end{array}$ \\
\hline & & & & & 32.95 & 36.00 & II-Bom & 1 & 96 & 100 \\
\hline & & & & & 36.00 & 38.80 & I-Muito Bom & 1 & 100 & 100 \\
\hline & & & & & 38.80 & 41.90 & III - Regular & 3 & 50 & 88 \\
\hline & & & & & 41.90 & 45.00 & III - Regular & 2 & 88 & 100 \\
\hline & & & & & 45.00 & 48.10 & III-Regular & 2 & 67 & 100 \\
\hline & & & & & 48.10 & 51.10 & I-Muito Bom & 1 & 100 & 100 \\
\hline & & & & & 51.10 & 54.10 & II- Bom & 1 & 95 & 100 \\
\hline & & & & & 54.10 & 55.20 & II-Bom & 1 & 90 & 100 \\
\hline \multirow[t]{9}{*}{4511} & 1.89 & 0.00 & 5.00 & AT & 19.05 & 20.05 & III - Regular & 5 & 0 & 35 \\
\hline & & 5.00 & 19.05 & SAR & 20.05 & 22.50 & II-Bom & 2 & 43 & 52 \\
\hline & & 19.05 & 40.00 & ROCHA & 22.50 & 24.50 & III-Regular & 3 & 44 & 64 \\
\hline & & & & & 24.50 & 27.50 & II-Bom & 3 & 87 & 100 \\
\hline & & & & & 27.50 & 30.50 & III-Regular & 4 & 21 & 50 \\
\hline & & & & & 30.50 & 33.50 & II-Bom & 2 & 85 & 90 \\
\hline & & & & & 33.50 & 36.50 & IV-Pobre & 3 & 59 & 85 \\
\hline & & & & & 36.50 & 39.50 & IV-Pobre & 3 & 56 & 78 \\
\hline & & & & & 39.50 & 40.00 & II-Bom & 3 & 80 & 100 \\
\hline \multirow[t]{5}{*}{4512} & 3.68 & 0.00 & 4.00 & & 22.47 & 24.50 & IV-Pobre & 5 & 43 & 92 \\
\hline & & 4.00 & 13.00 & & 24.50 & 27.50 & III-Regular & 2 & 100 & 100 \\
\hline & & 13.00 & 22.47 & & 27.50 & 30.50 & III-Regular & 2 & 83 & 100 \\
\hline & & 22.47 & 36.00 & & 30.50 & 33.50 & II-Bom & 3 & 95 & 100 \\
\hline & & & & & 33.50 & 36.00 & II - Bom & 3 & 90 & 100 \\
\hline \multirow[t]{22}{*}{4513} & 5.45 & 0.00 & 4.46 & AT & 24.06 & 26.00 & V-Muito Pobre & 5 & 0 & 47 \\
\hline & & 4.46 & 8.20 & SSBP & 26.00 & 27.70 & IV-Pobre & 3 & 52 & 90 \\
\hline & & 8.20 & 24.06 & SAR & 27.70 & 29.70 & II-Bom & 2 & 71 & 100 \\
\hline & & 24.06 & 65.00 & ROCHA & 29.70 & 30.40 & V-Muito Pobre & 4 & 30 & 100 \\
\hline & & & & & 30.40 & 33.40 & III-Regular & 3 & 58 & 97 \\
\hline & & & & & 33.40 & 35.20 & II-Bom & 2 & 67 & 95 \\
\hline & & & & & 35.20 & 36.45 & II- Bom & 2 & 73 & 100 \\
\hline & & & & & 36.45 & 39.45 & III-Regular & 2 & 63 & 92 \\
\hline & & & & & 39.45 & 40.85 & III - Regular & 2 & 75 & 99 \\
\hline & & & & & 40.85 & 42.35 & V-Muito Pobre & 5 & 13 & 67 \\
\hline & & & & & 42.35 & 44.15 & IV - Pobre & 3 & 57 & 92 \\
\hline & & & & & 44.15 & 46.25 & II-Bom & 2 & 68 & 82 \\
\hline & & & & & 46.25 & 47.30 & IV-Pobre & 3 & 45 & 100 \\
\hline & & & & & 47.30 & 50.00 & III-Regular & 3 & 58 & 80 \\
\hline & & & & & 50.00 & 51.40 & III-Regular & 3 & 30 & 90 \\
\hline & & & & & 51.40 & 52.60 & I-Muito Bom & 1 & 89 & 95 \\
\hline & & & & & 52.60 & 54.40 & II - Bom & 2 & 73 & 79 \\
\hline & & & & & 54.40 & 55.00 & IV-Pobre & 3 & 56 & 85 \\
\hline & & & & & 55.00 & 55.70 & V - Muito Pobre & 5 & 0 & 50 \\
\hline & & & & & 55.70 & 56.50 & I-Muito Bom & 1 & 81 & 89 \\
\hline & & & & & 56.50 & 61.40 & I-Muito Bom & 1 & 95 & 100 \\
\hline & & & & & 61.40 & 65.00 & I-Muito Bom & 1 & 100 & 100 \\
\hline \multirow[t]{14}{*}{4514} & 3.97 & 0.00 & 7.47 & AT & 22.65 & 24.65 & IV-Pobre & 3 & 0 & 59 \\
\hline & & 7.47 & 8.73 & $\mathrm{AL}$ & 24.65 & 26.15 & IV-Pobre & 3 & 81 & 100 \\
\hline & & 8.73 & 22.65 & SAR & 26.15 & 29.75 & I-Muito Bom & 1 & 100 & 100 \\
\hline & & 22.65 & 60.25 & ROCHA & 29.75 & 30.75 & IV-Pobre & 3 & 0 & 80 \\
\hline & & & & & 30.75 & 31.75 & I-Muito Bom & 1 & 100 & 100 \\
\hline & & & & & 31.75 & 33.25 & IV-Pobre & 3 & 58 & 100 \\
\hline & & & & & 33.25 & 37.85 & II-Bom & 2 & 97 & 100 \\
\hline & & & & & 37.85 & 40.15 & II-Bom & 2 & 93 & 100 \\
\hline & & & & & 40.15 & 41.90 & II - Bom & 2 & 100 & 100 \\
\hline & & & & & 41.90 & 43.65 & I-Muito Bom & 1 & 100 & 100 \\
\hline & & & & & 43.65 & 45.05 & III - Regular & 2 & 90 & 100 \\
\hline & & & & & 45.05 & 46.55 & I-Muito Bom & 1 & 100 & 100 \\
\hline & & & & & 46.55 & 49.15 & III - Regular & 2 & 100 & 100 \\
\hline & & & & & 49.15 & 60.25 & II-Bom & 1 & 100 & 100 \\
\hline \multirow[t]{3}{*}{4515} & 3.00 & 0.00 & 5.80 & & 26.04 & 27.30 & II-Bom & 2 & 60 & 60 \\
\hline & & 5.80 & 26.04 & & 27.30 & 30.30 & II-Bom & 2 & 100 & 100 \\
\hline & & 26.04 & 65.00 & & 30.30 & 33.10 & III-Regular & 2 & 100 & 100 \\
\hline
\end{tabular}




\begin{tabular}{|c|c|c|c|c|c|c|c|c|c|c|}
\hline $\begin{array}{c}\text { Numero da } \\
\text { sondagem (m) }\end{array}$ & $\begin{array}{c}\text { Nivel de Água } \\
\text { (m) }\end{array}$ & Topo & Base & Geologia & $\begin{array}{c}\text { Topo } \\
\text { (m, 2DP) }\end{array}$ & $\begin{array}{c}\text { Base } \\
\text { (m, 2DP) }\end{array}$ & Classe de maciço & $\begin{array}{l}\text { Grau } \\
\text { Fratur. } \\
\text { (lista) }\end{array}$ & $\begin{array}{l}\text { RQD } \\
(\%)\end{array}$ & $\begin{array}{c}\text { Recuperação } \\
(\%)\end{array}$ \\
\hline & & & & & 33.10 & 36.10 & IV-Pobre & 3 & 75 & 100 \\
\hline & & & & & 36.10 & 38.70 & IV-Pobre & 3 & 79 & 100 \\
\hline & & & & & 38.70 & 39.20 & II - Bom & 3 & 81 & 100 \\
\hline & & & & & 39.20 & 39.90 & V-Muito Pobre & 4 & 0 & 100 \\
\hline & & & & & 39.90 & 40.80 & V-Muito Pobre & 4 & 38 & 75 \\
\hline & & & & & 40.80 & 43.80 & III - Regular & 2 & 89 & 100 \\
\hline & & & & & 43.80 & 46.20 & III - Regular & 2 & 100 & 100 \\
\hline & & & & & 46.20 & 49.20 & III - Regular & 3 & 79 & 100 \\
\hline & & & & & 49.20 & 52.50 & III - Regular & 3 & 74 & 95 \\
\hline & & & & & 52.50 & 53.80 & III - Regular & 3 & 79 & 100 \\
\hline & & & & & 53.80 & 56.50 & II-Bom & 2 & 85 & 100 \\
\hline & & & & & 56.50 & 59.50 & III-Regular & 3 & 79 & 100 \\
\hline & & & & & 59.50 & 62.50 & IV - Pobre & 3 & 81 & 100 \\
\hline & & & & & 62.50 & 65.00 & I-Muito Bom & 2 & 100 & 100 \\
\hline \multirow[t]{10}{*}{4516} & 5.82 & 0.00 & 3.73 & AT & 20.80 & 22.30 & V-Muito Pobre & 5 & 0 & 25 \\
\hline & & 3.73 & 6.68 & $\mathrm{AL}$ & 22.30 & 23.90 & II - Bom & 3 & 80 & 100 \\
\hline & & 6.68 & 20.80 & SAR & 23.90 & 25.40 & III - Regular & 3 & 78 & 100 \\
\hline & & 20.80 & 52.35 & ROCHA & 25.40 & 32.90 & II - Bom & 1 & 95 & 100 \\
\hline & & & & & 32.90 & 34.10 & III-Regular & 2 & 75 & 100 \\
\hline & & & & & 34.10 & 35.80 & I - Muito Bom & 1 & 95 & 100 \\
\hline & & & & & 35.80 & 37.30 & III - Regular & 3 & 67 & 100 \\
\hline & & & & & 37.30 & 43.40 & III - Regular & 2 & 98 & 100 \\
\hline & & & & & 43.40 & 50.80 & I-Muito Bom & 1 & 100 & 100 \\
\hline & & & & & 50.80 & 52.35 & II-Bom & 2 & 75 & 100 \\
\hline \multirow[t]{7}{*}{4517} & 2.45 & 0.00 & 2.70 & AT & 39.95 & 41.00 & III-Regular & 3 & 25 & 95 \\
\hline & & 2.70 & 22.85 & SAR & 41.00 & 42.00 & III-Regular & 3 & 25 & 100 \\
\hline & & 22.85 & 28.05 & ROCHA & 42.00 & 43.60 & III - Regular & 3 & 34 & 100 \\
\hline & & 28.05 & 36.20 & SAR & 43.60 & 45.00 & III - Regular & 3 & 32 & 100 \\
\hline & & 36.20 & 38.05 & ROCHA & & & & & & \\
\hline & & 38.05 & 39.95 & SAR & & & & & & \\
\hline & & 39.95 & 45.00 & ROCHA & & & & & & \\
\hline \multirow[t]{14}{*}{4518} & 2.70 & 0.00 & 2.00 & AT & 28.00 & 29.00 & V-Muito Pobre & 5 & 0 & 65 \\
\hline & & 2.00 & 28.00 & SAR & 29.00 & 30.40 & IV - Pobre & 3 & 38 & 88 \\
\hline & & 28.00 & 60.34 & ROCHA & 30.40 & 31.20 & IV-Pobre & 3 & 55 & 91 \\
\hline & & & & & 31.20 & 33.50 & IV - Pobre & 3 & 52 & 99 \\
\hline & & & & & 33.50 & 35.20 & IV-Pobre & 3 & 48 & 95 \\
\hline & & & & & 35.20 & 35.70 & V-Muito Pobre & 4 & 20 & 95 \\
\hline & & & & & 35.70 & 37.00 & III - Regular & 3 & 45 & 98 \\
\hline & & & & & 37.00 & 39.50 & II - Bom & 2 & 69 & 97 \\
\hline & & & & & 39.50 & 45.50 & III - Regular & 2 & 71 & 100 \\
\hline & & & & & 45.50 & 46.90 & II - Bom & 2 & 60 & 100 \\
\hline & & & & & 46.90 & 49.90 & III - Regular & 2 & 81 & 100 \\
\hline & & & & & 49.90 & 52.90 & I - Muito Bom & 1 & 100 & 100 \\
\hline & & & & & 52.90 & 55.20 & I - Muito Bom & 1 & 94 & 100 \\
\hline & & & & & 55.20 & 60.34 & I - Muito Bom & 1 & 98 & 100 \\
\hline \multirow[t]{16}{*}{4520} & 3.71 & 0.00 & 4.00 & AT & 29.04 & 29.96 & IV - Pobre & 3 & 45 & 53 \\
\hline & & 4.00 & 29.04 & SAR & 29.96 & 31.96 & III - Regular & 3 & 35 & 47 \\
\hline & & 29.04 & 60.16 & ROCHA & 31.96 & 34.16 & II - Bom & 2 & 76 & 100 \\
\hline & & & & & 34.16 & 35.56 & IV-Pobre & 4 & 21 & 76 \\
\hline & & & & & 35.56 & 36.96 & V-Muito Pobre & 4 & 19 & 50 \\
\hline & & & & & 36.96 & 40.96 & V-Muito Pobre & 5 & 0 & 40 \\
\hline & & & & & 40.96 & 41.96 & V-Muito Pobre & 4 & 18 & 37 \\
\hline & & & & & 41.96 & 42.61 & III - Regular & 4 & 38 & 55 \\
\hline & & & & & 42.61 & 45.01 & V-Muito Pobre & 5 & 0 & 60 \\
\hline & & & & & 45.01 & 46.01 & III - Regular & 4 & 38 & 86 \\
\hline & & & & & 46.01 & 47.71 & I - Muito Bom & 1 & 82 & 94 \\
\hline & & & & & 47.71 & 48.21 & III - Regular & 4 & 30 & 100 \\
\hline & & & & & 48.21 & 49.81 & III - Regular & 3 & 40 & 90 \\
\hline & & & & & 49.81 & 51.01 & III - Regular & 4 & 25 & 90 \\
\hline & & & & & 51.01 & 51.71 & III - Regular & 4 & 21 & 100 \\
\hline & & & & & 51.71 & 52.16 & V-Muito Pobre & 5 & 0 & 50 \\
\hline
\end{tabular}




\begin{tabular}{|c|c|c|c|c|c|c|c|c|c|c|}
\hline $\begin{array}{c}\text { Numero da } \\
\text { sondagem }(\mathrm{m})\end{array}$ & $\begin{array}{c}\text { Nivel de Água } \\
(\mathrm{m})\end{array}$ & Topo & Base & Geologia & $\begin{array}{c}\text { Topo } \\
\text { (m, 2DP) }\end{array}$ & $\begin{array}{c}\text { Base } \\
(\mathrm{m}, 2 \mathrm{DP})\end{array}$ & Classe de maciço & $\begin{array}{l}\text { Grau } \\
\text { Fratur. } \\
\text { (lista) }\end{array}$ & $\begin{array}{r}\text { RQD } \\
(\%)\end{array}$ & $\begin{array}{c}\text { Recuperação } \\
\text { (\%) }\end{array}$ \\
\hline & & & & & 52.16 & 53.76 & I-Muito Bom & 1 & 90 & 92 \\
\hline & & & & & 53.76 & 60.16 & I-Muito Bom & 1 & 100 & 100 \\
\hline \multirow[t]{6}{*}{4522} & 15.10 & 0.00 & 4.61 & AT & 17.40 & 20.40 & III - Regular & 3 & 32 & 32 \\
\hline & & 4.61 & 17.40 & SAR & 20.40 & 23.40 & II-Bom & 2 & 85 & 100 \\
\hline & & 17.40 & 42.30 & ROCHA & 23.40 & 30.80 & II-Bom & 2 & 86 & 100 \\
\hline & & & & & 30.80 & 34.00 & III - Regular & 3 & 62 & 62 \\
\hline & & & & & 34.00 & 35.00 & II-Bom & 2 & 81 & 100 \\
\hline & & & & & 35.00 & 43.20 & II-Bom & 2 & 85 & 85 \\
\hline \multirow[t]{14}{*}{4523} & 5.67 & 0.00 & 17.90 & SAR & 17.90 & 19.00 & II - Bom & 2 & 70 & 95 \\
\hline & & 17.90 & 58.70 & ROCHA & 19.00 & 22.00 & IV-Pobre & 3 & 50 & 83 \\
\hline & & & & & 22.00 & 27.50 & I-Muito Bom & 1 & 100 & 100 \\
\hline & & & & & 27.50 & 30.50 & I-Muito Bom & 1 & 90 & 95 \\
\hline & & & & & 30.50 & 33.00 & I-Muito Bom & 1 & 100 & 100 \\
\hline & & & & & 33.00 & 39.20 & III - Regular & 1 & 90 & 100 \\
\hline & & & & & 39.20 & 42.20 & III - Regular & 2 & 75 & 100 \\
\hline & & & & & 42.20 & 44.20 & II- Bom & 1 & 92 & 92 \\
\hline & & & & & 44.20 & 47.00 & IV-Pobre & 3 & 70 & 100 \\
\hline & & & & & 47.00 & 50.10 & III - Regular & 2 & 89 & 100 \\
\hline & & & & & 50.10 & 53.00 & II-Bom & 1 & 90 & 100 \\
\hline & & & & & 53.00 & 55.20 & III-Regular & 2 & 78 & 100 \\
\hline & & & & & 55.20 & 56.20 & IV-Pobre & 3 & 55 & 100 \\
\hline & & & & & 56.20 & 58.70 & IV-Pobre & 3 & 48 & 100 \\
\hline \multirow[t]{12}{*}{4524} & 10.66 & 0.00 & 4.45 & AT & 22.07 & 23.07 & V-Muito Pobre & 4 & 21 & 100 \\
\hline & & 4.45 & 22.07 & SAR & 23.07 & 25.73 & II- Bom & 1 & 100 & 100 \\
\hline & & 22.07 & 58.37 & ROCHA & 25.73 & 28.93 & V-Muito Pobre & 5 & 0 & 80 \\
\hline & & & & & 28.93 & 29.91 & IV-Pobre & 2 & 73 & 100 \\
\hline & & & & & 29.91 & 32.77 & II - Bom & 1 & 95 & 100 \\
\hline & & & & & 32.77 & 35.92 & V-Muito Pobre & 4 & 25 & 95 \\
\hline & & & & & 35.92 & 38.08 & III-Regular & 1 & 92 & 100 \\
\hline & & & & & 38.08 & 39.08 & V-Muito Pobre & 4 & 20 & 97 \\
\hline & & & & & 39.08 & 41.18 & IV-Pobre & 3 & 60 & 98 \\
\hline & & & & & 41.18 & 43.18 & III - Regular & 2 & 78 & 100 \\
\hline & & & & & 43.18 & 52.55 & II - Bom & 1 & 95 & 100 \\
\hline & & & & & 52.55 & 58.37 & V-Muito Pobre & 4 & 10 & 75 \\
\hline \multirow[t]{15}{*}{4525} & 7.54 & 0.00 & 2.50 & AT & 20.15 & 21.05 & II-Bom & 2 & 85 & 93 \\
\hline & & 2.50 & 20.15 & SAR & 21.05 & 26.75 & II-Bom & 1 & 100 & 100 \\
\hline & & 20.15 & 50.00 & ROCHA & 26.75 & 27.75 & III - Regular & 2 & 81 & 93 \\
\hline & & & & & 27.75 & 30.75 & I-Muito Bom & 1 & 100 & 100 \\
\hline & & & & & 30.75 & 32.90 & III-Regular & 2 & 95 & 95 \\
\hline & & & & & 32.90 & 34.00 & III-Regular & 2 & 80 & 95 \\
\hline & & & & & 34.00 & 38.10 & II- Bom & 1 & 100 & 100 \\
\hline & & & & & 38.10 & 38.60 & III-Regular & 3 & 79 & 84 \\
\hline & & & & & 38.60 & 40.00 & I-Muito Bom & 1 & 100 & 100 \\
\hline & & & & & 40.00 & 41.00 & III - Regular & 2 & 100 & 100 \\
\hline & & & & & 41.00 & 42.30 & I-Muito Bom & 1 & 100 & 100 \\
\hline & & & & & 42.30 & 45.00 & III - Regular & 2 & 83 & 100 \\
\hline & & & & & 45.00 & 46.00 & II-Bom & 1 & 100 & 100 \\
\hline & & & & & 46.00 & 48.60 & III-Regular & 2 & 90 & 96 \\
\hline & & & & & 48.60 & 50.00 & III-Regular & 3 & 70 & 96 \\
\hline \multirow[t]{8}{*}{4526} & 12.00 & 0.00 & 2.55 & AT & 16.50 & 19.00 & III - Regular & 2 & 44 & 72 \\
\hline & & 2.55 & 16.50 & SAR & 19.00 & 22.00 & II-Bom & 2 & 85 & 90 \\
\hline & & 16.50 & 40.00 & ROCHA & 22.00 & 25.00 & II-Bom & 2 & 87 & 99 \\
\hline & & & & & 25.00 & 28.00 & II- Bom & 2 & 95 & 95 \\
\hline & & & & & 28.00 & 31.20 & I-Muito Bom & 1 & 100 & 100 \\
\hline & & & & & 31.20 & 34.00 & II-Bom & 2 & 93 & 100 \\
\hline & & & & & 34.00 & 37.00 & II-Bom & 2 & 95 & 100 \\
\hline & & & & & 37.00 & 40.00 & II - Bom & 2 & 70 & 70 \\
\hline \multirow[t]{4}{*}{4527} & 9.02 & 0.00 & 21.27 & SAR & 21.27 & 22.00 & III-Regular & 2 & 62 & 85 \\
\hline & & 21.27 & 58.18 & ROCHA & 22.00 & 24.50 & III-Regular & 2 & 68 & 88 \\
\hline & & & & & 24.50 & 36.00 & I-Muito Bom & 1 & 100 & 100 \\
\hline & & & & & 36.00 & 39.10 & II - Bom & 1 & 95 & 99 \\
\hline
\end{tabular}




\begin{tabular}{|c|c|c|c|c|c|c|c|c|c|c|}
\hline $\begin{array}{c}\text { Numero da } \\
\text { sondagem }(\mathrm{m})\end{array}$ & $\begin{array}{c}\text { Nivel de Água } \\
(\mathrm{m})\end{array}$ & Topo & Base & Geologia & $\begin{array}{c}\text { Topo } \\
\text { (m, 2DP) }\end{array}$ & $\begin{array}{c}\text { Base } \\
\text { (m, 2DP) }\end{array}$ & Classe de maciço & $\begin{array}{l}\text { Grau } \\
\text { Fratur. } \\
\text { (lista) }\end{array}$ & $\begin{array}{r}\text { RQD } \\
(\%)\end{array}$ & $\begin{array}{c}\text { Recuperação } \\
\text { (\%) }\end{array}$ \\
\hline & & & & & 39.10 & 42.00 & III - Regular & 2 & 80 & 98 \\
\hline & & & & & 42.00 & 45.00 & I-Muito Bom & 1 & 90 & 100 \\
\hline & & & & & 45.00 & 48.00 & III - Regular & 2 & 71 & 100 \\
\hline & & & & & 48.00 & 50.60 & IV-Pobre & 3 & 58 & 100 \\
\hline & & & & & 50.60 & 53.30 & V-Muito Pobre & 3 & 50 & 89 \\
\hline & & & & & 53.30 & 56.10 & II-Bom & 1 & 85 & 98 \\
\hline & & & & & 56.10 & 58.18 & I-Muito Bom & 1 & 100 & 100 \\
\hline \multirow[t]{8}{*}{4528} & 9.80 & 0.00 & 4.85 & AT & 12.40 & 15.40 & III - Regular & 2 & 27 & 48 \\
\hline & & 4.85 & 12.40 & SAR & 15.40 & 18.40 & II - Bom & 2 & 85 & 98 \\
\hline & & 12.40 & 36.40 & ROCHA & 18.40 & 21.40 & II-Bom & 2 & 91 & 90 \\
\hline & & & & & 21.40 & 24.40 & IV-Pobre & 3 & 90 & 100 \\
\hline & & & & & 24.40 & 27.40 & IV-Pobre & 3 & 93 & 98 \\
\hline & & & & & 27.40 & 30.40 & IV-Pobre & 3 & 98 & 98 \\
\hline & & & & & 30.40 & 33.40 & III - Regular & 2 & 94 & 100 \\
\hline & & & & & 33.40 & 36.40 & IV-Pobre & 3 & 97 & 100 \\
\hline \multirow[t]{9}{*}{4529} & 8.34 & 0.00 & 6.60 & AT & 10.55 & 12.00 & II- Bom & 2 & 86 & 86 \\
\hline & & 6.60 & 10.55 & SAR & 12.00 & 15.00 & II-Bom & 2 & 88 & 100 \\
\hline & & 10.55 & 35.00 & ROCHA & 15.00 & 18.00 & II-Bom & 2 & 98 & 98 \\
\hline & & & & & 18.00 & 21.00 & III - Regular & 4 & 89 & 90 \\
\hline & & & & & 21.00 & 24.00 & II - Bom & 2 & 78 & 80 \\
\hline & & & & & 24.00 & 27.00 & II - Bom & 2 & 79 & 79 \\
\hline & & & & & 27.00 & 30.00 & II - Bom & 2 & 89 & 89 \\
\hline & & & & & 30.00 & 33.00 & III-Regular & 4 & 55 & 77 \\
\hline & & & & & 33.00 & 35.00 & II-Bom & 3 & 93 & 100 \\
\hline \multirow[t]{5}{*}{4530} & 7.30 & 0.00 & 5.10 & AT & 14.20 & 15.00 & III - Regular & 2 & 23 & 100 \\
\hline & & 5.10 & 14.20 & SAR & 15.00 & 23.60 & III-Regular & 1 & 95 & 100 \\
\hline & & 14.20 & 32.65 & ROCHA & 23.60 & 24.10 & IV-Pobre & 3 & 0 & 100 \\
\hline & & & & & 24.10 & 25.00 & III-Regular & 2 & 73 & 100 \\
\hline & & & & & 25.00 & 32.65 & I-Muito Bom & 1 & 95 & 100 \\
\hline \multirow[t]{14}{*}{4531} & 5.13 & 0.00 & 4.00 & AT & 6.43 & 7.43 & V-Muito Pobre & 4 & 15 & 100 \\
\hline & & 4.00 & 5.43 & SAR & 7.43 & 8.00 & V-Muito Pobre & 5 & 0 & 66 \\
\hline & & 5.43 & 40.12 & ROCHA & 8.00 & 9.50 & III - Regular & 3 & 60 & 95 \\
\hline & & & & & 9.50 & 12.50 & II-Bom & 2 & 68 & 100 \\
\hline & & & & & 12.50 & 14.90 & I-Muito Bom & 1 & 100 & 100 \\
\hline & & & & & 14.90 & 15.90 & II-Bom & 2 & 78 & 100 \\
\hline & & & & & 15.90 & 20.00 & I-Muito Bom & 1 & 100 & 100 \\
\hline & & & & & 20.00 & 22.50 & III - Regular & 2 & 75 & 98 \\
\hline & & & & & 22.50 & 30.50 & I-Muito Bom & 1 & 100 & 100 \\
\hline & & & & & 30.50 & 32.20 & III-Regular & 1 & 87 & 100 \\
\hline & & & & & 32.20 & 33.70 & IV-Pobre & 3 & 55 & 100 \\
\hline & & & & & 33.70 & 36.60 & II-Bom & 2 & 79 & 100 \\
\hline & & & & & 36.60 & 39.60 & IV-Pobre & 3 & 60 & 100 \\
\hline & & & & & 39.60 & 40.12 & I - Muito Bom & 1 & 95 & 100 \\
\hline \multirow[t]{15}{*}{4532} & 4.20 & 0.00 & 3.90 & AT & 7.00 & 8.00 & V-Muito Pobre & 4 & 36 & 95 \\
\hline & & 3.90 & 7.00 & SAR & 8.00 & 8.62 & II-Bom & 3 & 82 & 100 \\
\hline & & 7.00 & 39.40 & ROCHA & 8.62 & 9.55 & III-Regular & 3 & 40 & 73 \\
\hline & & & & & 9.55 & 11.05 & II-Bom & 3 & 94 & 100 \\
\hline & & & & & 11.05 & 12.30 & II-Bom & 3 & 94 & 98 \\
\hline & & & & & 12.30 & 14.07 & II- Bom & 3 & 86 & 95 \\
\hline & & & & & 14.07 & 15.57 & III - Regular & 3 & 65 & 100 \\
\hline & & & & & 15.57 & 18.57 & III-Regular & 3 & 80 & 98 \\
\hline & & & & & 18.57 & 21.30 & III-Regular & 2 & 87 & 90 \\
\hline & & & & & 21.30 & 24.30 & III-Regular & 2 & 98 & 100 \\
\hline & & & & & 24.30 & 27.30 & III-Regular & 2 & 88 & 98 \\
\hline & & & & & 27.30 & 30.30 & III - Regular & 2 & 96 & 99 \\
\hline & & & & & 30.30 & 33.30 & III - Regular & 2 & 100 & 100 \\
\hline & & & & & 33.30 & 36.30 & III - Regular & 2 & 96 & 98 \\
\hline & & & & & 36.30 & 39.40 & III-Regular & 3 & 58 & 93 \\
\hline \multirow[t]{3}{*}{4533} & 4.30 & 0.00 & 5.00 & AT & 10.90 & 11.30 & III - Regular & 4 & 25 & 100 \\
\hline & & 5.00 & 7.90 & $\mathrm{AL}$ & 11.30 & 12.30 & III - Regular & 4 & 20 & 80 \\
\hline & & 7.90 & 10.90 & SAR & 12.30 & 13.70 & II - Bom & 2 & 45 & 60 \\
\hline
\end{tabular}




\begin{tabular}{|c|c|c|c|c|c|c|c|c|c|c|}
\hline $\begin{array}{c}\text { Numero da } \\
\text { sondagem }(\mathrm{m})\end{array}$ & $\begin{array}{c}\text { Nivel de Água } \\
(\mathrm{m})\end{array}$ & Topo & Base & Geologia & $\begin{array}{c}\text { Topo } \\
\text { (m, 2DP) }\end{array}$ & $\begin{array}{c}\text { Base } \\
(\mathrm{m}, 2 \mathrm{DP})\end{array}$ & Classe de maciço & $\begin{array}{l}\text { Grau } \\
\text { Fratur. } \\
\text { (lista) }\end{array}$ & $\begin{array}{r}\text { RQD } \\
(\%)\end{array}$ & $\begin{array}{c}\text { Recuperação } \\
\text { (\%) }\end{array}$ \\
\hline & & 10.90 & 40.00 & ROCHA & 13.70 & 15.20 & II-Bom & 2 & 60 & 70 \\
\hline & & & & & 15.20 & 16.20 & II-Bom & 2 & 45 & 60 \\
\hline & & & & & 16.20 & 17.30 & II-Bom & 2 & 82 & 85 \\
\hline & & & & & 17.30 & 20.30 & II-Bom & 2 & 97 & 100 \\
\hline & & & & & 20.30 & 23.30 & II - Bom & 2 & 95 & 100 \\
\hline & & & & & 23.30 & 26.30 & II-Bom & 2 & 92 & 100 \\
\hline & & & & & 26.30 & 29.30 & III - Regular & 2 & 95 & 100 \\
\hline & & & & & 29.30 & 32.30 & IV-Pobre & 3 & 55 & 100 \\
\hline & & & & & 32.30 & 35.30 & III - Regular & 2 & 95 & 85 \\
\hline & & & & & 35.30 & 37.90 & II-Bom & 2 & 60 & 80 \\
\hline & & & & & 37.90 & 40.00 & II-Bom & 2 & 50 & 80 \\
\hline \multirow[t]{10}{*}{4534} & 3.84 & 0.00 & 2.40 & AT & 13.13 & 14.63 & V-Muito Pobre & 5 & 0 & 25 \\
\hline & & 2.40 & 9.00 & $\mathrm{AL}$ & 14.63 & 15.90 & V-Muito Pobre & 4 & 0 & 100 \\
\hline & & 9.00 & 13.13 & SAR & 15.90 & 17.60 & IV-Pobre & 3 & 40 & 100 \\
\hline & & 13.13 & 40.10 & ROCHA & 17.60 & 20.50 & III-Regular & 2 & 85 & 92 \\
\hline & & & & & 20.50 & 20.80 & V-Muito Pobre & 5 & 0 & 100 \\
\hline & & & & & 20.80 & 22.20 & I-Muito Bom & 1 & 90 & 100 \\
\hline & & & & & 22.20 & 22.80 & V-Muito Pobre & 5 & 0 & 100 \\
\hline & & & & & 22.80 & 27.80 & II-Bom & 2 & 80 & 100 \\
\hline & & & & & 27.80 & 37.00 & II - Bom & 2 & 90 & 100 \\
\hline & & & & & 37.00 & 40.10 & II - Bom & 2 & 100 & 100 \\
\hline \multirow[t]{9}{*}{4535} & 4.70 & 0.00 & 5.51 & & 7.60 & 9.80 & III-Regular & 5 & 7 & 60 \\
\hline & & 5.51 & 7.60 & & 9.80 & 10.20 & III-Regular & 2 & 86 & 87 \\
\hline & & 7.60 & 40.07 & & 10.20 & 14.10 & IV-Pobre & 3 & 72 & 100 \\
\hline & & & & & 14.10 & 15.60 & IV-Pobre & 3 & 65 & 100 \\
\hline & & & & & 15.60 & 21.10 & III-Regular & 2 & 95 & 100 \\
\hline & & & & & 21.10 & 21.50 & V-Muito Pobre & 4 & 35 & 100 \\
\hline & & & & & 21.50 & 30.10 & III - Regular & 2 & 95 & 100 \\
\hline & & & & & 30.10 & 30.90 & \begin{tabular}{|l|} 
V-Muito Pobre \\
\end{tabular} & 4 & 0 & 87 \\
\hline & & & & & 30.90 & 40.00 & III-Regular & 2 & 95 & 100 \\
\hline \multirow[t]{10}{*}{4536} & 5.08 & 0.00 & 4.80 & AT & 14.80 & 16.30 & V-Muito Pobre & 4 & 37 & 81 \\
\hline & & 4.80 & 14.80 & SAR & 16.30 & 18.20 & V-Muito Pobre & 4 & 18 & 70 \\
\hline & & 14.80 & 40.00 & ROCHA & 18.20 & 21.20 & I- Muito Bom & 1 & 84 & 98 \\
\hline & & & & & 21.20 & 24.20 & I-Muito Bom & 1 & 87 & 100 \\
\hline & & & & & 24.20 & 27.20 & IV-Pobre & 2 & 78 & 100 \\
\hline & & & & & 27.20 & 30.20 & I-Muito Bom & 1 & 92 & 100 \\
\hline & & & & & 30.20 & 33.20 & I-Muito Bom & 1 & 95 & 100 \\
\hline & & & & & 33.20 & 36.20 & I-Muito Bom & 1 & 83 & 100 \\
\hline & & & & & 36.20 & 39.20 & I-Muito Bom & 1 & 90 & 100 \\
\hline & & & & & 39.20 & 40.00 & I - Muito Bom & 1 & 70 & 100 \\
\hline \multirow[t]{16}{*}{4537} & 5.61 & 0.00 & 1.00 & AT & 6.10 & 7.00 & V-Muito Pobre & 0 & 5 & 62 \\
\hline & & 1.00 & 6.10 & SAR & 7.00 & 8.10 & V-Muito Pobre & 0 & 5 & 41 \\
\hline & & 6.10 & 40.15 & ROCHA & 8.10 & 8.60 & V-Muito Pobre & 0 & 5 & 100 \\
\hline & & & & & 8.60 & 9.50 & V-Muito Pobre & 0 & 5 & 65 \\
\hline & & & & & 9.50 & 10.10 & V-Muito Pobre & 0 & 5 & 92 \\
\hline & & & & & 10.10 & 13.10 & IV-Pobre & 95 & 5 & 100 \\
\hline & & & & & 13.10 & 16.10 & I-Muito Bom & 100 & 1 & 100 \\
\hline & & & & & 16.10 & 18.10 & III-Regular & 80 & 1 & 100 \\
\hline & & & & & 18.10 & 20.20 & II-Bom & 96 & 2 & 100 \\
\hline & & & & & 20.20 & 23.30 & III-Regular & 96 & 1 & 100 \\
\hline & & & & & 23.30 & 26.40 & II-Bom & 100 & 1 & 100 \\
\hline & & & & & 26.40 & 29.50 & I- Muito Bom & 98 & 1 & 100 \\
\hline & & & & & 29.50 & 32.50 & II - Bom & 100 & 1 & 100 \\
\hline & & & & & 32.50 & 35.50 & III-Regular & 90 & 1 & 100 \\
\hline & & & & & 35.50 & 38.20 & III-Regular & 90 & 1 & 100 \\
\hline & & & & & 38.20 & 40.15 & I - Muito Bom & 100 & 1 & 100 \\
\hline \multirow[t]{5}{*}{4538} & 4.90 & 0 & 3.7 & AT & 6.12 & 8.93 & V-Muito Pobre & 5 & 0 & 35 \\
\hline & & 3.7 & 6.12 & SAR & 8.93 & 9.93 & V-Muito Pobre & 4 & 20 & 45 \\
\hline & & 6.12 & 40.10 & ROCHA & 9.93 & 10.93 & III-Regular & 2 & 79 & 98 \\
\hline & & & & & 10.93 & 12.20 & III-Regular & 2 & 98 & 100 \\
\hline & & & & & 12.20 & 15.20 & II-Bom & 2 & 85 & 100 \\
\hline
\end{tabular}




\begin{tabular}{|c|c|c|c|c|c|c|c|c|c|c|}
\hline $\begin{array}{c}\text { Numero da } \\
\text { sondagem }(\mathrm{m})\end{array}$ & $\begin{array}{c}\text { Nivel de Água } \\
(\mathrm{m})\end{array}$ & Topo & Base & Geologia & $\begin{array}{c}\text { Topo } \\
\text { (m, 2DP) }\end{array}$ & $\begin{array}{c}\text { Base } \\
\text { (m, 2DP) }\end{array}$ & Classe de maciço & $\begin{array}{l}\text { Grau } \\
\text { Fratur. } \\
\text { (lista) }\end{array}$ & $\begin{array}{r}\text { RQD } \\
(\%)\end{array}$ & $\begin{array}{c}\text { Recuperação } \\
\text { (\%) }\end{array}$ \\
\hline & & & & & 15.20 & 18.20 & II - Bom & 2 & 98 & 100 \\
\hline & & & & & 18.20 & 21.20 & III-Regular & 2 & 100 & 100 \\
\hline & & & & & 21.20 & 24.20 & III - Regular & 2 & 91 & 100 \\
\hline & & & & & 24.20 & 27.20 & III - Regular & 2 & 89 & 100 \\
\hline & & & & & 27.20 & 30.20 & III - Regular & 2 & 100 & 100 \\
\hline & & & & & 30.20 & 33.20 & III-Regular & 2 & 98 & 100 \\
\hline & & & & & 33.20 & 36.20 & III - Regular & 1 & 80 & 100 \\
\hline & & & & & 36.20 & 39.20 & III - Regular & 2 & 95 & 100 \\
\hline & & & & & 39.20 & 40.10 & III - Regular & 1 & 80 & 100 \\
\hline \multirow{10}{*}{4540} & 7.50 & 0.00 & 6.90 & AT & 12.65 & 15.65 & IV-Pobre & 2 & 39 & 93 \\
\hline & & 6.90 & 12.65 & SAR & 15.65 & 18.65 & I-Muito Bom & 1 & 96 & 98 \\
\hline & & 12.65 & 40.00 & $\mathrm{ROCHA}$ & 18.65 & 21.65 & I-Muito Bom & 1 & 96 & 96 \\
\hline & & & & & 21.65 & 24.65 & I-Muito Bom & 1 & 96 & 99 \\
\hline & & & & & 24.65 & 27.65 & I-Muito Bom & 1 & 96 & 100 \\
\hline & & & & & 27.65 & 30.65 & I-Muito Bom & 1 & 96 & 100 \\
\hline & & & & & 30.65 & 33.65 & I-Muito Bom & 1 & 96 & 100 \\
\hline & & & & & 33.65 & 36.65 & I-Muito Bom & 1 & 96 & 100 \\
\hline & & & & & 36.65 & 38.15 & I-Muito Bom & 1 & 96 & 100 \\
\hline & & & & & 38.15 & 40.00 & 1-Muito Bom & 1 & 96 & 100 \\
\hline \multirow[t]{14}{*}{4541} & 4.00 & 0.00 & 4.00 & AT & 8.04 & 9.04 & IV-Pobre & 4 & 18 & 74 \\
\hline & & 4.00 & 8.04 & SAR & 9.04 & 9.24 & III - Regular & 3 & 50 & 100 \\
\hline & & 8.04 & 38.10 & ROCHA & 9.24 & 12.24 & II - Bom & 2 & 68 & 100 \\
\hline & & & & & 12.24 & 13.94 & IV-Pobre & 4 & 30 & 90 \\
\hline & & & & & 13.94 & 15.34 & II-Bom & 2 & 79 & 99 \\
\hline & & & & & 15.34 & 18.34 & II-Bom & 2 & 62 & 100 \\
\hline & & & & & 18.34 & 21.34 & IV-Pobre & 3 & 49 & 99 \\
\hline & & & & & 21.34 & 24.34 & III - Regular & 1 & 90 & 100 \\
\hline & & & & & 24.34 & 27.34 & III - Regular & 2 & 78 & 100 \\
\hline & & & & & 27.34 & 29.34 & III-Regular & 1 & 70 & 100 \\
\hline & & & & & 29.34 & 30.34 & I- Muito Bom & 1 & 100 & 100 \\
\hline & & & & & 30.34 & 33.34 & I-Muito Bom & 1 & 82 & 100 \\
\hline & & & & & 33.34 & 36.34 & III - Regular & 1 & 96 & 100 \\
\hline & & & & & 36.34 & 38.10 & I- Muito Bom & 1 & 99 & 100 \\
\hline \multirow[t]{9}{*}{4542} & 4.01 & 0.00 & 3.35 & AT & 9.60 & 12.10 & III-Regular & 2 & 88 & 100 \\
\hline & & 3.35 & 9.60 & SAR & 12.10 & 12.60 & \begin{tabular}{|l|} 
V-Muito Pobre \\
\end{tabular} & 5 & 38 & 99 \\
\hline & & 9.60 & 40.25 & ROCHA & 12.60 & 14.10 & I-Muito Bom & 1 & 100 & 100 \\
\hline & & & & & 14.10 & 15.60 & IV-Pobre & 3 & 80 & 100 \\
\hline & & & & & 15.60 & 20.60 & III - Regular & 2 & 85 & 100 \\
\hline & & & & & 20.60 & 23.60 & II - Bom & 2 & 100 & 100 \\
\hline & & & & & 23.60 & 34.70 & III - Regular & 2 & 89 & 100 \\
\hline & & & & & 34.70 & 35.70 & V - Muito Pobre & 4 & 20 & 100 \\
\hline & & & & & 35.70 & 40.25 & II - Bom & 2 & 100 & 100 \\
\hline \multirow[t]{16}{*}{4543} & 4.68 & 0.00 & 2.51 & AT & 2.51 & 5.65 & V-Muito Pobre & 5 & 12 & 78 \\
\hline & & 2.51 & 40.70 & ROCHA & 5.65 & 8.65 & III - Regular & 2 & 78 & 90 \\
\hline & & & & & 8.65 & 11.45 & IV-Pobre & 3 & 60 & 100 \\
\hline & & & & & 11.45 & 17.15 & II - Bom & 3 & 98 & 100 \\
\hline & & & & & 17.15 & 18.65 & I-Muito Bom & 1 & 86 & 100 \\
\hline & & & & & 18.65 & 20.35 & IV-Pobre & 3 & 50 & 99 \\
\hline & & & & & 20.35 & 22.85 & IV-Pobre & 2 & 75 & 98 \\
\hline & & & & & 22.85 & 23.65 & IV-Pobre & 2 & 27 & 95 \\
\hline & & & & & 23.65 & 25.15 & III-Regular & 4 & 33 & 99 \\
\hline & & & & & 25.15 & 26.15 & IV-Pobre & 3 & 55 & 100 \\
\hline & & & & & 26.15 & 28.00 & V-Muito Pobre & 4 & 13 & 100 \\
\hline & & & & & 28.00 & 29.60 & III-Regular & 4 & 74 & 95 \\
\hline & & & & & 29.60 & 32.60 & III-Regular & 4 & 68 & 100 \\
\hline & & & & & 32.60 & 35.60 & IV-Pobre & 2 & 73 & 100 \\
\hline & & & & & 35.60 & 38.60 & IV-Pobre & 2 & 62 & 100 \\
\hline & & & & & 38.60 & 41.70 & IV - Pobre & 3 & 42 & 100 \\
\hline \multirow[t]{3}{*}{4544} & 4.00 & 0.00 & 4.00 & & 4.61 & 5.11 & V-Muito Pobre & 5 & 0 & 65 \\
\hline & & 4.00 & 4.61 & & 5.11 & 6.61 & III - Regular & 4 & 28 & 100 \\
\hline & & 4.61 & 40.22 & & 6.61 & 8.41 & IV-Pobre & 3 & 40 & 100 \\
\hline
\end{tabular}




\begin{tabular}{|c|c|c|c|c|c|c|c|c|c|c|}
\hline $\begin{array}{c}\text { Numero da } \\
\text { sondagem (m) }\end{array}$ & $\begin{array}{c}\text { Nivel de Água } \\
\text { (m) }\end{array}$ & Topo & Base & Geologia & $\begin{array}{c}\text { Topo } \\
\text { (m, 2DP) }\end{array}$ & $\begin{array}{c}\text { Base } \\
(\mathrm{m}, 2 \mathrm{DP})\end{array}$ & Classe de maciço & $\begin{array}{l}\text { Grau } \\
\text { Fratur. } \\
\text { (lista) }\end{array}$ & $\begin{array}{l}\text { RQD } \\
(\%)\end{array}$ & $\begin{array}{c}\text { Recuperação } \\
(\%)\end{array}$ \\
\hline & & & & & 8.41 & 9.41 & IV-Pobre & 3 & 42 & 100 \\
\hline & & & & & 9.41 & 12.00 & V-Muito Pobre & 5 & 0 & 100 \\
\hline & & & & & 12.00 & 13.30 & III - Regular & 3 & 37 & 100 \\
\hline & & & & & 13.30 & 14.80 & II - Bom & 2 & 69 & 100 \\
\hline & & & & & 14.80 & 15.80 & IV-Pobre & 3 & 52 & 100 \\
\hline & & & & & 15.80 & 17.00 & IV-Pobre & 3 & 61 & 100 \\
\hline & & & & & 17.00 & 18.00 & V-Muito Pobre & 4 & 22 & 75 \\
\hline & & & & & 18.00 & 20.00 & IV-Pobre & 3 & 59 & 95 \\
\hline & & & & & 20.00 & 21.00 & V-Muito Pobre & 5 & 0 & 100 \\
\hline & & & & & 21.00 & 24.50 & V-Muito Pobre & 4 & 20 & 99 \\
\hline & & & & & 24.50 & 26.20 & IV-Pobre & 3 & 47 & 100 \\
\hline & & & & & 26.20 & 28.00 & V-Muito Pobre & 4 & 28 & 100 \\
\hline & & & & & 28.00 & 30.00 & V-Muito Pobre & 3 & 31 & 100 \\
\hline & & & & & 30.00 & 32.80 & II- Bom & 2 & 70 & 95 \\
\hline & & & & & 32.80 & 33.80 & V-Muito Pobre & 4 & 17 & 100 \\
\hline & & & & & 33.80 & 35.80 & IV-Pobre & 2 & 64 & 100 \\
\hline & & & & & 35.80 & 40.22 & I-Muito Bom & 1 & 100 & 100 \\
\hline \multirow[t]{16}{*}{4545} & 4.53 & 0.00 & 3.90 & AT & 3.90 & 5.40 & V-Muito Pobre & 5 & 0 & 50 \\
\hline & & 3.90 & 40.25 & ROCHA & 5.40 & 8.40 & IV-Pobre & 3 & 52 & 88 \\
\hline & & & & & 8.40 & 10.60 & III - Regular & 3 & 53 & 100 \\
\hline & & & & & 10.60 & 13.90 & III - Regular & 2 & 73 & 99 \\
\hline & & & & & 13.90 & 16.00 & III - Regular & 2 & 81 & 99 \\
\hline & & & & & 16.00 & 18.50 & I-Muito Bom & 1 & 90 & 95 \\
\hline & & & & & 18.50 & 21.50 & III-Regular & 3 & 40 & 90 \\
\hline & & & & & 21.50 & 23.20 & V-Muito Pobre & 4 & 15 & 95 \\
\hline & & & & & 23.20 & 25.20 & I-Muito Bom & 1 & 81 & 100 \\
\hline & & & & & 25.20 & 28.00 & V-Muito Pobre & 4 & 20 & 100 \\
\hline & & & & & 28.00 & 29.80 & II - Bom & 2 & 78 & 95 \\
\hline & & & & & 29.80 & 31.10 & V-Muito Pobre & 5 & 0 & 100 \\
\hline & & & & & 31.10 & 32.30 & V-Muito Pobre & 4 & 24 & 100 \\
\hline & & & & & 32.30 & 34.60 & IV-Pobre & 3 & 52 & 100 \\
\hline & & & & & 34.60 & 35.80 & IV-Pobre & 3 & 38 & 100 \\
\hline & & & & & 35.80 & 40.25 & IV-Pobre & 3 & 35 & 100 \\
\hline \multirow[t]{16}{*}{4546} & 4.64 & 0.00 & 1.94 & AT & 3.00 & 6.10 & V-Muito Pobre & 5 & 0 & 83 \\
\hline & & 1.94 & 3.00 & SAR & 6.10 & 6.90 & III - Regular & 2 & 61 & 100 \\
\hline & & 3.00 & 40.20 & ROCHA & 6.90 & 8.00 & III - Regular & 2 & 63 & 100 \\
\hline & & & & & 8.00 & 9.30 & I-Muito Bom & 1 & 88 & 100 \\
\hline & & & & & 9.30 & 12.30 & IV - Pobre & 2 & 73 & 98 \\
\hline & & & & & 12.30 & 15.30 & III - Regular & 1 & 86 & 100 \\
\hline & & & & & 15.30 & 17.30 & III - Regular & 2 & 69 & 100 \\
\hline & & & & & 17.30 & 20.10 & IV-Pobre & 3 & 60 & 98 \\
\hline & & & & & 20.10 & 22.50 & I-Muito Bom & 1 & 100 & 100 \\
\hline & & & & & 22.50 & 23.80 & I-Muito Bom & 1 & 90 & 100 \\
\hline & & & & & 23.80 & 26.30 & II - Bom & 1 & 92 & 100 \\
\hline & & & & & 26.30 & 29.30 & III - Regular & 2 & 80 & 100 \\
\hline & & & & & 29.30 & 32.30 & I-Muito Bom & 1 & 100 & 100 \\
\hline & & & & & 32.30 & 35.30 & III-Regular & 2 & 80 & 100 \\
\hline & & & & & 35.30 & 38.30 & III-Regular & 2 & 69 & 100 \\
\hline & & & & & 38.30 & 40.20 & III - Regular & 2 & 71 & 100 \\
\hline \multirow[t]{11}{*}{4548} & 6.80 & 0.00 & 1.00 & AT & 11.04 & 12.00 & III - Regular & 5 & 20 & 30 \\
\hline & & 1.00 & 11.04 & SAR & 12.00 & 15.00 & III - Regular & 3 & 72 & 100 \\
\hline & & 11.04 & 45.00 & ROCHA & 15.00 & 18.00 & III - Regular & 5 & 55 & 95 \\
\hline & & & & & 18.00 & 21.00 & III-Regular & 5 & 70 & 95 \\
\hline & & & & & 21.00 & 24.00 & III - Regular & 5 & 89 & 95 \\
\hline & & & & & 24.00 & 27.00 & II - Bom & 5 & 98 & 100 \\
\hline & & & & & 27.00 & 30.00 & II - Bom & 2 & 96 & 100 \\
\hline & & & & & 30.00 & 33.00 & III - Regular & 3 & 92 & 100 \\
\hline & & & & & 33.00 & 36.00 & III - Regular & 5 & 80 & 100 \\
\hline & & & & & 36.00 & 39.00 & II - Bom & 3 & 80 & 100 \\
\hline & & & & & 39.00 & 45.00 & II - Bom & 3 & 100 & 100 \\
\hline \begin{tabular}{l|l|}
4549 \\
\end{tabular} & \begin{tabular}{l|l|}
5.87 \\
\end{tabular} & 0.00 & 4.50 & AT & 11.88 & 13.55 & II - Bom & 2 & 26 & 40 \\
\hline
\end{tabular}




\begin{tabular}{|c|c|c|c|c|c|c|c|c|c|c|}
\hline $\begin{array}{c}\text { Numero da } \\
\text { sondagem }(m)\end{array}$ & $\begin{array}{c}\text { Nivel de Água } \\
\text { (m) }\end{array}$ & Topo & Base & Geologia & $\begin{array}{c}\text { Topo } \\
\text { (m, 2DP) }\end{array}$ & $\begin{array}{c}\text { Base } \\
\text { (m, 2DP) }\end{array}$ & Classe de maciço & $\begin{array}{l}\text { Grau } \\
\text { Fratur. } \\
\text { (lista) }\end{array}$ & $\begin{array}{r}R Q D \\
(\%)\end{array}$ & $\begin{array}{c}\text { Recuperação } \\
\text { (\%) }\end{array}$ \\
\hline & & 4.50 & 11.88 & SAR & 13.55 & 15.22 & III-Regular & 3 & 49 & 55 \\
\hline & & 11.88 & 37.00 & ROCHA & 15.22 & 18.22 & II - Bom & 2 & 86 & 98 \\
\hline & & & & & 18.22 & 24.22 & II - Bom & 2 & 100 & 100 \\
\hline & & & & & 24.22 & 27.22 & II-Bom & 5 & 96 & 100 \\
\hline & & & & & 27.22 & 30.22 & II - Bom & 2 & 100 & 100 \\
\hline & & & & & 30.22 & 33.22 & II-Bom & 2 & 98 & 100 \\
\hline & & & & & 33.22 & 36.22 & II - Bom & 2 & 100 & 100 \\
\hline & & & & & 36.22 & 37.00 & II - Bom & 2 & 94 & 100 \\
\hline \multirow[t]{5}{*}{4550} & 3.12 & 0.00 & 3.85 & AT & 13.70 & 18.80 & I-Muito Bom & 1 & 100 & 100 \\
\hline & & 3.85 & 6.15 & $\mathrm{AL}$ & 18.80 & 29.30 & II-Bom & 1 & 100 & 100 \\
\hline & & 6.15 & 13.70 & SAR & 29.30 & 30.00 & II-Bom & 3 & 62 & 80 \\
\hline & & 13.70 & 35.92 & ROCHA & 30.00 & 34.60 & II-Bom & 1 & 100 & 100 \\
\hline & & & & & 34.60 & 35.92 & II-Bom & 2 & 83 & 100 \\
\hline \multirow[t]{4}{*}{4551} & 2.07 & 0.00 & 2.85 & AT & 12.50 & 25.10 & II-Bom & 1 & 100 & 100 \\
\hline & & 2.85 & 6.00 & $\mathrm{AL}$ & 25.10 & 26.60 & III - Regular & 2 & 87 & 100 \\
\hline & & 6.00 & 12.50 & SAR & 26.60 & 29.30 & II- Bom & 1 & 100 & 100 \\
\hline & & 12.50 & 36.50 & ROCHA & 29.30 & 36.50 & III - Regular & 2 & 99 & 100 \\
\hline \multirow[t]{10}{*}{4552} & 10.14 & 0.00 & 2.80 & AT & 13.90 & 15.30 & II - Bom & 2 & 98 & 85 \\
\hline & & 2.80 & 5.15 & $\mathrm{AL}$ & 15.30 & 17.10 & I-Muito Bom & 1 & 100 & 100 \\
\hline & & 5.15 & 7.10 & SBSP & 17.10 & 17.30 & V-Muito Pobre & 5 & 0 & 90 \\
\hline & & 7.10 & 13.90 & SAR & 17.30 & 19.80 & II-Bom & 2 & 100 & 100 \\
\hline & & 13.90 & 36.60 & ROCHA & 19.80 & 22.20 & II- Bom & 2 & 81 & 90 \\
\hline & & & & & 22.20 & 23.80 & II-Bom & 2 & 80 & 80 \\
\hline & & & & & 23.80 & 27.00 & III-Regular & 3 & 20 & 70 \\
\hline & & & & & 27.00 & 30.00 & II-Bom & 2 & 98 & 100 \\
\hline & & & & & 30.00 & 31.80 & III-Regular & 3 & 50 & 100 \\
\hline & & & & & 31.80 & 36.60 & II - Bom & 2 & 90 & 100 \\
\hline \multirow[t]{7}{*}{4553} & 2.10 & 0.00 & 2.98 & AT & 20.30 & 21.00 & IV-Pobre & 4 & 0 & 80 \\
\hline & & 2.98 & 5.40 & $\mathrm{AL}$ & 21.00 & 24.90 & II-Bom & 1 & 100 & 100 \\
\hline & & 5.40 & 20.30 & SAR & 24.90 & 25.70 & III-Regular & 2 & 100 & 100 \\
\hline & & 20.30 & 36.30 & ROCHA & 25.70 & 26.70 & III - Regular & 3 & 75 & 98 \\
\hline & & & & & 26.70 & 32.50 & II - Bom & 1 & 98 & 100 \\
\hline & & & & & 32.50 & 34.70 & III - Regular & 2 & 79 & 80 \\
\hline & & & & & 34.70 & 36.30 & III-Regular & 2 & 93 & 100 \\
\hline \multirow[t]{10}{*}{4554} & 4.02 & 0.00 & 3.90 & AT & 15.30 & 16.90 & III - Regular & 2 & 82 & 100 \\
\hline & & 3.90 & 10.55 & $\mathrm{AL}$ & 16.90 & 20.10 & III - Regular & 2 & 93 & 100 \\
\hline & & 10.55 & 15.30 & SAR & 20.10 & 21.80 & III - Regular & 2 & 81 & 90 \\
\hline & & 15.30 & 36.10 & ROCHA & 21.80 & 25.60 & III - Regular & 2 & 99 & 100 \\
\hline & & & & & 25.60 & 26.60 & IV-Pobre & 3 & 60 & 100 \\
\hline & & & & & 26.60 & 27.60 & I-Muito Bom & 1 & 100 & 100 \\
\hline & & & & & 27.60 & 29.00 & IV-Pobre & 3 & 63 & 63 \\
\hline & & & & & 29.00 & 31.00 & I-Muito Bom & 1 & 100 & 100 \\
\hline & & & & & 31.00 & 32.95 & III - Regular & 3 & 70 & 90 \\
\hline & & & & & 32.95 & 36.10 & III-Regular & 2 & 100 & 100 \\
\hline \multirow[t]{5}{*}{4555} & 7.63 & 0.00 & 5.90 & AT & 17.94 & 19.04 & IV-Pobre & 3 & 30 & 70 \\
\hline & & 5.90 & 17.94 & SAR & 19.04 & 25.30 & I-Muito Bom & 1 & 95 & 100 \\
\hline & & 17.94 & 40.29 & ROCHA & 25.30 & 27.20 & I-Muito Bom & 1 & 90 & 100 \\
\hline & & & & & 27.20 & 35.00 & I-Muito Bom & 1 & 81 & 98 \\
\hline & & & & & 35.00 & 40.29 & I-Muito Bom & 1 & 90 & 100 \\
\hline \multirow[t]{9}{*}{4556} & 11.10 & 0.00 & 1.00 & AT & 18.22 & 21.22 & II-Bom & 3 & 81 & 95 \\
\hline & & 1.00 & 18.22 & SAR & 21.22 & 24.22 & IV-Pobre & 3 & 67 & 91 \\
\hline & & 18.22 & 45.00 & ROCHA & 24.22 & 27.22 & IV-Pobre & 4 & 27 & 67 \\
\hline & & & & & 27.22 & 30.22 & V-Muito Pobre & 4 & 17 & 60 \\
\hline & & & & & 30.22 & 33.22 & III-Regular & 4 & 77 & 100 \\
\hline & & & & & 33.22 & 36.22 & III - Regular & 3 & 73 & 92 \\
\hline & & & & & 36.22 & 39.22 & II - Bom & 2 & 88 & 100 \\
\hline & & & & & 39.22 & 42.22 & II-Bom & 2 & 93 & 100 \\
\hline & & & & & 42.22 & 45.00 & II- Bom & 2 & 97 & 100 \\
\hline \multirow[t]{3}{*}{4559} & 9.10 & 0.00 & 5.10 & AT & 10.70 & 12.42 & I-Muito Bom & 1 & 73 & 73 \\
\hline & & 5.10 & 10.70 & SAR & 12.42 & 15.42 & II - Bom & 2 & 91 & 100 \\
\hline & & 10.70 & 50.00 & ROCHA & 15.42 & 18.42 & II-Bom & 2 & 87 & 95 \\
\hline
\end{tabular}




\begin{tabular}{|c|c|c|c|c|c|c|c|c|c|c|}
\hline $\begin{array}{c}\text { Numero da } \\
\text { sondagem }(\mathrm{m})\end{array}$ & $\begin{array}{c}\text { Nivel de Água } \\
(\mathrm{m})\end{array}$ & Topo & Base & Geologia & $\begin{array}{c}\text { Topo } \\
\text { (m, 2DP) }\end{array}$ & $\begin{array}{c}\text { Base } \\
\text { (m, 2DP) }\end{array}$ & Classe de maciço & $\begin{array}{l}\text { Grau } \\
\text { Fratur. } \\
\text { (lista) }\end{array}$ & $\begin{array}{r}\text { RQD } \\
(\%)\end{array}$ & $\begin{array}{c}\text { Recuperação } \\
\text { (\%) }\end{array}$ \\
\hline & & & & & 18.42 & 21.42 & I-Muito Bom & 1 & 100 & 100 \\
\hline & & & & & 21.42 & 24.42 & III-Regular & 3 & 50 & 90 \\
\hline & & & & & 24.42 & 25.92 & II - Bom & 2 & 69 & 90 \\
\hline & & & & & 25.92 & 27.42 & II-Bom & 2 & 81 & 100 \\
\hline & & & & & 27.42 & 30.42 & III - Regular & 2 & 48 & 100 \\
\hline & & & & & 30.42 & 33.42 & II-Bom & 2 & 93 & 98 \\
\hline & & & & & 33.42 & 36.42 & II-Bom & 2 & 79 & 100 \\
\hline & & & & & 36.42 & 39.42 & I-Muito Bom & 1 & 100 & 100 \\
\hline & & & & & 39.42 & 42.42 & I-Muito Bom & 1 & 100 & 100 \\
\hline & & & & & 42.42 & 45.00 & I-Muito Bom & 1 & 97 & 100 \\
\hline & & & & & 45.00 & 48.00 & I-Muito Bom & 1 & 90 & 100 \\
\hline & & & & & 48.00 & 50.00 & I-Muito Bom & 1 & 98 & 100 \\
\hline 4560 & 9.80 & 0.00 & 4.45 & AT & 14.20 & 15.00 & V-Muito Pobre & 5 & 0 & 38 \\
\hline & & 4.45 & 14.20 & SAR & 15.00 & 15.70 & V-Muito Pobre & 4 & 25 & 70 \\
\hline & & 14.20 & 50.00 & ROCHA & 15.70 & 18.70 & II - Bom & 2 & 68 & 100 \\
\hline & & & & & 18.70 & 20.60 & II-Bom & 3 & 50 & 98 \\
\hline & & & & & 20.60 & 21.70 & I-Muito Bom & 1 & 100 & 100 \\
\hline & & & & & 21.70 & 24.70 & I-Muito Bom & 1 & 95 & 100 \\
\hline & & & & & 24.70 & 27.30 & I-Muito Bom & 1 & 79 & 100 \\
\hline & & & & & 27.30 & 27.80 & I-Muito Bom & 1 & 98 & 100 \\
\hline & & & & & 27.80 & 30.90 & I-Muito Bom & 1 & 96 & 100 \\
\hline & & & & & 30.90 & 34.00 & III - Regular & 2 & 70 & 100 \\
\hline & & & & & 34.00 & 36.80 & I-Muito Bom & 1 & 95 & 100 \\
\hline & & & & & 36.80 & 39.80 & I-Muito Bom & 1 & 92 & 100 \\
\hline & & & & & 39.80 & 43.35 & I-Muito Bom & 1 & 90 & 100 \\
\hline & & & & & 43.35 & 45.15 & V-Muito Pobre & 5 & 0 & 57 \\
\hline & & & & & 45.15 & 46.65 & I-Muito Bom & 1 & 100 & 100 \\
\hline & & & & & 46.65 & 49.00 & III - Regular & 4 & 10 & 80 \\
\hline & & & & & 49.00 & 50.00 & V-Muito Pobre & 5 & 0 & 20 \\
\hline 4561 & 11.35 & 0.00 & 3.00 & AT & 15.40 & 18.40 & II- Bom & 2 & 80 & 100 \\
\hline & & 3.00 & 15.40 & SAR & 18.40 & 21.40 & II-Bom & 1 & 90 & 100 \\
\hline & & 15.40 & 50.53 & ROCHA & 21.40 & 24.40 & I-Muito Bom & 1 & 100 & 100 \\
\hline & & & & & 24.40 & 27.40 & I-Muito Bom & 1 & 95 & 100 \\
\hline & & & & & 27.40 & 30.10 & I-Muito Bom & 1 & 90 & 100 \\
\hline & & & & & 30.10 & 32.50 & III - Regular & 1 & 39 & 80 \\
\hline & & & & & 32.50 & 36.50 & I-Muito Bom & 1 & 85 & 100 \\
\hline & & & & & 36.50 & 39.50 & I-Muito Bom & 1 & 95 & 100 \\
\hline & & & & & 39.50 & 42.50 & I-Muito Bom & 1 & 100 & 100 \\
\hline & & & & & 42.50 & 45.50 & I-Muito Bom & 1 & 92 & 100 \\
\hline & & & & & 45.50 & 48.50 & I-Muito Bom & 1 & 88 & 100 \\
\hline & & & & & 48.50 & 50.00 & I - Muito Bom & 1 & 100 & 100 \\
\hline 4562 & 12.04 & 0.00 & 4.85 & at & 9.50 & 10.20 & II-Bom & 2 & 81 & 100 \\
\hline & & 4.85 & 9.50 & sar & 10.20 & 10.80 & III-Regular & 5 & 18 & 100 \\
\hline & & 9.50 & 47.48 & rocha & 10.80 & 19.20 & I-Muito Bom & 1 & 99 & 100 \\
\hline & & & & & 19.20 & 22.40 & I-Muito Bom & 2 & 90 & 99 \\
\hline & & & & & 22.40 & 23.40 & III - Regular & 4 & 37 & 100 \\
\hline & & & & & 23.40 & 25.40 & I-Muito Bom & 2 & 90 & 100 \\
\hline & & & & & 25.40 & 31.60 & I-Muito Bom & 1 & 99 & 100 \\
\hline & & & & & 31.60 & 36.20 & I-Muito Bom & 2 & 95 & 95 \\
\hline & & & & & 36.20 & 37.80 & II-Bom & 2 & 67 & 95 \\
\hline & & & & & 37.80 & 39.30 & I- Muito Bom & 2 & 95 & 95 \\
\hline & & & & & 39.30 & 40.20 & I-Muito Bom & 2 & 85 & 95 \\
\hline & & & & & 40.20 & 47.48 & I-Muito Bom & 1 & 100 & 100 \\
\hline 4563 & 12.45 & 0.00 & 1.00 & AT & 14.15 & 14.90 & IV-Pobre & 4 & 0 & 64 \\
\hline & & 1.00 & 14.15 & SAR & 14.90 & 16.40 & I-Muito Bom & 1 & 95 & 95 \\
\hline & & 14.15 & 48.43 & ROCHA & 16.40 & 25.60 & II-Bom & 2 & 100 & 100 \\
\hline & & & & & 25.60 & 28.70 & III - Regular & 3 & 30 & 95 \\
\hline & & & & & 28.70 & 34.30 & I- Muito Bom & 1 & 95 & 95 \\
\hline & & & & & 34.30 & 45.70 & II - Bom & 1 & 100 & 100 \\
\hline & & & & & 45.70 & 48.43 & II - Bom & 2 & 92 & 100 \\
\hline 4564 & 5.00 & 0.00 & 14.04 & SAR & 14.04 & 15.50 & III-Regular & 3 & 53 & 69 \\
\hline
\end{tabular}




\begin{tabular}{|c|c|c|c|c|c|c|c|c|c|c|}
\hline $\begin{array}{c}\text { Numero da } \\
\text { sondagem (m) }\end{array}$ & $\begin{array}{c}\text { Nivel de Água } \\
\text { (m) }\end{array}$ & Topo & Base & Geologia & $\begin{array}{c}\text { Topo } \\
\text { (m, 2DP) }\end{array}$ & $\begin{array}{c}\text { Base } \\
\text { (m, 2DP) }\end{array}$ & Classe de maciço & $\begin{array}{l}\text { Grau } \\
\text { Fratur. } \\
\text { (lista) }\end{array}$ & $\begin{array}{l}\text { RQD } \\
(\%)\end{array}$ & $\begin{array}{c}\text { Recuperação } \\
(\%)\end{array}$ \\
\hline & & 14.04 & 50.41 & ROCHA & 15.50 & 17.60 & III - Regular & 3 & 40 & 100 \\
\hline & & & & & 17.60 & 20.60 & I-Muito Bom & 1 & 90 & 99 \\
\hline & & & & & 20.60 & 21.10 & I - Muito Bom & 1 & 100 & 100 \\
\hline & & & & & 21.10 & 23.85 & I-Muito Bom & 1 & 90 & 100 \\
\hline & & & & & 23.85 & 26.35 & I - Muito Bom & 1 & 100 & 100 \\
\hline & & & & & 26.35 & 29.35 & I-Muito Bom & 1 & 98 & 100 \\
\hline & & & & & 29.35 & 30.20 & I - Muito Bom & 1 & 100 & 100 \\
\hline & & & & & 30.20 & 32.05 & II-Bom & 2 & 85 & 100 \\
\hline & & & & & 32.05 & 33.20 & IV-Pobre & 4 & 25 & 80 \\
\hline & & & & & 33.20 & 35.40 & V-Muito Pobre & 5 & 13 & 71 \\
\hline & & & & & 35.40 & 38.40 & II-Bom & 2 & 75 & 78 \\
\hline & & & & & 38.40 & 41.40 & II-Bom & 2 & 71 & 85 \\
\hline & & & & & 41.40 & 44.40 & II - Bom & 2 & 70 & 90 \\
\hline & & & & & 44.40 & 47.40 & I-Muito Bom & 1 & 84 & 99 \\
\hline & & & & & 47.40 & 50.41 & I-Muito Bom & 1 & 95 & 100 \\
\hline \multirow[t]{14}{*}{4566} & 7.85 & 0.00 & 9.30 & SAR & 9.30 & 10.90 & IV-Pobre & 2 & 67 & 100 \\
\hline & & 9.30 & 55.15 & ROCHA & 10.90 & 14.40 & V-Muito Pobre & 4 & 0 & 60 \\
\hline & & & & & 14.40 & 17.00 & III - Regular & 1 & 100 & 100 \\
\hline & & & & & 17.00 & 18.10 & III-Regular & 2 & 86 & 82 \\
\hline & & & & & 18.10 & 28.90 & II-Bom & 1 & 100 & 100 \\
\hline & & & & & 28.90 & 29.20 & IV-Pobre & 3 & 82 & 94 \\
\hline & & & & & 29.20 & 35.20 & II - Bom & 1 & 100 & 100 \\
\hline & & & & & 35.20 & 37.10 & II- Bom & 2 & 85 & 100 \\
\hline & & & & & 37.10 & 39.90 & II-Bom & 1 & 100 & 100 \\
\hline & & & & & 39.90 & 40.60 & II- Bom & 2 & 91 & 99 \\
\hline & & & & & 40.60 & 41.50 & II - Bom & 1 & 100 & 100 \\
\hline & & & & & 41.50 & 42.50 & II - Bom & 2 & 90 & 100 \\
\hline & & & & & 42.50 & 49.00 & I-Muito Bom & 1 & 92 & 100 \\
\hline & & & & & 49.00 & 55.15 & II - Bom & 2 & 90 & 100 \\
\hline \multirow[t]{15}{*}{4567} & 23.28 & 0.00 & 2.00 & AT & 30.40 & 31.05 & V-Muito Pobre & 5 & 0 & 22 \\
\hline & & 2.00 & 4.45 & SBSP & 31.05 & 32.75 & III - Regular & 4 & 30 & 82 \\
\hline & & 4.45 & 30.40 & SAR & 32.75 & 35.90 & II - Bom & 2 & 72 & 98 \\
\hline & & 30.40 & 70.01 & ROCHA & 35.90 & 38.75 & I - Muito Bom & 1 & 85 & 96 \\
\hline & & & & & 38.75 & 41.80 & I-Muito Bom & 1 & 92 & 100 \\
\hline & & & & & 41.80 & 44.85 & II - Bom & 2 & 75 & 96 \\
\hline & & & & & 44.85 & 47.70 & II- Bom & 2 & 68 & 100 \\
\hline & & & & & 47.70 & 50.70 & I-Muito Bom & 1 & 92 & 100 \\
\hline & & & & & 50.70 & 53.60 & I - Muito Bom & 1 & 90 & 100 \\
\hline & & & & & 53.60 & 56.65 & II-Bom & 2 & 80 & 100 \\
\hline & & & & & 56.65 & 59.70 & I-Muito Bom & 1 & 88 & 100 \\
\hline & & & & & 59.70 & 62.70 & I-Muito Bom & 1 & 80 & 96 \\
\hline & & & & & 62.70 & 65.75 & II- Bom & 2 & 67 & 100 \\
\hline & & & & & 65.75 & 69.00 & I-Muito Bom & 1 & 82 & 100 \\
\hline & & & & & 69.00 & 70.01 & I - Muito Bom & 1 & 100 & 100 \\
\hline \multirow[t]{10}{*}{4568} & 7.31 & 0.00 & 2.00 & AT & 34.10 & 35.55 & IV-Pobre & $\frac{1}{4}$ & 18 & $\frac{100}{38}$ \\
\hline & & 2.00 & 25.05 & SAR & 35.55 & 37.55 & III - Regular & 4 & 21 & 42 \\
\hline & & 25.05 & 59.18 & ROCHA & 37.55 & 38.75 & III - Regular & 3 & 51 & 92 \\
\hline & & & & & 38.75 & 41.40 & III - Regular & 3 & 55 & 93 \\
\hline & & & & & 41.40 & 44.40 & I - Muito Bom & 1 & 82 & 100 \\
\hline & & & & & 44.40 & 47.40 & I - Muito Bom & 1 & 82 & 100 \\
\hline & & & & & 47.40 & 50.50 & II-Bom & 2 & 80 & 100 \\
\hline & & & & & 50.50 & 53.60 & I - Muito Bom & 1 & 95 & 99 \\
\hline & & & & & 53.60 & 57.80 & I-Muito Bom & 1 & 84 & 100 \\
\hline & & & & & 57.80 & 59.18 & I-Muito Bom & 1 & 81 & 99 \\
\hline \multirow[t]{7}{*}{4569} & 24.63 & 0.00 & 5.46 & AT & 15.19 & 17.99 & V-Muito Pobre & 5 & 0 & 55 \\
\hline & & 5.46 & 15.19 & SAR & 17.99 & 19.49 & V-Muito Pobre & 4 & 25 & 68 \\
\hline & & 15.19 & 70.06 & ROCHA & 19.49 & 20.99 & IV - Pobre & 4 & 15 & 71 \\
\hline & & & & & 20.99 & 22.59 & I-Muito Bom & 1 & 89 & 100 \\
\hline & & & & & 22.59 & 23.79 & I - Muito Bom & 1 & 80 & 100 \\
\hline & & & & & 23.79 & 26.84 & I- Muito Bom & 1 & 85 & 100 \\
\hline & & & & & 26.84 & 29.89 & I-Muito Bom & 1 & 93 & 100 \\
\hline
\end{tabular}




\begin{tabular}{|c|c|c|c|c|c|c|c|c|c|c|}
\hline $\begin{array}{c}\text { Numero da } \\
\text { sondagem }(\mathrm{m})\end{array}$ & $\begin{array}{c}\text { Nivel de Água } \\
(\mathrm{m})\end{array}$ & Topo & Base & Geologia & $\begin{array}{c}\text { Toро } \\
\text { (m, 2DP) }\end{array}$ & $\begin{array}{c}\text { Base } \\
(\mathrm{m}, 2 \mathrm{DP})\end{array}$ & Classe de maciço & $\begin{array}{l}\text { Grau } \\
\text { Fratur. } \\
\text { (lista) }\end{array}$ & $\begin{array}{r}\text { RQD } \\
(\%)\end{array}$ & $\begin{array}{c}\text { Recuperação } \\
\text { (\%) }\end{array}$ \\
\hline & & & & & 29.89 & 32.89 & IV-Pobre & 2 & 60 & 88 \\
\hline & & & & & 32.89 & 37.84 & I-Muito Bom & 1 & 100 & 100 \\
\hline & & & & & 37.84 & 39.34 & IV-Pobre & 3 & 55 & 96 \\
\hline & & & & & 39.34 & 41.14 & II-Bom & 2 & 71 & 99 \\
\hline & & & & & 41.14 & 44.14 & II - Bom & 2 & 71 & 100 \\
\hline & & & & & 44.14 & 47.14 & I-Muito Bom & 1 & 82 & 98 \\
\hline & & & & & 47.14 & 50.14 & I-Muito Bom & 1 & 87 & 100 \\
\hline & & & & & 50.14 & 53.14 & I-Muito Bom & 1 & 95 & 100 \\
\hline & & & & & 53.14 & 56.14 & I-Muito Bom & 1 & 100 & 100 \\
\hline & & & & & 56.14 & 59.14 & I-Muito Bom & 1 & 90 & 100 \\
\hline & & & & & 59.14 & 62.14 & I-Muito Bom & 1 & 100 & 100 \\
\hline & & & & & 62.14 & 65.19 & I-Muito Bom & 1 & 95 & 100 \\
\hline & & & & & 65.19 & 68.24 & I-Muito Bom & 1 & 85 & 100 \\
\hline & & & & & 68.24 & 70.06 & I-Muito Bom & 1 & 96 & 100 \\
\hline \multirow[t]{10}{*}{4570} & 20.19 & 0.00 & 1.82 & AT & 15.60 & 17.50 & IV-Pobre & 3 & 63 & 0 \\
\hline & & 1.82 & 4.61 & SBSP & 17.50 & 19.00 & IV-Pobre & 3 & 73 & 95 \\
\hline & & 4.61 & 15.60 & SAR & 19.00 & 22.70 & II-Bom & 1 & 100 & 100 \\
\hline & & 15.60 & 55.10 & ROCHA & 22.70 & 23.70 & III - Regular & 2 & 80 & 100 \\
\hline & & & & & 23.70 & 28.00 & II-Bom & 1 & 95 & 100 \\
\hline & & & & & 28.00 & 29.80 & IV-Pobre & 2 & 20 & 70 \\
\hline & & & & & 29.80 & 31.50 & II-Bom & 1 & 90 & 90 \\
\hline & & & & & 31.50 & 33.80 & IV-Pobre & 3 & 90 & 90 \\
\hline & & & & & 33.80 & 53.70 & III - Regular & 2 & 99 & 97 \\
\hline & & & & & 53.70 & 55.10 & III-Regular & 2 & 90 & 78 \\
\hline \multirow[t]{10}{*}{4571} & 12.10 & 0.00 & 4.50 & AT & 32.82 & 35.35 & IV-Pobre & 3 & 50 & 95 \\
\hline & & 4.50 & 21.45 & SAR & 35.35 & 38.40 & II-Bom & 2 & 80 & 98 \\
\hline & & 21.45 & 28.27 & ROCHA & 38.40 & 41.45 & II- Bom & 2 & 79 & 100 \\
\hline & & 28.27 & 32.82 & SAR & 41.45 & 44.50 & II - Bom & 2 & 77 & 100 \\
\hline & & 32.82 & 60.50 & ROCHA & 44.50 & 47.55 & I-Muito Bom & 1 & 80 & 100 \\
\hline & & & & & 47.55 & 50.60 & II-Bom & 2 & 65 & 100 \\
\hline & & & & & 50.60 & 53.60 & II-Bom & 1 & 81 & 100 \\
\hline & & & & & 53.60 & 56.50 & I-Muito Bom & 1 & 93 & 100 \\
\hline & & & & & 56.50 & 58.90 & I-Muito Bom & 1 & 100 & 100 \\
\hline & & & & & 58.90 & 60.50 & III - Regular & 3 & 40 & 97 \\
\hline \multirow[t]{9}{*}{4572} & 19.90 & 0.00 & 4.50 & AT & 22.80 & 24.30 & III-Regular & 4 & 66 & 100 \\
\hline & & 4.50 & 22.80 & SAR & 24.30 & 27.30 & II-Bom & 3 & 88 & 98 \\
\hline & & 22.80 & 45.00 & $\mathrm{ROCHA}$ & 27.30 & 30.30 & II-Bom & 3 & 95 & 100 \\
\hline & & & & & 30.30 & 31.88 & III - Regular & 5 & 40 & 88 \\
\hline & & & & & 31.88 & 34.59 & III-Regular & 5 & 64 & 80 \\
\hline & & & & & 34.59 & 36.30 & II - Bom & 5 & 100 & 100 \\
\hline & & & & & 36.30 & 39.30 & II - Bom & 2 & 90 & 98 \\
\hline & & & & & 39.30 & 42.30 & II-Bom & 2 & 95 & 100 \\
\hline & & & & & 42.30 & 45.00 & II - Bom & 2 & 86 & 98 \\
\hline \multirow[t]{5}{*}{4573} & 8.58 & 0.00 & 11.45 & SBSP & 28.66 & 32.05 & III-Regular & 3 & 51 & 70 \\
\hline & & 11.45 & 28.66 & SAR & 32.05 & 35.10 & I-Muito Bom & 1 & 87 & 98 \\
\hline & & 28.66 & 44.22 & ROCHA & 35.10 & 38.15 & II - Bom & 2 & 79 & 100 \\
\hline & & & & & 38.15 & 41.20 & I-Muito Bom & 1 & 81 & 100 \\
\hline & & & & & 41.20 & 44.22 & I-Muito Bom & 1 & 85 & 100 \\
\hline \multirow[t]{6}{*}{4574} & 6.82 & 0.00 & 6.33 & AT & 32.10 & 32.90 & V-Muito Pobre & 5 & 0 & 30 \\
\hline & & 6.33 & 9.80 & $\mathrm{AL}$ & 32.90 & 35.20 & I-Muito Bom & 1 & 100 & 100 \\
\hline & & 9.80 & 25.24 & SAR & 35.20 & 37.30 & III - Regular & 2 & 97 & 100 \\
\hline & & 25.24 & 26.74 & ROCHA & 37.30 & 38.70 & III-Regular & 2 & 70 & 70 \\
\hline & & 26.74 & 32.10 & SAR & 38.70 & 40.40 & IV-Pobre & 2 & 93 & 100 \\
\hline & & 32.10 & 40.40 & ROCHA & & & & & & \\
\hline \multirow[t]{7}{*}{4575} & 8.43 & 0.00 & 6.05 & AT & 25.10 & 27.30 & V-Muito Pobre & 4 & 0 & 75 \\
\hline & & 6.05 & 25.10 & SAR & 27.30 & 28.70 & III - Regular & 2 & 70 & 100 \\
\hline & & 25.10 & 45.30 & ROCHA & 28.70 & 29.10 & IV-Pobre & 2 & 55 & 100 \\
\hline & & & & & 29.10 & 31.10 & III-Regular & 2 & 85 & 100 \\
\hline & & & & & 31.10 & 32.60 & I-Muito Bom & 1 & 100 & 100 \\
\hline & & & & & 32.60 & 35.10 & IV-Pobre & 3 & 75 & 61.5 \\
\hline & & & & & 35.10 & 37.70 & I-Muito Bom & 1 & 100 & 100 \\
\hline
\end{tabular}




\begin{tabular}{|c|c|c|c|c|c|c|c|c|c|c|}
\hline $\begin{array}{c}\text { Numero da } \\
\text { sondagem }(m)\end{array}$ & $\begin{array}{c}\text { Nivel de Água } \\
\text { (m) }\end{array}$ & Topo & Base & Geologia & $\begin{array}{c}\text { Topo } \\
\text { (m, 2DP) }\end{array}$ & $\begin{array}{c}\text { Base } \\
\text { (m, 2DP) }\end{array}$ & Classe de maciço & $\begin{array}{l}\text { Grau } \\
\text { Fratur. } \\
\text { (lista) }\end{array}$ & $\begin{array}{r}R Q D \\
(\%)\end{array}$ & $\begin{array}{c}\text { Recuperação } \\
\text { (\%) }\end{array}$ \\
\hline & & & & & 37.70 & 40.50 & III - Regular & 2 & 90 & 80 \\
\hline & & & & & 40.50 & 42.10 & IV-Pobre & 2 & 60 & 90 \\
\hline & & & & & 42.10 & 43.15 & III - Regular & 2 & 82 & 100 \\
\hline & & & & & 43.15 & 45.30 & IV-Pobre & 3 & 30 & 100 \\
\hline \multirow[t]{4}{*}{\begin{tabular}{ll|}
4576 \\
\end{tabular}} & 8.39 & 0.00 & 11.80 & AT & 38.38 & 40.18 & IV-Pobre & 2 & 30 & 80 \\
\hline & & 11.80 & 16.80 & $\mathrm{AL}$ & & & & & & \\
\hline & & 16.80 & 38.38 & SAR & & & & & & \\
\hline & & 38.38 & 40.18 & ROCHA & & & & & & \\
\hline \multirow[t]{9}{*}{\begin{tabular}{l|l|}
4578 \\
\end{tabular}} & 1.90 & 0.00 & 4.80 & AT & 18.30 & 19.00 & III-Regular & 3 & 75 & 100 \\
\hline & & 4.80 & 6.75 & $\mathrm{AL}$ & 19.00 & 21.50 & I-Muito Bom & 1 & 100 & 100 \\
\hline & & 6.75 & 18.30 & SAR & 21.50 & 23.20 & III- Regular & 2 & 90 & 85.5 \\
\hline & & 18.30 & 39.80 & ROCHA & 23.20 & 25.20 & I-Muito Bom & 1 & 100 & 100 \\
\hline & & & & & 25.20 & 29.50 & III-Regular & 2 & 90 & 90 \\
\hline & & & & & 29.50 & 31.50 & I- Muito Bom & 1 & 100 & 100 \\
\hline & & & & & 31.50 & 32.50 & III - Regular & 3 & 70 & 50 \\
\hline & & & & & 32.50 & 35.00 & II-Bom & 1 & 90 & 100 \\
\hline & & & & & 35.00 & 39.80 & I-Muito Bom & 1 & 100 & 100 \\
\hline \multirow[t]{6}{*}{\begin{tabular}{l|l|}
4580 \\
\end{tabular}} & 8.10 & 0.00 & 5.00 & AT & 28.20 & 31.10 & III - Regular & 4 & 32 & 100 \\
\hline & & 5.00 & 28.20 & SAR & 31.10 & 34.10 & III - Regular & 4 & 86 & 90 \\
\hline & & 28.20 & 45.00 & ROCHA & 34.10 & 37.10 & III - Regular & 3 & 91 & 100 \\
\hline & & & & & 37.10 & 40.10 & III-Regular & 3 & 54 & 100 \\
\hline & & & & & 40.10 & 43.10 & II- Bom & 2 & 100 & 100 \\
\hline & & & & & 43.10 & 45.00 & II-Bom & 2 & 60 & 100 \\
\hline \multirow[t]{8}{*}{4582} & 6.86 & 0.00 & 5.70 & AT & 26.10 & 26.30 & V-Muito Pobre & 5 & 0 & 20 \\
\hline & & 5.70 & 26.10 & SBSP & 26.30 & 27.60 & III - Regular & 2 & 81 & 81 \\
\hline & & 26.10 & 46.10 & SAR & 27.60 & 29.10 & V-Muito Pobre & 4 & 40 & 70 \\
\hline & & & & & 29.10 & 30.10 & III - Regular & 2 & 85 & 85 \\
\hline & & & & & 30.10 & 34.20 & III-Regular & 2 & 95 & 100 \\
\hline & & & & & 34.20 & 34.80 & V-Muito Pobre & 5 & 0 & 10 \\
\hline & & & & & 34.80 & 36.90 & IV-Pobre & 3 & 70 & 100 \\
\hline & & & & & 36.90 & 46.10 & III - Regular & 2 & 90 & 100 \\
\hline \multirow[t]{11}{*}{ 4583 } & 5.92 & 0.00 & 4.80 & AT & 26.35 & 27.50 & V-Muito Pobre & 4 & 0 & 65 \\
\hline & & 4.80 & 8.85 & $\mathrm{AL}$ & 27.50 & 28.80 & III- Regular & 2 & 72 & 80 \\
\hline & & 8.85 & 16.70 & SBSP & 28.80 & 30.20 & IV-Pobre & 3 & 80 & 100 \\
\hline & & 16.70 & 26.35 & SAR & 30.20 & 34.20 & II-Bom & 1 & 100 & 100 \\
\hline & & 26.35 & 48.20 & ROCHA & 34.20 & 35.70 & IV-Pobre & 3 & 30 & 100 \\
\hline & & & & & 35.70 & 36.00 & V-Muito Pobre & 5 & 0 & 100 \\
\hline & & & & & 36.00 & 37.50 & III-Regular & 2 & 90 & 100 \\
\hline & & & & & 37.50 & 37.90 & V-Muito Pobre & 5 & 0 & 90 \\
\hline & & & & & 37.90 & 44.50 & III - Regular & 2 & 90 & 90 \\
\hline & & & & & 44.50 & 44.60 & V-Muito Pobre & 4 & 0 & 100 \\
\hline & & & & & 44.60 & 48.20 & III - Regular & 2 & 84 & 90 \\
\hline \multirow[t]{2}{*}{4584} & 4.50 & 0.00 & 4.60 & AT & & & & & & \\
\hline & & 4.60 & 26.85 & SAR & & & & & & \\
\hline \multirow[t]{4}{*}{4585} & 3.50 & 0.00 & 4.90 & AT & & & & & & \\
\hline & & 4.90 & 6.85 & SBSP & & & & & & \\
\hline & & 6.85 & 26.10 & SAR & & & & & & \\
\hline & & 26.10 & 43.70 & ROCHA & & & & & & \\
\hline \multirow[t]{6}{*}{4586} & 23.84 & 0.00 & 5.58 & AT & 39.60 & 42.80 & IV-Pobre & 3 & 20 & 55 \\
\hline & & 5.58 & 7.73 & SBSP & 42.80 & 45.40 & II-Bom & 2 & 73 & 95 \\
\hline & & 7.73 & 39.60 & SAR & 45.40 & 46.70 & I-Muito Bom & 1 & 100 & 100 \\
\hline & & 39.60 & 50.20 & ROCHA & 46.70 & 47.00 & IV-Pobre & 3 & 0 & 100 \\
\hline & & & & & 47.00 & 48.60 & III-Regular & 2 & 100 & 100 \\
\hline & & & & & 48.60 & 50.20 & III - Regular & 2 & 90 & 100 \\
\hline \multirow[t]{2}{*}{$\begin{array}{l}4587 \\
\end{array}$} & 3.27 & 0.00 & 4.62 & AT & & & & & & \\
\hline & & 4.62 & 40.14 & SAR & & & & & & \\
\hline \multirow[t]{5}{*}{4588} & 4.75 & 0.00 & 3.90 & AT & 39.03 & 40.00 & V-Muito Pobre & 5 & 0 & 20 \\
\hline & & 3.90 & 28.80 & SAR & & & & & & \\
\hline & & 28.80 & 30.00 & ROCHA & & & & & & \\
\hline & & 30.00 & 39.03 & SAR & & & & & & \\
\hline & & 39.03 & 40.00 & ROCHA & & & & & & \\
\hline
\end{tabular}




\begin{tabular}{|c|c|c|c|c|c|c|c|c|c|c|}
\hline $\begin{array}{c}\text { Numero da } \\
\text { sondagem }(m)\end{array}$ & $\begin{array}{c}\text { Nivel de Água } \\
\text { (m) }\end{array}$ & Topo & Base & Geologia & $\begin{array}{c}\text { Topo } \\
\text { (m, 2DP) }\end{array}$ & $\begin{array}{c}\text { Base } \\
\text { (m, 2DP) }\end{array}$ & Classe de maciço & $\begin{array}{l}\text { Grau } \\
\text { Fratur. } \\
\text { (lista) }\end{array}$ & $\begin{array}{l}\text { RQD } \\
(\%)\end{array}$ & $\begin{array}{c}\text { Recuperação } \\
\text { (\%) }\end{array}$ \\
\hline \multirow[t]{4}{*}{4589} & 2.34 & 0.00 & 2.80 & AT & 41.10 & 44.10 & & 5 & 20 & 60 \\
\hline & & 2.80 & 4.05 & SBSP & & & & & & \\
\hline & & 4.05 & 41.10 & SAR & & & & & & \\
\hline & & 41.10 & 44.10 & ROCHA & & & & & & \\
\hline \multirow[t]{4}{*}{4590} & 5.92 & 0.00 & 4.00 & AT & 39.27 & 40.50 & IV-Pobre & 2 & 0 & 100 \\
\hline & & 4.00 & 39.27 & SAR & 40.50 & 42.72 & IV-Pobre & 2 & 65 & 92 \\
\hline & & 39.27 & 45.02 & ROCHA & 42.72 & 44.80 & III-Regular & 1 & 92 & 92 \\
\hline & & & & & 44.80 & 45.02 & V-Muito Pobre & 5 & 0 & 0 \\
\hline \multirow[t]{2}{*}{4592} & 3.69 & 0.00 & 2.50 & AT & & & & & & \\
\hline & & 2.50 & 40.37 & SAR & & & & & & \\
\hline \multirow[t]{2}{*}{4593} & 4.00 & 0.00 & 2.00 & AT & & & & & & \\
\hline & & 2.00 & 40.22 & SAR & & & & & & \\
\hline \multirow[t]{2}{*}{4594} & 4.18 & 0.00 & 1.15 & AT & & & & & & \\
\hline & & 1.15 & 40.31 & SAR & & & & & & \\
\hline \multirow[t]{2}{*}{4595} & 6.95 & 0.00 & 4.85 & AT & & & & & & \\
\hline & & 4.85 & 40.33 & SAR & & & & & & \\
\hline \multirow[t]{11}{*}{4596} & 20.40 & 0.00 & 4.80 & AT & 28.97 & 30.77 & II-Bom & 2 & 62 & 65 \\
\hline & & 4.80 & 28.97 & SAR & 30.77 & 33.77 & II-Bom & 2 & 80 & 87 \\
\hline & & 28.97 & 50.00 & ROCHA & 33.77 & 36.77 & \begin{tabular}{|l|} 
V-Muito Pobre \\
\end{tabular} & 5 & 30 & 60 \\
\hline & & & & & 36.77 & 38.47 & II - Bom & 2 & 42 & 50 \\
\hline & & & & & 38.47 & 40.18 & II-Bom & 2 & 40 & 45 \\
\hline & & & & & 40.18 & 41.88 & V-Muito Pobre & 5 & 29 & 60 \\
\hline & & & & & 41.88 & 43.88 & \begin{tabular}{|l|} 
V-Muito Pabre \\
\end{tabular} & 5 & 49 & 70 \\
\hline & & & & & 43.88 & 45.38 & IV-Pobre & 5 & 75 & 92 \\
\hline & & & & & 45.38 & 46.88 & V-Muito Pobre & 4 & 46 & 76 \\
\hline & & & & & 46.88 & 48.38 & V-Muito Pobre & 4 & 44 & 59 \\
\hline & & & & & 48.38 & 50.00 & V-Muito Pobre & 4 & 23 & 50 \\
\hline \multirow[t]{12}{*}{4598} & 18.86 & 0.00 & 12.45 & SBSP & 19.04 & -20.40 & IV-Pobre & 3 & 45 & 55 \\
\hline & & 12.45 & 19.04 & SAR & 20.40 & -20.75 & I-Muito Bom & 1 & 100 & 100 \\
\hline & & 19.04 & 50.13 & ROCHA & 20.75 & -23.40 & I-Muito Bom & 1 & 90 & 100 \\
\hline & & & & & 23.40 & -26.40 & I-Muito Bom & 1 & 100 & 100 \\
\hline & & & & & 26.40 & -29.45 & I-Muito Bom & 1 & 87 & 95 \\
\hline & & & & & 29.45 & -32.45 & I- Muito Bom & 1 & 95 & 100 \\
\hline & & & & & 32.45 & -35.45 & I-Muito Bom & 1 & 92 & 95 \\
\hline & & & & & 35.45 & -38.55 & 1-Muito Bom & 1 & 90 & 100 \\
\hline & & & & & 38.55 & -41.65 & I-Muito Bom & 1 & 100 & 100 \\
\hline & & & & & 41.65 & -44.75 & I-Muito Bom & 1 & 100 & 100 \\
\hline & & & & & 44.75 & -47.85 & I-Muito Bom & 1 & 100 & 100 \\
\hline & & & & & 47.85 & -50.13 & II- Bom & 1 & 83 & 100 \\
\hline \multirow[t]{9}{*}{4599} & 3.73 & 0.00 & 4.48 & AT & 24.10 & 24.80 & IV-Pobre & 4 & 40 & 97 \\
\hline & & 4.48 & 24.10 & SAR & 24.80 & 26.90 & V-Muito Pobre & 4 & 0 & 47 \\
\hline & & 24.10 & 39.46 & ROCHA & 26.90 & 29.55 & V-Muito Pobre & 3 & 11 & 19 \\
\hline & & & & & 29.55 & 30.05 & \begin{tabular}{|l|} 
V-Muito Pobre \\
\end{tabular} & 4 & 0 & 92 \\
\hline & & & & & 30.05 & 30.55 & II- Bom & 3 & 67 & 100 \\
\hline & & & & & 30.55 & 30.75 & V-Muito Pobre & 5 & 0 & 100 \\
\hline & & & & & 30.75 & 31.55 & II-Bom & 2 & 82 & 100 \\
\hline & & & & & 31.55 & 33.50 & II - Bom & 2 & 85 & 100 \\
\hline & & & & & 33.50 & 39.46 & I- Muito Bom & 1 & 100 & 100 \\
\hline \multirow[t]{5}{*}{4600} & 7.10 & 0.00 & 2.53 & AT & 40.89 & 42.89 & V-Muito Pobre & 4 & 0 & 35 \\
\hline & & 2.53 & 27.04 & SAR & 42.89 & 45.00 & V-Muito Pobre & 4 & 23 & 42 \\
\hline & & 27.04 & 39.04 & ROCHA & & & & & & \\
\hline & & 39.04 & 40.89 & SAR & & & & & & \\
\hline & & 40.89 & 45.00 & ROCHA & & & & & & \\
\hline \multirow[t]{4}{*}{4601} & 4.28 & 0.00 & 5.00 & AT & 39.13 & 40.50 & \begin{tabular}{|l|} 
V-Muito Pobre \\
\end{tabular} & 5 & 0 & 68 \\
\hline & & 5.00 & 9.46 & SBSP & & & & & & \\
\hline & & 9.46 & 39.13 & SAR & & & & & & \\
\hline & & 39.13 & 40.50 & ROCHA & & & & & & \\
\hline \multirow[t]{2}{*}{4602} & 12.46 & 0.00 & 9.15 & AT & & & & & & \\
\hline & & 9.15 & 35.01 & SAR & & & & & & \\
\hline \multirow[t]{2}{*}{4604} & 10.66 & 0.00 & 6.60 & AT & 27.03 & 28.00 & V-Muito Pobre & 5 & 26 & 93 \\
\hline & & 6.60 & 10.00 & $\mathrm{AL}$ & 28.00 & 31.00 & IV-Pobre & 5 & 35 & 62 \\
\hline
\end{tabular}




\begin{tabular}{|c|c|c|c|c|c|c|c|c|c|c|}
\hline $\begin{array}{c}\text { Numero da } \\
\text { sondagem }(\mathrm{m})\end{array}$ & $\begin{array}{c}\text { Nivel de Água } \\
(\mathrm{m})\end{array}$ & Topo & Base & Geologia & $\begin{array}{c}\text { Topo } \\
\text { (m, 2DP) }\end{array}$ & $\begin{array}{c}\text { Base } \\
(\mathrm{m}, 2 \mathrm{DP})\end{array}$ & Classe de maciço & $\begin{array}{l}\text { Grau } \\
\text { Fratur. } \\
\text { (lista) }\end{array}$ & $\begin{array}{r}\text { RQD } \\
(\%)\end{array}$ & $\begin{array}{c}\text { Recuperação } \\
\text { (\%) }\end{array}$ \\
\hline & & 10.00 & 27.03 & SAR & 31.00 & 34.00 & IV-Pobre & 4 & 57 & 82 \\
\hline & & 27.03 & 40.00 & ROCHA & 34.00 & 37.00 & IV-Pobre & 3 & 41 & 57 \\
\hline & & & & & 37.00 & 40.00 & III - Regular & 3 & 75 & 90 \\
\hline \multirow[t]{9}{*}{4605} & 7.84 & 0.00 & 4.96 & AT & 33.30 & 35.80 & II-Bom & 2 & 100 & 100 \\
\hline & & 4.96 & 21.09 & SAR & 35.80 & 38.10 & III-Regular & 3 & 65 & 85 \\
\hline & & 21.09 & 22.00 & ROCHA & 38.10 & 42.20 & II- Bom & 2 & 90 & 100 \\
\hline & & 22.00 & 23.50 & SAR & 42.20 & 44.30 & I-Muito Bom & 1 & 100 & 100 \\
\hline & & 23.50 & 25.00 & ROCHA & 44.30 & 46.10 & III - Regular & 2 & 20 & 65 \\
\hline & & 25.00 & 26.70 & SAR & & & & & & \\
\hline & & 26.70 & 32.15 & ROCHA & & & & & & \\
\hline & & 32.15 & 33.30 & SAR & & & & & & \\
\hline & & 33.30 & 46.10 & ROCHA & & & & & & \\
\hline \multirow[t]{9}{*}{4607} & 9.10 & 0.00 & 11.00 & AT & 23.90 & 25.00 & V-Muito Pobre & 4 & 0 & 47 \\
\hline & & 11.00 & 23.90 & SAR & 25.00 & 26.50 & V-Muito Pobre & 4 & 0 & 30 \\
\hline & & 23.90 & 45.00 & ROCHA & 26.50 & 28.00 & IV-Pobre & 5 & 53 & 78 \\
\hline & & & & & 28.00 & 31.00 & IV-Pobre & 5 & 42 & 84 \\
\hline & & & & & 31.00 & 34.00 & V-Muito Pobre & 4 & 14 & 45 \\
\hline & & & & & 34.00 & 37.00 & IV-Pobre & 4 & 36 & 64 \\
\hline & & & & & 37.00 & 40.00 & IV - Pobre & 4 & 78 & 100 \\
\hline & & & & & 40.00 & 43.00 & IV - Pobre & 5 & 52 & 92 \\
\hline & & & & & 43.00 & 45.00 & III - Regular & 3 & 100 & 90 \\
\hline \multirow[t]{10}{*}{4608} & 9.26 & 0.00 & 10.80 & SBSP & 34.03 & 34.70 & V-Muito Pobre & 5 & 0 & 75 \\
\hline & & 10.80 & 27.03 & SAR & 34.70 & 35.80 & V-Muito Pobre & 4 & 12 & 40 \\
\hline & & 27.03 & 29.00 & ROCHA & 35.80 & 36.35 & V-Muito Pobre & 5 & 0 & 48 \\
\hline & & 29.00 & 34.03 & SAR & 36.35 & 39.05 & III-Regular & 3 & 50 & 82 \\
\hline & & 34.03 & 45.00 & ROCHA & 39.05 & 41.10 & III-Regular & 4 & 29 & 70 \\
\hline & & & & & 41.10 & 42.30 & IV-Pobre & 4 & 19 & 55 \\
\hline & & & & & 42.30 & 43.00 & V-Muito Pobre & 5 & 0 & 70 \\
\hline & & & & & 43.00 & 44.00 & V-Muito Pobre & 5 & 0 & 60 \\
\hline & & & & & 44.00 & 44.30 & V-Muito Pobre & 3 & 50 & 100 \\
\hline & & & & & 44.30 & 45.00 & II - Bom & 2 & 77 & 90 \\
\hline \multirow[t]{9}{*}{4609} & 2.85 & 0.00 & 18.80 & SAR & 19.15 & 20.00 & V-Muito Pobre & 5 & 0 & 33 \\
\hline & & 18.80 & 40.00 & ROCHA & 20.00 & 21.10 & V-Muito Pobre & 4 & 30 & 52 \\
\hline & & & & & 21.10 & 24.90 & V-Muito Pobre & 5 & 0 & 35 \\
\hline & & & & & 24.90 & 27.20 & III-Regular & 3 & 34 & 71 \\
\hline & & & & & 27.20 & 30.20 & III - Regular & 3 & 58 & 100 \\
\hline & & & & & 30.20 & 33.20 & III-Regular & 3 & 40 & 90 \\
\hline & & & & & 33.20 & 36.20 & III - Regular & 3 & 33 & 80 \\
\hline & & & & & 36.20 & 39.10 & II-Bom & 2 & 70 & 100 \\
\hline & & & & & 39.10 & 40.00 & III-Regular & 3 & 59 & 89 \\
\hline \multirow[t]{10}{*}{4610} & 0.45 & 0.00 & 1.00 & AT & 14.98 & 16.00 & V-Muito Pobre & 4 & 8 & 68 \\
\hline & & 1.00 & 7.46 & $\mathrm{AL}$ & 16.00 & 17.50 & IV-Pobre & 3 & 34 & 60 \\
\hline & & 7.46 & 14.98 & SAR & 17.50 & 20.50 & II-Bom & 2 & 71 & 93 \\
\hline & & 14.98 & 40.10 & ROCHA & 20.50 & 23.30 & I-Muito Bom & 1 & 91 & 99 \\
\hline & & & & & 23.30 & 26.10 & II-Bom & 2 & 89 & 100 \\
\hline & & & & & 26.10 & 29.10 & I-Muito Bom & 1 & 95 & 100 \\
\hline & & & & & 29.10 & 32.10 & I-Muito Bom & 1 & 99 & 100 \\
\hline & & & & & 32.10 & 35.10 & I-Muito Bom & 1 & 90 & 100 \\
\hline & & & & & 35.10 & 38.10 & II- Bom & 2 & 87 & 99 \\
\hline & & & & & 38.10 & 40.10 & I- Muito Bom & 1 & 100 & 100 \\
\hline \multirow[t]{11}{*}{4611} & 5.40 & 0.00 & 20.88 & SAR & 20.88 & 21.20 & V-Muito Pobre & 5 & 0 & 100 \\
\hline & & 20.88 & 40.31 & ROCHA & 21.20 & 24.20 & II-Bom & 2 & 71 & 99 \\
\hline & & & & & 24.20 & 25.20 & V-Muito Pobre & 4 & 10 & 11 \\
\hline & & & & & 25.20 & 26.20 & V-Muito Pobre & 5 & 0 & 10 \\
\hline & & & & & 26.20 & 27.20 & V-Muito Pobre & 4 & 14 & 27 \\
\hline & & & & & 27.20 & 29.20 & III - Regular & 2 & 77 & 100 \\
\hline & & & & & 29.20 & 30.20 & II-Bom & 2 & 70 & 91 \\
\hline & & & & & 30.20 & 33.20 & I-Muito Bom & 1 & 96 & 100 \\
\hline & & & & & 33.20 & 35.45 & II-Bom & 2 & 75 & 90 \\
\hline & & & & & 35.45 & 36.90 & II-Bom & 2 & 67 & 99 \\
\hline & & & & & 36.90 & 39.30 & II-Bom & 2 & 71 & 100 \\
\hline
\end{tabular}




\begin{tabular}{|c|c|c|c|c|c|c|c|c|c|c|}
\hline $\begin{array}{c}\text { Numero da } \\
\text { sondagem }(\mathrm{m})\end{array}$ & $\begin{array}{c}\text { Nivel de Água } \\
\text { (m) }\end{array}$ & Topo & Base & Geologia & $\begin{array}{c}\text { Topo } \\
\text { (m, 2DP) }\end{array}$ & $\begin{array}{c}\text { Base } \\
\text { (m, 2DP) }\end{array}$ & Classe de maciço & $\begin{array}{l}\text { Grau } \\
\text { Fratur. } \\
\text { (lista) }\end{array}$ & $\begin{array}{r}R Q D \\
(\%)\end{array}$ & $\begin{array}{c}\text { Recuperação } \\
\text { (\%) }\end{array}$ \\
\hline & & & & & 39.30 & 40.31 & I-Muito Bom & 1 & 95 & 100 \\
\hline \multirow[t]{3}{*}{4612} & 17.02 & 0.00 & 5.63 & AT & & & & & & \\
\hline & & 5.63 & 25.53 & SAR & & & & & & \\
\hline & & 25.53 & 45.08 & ROCHA & & & & & & \\
\hline \multirow[t]{7}{*}{4613} & 5.90 & 0.00 & 1.70 & AT & 32.05 & 37.20 & V-Muito Pobre & 3 & 0 & 38 \\
\hline & & 1.70 & 19.20 & SAR & 37.20 & 42.80 & III - Regular & 2 & 82 & 91 \\
\hline & & 19.20 & 27.50 & ROCHA & 42.80 & 45.00 & II-Bom & 1 & 100 & 100 \\
\hline & & 27.50 & 29.00 & SAR & 45.00 & 48.70 & II-Bom & 2 & 100 & 100 \\
\hline & & 29.00 & 30.60 & ROCHA & 48.70 & 49.90 & II - Bom & 1 & 90 & 100 \\
\hline & & 30.60 & 32.05 & SAR & 49.90 & 55.10 & II-Bom & 2 & 100 & 100 \\
\hline & & 32.05 & 55.10 & ROCHA & & & & & & \\
\hline \multirow[t]{14}{*}{4614} & 9.15 & 0.00 & 6.45 & AT & 17.46 & 18.00 & V-Muito Pobre & 5 & 0 & 79 \\
\hline & & 6.45 & 17.46 & SAR & 18.00 & 20.50 & I-Muito Bom & 1 & 84 & 100 \\
\hline & & 17.46 & 55.12 & ROCHA & 20.50 & 23.50 & I-Muito Bom & 1 & 90 & 95 \\
\hline & & & & & 23.50 & 26.50 & I-Muito Bom & 1 & 97 & 100 \\
\hline & & & & & 26.50 & 29.50 & I-Muito Bom & 1 & 92 & 100 \\
\hline & & & & & 29.50 & 32.50 & II-Bom & 2 & 70 & 100 \\
\hline & & & & & 32.50 & 35.50 & II-Bom & 2 & 81 & 100 \\
\hline & & & & & 35.50 & 38.50 & II - Bom & 2 & 80 & 100 \\
\hline & & & & & 38.50 & 41.50 & I-Muito Bom & 1 & 94 & 100 \\
\hline & & & & & 41.50 & 44.50 & II- Bom & 2 & 60 & 100 \\
\hline & & & & & 44.50 & 47.50 & I-Muito Bom & 1 & 83 & 100 \\
\hline & & & & & 47.50 & 50.50 & 1-Muito Bom & 1 & 97 & 100 \\
\hline & & & & & 50.50 & 53.50 & I-Muito Bom & 1 & 95 & 100 \\
\hline & & & & & 53.50 & 55.12 & I- Muito Bom & 1 & 99 & 100 \\
\hline \multirow[t]{14}{*}{4617} & 3.80 & 0.00 & 2.00 & AT & 6.20 & 6.70 & V-Muito Pobre & 5 & 0 & 55 \\
\hline & & 2.00 & 6.20 & SAR & 6.70 & 8.20 & II- Bom & 2 & 80 & 99 \\
\hline & & 6.20 & 40.10 & ROCHA & 8.20 & 9.70 & II-Bom & 2 & 68 & 75 \\
\hline & & & & & 9.70 & 12.70 & I-Muito Bom & 1 & 90 & 100 \\
\hline & & & & & 12.70 & 15.70 & II-Bom & 2 & 69 & 100 \\
\hline & & & & & 15.70 & 18.70 & III - Regular & 3 & 60 & 99 \\
\hline & & & & & 18.70 & 21.70 & II - Bom & 2 & 77 & 99 \\
\hline & & & & & 21.70 & 24.70 & II-Bom & 2 & 72 & 99 \\
\hline & & & & & 24.70 & 27.70 & III-Regular & 3 & 60 & 97 \\
\hline & & & & & 27.70 & 30.70 & II-Bom & 2 & 72 & 92 \\
\hline & & & & & 30.70 & 33.70 & I-Muito Bom & 1 & 96 & 100 \\
\hline & & & & & 33.70 & 36.40 & II- Bom & 2 & 85 & 100 \\
\hline & & & & & 36.40 & 38.10 & II-Bom & 3 & 55 & 100 \\
\hline & & & & & 38.10 & 40.10 & II-Bom & 2 & 70 & 100 \\
\hline \multirow[t]{5}{*}{4619} & 6.30 & 0.00 & 3.30 & AT & 7.40 & 8.50 & III-Regular & 3 & 10 & 58 \\
\hline & & 3.30 & 7.40 & SAR & 8.50 & 10.00 & III-Regular & 3 & 10 & 100 \\
\hline & & 7.40 & 40.30 & ROCHA & 10.00 & 15.50 & I-Muito Bom & 1 & 100 & 100 \\
\hline & & & & & 15.50 & 16.10 & II-Bom & 2 & 50 & 100 \\
\hline & & & & & 16.10 & 40.30 & I-Muito Bom & 1 & 98 & 100 \\
\hline \multirow[t]{3}{*}{4620} & 3.04 & 0.00 & 1.50 & AT & & & & & & \\
\hline & & & 10.90 & SAR & & & & & & \\
\hline & & & 40.45 & ROCHA & & & & & & \\
\hline \multirow[t]{14}{*}{4622} & 6.26 & 0.00 & 13.63 & SAR & 13.63 & 14.45 & V-Muito Pobre & 3 & 50 & 66 \\
\hline & & 13.63 & 55.09 & ROCHA & 14.45 & 17.45 & II-Bom & 2 & 78 & 97 \\
\hline & & & & & 17.45 & 20.45 & II-Bom & 2 & 65 & 90 \\
\hline & & & & & 20.45 & 23.45 & III-Regular & 3 & 55 & 77 \\
\hline & & & & & 23.45 & 26.45 & I-Muito Bom & 1 & 100 & 100 \\
\hline & & & & & 26.45 & 29.45 & II-Bom & 1 & 90 & 100 \\
\hline & & & & & 29.45 & 32.45 & I-Muito Bom & 1 & 97 & 100 \\
\hline & & & & & 32.45 & 35.45 & I-Muito Bom & 1 & 85 & 100 \\
\hline & & & & & 35.45 & 38.45 & I-Muito Bom & 1 & 97 & 97 \\
\hline & & & & & 38.45 & 40.25 & I-Muito Bom & 1 & 100 & 100 \\
\hline & & & & & 40.25 & 44.45 & III - Regular & 2 & 67 & 90 \\
\hline & & & & & 44.45 & 47.45 & I-Muito Bom & 1 & 89 & 100 \\
\hline & & & & & 47.45 & 49.20 & IV-Pobre & 3 & 60 & 80 \\
\hline & & & & & 49.20 & 52.30 & 1-Muito Bom & 1 & 90 & 100 \\
\hline
\end{tabular}




\begin{tabular}{|c|c|c|c|c|c|c|c|c|c|c|}
\hline $\begin{array}{c}\text { Numero da } \\
\text { sondagem }(\mathrm{m})\end{array}$ & $\begin{array}{c}\text { Nivel de Água } \\
\text { (m) }\end{array}$ & Topo & Base & Geologia & $\begin{array}{c}\text { Topo } \\
\text { (m, 2DP) }\end{array}$ & $\begin{array}{c}\text { Base } \\
(\mathrm{m}, 2 \mathrm{DP})\end{array}$ & Classe de maciço & $\begin{array}{l}\text { Grau } \\
\text { Fratur. } \\
\text { (lista) }\end{array}$ & $\begin{array}{r}\text { RQD } \\
(\%)\end{array}$ & $\begin{array}{c}\text { Recuperação } \\
\text { (\%) }\end{array}$ \\
\hline & & & & & 52.30 & 55.09 & I - Muito Bom & 1 & 82 & 99 \\
\hline \multirow[t]{7}{*}{4623} & 6.17 & 0.00 & 0.50 & AT & 21.75 & 23.05 & IV-Pobre & 4 & 17 & 81 \\
\hline & & 0.50 & 7.45 & SBSP & 23.05 & 24.95 & IV-Pobre & 4 & 26 & 76 \\
\hline & & 7.45 & 21.75 & SAR & 24.95 & 27.35 & III-Regular & 3 & 40 & 94 \\
\hline & & 21.75 & 35.14 & ROCHA & 27.35 & 30.10 & III-Regular & 3 & 30 & 48 \\
\hline & & & & & 30.10 & 30.90 & V-Muito Pobre & 5 & 0 & 26 \\
\hline & & & & & 30.90 & 33.15 & II-Bom & 3 & 59 & 92 \\
\hline & & & & & 33.15 & 35.14 & II-Bom & 3 & 60 & 96 \\
\hline \multirow[t]{11}{*}{4624} & 4.81 & 0.00 & 0.51 & AT & 17.42 & 18.22 & V-Muito Pobre & 5 & 0 & 80 \\
\hline & & 0.51 & 10.00 & SBSP & 18.22 & 19.55 & V-Muito Pobre & 5 & 0 & 60 \\
\hline & & 10.00 & 17.42 & SAR & 19.55 & 21.00 & IV-Pobre & 3 & 40 & 82 \\
\hline & & 17.42 & 35.45 & ROCHA & 21.00 & 22.50 & III - Regular & 4 & 17 & 82 \\
\hline & & & & & 22.50 & 24.00 & III-Regular & 3 & 58 & 91 \\
\hline & & & & & 24.00 & 25.50 & III - Regular & 3 & 49 & 80 \\
\hline & & & & & 25.50 & 26.95 & I-Muito Bom & 1 & 96 & 100 \\
\hline & & & & & 26.95 & 30.00 & III - Regular & 1 & 74 & 95 \\
\hline & & & & & 30.00 & 31.30 & I-Muito Bom & 1 & 100 & 100 \\
\hline & & & & & 31.30 & 32.95 & I-Muito Bom & 1 & 100 & 100 \\
\hline & & & & & 32.95 & 35.45 & I - Muito Bom & 1 & 100 & 100 \\
\hline \multirow[t]{10}{*}{4635} & 3.42 & 0.00 & 3.00 & AT & 7.96 & 8.61 & V-Muito Pobre & 5 & 0 & 100 \\
\hline & & 3.00 & 7.95 & SAR & 8.61 & 10.66 & V-Muito Pobre & 5 & 0 & 75 \\
\hline & & 7.95 & 30.62 & ROCHA & 10.66 & 13.01 & I-Muito Bom & 1 & 90 & 100 \\
\hline & & & & & 13.01 & 13.96 & III - Regular & 4 & 25 & 100 \\
\hline & & & & & 13.96 & 18.36 & II- Bom & 2 & 85 & 100 \\
\hline & & & & & 18.36 & 20.06 & III - Regular & 3 & 40 & 100 \\
\hline & & & & & 20.06 & 23.06 & I-Muito Bom & 1 & 95 & 100 \\
\hline & & & & & 23.06 & 26.11 & I- Muito Bom & 1 & 92 & 100 \\
\hline & & & & & 26.11 & 29.11 & II-Bom & 2 & 82 & 100 \\
\hline & & & & & 29.11 & 30.62 & I-Muito Bom & 1 & 94 & 100 \\
\hline \multirow[t]{13}{*}{4638} & 5.02 & 0.00 & 3.20 & AT & 9.43 & 12.00 & II-Bom & 2 & 74 & 100 \\
\hline & & 3.20 & 9.00 & $\mathrm{AL}$ & 12.00 & 12.90 & I-Muito Bom & 1 & 91 & 100 \\
\hline & & 9.00 & 9.43 & SAR & 12.90 & 14.80 & I - Muito Bom & 1 & 85 & 100 \\
\hline & & 9.43 & 40.60 & ROCHA & 14.80 & 17.10 & II-Bom & 1 & 96 & 100 \\
\hline & & & & & 17.10 & 20.10 & I-Muito Bom & 1 & 100 & 100 \\
\hline & & & & & 20.10 & 23.00 & II-Bom & 2 & 75 & 90 \\
\hline & & & & & 23.00 & 25.80 & I-Muito Bom & 1 & 95 & 100 \\
\hline & & & & & 25.80 & 28.40 & I-Muito Bom & 1 & 90 & 100 \\
\hline & & & & & 28.40 & 31.40 & II-Bom & 2 & 86 & 100 \\
\hline & & & & & 31.40 & 34.50 & II-Bom & 2 & 72 & 100 \\
\hline & & & & & 34.50 & 36.10 & II-Bom & 3 & 40 & 100 \\
\hline & & & & & 36.10 & 39.10 & II-Bom & 2 & 82 & 100 \\
\hline & & & & & 39.10 & 40.60 & II-Bom & 2 & 71 & 95 \\
\hline & & & & & & & & & & \\
\hline & & & & & & & & & & \\
\hline & & & & & & & & & & \\
\hline & & & & & & & & & & \\
\hline & & & & & & & & & & \\
\hline & & & & & & & & & & \\
\hline & & & & & & & & & & \\
\hline & & & & & & & & & & \\
\hline & & & & & & & & & & \\
\hline & & & & & & & & & & \\
\hline & & & & & & & & & & \\
\hline & & & & & & & & & & \\
\hline & & & & & & & & & & \\
\hline & & & & & & & & & & \\
\hline & & & & & & & & & & \\
\hline & & & & & & & & & & \\
\hline & & & & & & & & & & \\
\hline & & & & & & & & & & \\
\hline & & & & & & & & & & \\
\hline
\end{tabular}


APÊNDICE III - PERFIS GEOLÓGICO GEOTÉCNICOS 


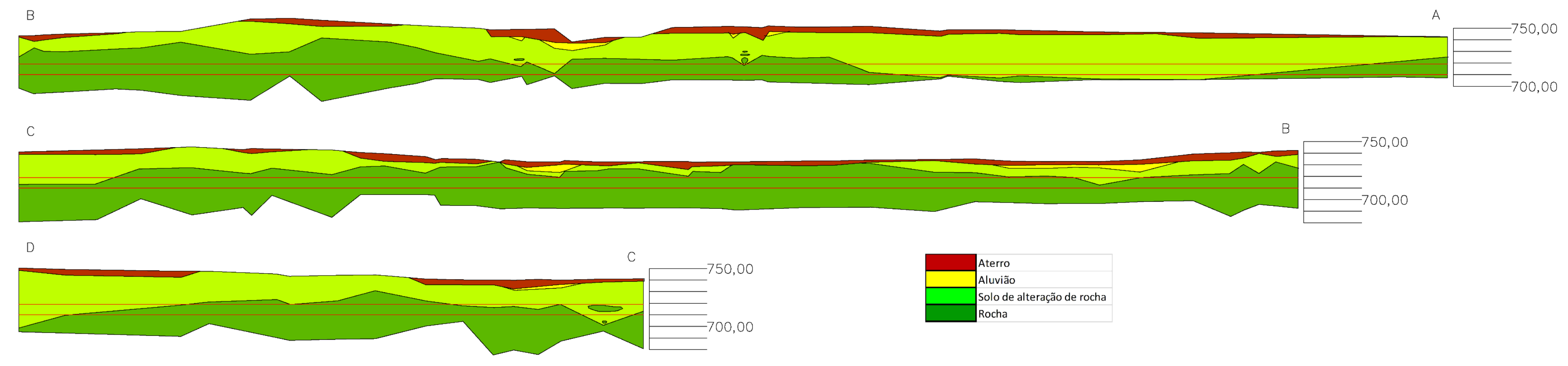



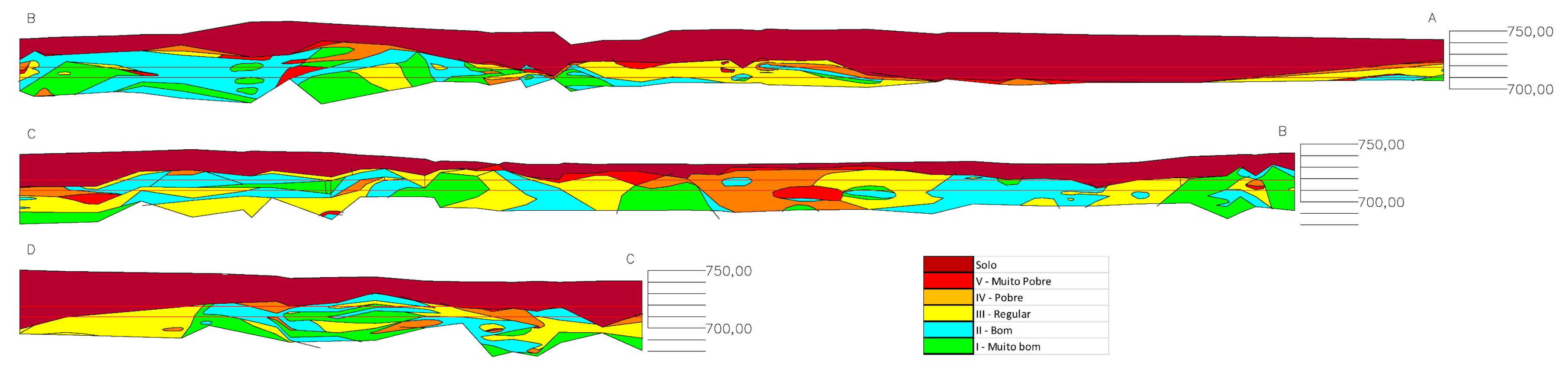
ANEXO I - IMAGENS TELEVISIONADAS 


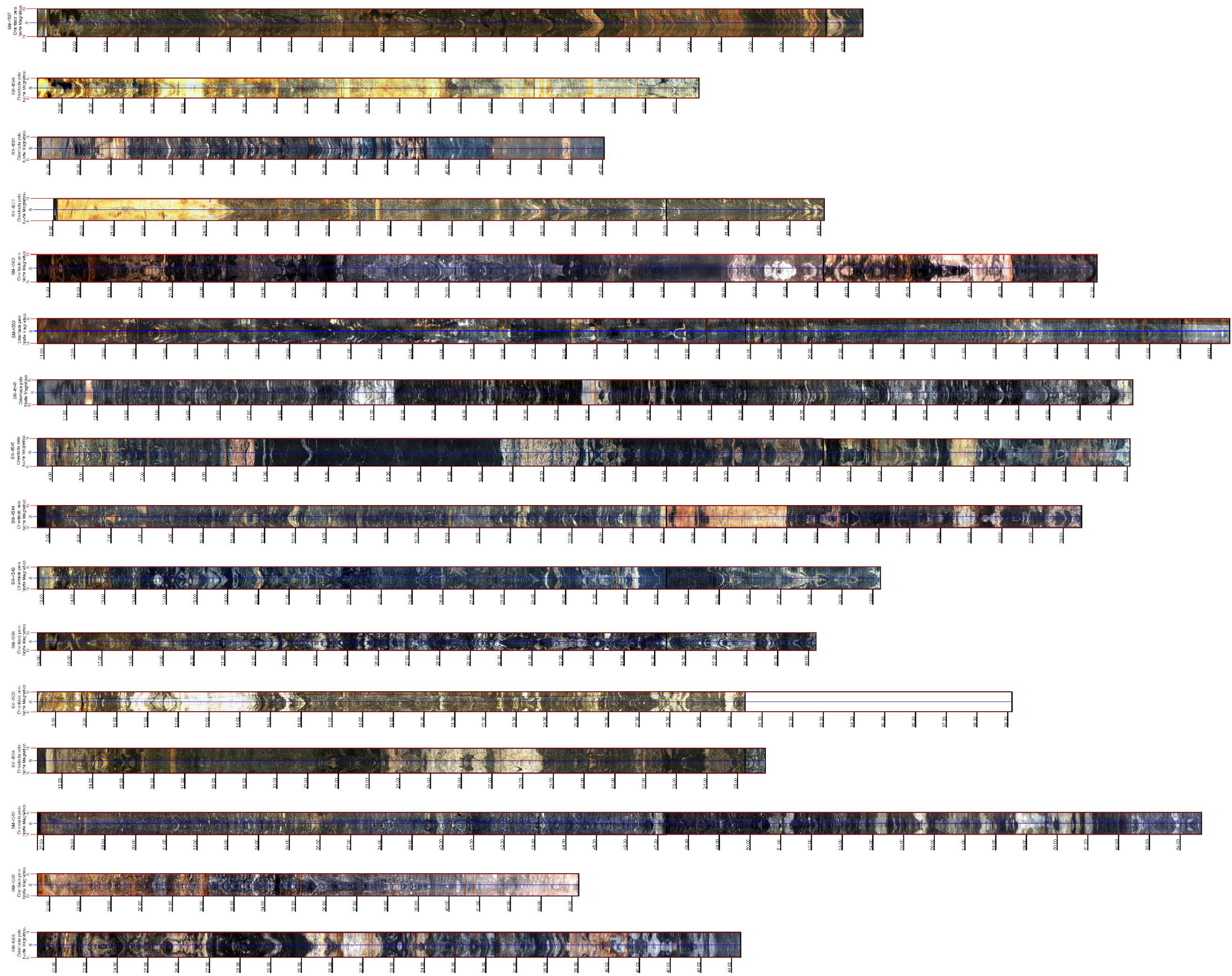

